CLÁUDIO NEVES BORGES

\title{
MODELAGEM MATEMÁTICA DO PROCESSO INDUSTRIAL DE COQUEAMENTO RETARDADO
}

São Paulo

2016 
CLÁUDIO NEVES BORGES

\section{MODELAGEM MATEMÁTICA DO PROCESSO INDUSTRIAL DE COQUEAMENTO RETARDADO}

Tese apresentada à Escola Politécnica da Universidade de São Paulo para obtenção do Título de Doutor em Ciências

SÃO PAULO 
CLÁUDIO NEVES BORGES

\section{MODELAGEM MATEMÁTICA DO PROCESSO INDUSTRIAL DE COQUEAMENTO RETARDADO}

Tese apresentada à Escola Politécnica da Universidade de São Paulo para obtenção do Título de Doutor em Ciências

Área de Concentração:

Engenharia Química

Orientador:

Profa. Dra. Rita Maria de Brito Alves

Co-orientadora:

Dra. Maria Anita Mendes

SÃO PAULO 
Este exemplar foi revisado e corrigido em relação à versão original, sob responsabilidade única do autor e com a anuência de seu orientador.

São Paulo, $\quad$ de

de

Assinatura do autor:

Assinatura do orientador:

Catalogação-na-publicação

Borges, Cláudio Neves

MODELAGEM MATEMÁTICA DO PROCESSO INDUSTRIAL DE COQUEAMENTO RETARDADO / C. N. Borges -- versão corr. -- São Paulo, 2016.

$192 \mathrm{p}$.

Tese (Doutorado) - Escola Politécnica da Universidade de São Paulo. Departamento de Engenharia Química.

1.coqueamento retardado 2.forno 3.reator de coque 4.modelagem I.Universidade de São Paulo. Escola Politécnica. Departamento de Engenharia Química II.t. 


\section{DEDICATÓRIA}

A todos os meus mestres, que ao longo de minha vida me mostraram o valor de educação, e a Deus por me dar forças para conseguir superar todas as dificuldades enfrentadas nesta jornada. 


\section{AGRADECIMENTOS}

A prof. Dra. Rita Maria de Brito Alves pela orientação e dedicação, tornando possível a realização deste trabalho.

A pesquisadora Dra. Maria Anita Mendes pela co-orientação.

Agradeço também a Petrobras por estimular este tipo de trabalho, por disponibilizar a estrutura do CETAI (Centro de Excelência em Tecnologia de Aplicação em Automação Industrial), por fornecer a estrutura logística para o desenvolvimento do trabalho fora do ambiente de trabalho, e por fornecer, sem restrições, os dados necessários ao projeto.

À Petrocoque pelo apoio nas realizações das análises de coque verde e calcinado dos diversos testes realizados na unidade durante a elaboração deste trabalho.

Aos técnicos de operação da unidade de coqueamento retardado da Refinaria Presidente Bernardes pelo auxílio de coleta de informações de processo durante os diversos testes de corridas realizadas na unidade durante a elaboração deste trabalho.

Aos técnicos químicos do laboratório da Refinaria Presidente Bernardes pelas realizações das análises das amostras dos diversos testes de corridas.

As minhas queridas e amada Dulce e Mariana, esposa e filha, que me apoiaram nas diversas madrugadas, feriados e fins de semana que fiquei trabalhando sobre esta tese.

Agradeço a ajuda e o apoio de José Eduardo, Guilherme e Rodrigo no desenvolvimento do trabalho. 
"A diferença entre o vencedor e o perdedor não é a força nem o conhecimento, mas, sim, a vontade de vencer".

Vince Lombardi 


\section{RESUMO}

A unidade de coqueamento retardado é um processo térmico de conversão, utilizado pelas refinarias, para converter cargas residuais em produtos de baixo peso molecular e com alto valor agregado (gases, nafta e gasóleo) e coque verde de petróleo. Um pequeno aumento no rendimento líquido da unidade de coqueamento retardado proporciona benefícios económicos consideráveis, especialmente no destilado líquido. A concorrência no mercado, as restrições sobre as especificações do produto e gargalos operacionais exigem um melhor planejamento da produção. Portanto, o desenvolvimento de novas estratégias e modelos matemáticos, focados em melhores condições de operação do processo industrial e formulações de produtos, é essencial para alcançar melhores rendimentos e um acompanhamento mais preciso da qualidade do produto. Este trabalho tem como objetivo o desenvolvimento de modelo matemático do conjunto forno-reator do processo de coqueamento, a partir de informações obtidas em uma planta industrial. O modelo proposto é baseado na caracterização da carga e dos produtos em pseudocomponentes, modelos cinéticos de grupos e condições de equilíbrio liquidovapor. Além disso, são discutidos os principais desafios para o desenvolver o modelo matemático do forno e do reator, bem como a caracterização rigorosa do resíduo de vácuo e dos produtos para determinar os parâmetros que afetam a morfologia do coque e a zona de reação no interior do reator de coque.

Palavra-chave: Coqueamento retardado, coque, fornos, reator de coque, modelagem matemática 


\begin{abstract}
The delayed coke unit is a thermal conversion process, used by the crude oil refineries, to convert residual feedstocks into products of low molecular weight and high aggregated value (gases, naphtha and gasoil) and green coke. A small increase in the net yield in the delayed coke unit results in considerable economic benefits, particularly in the liquid distillates. The market competition, the restrictions on the product specifications and the operational bottlenecks require a better production planning. Therefore, the development of new strategies and mathematical models, focused in better industrial process operating conditions and product formulations, is essential to achieve better yields and a more precise product quality monitoring. The objective of this work is the development of a furnace-reactor mathematical model of the delayed coke process based on industrial plant information. The proposed model is based on the feed and product characterization as pseudo components, group kinetical models and liquid-vapor equilibrium. Furthermore, the main challenges to develop the furnace and reactor mathematical model are discussed, as well as the vacuum residual and the coke unit products rigorous characterization to determine the parameters that impact the coke morphology and the reaction zone inside the coke reactor.
\end{abstract}

Keywords: delayed coke, coke, furnace, coke reactor, mathematical model 


\section{LISTA DE GRÁFICOS}

Figura 1.1 - Demanda mundial de coque verde de petróleo grau anodo.................22

Figura 1.2 - Produção mundial de coque verde de petróleo....................................23

Figura 2.1 - Proposta de modelo cinético com cinco grupos. ....................................31

Figura 3.1 - Esquema básico de uma refinaria de petróleo (SPEIGHT, 1999). ........37

Figura 3.2 - Esquema simplificado do processo de coqueamento retardado. ...........40

Figura 3.3 - Curva de ponto de destilação verdadeiro para o petróleo (SPEIGHT,

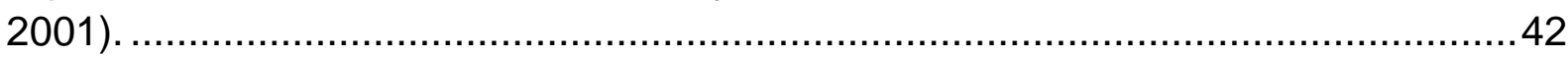

Figura 3.4 - Estabilidade de resíduo (HUS, 1981) ……................................... 43

Figura 3.5 - Mecanismo para o coqueamento (SAYLES e ROMERO, 2011)...........45

Figura 3.6 - Perfil típico numa serpentina do forno de coqueamento (ROSE, 1971).

Figura 3.7 - Início do craqueamento térmico incipiente (MEKLER, 1950).

Figura 3.8 - Tempo de residência do óleo com temperatura (AKBAR e GEELEN, 1981).

Figura 3.9 - Detalhes do enchimento do reator de coque (ELLIS, 1993).

Figura 3.10 - Produtos de coqueamento a partir de frações de petróleo. (SPEIGHT, 1998).

Figura 3.11 - Esquema simplificado do fundo da torre fracionadora. .55

Figura 3.12 - Efeito da temperatura no reator de coque sobre o teor de matéria

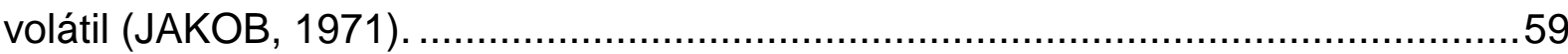

Figura 3.13 - Amostra de shot-coke (ELLIOTT, 2008; FAEGH e COLLINS, 2010). . 62

Figura 3.14 - Amostra de coque esponja (ELLIOTT, 2008) ....................................64

Figura 3.15 - Amostra de coque agulha (ELLIOTT, 2008) ......................................65

Figura 4.1 - Fluxograma com os pontos de coletas de amostras. ..........................68

Figura 4.2 - Separação do petróleo conforme a solubilidade em saturados, aromáticos, resinas e asfaltenos (Speight, 2006)

Figura 4.3 - Procedimento utilizado para precipitar a fração de asfaltenos de uma

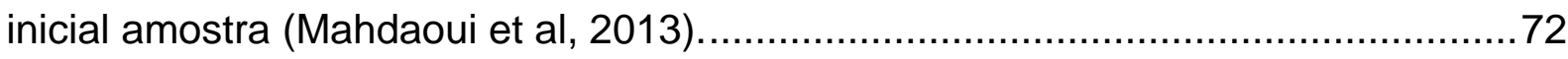

Figura 4.4 - Variação de rendimento de coque..................................................74

Figura 4.5 - Curva de destilação simulada do resíduo HT750 de vácuo ...................75

Figura 4.6 - Análise do comportamento da curva de destilação do resíduo de vácuo.

Figura 4.7 - Fator de aromaticidade em função da relação atômica H/C. ...............79

Figura 4.8 - Espectro de massa e curva de distribuição de $\mathrm{m} / \mathrm{z}$............................82

Figura 4.9 - Variação da massa específica com o teor de carbono fixo. ...................92

Figura 4.10 - Efeito da morfologia do coque de petróleo no VCM. .........................94

Figura 4.11 - Estimativa do HGI (Hardgrove Grindability Index). (PERRUCHOUD,

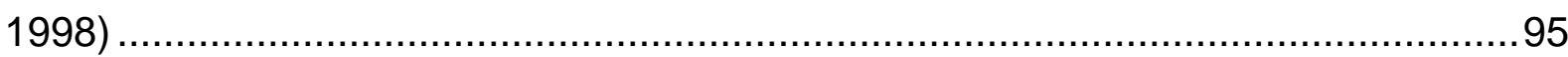

Figura 4.12 - Qualidade do coque verde dos testes de corridas. ...........................95

Figura 4.13 - Influência do HGI do coque verde na densidade aparente. .................96 
Figura 5.1 - Sequência de operações e o procedimento de reconciliação. ...............99

Figura 5.2 - Vazões de carga e produtos ao longo do tempo ...............................100

Figura 5.3 - Histograma das vazões de cargas e produtos (Ciclo N. ${ }^{\circ} 1$ ) ...............103

Figura 5.4 - Histograma das vazões de cargas e produtos (Ciclo N. $\left.{ }^{\circ} 10\right)$..............104

Figura 5.5 - Vaso de topo da fracionadora principal. ........................................110

Figura 5.6 - Esquema de simulação. ............................................................110

Figura 5.7 - Curva de destilação ASTM D-86 corrigida da nafta. .........................112

Figura 5.8 - Curva de destilação ASTM D-86 da nafta.......................................114

Figura 5.9 - - Curva de destilação ASTM D-86 do gasóleo leve...........................114

Figura 5.10 - Curva de destilação ASTM D-86 do gasóleo pesado.......................115

Figura 5.11 - Desenho esquemático do sistema. ................................................118

Figura 6.1 - Metodologia para modelagem matemática. .....................................126

Figura 6.2 - Curva de destilação de ponto de ebulição verdadeiro do vapor de topo

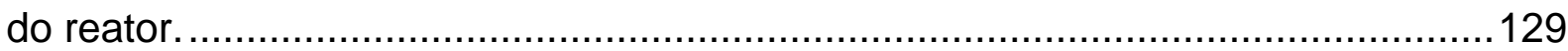

Figura 6.3 - Estratégia para determinação do reciclo........................................130

Figura 6.4 - Esquema no sistema forno-reator. ...............................................133

Figura 6.5 - Esquema do forno de coqueamento. .........................................136

Figura 6.6 - Esquema simplificado de uma fornalha........................................137

Figura 6.7 - Fator de correção do fluxo de calor (API RP 530)............................148

Figura 6.8 - Diagrama de bloco representando as seções do forno. ......................151

Figura 6.9 - Escoamento de fluido no interior do tubo. ......................................155

Figura 6.10 - Mapa de Baker para escoamento em tubo horizontal. ......................157

Figura 6.11 - Esquema das reações com cinco grupos.....................................158

Figura 6.12 - Esquema do reator de coque .....................................................160

Figura 6.13 - Esquema do modelo proposto para o reator..................................161

Figura 6.14 - Algoritmo usado na simulação do forno de coqueamento..................164

Figura 6.15 - Curva de destilação completa do vapor de topo do reator de coque.165

Figura 6.16 - Curva de destilação calculada completa do reciclo contido no vapor de

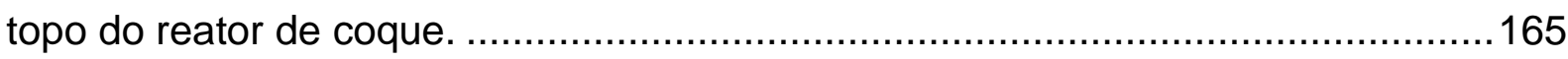

Figura 6.17 - Perfil de temperatura ao longo da serpentina. ..............................167

Figura 6.18 - Perfil da diferença de temperatura entre a parede e o fluido. ...........168

Figura 6.19 - Perfis de pressão e temperatura ao longo da serpentina...................169

Figura 6.20 - Fração mássica vaporizada do fluido ao longo da serpentina...........170

Figura 6.21 - Curva de destilação de ponto de ebulição do vapor de topo do reator. 


\section{LISTA DE TABELAS}

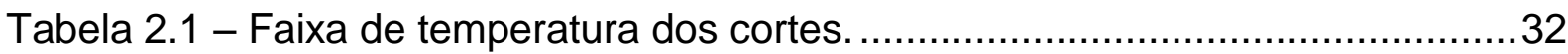

Tabela 3.1 - Valores típicos de fluxo de calor na seção de reação. ..........................50

Tabela 3.2 - Dimensões do reator de coque (SAWARKAR, 2007) .........................52

Tabela 3.3 - Condições operacionais típicas para produção de diferentes coques.. 56

Tabela 3.4 - Influência da razão de reciclo no gasóleo pesado...............................57

Tabela 3.5 - Influência da pressão sobre os rendimentos. ......................................60

Tabela 3.6 - Distribuição do enxofre e nitrogênio nos produtos em relação a carga.

Tabela 3.7 - Características do resíduo de vácuo do petróleo venezuelano Orinoco.

Tabela 3.8 - Características da carga para produção de coque agulha. .................65

Tabela 4.1 - Rendimento de coque verde e propriedades do resíduo de vácuo. .....73

Tabela 4.2 - Valores de massa específica, $\mathrm{kg} / \mathrm{m}^{3} @ 20^{\circ} \mathrm{C}$.....................................77

Tabela 4.3 - Valores de razão atômica H/C para frações.........................................77

Tabela 4.4 - Valores de razão atômica H/C de vários resíduo de vácuo....................78

Tabela 4.5 - Resultados de SARA e aromaticidade do resíduo de vácuo. .................80

Tabela 4.6 - Principais resíduos de vácuo presentes no petróleo. ...........................86

Tabela 4.7 - Valores dos coeficientes da reta $10 \times 90$ de cada amostra. .................87

Tabela 4.8 - Curva da relação $(\mathrm{m} / \mathrm{z})$ para os cortes. ............................................ 87

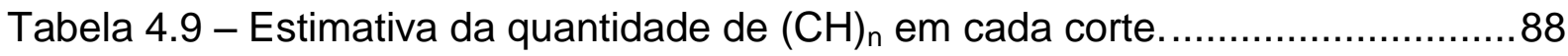

Tabela 4.10 - Resultado de análise de produtos num ciclo de operação. .................89

Tabela 4.11 - Massa específica do coque verde de petróleo. (SPEIGHT, 1994) ......92

Tabela 4.12 - Características do coque verde....................................................93

Tabela 5.1 - Informações sobre os ciclos de enchimento do reator de coque..........99

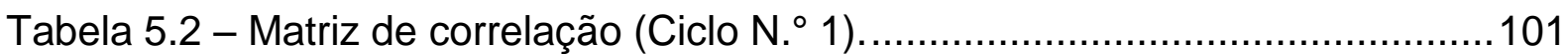

Tabela 5.3 - Matriz de correlação (Ciclo N. ${ }^{\circ}$ 10) ................................................102

Tabela 5.4 - Composição do gás........................................................................111

Tabela 5.5 - Propriedades da corrente de nafta. ...............................................112

Tabela 5.6 - Propriedades das correntes de gasóleos. ......................................113

Tabela 6.1- Quadro de correlações. ...............................................................128

Tabela 6.2 - Propriedades físicas de pseudocomponentes e fração de petróleo. ..128

Tabela 6.3 - Faixa de temperatura dos grupos do modelo proposto. .....................133

Tabela 6.4 - Coeficientes da equação (6.47)..................................................147

Tabela 6.5 - Fator de correção de má distribuição de temperatura de parede.......149

Tabela 6.6 - Composição de produto de saída do forno de coqueamento. .............166

Tabela 6.7 -Parâmetros geométricos utilizado na simulação. ................................166

Tabela 6.8 - Informações do fluido no interior da serpentina. ................................166

Tabela 6.9 - Informações sobre a seção de convecção e de radiação do forno. ...168

Tabela 6.10 - Produtos na saída do forno de coqueamento.................................170

Tabela 6.11 - Comparação da temperatura de orvalho do vapor de topo do reator. 


\section{LISTA DE ABREVIATURAS E SIGLAS}

$\begin{array}{ll}\text { ASTM } & \text { American Standard for Tests Materials } \\ \text { CCR } & \text { Conradson Carbon Residue } \\ \text { EAA } & \text { European Aluminum Association } \\ \text { FCC } & \text { Fluid Catalytic Cracking } \\ \text { HGI } & \text { Hardgrove Grindability Index } \\ \text { HPLC } & \text { Cromatografia Líquida de Alta Resolução } \\ \text { MALDI } & \text { Matrix Assisted Laser Desorption/lonization } \\ \text { PEV } & \text { Ponto de Ebulição Verdadeiro } \\ \text { VCM } & \text { Volatile Combustible Material } \\ \text { VBD } & \text { Vibrated Bulk Density } \\ \text { TOF } & \text { Time of Flight }\end{array}$




\section{LISTA DE SIMBOLOS}

\begin{tabular}{|c|c|}
\hline Símbolo & Descrição \\
\hline A & Área da seção transversal interna do tubo \\
\hline$A_{i j}$ & Termo pré-exponicial da equação de Arrhenius \\
\hline $\operatorname{Ar}$ & Teores de aromáticos na fração de petróleo \\
\hline$A_{R}$ & $\begin{array}{l}\text { Área efetiva de refratário exposta na seção de } \\
\text { radiação }\end{array}$ \\
\hline As & Teores de asfaltenos na fração de petróleo \\
\hline$A_{T}$ & Área total das superfícies do forno \\
\hline $\mathrm{Bx}$ & Parâmetro de Baker \\
\hline By & Parâmetro de Baker \\
\hline $\mathrm{Ca}$ & Teor de carbono aromático na mistura \\
\hline $\mathrm{CF}$ & Teor de carbono fixo \\
\hline CFR & Razão do óleo de reciclo \\
\hline Cinzas & Teor de cinza no coque de petróleo \\
\hline $\mathrm{C}_{\mathrm{P}}$ & Calor específico do fluido a pressão constante \\
\hline $\mathrm{C}_{\mathrm{T}}$ & Teor de carbono total na mistura \\
\hline CCR & Resíduo de carbono Conradson \\
\hline $\mathrm{D}_{20 / 4 \mathrm{C}}$ & Densidade $20 / 4{ }^{\circ} \mathrm{C}$ \\
\hline $\mathrm{D}_{0}$ & Diâmetro externo do tubo \\
\hline$D_{i}$ & Diâmetro interno do tubo \\
\hline$E$ & Energia de ativação \\
\hline fa & Fator de aromaticidade \\
\hline$f_{D}$ & Fator de atrito de Darcy \\
\hline $\mathrm{F}_{\mathrm{C}}$ & Fator de correção de fluxo de calor circunferencial \\
\hline $\mathrm{F}_{\mathrm{L}}$ & Fator de correção de fluxo de calor longitudinal \\
\hline $\mathrm{F}_{\mathrm{T}}$ & $\begin{array}{l}\text { Fator de correção de má distribuição de fluxo de } \\
\text { calor pelo efeito do tipo de chama formado no } \\
\text { interior da seção de radiação }\end{array}$ \\
\hline
\end{tabular}


$(\mathrm{H} / \mathrm{C})_{\text {ATÔMCA }}$

$\mathrm{HGI}$

$h_{f}$

$\mathrm{h}_{\mathrm{L}}$

$\mathrm{h}_{\mathrm{v}}$

$\mathrm{h}_{\mathrm{TP}}$

K

$\mathrm{K}_{\text {coque }}$

$\mathrm{K}_{\text {fluido }}$

$\mathrm{K}_{\text {metal }}$

L

$\mathrm{L}_{\text {eq }}$

MBL

MCR

MV

PM

$\operatorname{Pr}_{f}$

$\dot{\mathrm{Q}}_{\mathrm{T} 1}$

$\dot{\mathrm{Q}}_{\mathrm{T} 2}$

$Q_{A B S}$

$Q_{\text {AR }}$

$\mathrm{q}_{\mathrm{AVG}}$
Aceleração da gravidade

Fluxo mássico do fluido no interior do tubo

Teor de hidrogênio na fração

Relação atômica hidrogênio-carbono

Índice de moagem

Coeficiente de transferência de calor por convecção o fluido no interior do tubo

Coeficiente de transferência de calor por convecção para fase líquida em regime turbulento.

Coeficiente de transferência de calor por convecção para fase vapor em regime turbulento.

Coeficiente de transferência de calor por convecção em escoamento bifásico.

Constante cinética

Coeficiente de condutividade térmica da camada de coque

Condutividade térmica do fluido no interior do tubo

Coeficiente de condutividade térmica da parede do tubo

Comprimento reto do tubo

Comprimento equivalente do acidente

Comprimento médio do feixe.

Micro resíduo de carbono

Matéria volátil

Peso molecular

Número de Prandtl

Calor absorvido na seção de pré-aquecimento

Calor absorvido na seção de reação química

Calor absorvido pelo no interior da serpentina

Calor sensível do ar alimentado para combustão acima de $60^{\circ} \mathrm{F}$

Fluxo médio de calor na seção de radiação 


\begin{tabular}{|c|c|}
\hline$Q_{\text {CONV }}$ & Calor absorvido na seção de convecção \\
\hline$q_{\text {Conv }}$ & Fluxo médio de calor na seção de radiação \\
\hline$Q_{\text {EXAUto }}$ & $\begin{array}{l}\text { Calor gases de combustão deixando a seção de } \\
\text { radiação }\end{array}$ \\
\hline $\mathrm{Q}_{\mathrm{GC}}$ & Calor sensível do combustível acima de $60^{\circ} \mathrm{F}$ \\
\hline$Q_{L I B}$ & $\begin{array}{l}\text { Calor total liberado pela combustão com base no } \\
\text { poder calorífico inferior }\end{array}$ \\
\hline $\mathrm{q}_{\max }$ & $\begin{array}{l}\text { Fluxo máximo de calor na seção de radiação com } \\
\text { na área externa do tubo }\end{array}$ \\
\hline$Q_{\text {PERDA }}$ & Calor perdido para vizinhança \\
\hline$Q_{\text {RAD }}$ & Calor absorvido na seção de radiação \\
\hline $\mathrm{R}$ & Constante de gás ideal \\
\hline $\operatorname{Re}$ & Teores de resina na fração de petróleo \\
\hline $\operatorname{Re}_{f}$ & Número de Reynolds \\
\hline $\mathrm{RV}$ & Resíduo de vácuo \\
\hline $\mathrm{Sa}$ & Teores de saturados na fração de petróleo \\
\hline SG & Densidade da fração a $15,6 / 15,6{ }^{\circ} \mathrm{C}$ \\
\hline $\mathrm{t}$ & Tempo \\
\hline $\mathrm{T}$ & Temperatura \\
\hline $\mathrm{T}_{\mathrm{b}}$ & Temperatura bulk do fluido \\
\hline$T_{G}$ & $\begin{array}{l}\text { Temperatura média dos gases de combustão na } \\
\text { saída da seção de radiação }\end{array}$ \\
\hline$\overline{\mathrm{T}}_{G}$ & $\begin{array}{l}\text { Temperatura média dos gases de combustão na } \\
\text { seção de radiação }\end{array}$ \\
\hline$T_{w}$ & Temperatura de parede \\
\hline $\mathrm{T}_{50}$ & Temperatura de ebulição \\
\hline $\mathrm{T}_{50}$ & Temperatura de ebulição \\
\hline$X_{i}$ & Vazão mássica da corrente i \\
\hline$Y_{\text {coque }}$ & Rendimento de coque \\
\hline$Y_{i}$ & Vazão mássica da corrente i \\
\hline $\mathrm{VCM}_{1}$ & Teor de matéria volátil combustível primário \\
\hline
\end{tabular}




\begin{tabular}{|c|c|}
\hline $\mathrm{VCM}_{2}$ & Teor de matéria volátil combustível secundário \\
\hline $\mathrm{VCM}_{3}$ & Teor de matéria volátil combustível terciário \\
\hline $\mathrm{VCM}_{\mathrm{T}}$ & Teor de matéria volátil combustível total \\
\hline $\mathrm{v}$ & Velocidade do fluido \\
\hline $\mathrm{W}_{\mathrm{L}}$ & Vazão mássica de líquido \\
\hline $\mathrm{W}_{\mathrm{v}}$ & Vazão mássica de gás \\
\hline$\alpha$ & \\
\hline$(\Delta \mathrm{H})_{\mathrm{i}}$ & Variação de entalpia no ponto i \\
\hline$\Delta \mathrm{P}_{\mathrm{A}}$ & $\begin{array}{l}\text { Perda de carga por aceleração do fluido no interior } \\
\text { da serpentina }\end{array}$ \\
\hline$\Delta \mathrm{P}_{\mathrm{C}}$ & Perda de carga por elevação do fluido \\
\hline$\Delta \mathrm{P}_{\mathrm{F}}$ & Perda de carga por atrito no interior da serpentina \\
\hline$\Delta P_{k}$ & Perda de carga por acidente no interior da serpentina \\
\hline$\Delta \mathrm{P}_{\text {TOTAL }}$ & Perda de carga total no interior da serpentina \\
\hline$\Delta \mathrm{T}_{\text {coque }}$ & $\begin{array}{l}\text { Diferença de temperatura através da camada de } \\
\text { coque }\end{array}$ \\
\hline$\Delta \mathrm{T}_{\text {filme }}$ & Diferença de temperatura através do filme de fluido \\
\hline$\Delta \mathrm{T}_{\text {metal }}$ & Diferença de temperatura através da parede do tubo \\
\hline$\Delta \mathrm{X}_{\mathrm{i}}$ & Variação de massa da corrente i \\
\hline$\varepsilon$ & Porosidade do leito de coque \\
\hline$\varepsilon_{\text {coque }}$ & Espessura da camada de coque \\
\hline$\varepsilon_{\mathrm{G}}$ & Emissividade dos gases de combustão \\
\hline$\varepsilon_{\text {metal }}$ & Espessura da parede do tubo \\
\hline$\varepsilon_{S}$ & $\begin{array}{l}\text { Emissividade da superfície dos tubos } \\
\text { (Valor típico: } 0,80-0,90)\end{array}$ \\
\hline $\mathfrak{J}$ & Fator de forma global da fornalha \\
\hline$\rho$ & Massa específica da mistura \\
\hline$\rho_{\text {Ar }}$ & Massa específica das frações de aromáticos \\
\hline$\rho_{\text {As }}$ & Massa específica das frações de asfaltenos \\
\hline$\rho_{\mathrm{AVG}}$ & Massa específica média no segmento \\
\hline
\end{tabular}




$\begin{array}{ll}\rho_{\mathrm{BULK}} & \text { Massa específica aparente do coque } \\ \rho_{\mathrm{L}} & \text { Massa específica da fase líquida } \\ \rho_{\mathrm{Re}} & \text { Massa específica das frações de resinas } \\ \rho_{\mathrm{REAL}} & \text { Massa específica real do coque } \\ \rho_{\mathrm{Sa}} & \text { Massa específica das frações de saturados } \\ \rho_{\mathrm{V}} & \text { Massa específica da fase vapor } \\ \mu_{\mathrm{b}} & \text { Viscosidade do líquido na temperatura bulk } \\ \mu_{\mathrm{L}} & \text { Viscosidade da fase líquida } \\ \mu_{\mathrm{V}} & \text { Viscosidade da fase vapor } \\ \mu_{\mathrm{W}} & \text { Viscosidade do líquido na temperatura da parede } \\ \sigma_{\mathrm{L}} & \text { Tensão superficial do líquido }\end{array}$




\section{SUMÁRIO}

1. INTRODUÇÃO

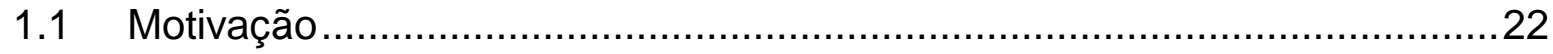

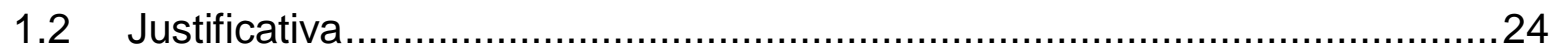

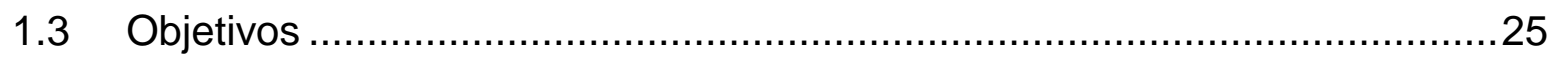

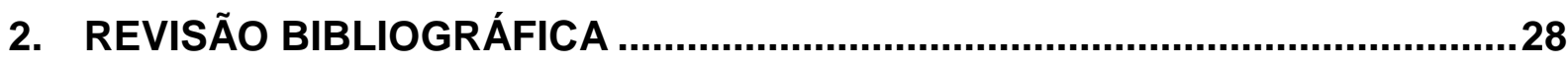

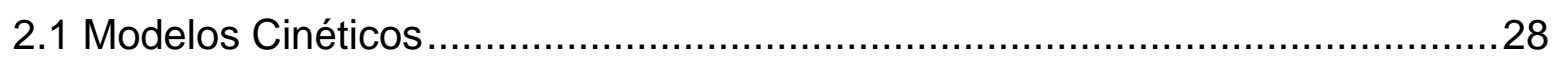

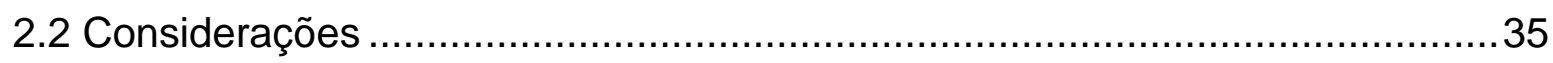

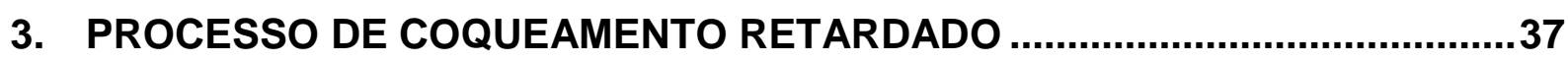

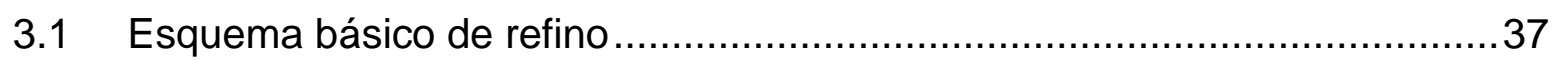

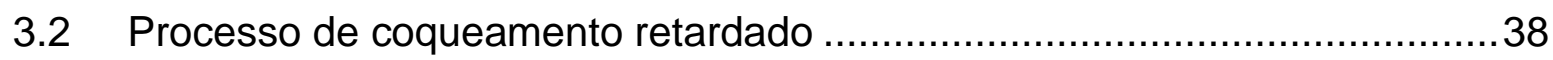

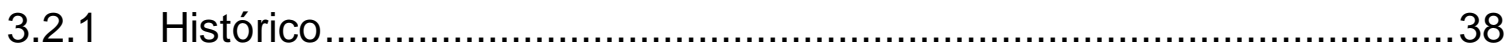

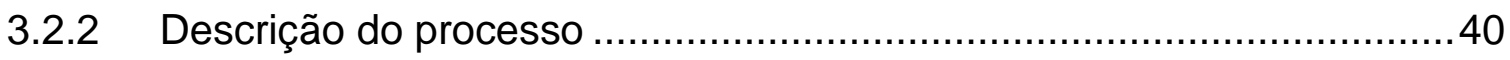

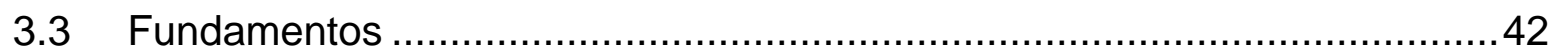

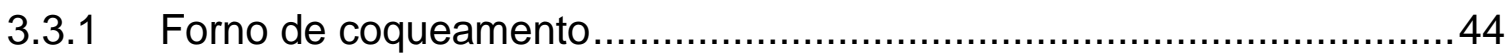

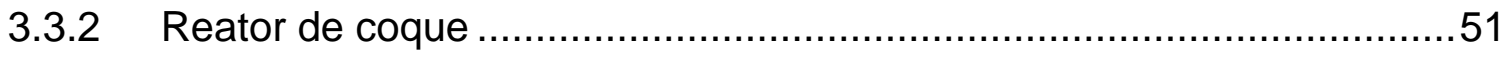

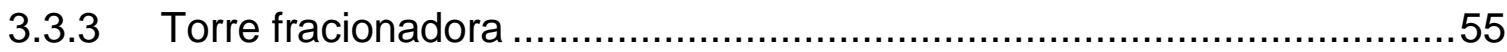

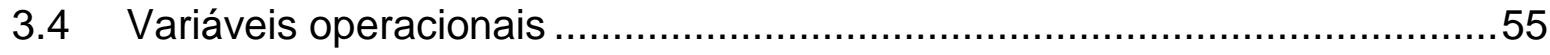

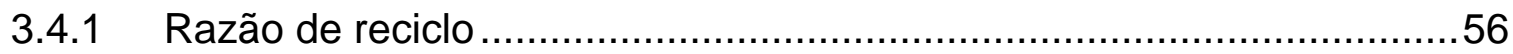

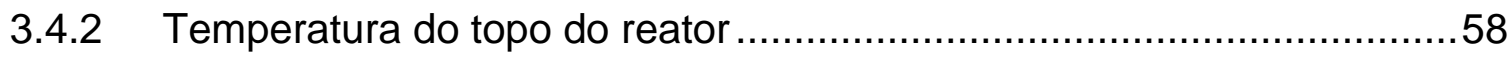

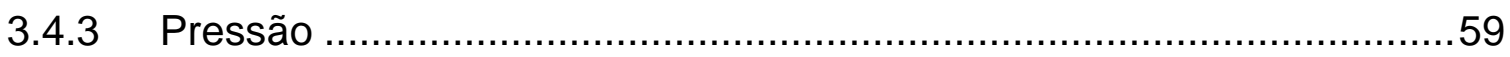

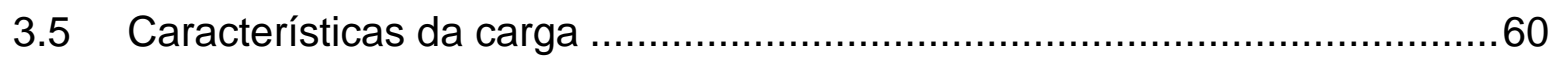

3.6 Tipos e parâmetros de qualidade do coque de petróleo .............................62

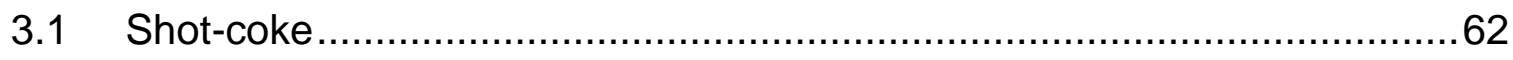

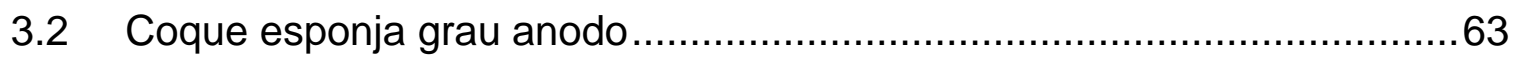

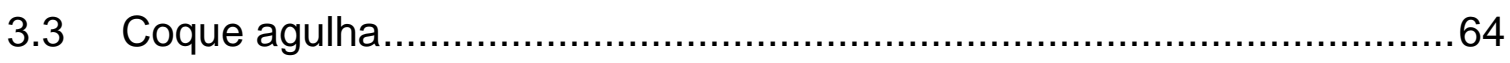

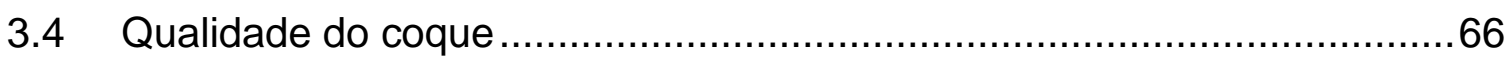




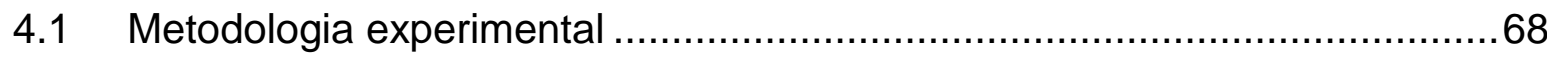

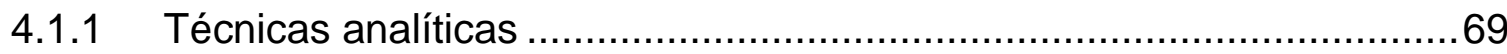

4.1.2 Caracterização do resíduo de vácuo ............................................69

4.1.3 Caracterização de asfaltenos por espectrometria de massa ................70

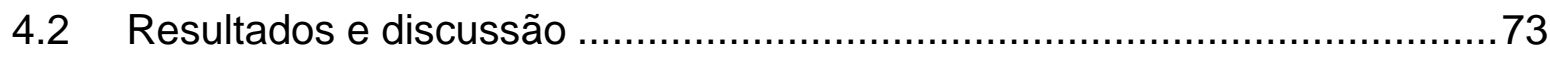

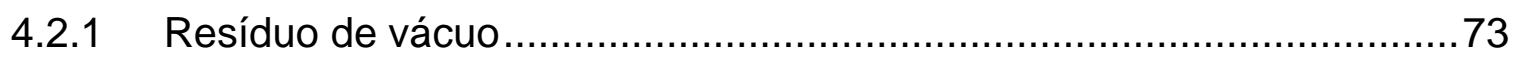

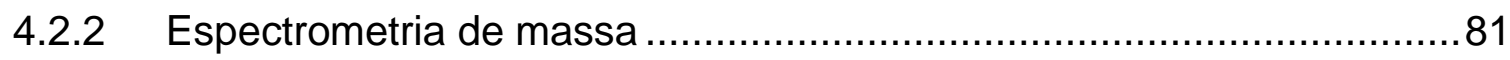

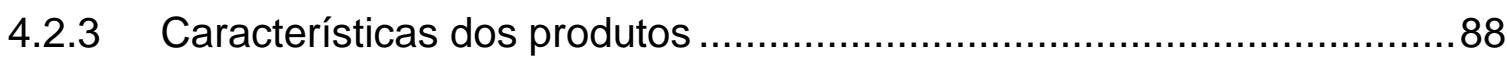

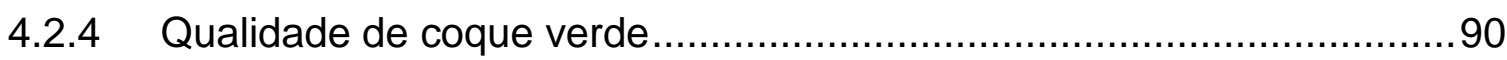

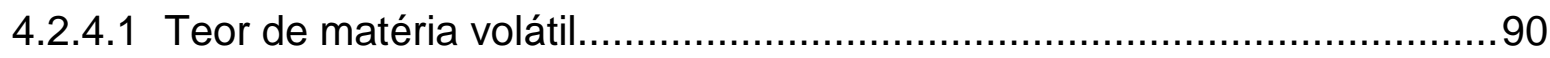

4.2.4.2 Massa específica de coque verde ..............................................91

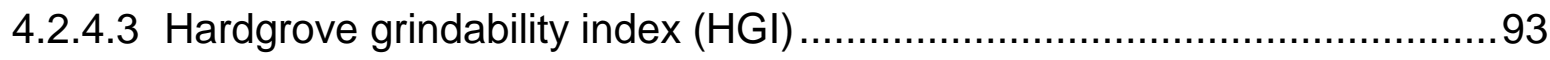

5. RECONCILIAÇÃO DE DADOS..................................................................97

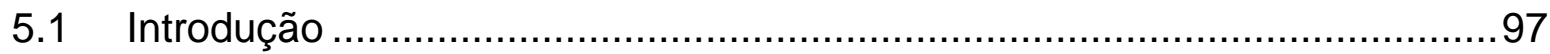

5.2 Seleção de variáveis e coleta de dados ..................................................98

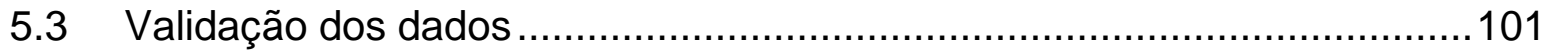

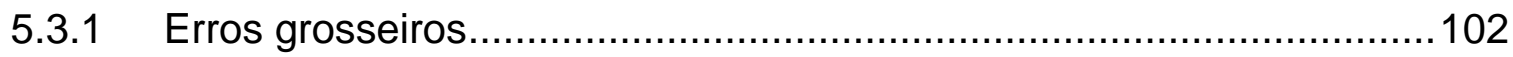

5.3.2 Correção de vazão medida por placa de orifício ................................105

5.3.3 Avaliação das análises de laboratório .........................................108

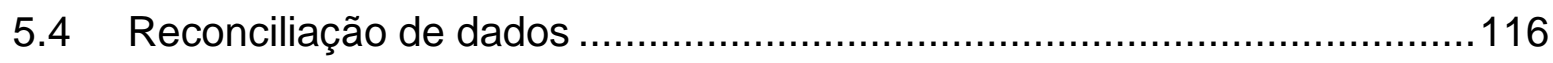

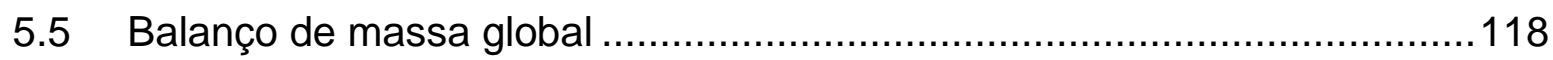

5.6 Determinação da composição elementar dos produtos ..........................120

5.7 Caracterização do resíduo de vácuo ............................................ 125

5.7.1 Propriedades físico-químicas ................................................ 125

6. MODELAGEM MATEMÁTICA ................................................................126

6.1 Caracterização das frações em pseudo-componentes ..........................126 
6.2 Caracterização do vapor de topo do reator de coque .............................129

6.3 Balanço de massa e energia do sistema forno-reator ..............................133

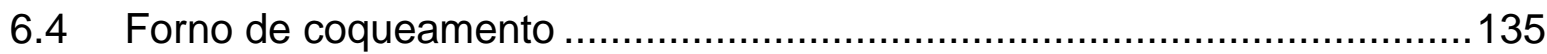

6.4.1 Balanço de energia no forno de coqueamento - combustão …............135

6.4.2 Determinação do fluxo de calor na seção de radiação ........................138

6.4.3 Temperatura máxima de parede do tubo..........................................145

6.4.4 Cálculo do excesso de ar .............................................................149

6.4.5 Modelo matemático do forno de coqueamento .................................150

6.5 Modelo matemático de craqueamento térmico no reator de coque ...........159

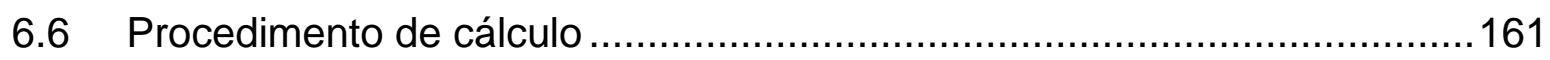

6.6.1 Caracterização das frações em pseudocomponentes ..........................161

6.6.2 Cálculos de equilíbrio líquido-vapor (ELV) de modo a caracterizar o vapor de topo (reciclo). ...............................................................................161

6.6.3 Cálculo dos balanços de massa e energia forno- reator......................161

6.6.4 Cálculo de perfil de pressão e conversão no interior da serpentina do

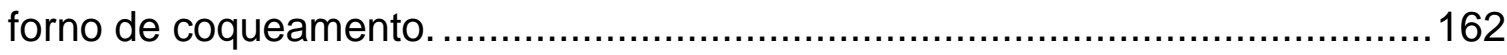

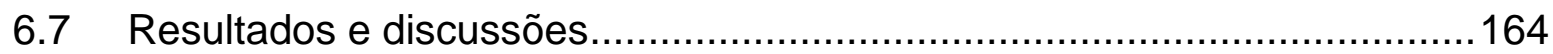

6.7.1 Determinação do vapor de topo do reator de coque............................164

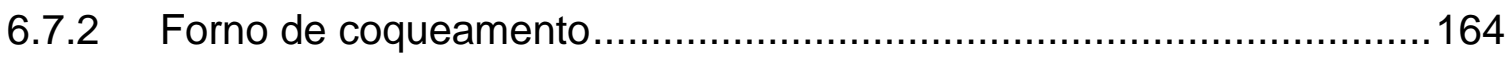

6.7.3 Comparação de resultados...........................................................170

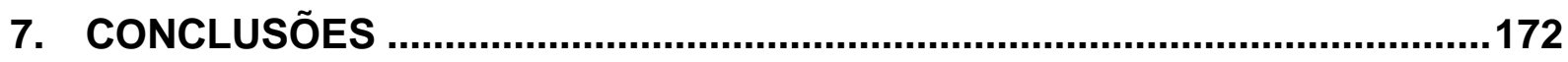

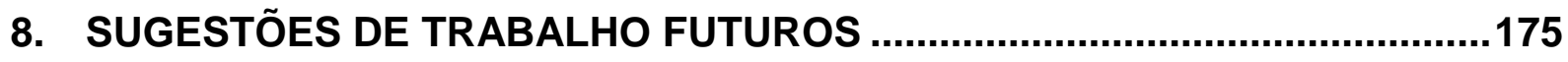

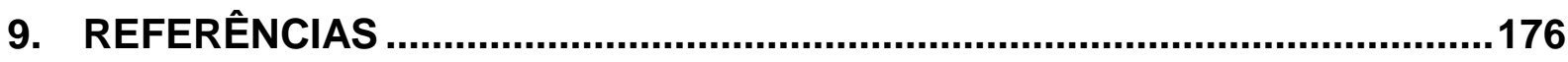

A. ESPECTROMETRIA DE MASSA EM IDENTIFICAÇÃO QUÍMICA...................191

B. DETERMINAÇÃO DO VAPOR DE TOPO DO REATOR COQUE ...................197 


\section{INTRODUÇÃO}

\subsection{Motivação}

Atualmente, os Estados Unidos e Canadá são grandes produtores mundiais de alumínio. Entretanto, nenhum deles possui jazidas de bauxita em seu território, dependendo exclusivamente de importação. O Brasil ocupa a terceira posição mundial de reservas de bauxita, perdendo apenas para Austrália e Guiné. O processamento desta bauxita resulta na produção de alumínio primário, na utilização da indústria química (sulfato de alumínio), na fabricação de abrasivos e de refratários.

No processo de produção de alumínio primário é consumido aproximadamente 0,40 tonelada de carbono por tonelada de metal produzido numa cuba eletrolítica moderna (EDWARDS, 2015). Uma fonte rica em carbono utilizada na fabricação dos anodos é o coque calcinado. O coque verde de petróleo grau anodo é matéria-prima essencial para obtenção de coque calcinado. A Figura 1.1 apresenta a demanda de coque verde grau anodo no mercado mundial. (Calcined Petroleum Coke Report 2014, Jacobs Consultancy). Em 2014, a produção mundial de coque grau anodo foi de 28,6 milhões de tonelada.

Figura 1.1 - Demanda mundial de coque verde de petróleo grau anodo.

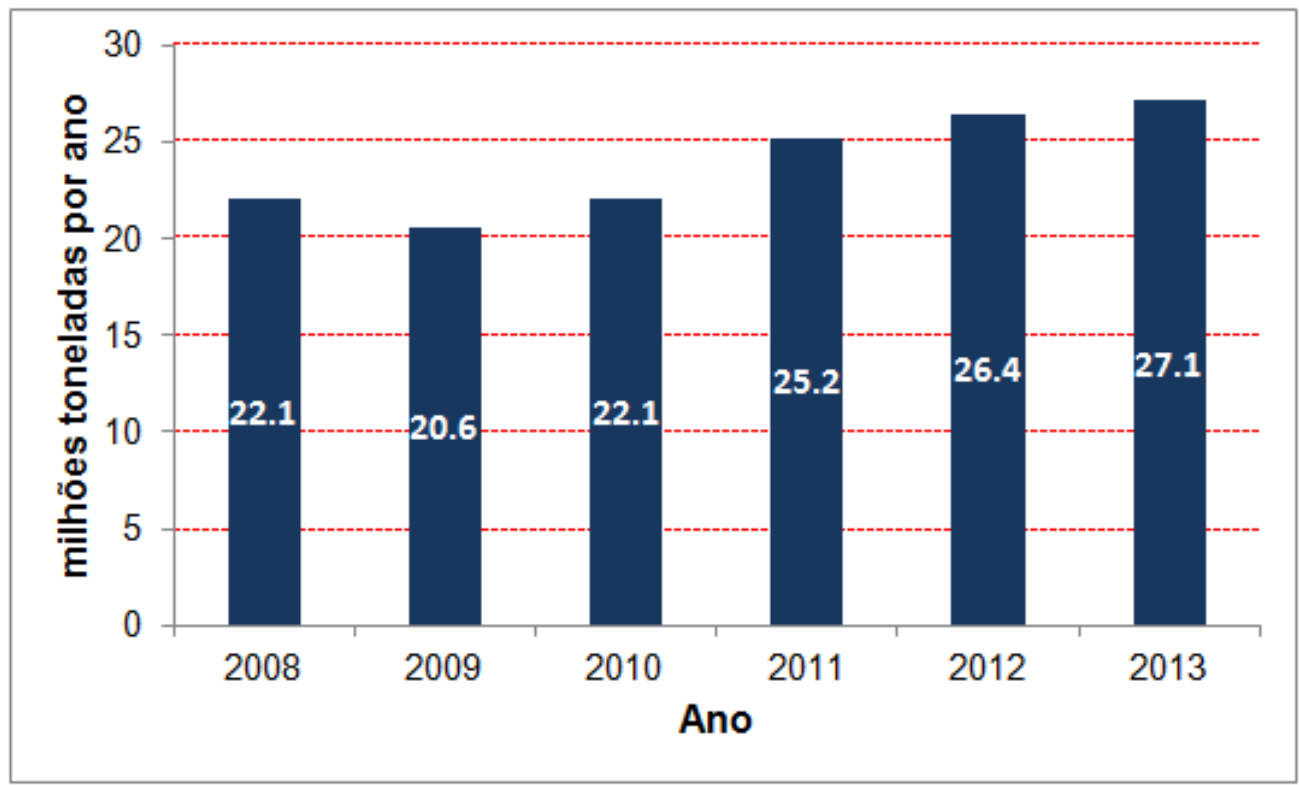


Na Figura 1.2 é mostrado o crescimento da produção mundial de coque verde de petróleo. A previsão da demanda de coque verde grau anodo é de 34,3 milhões de toneladas, em 2019. (Calcined Petroleum Coke Report 2014, Jacobs Consultancy). No entanto, apenas parte do coque verde produzido é destinada a produção de coque calcinado grau anodo. A maioria das novas unidades de coqueamento retardado é destinada à produção de coque combustível.

Figura 1.2 - Produção mundial de coque verde de petróleo.

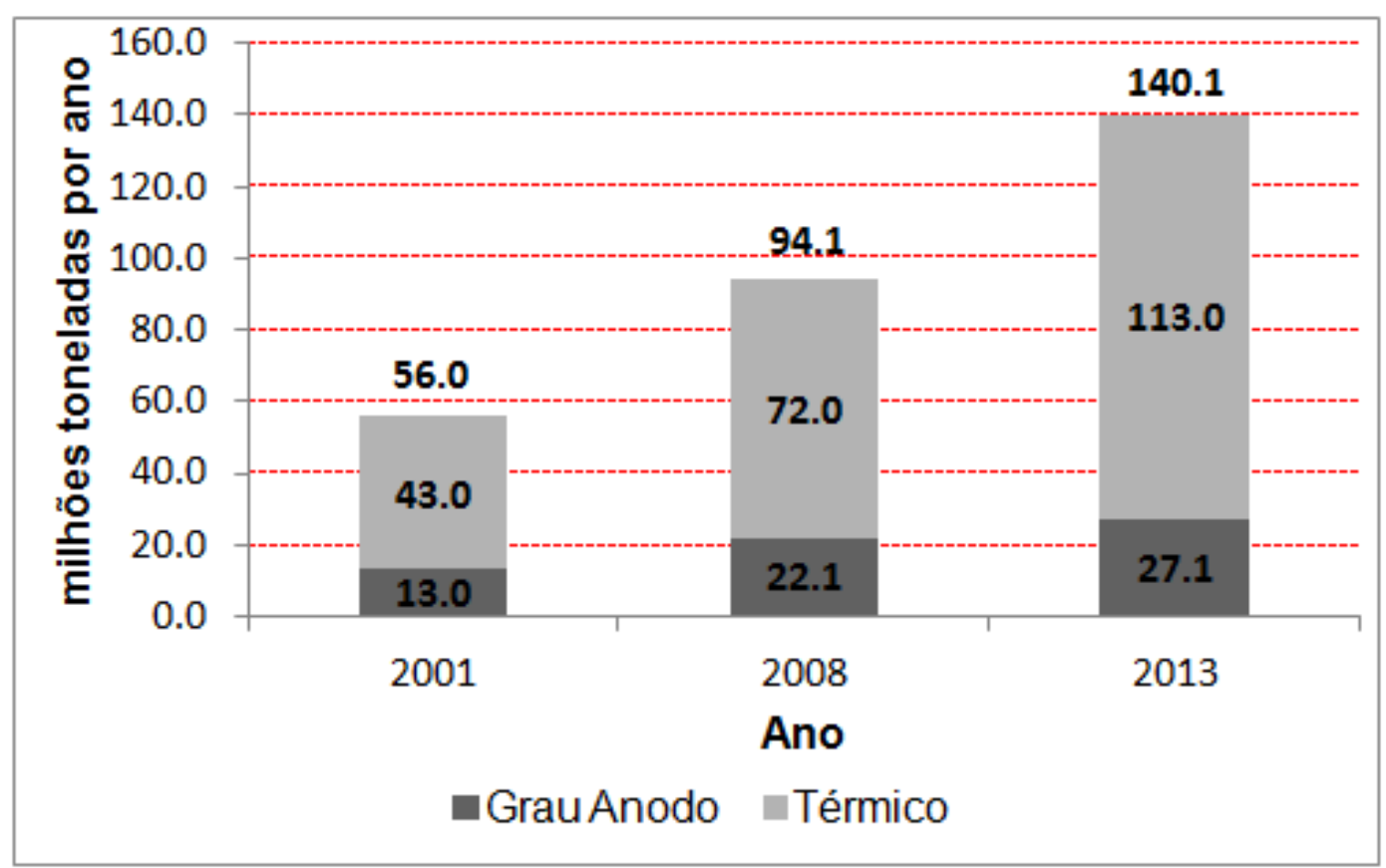

As características químicas do petróleo e o estado da arte da tecnologia atual das unidades de coqueamento retardado são os fatores contribuintes para limitação do aumento da produção de coque verde grau anodo, devido aos rigorosos parâmetros de qualidade para atender à indústria de alumínio.

Atualmente, a única rota para produção de alumínio é através da utilização de fonte de carbono como agente redutor, Anodo Pré-Cozido e Anodo Söderberg. Desta forma, vários pesquisadores têm estudado os processos de conversão térmica, incluindo o processo de coqueamento retardado, viscorredução e eureca (GARY, et al, 2007; ALHUMAIDAN et al., 2013 e ROSAL, 2013). A partir de 2000, foi iniciado um projeto de pesquisa e desenvolvimento no processo de coqueamento com a Universidade de Tulsa e diversas empresas (VOLK et al, 2002). A Petrobras também 
instalou uma planta piloto em seu Centro de Pesquisa para avaliar o processo de coqueamento retardado.

\subsection{Justificativa}

O coque verde de petróleo é um produto obtido do processamento de frações líquidas em Unidades de Coqueamento Retardado (UCR). A Unidade de Coqueamento Retardado é um processo de conversão térmica, conhecido na indústria de petróleo como processo de "fundo de barril". Esta unidade tem um papel fundamental na conversão de resíduo de vácuo em produtos de maior valor agregado, proporcionando assim um acréscimo de rentabilidade do esquema de refino.

O coque verde é um material com elevado teor de carbono fixo composto por hidrocarbonetos e baixos teores de compostos inorgânicos. Sua aparência é de um granel formado por fragmentos sólidos de cor negra, sendo que o termo "verde" em sua denominação se refere ao estágio do seu processo de produção.

O coque verde de petróleo produzido no Brasil tem como grande diferencial o baixo teor de enxofre, raro em comparação ao nível mundial, sendo um produto de maior valor agregado e de menor impacto ambiental.

A crescente competitividade do mercado, as alterações frequentes nos preços/demanda de derivados e na disponibilidade de petróleo, bem como restrições nas especificações de produtos e gargalos operacionais exigem respostas rápidas da indústria e melhor controle do planejamento de produção. Com isso, torna-se necessário o desenvolvimento de novas estratégias e modelos matemáticos voltados à otimização operacional dos processos industriais e formulações dos produtos.

A indústria petrolífera tem recorrido a "softwares" comerciais (Petrosim/DC-Sim da empresa KBC, PIMS da AspenTech, etc.) para realizar a simulação integrada de toda a refinaria. Os modelos utilizados são lineares e não-lineares que são calibrados com os dados obtidos em corridas realizadas nas unidades industriais. A 
dificuldade em se obter uma modelagem e simulação com boa aderência com a unidade industrial está na qualidade dos dados e grau de detalhes dos modelos utilizados, os quais são altamente empíricos.

\subsection{Objetivos}

O objetivo geral deste trabalho é desenvolver uma metodologia para modelagem do processo de coqueamento retardado com base em informação obtidas em unidades industriais. A ideia básica é desenvolver um modelo matemático com base na cinética das reações e em condições de equilíbrio líquido-vapor para melhor avaliar as influências das características das cargas residuais e das variáveis operacionais nos rendimentos dos produtos e na qualidade do coque verde da unidade de coqueamento retardado. Deste modo, tem-se a finalidade de identificar cargas que possam contribuir de forma mais significativa no atendimento dos objetivos operacionais de uma planta industrial.

O trabalho tem como objetivos específicos estudar as incertezas, validade de correlações e estratégia de modelagem do processo de coqueamento retardado de maneira a atender uma representatividade aceitável de rendimentos e de qualidade de produtos, bem como o critério de mínima quantidade de ensaios em laboratório.

Assim, foram realizadas análises espectrométricas dos asfaltenos presentes nos resíduos de modo a caracterizá-los com maior nível de detalhe molecular. Através desta análise foi possível relacionar as propriedades químicas da carga com as características específicas do produto desejado.

A partir destas informações, mais precisas quanto às características moleculares da carga da unidade de coqueamento retardado, é possível compreender as características do reciclo e dos produtos, bem como desenvolver um modelo matemático para o processo com o propósito de maximizar a conversão de cargas residuais em produtos mais leves e de maior valor agregado, além de produzir coque com a qualidade desejada. 
A apresentação do trabalho é dividida em capítulos, a saber:

No capítulo 2, é apresentada uma revisão do estado da arte do desenvolvimento de modelos matemáticos do processo de coqueamento retardado, enfatizando os principais modelos cinéticos encontrados na literatura científica. Estes conceitos abrangem a modelagem do forno de coqueamento e do reator de coque.

No capítulo 3, são mostrados aspectos referentes à fundamentação teórica necessária para compreensão do processo de coqueamento retardado e construção do modelo matemático proposto, incluindo caracterização da carga, parâmetros de qualidade dos produtos, cinética química e variáveis operacionais. Também é apresentada a descrição do processo industrial.

capítulo 4 apresenta as estratégias para caracterização da carga e dos produtos. São considerados aspectos da abordagem de pseudocomponentes para representar as frações de petróleo e estratégias de caracterização do resíduo de vácuo por técnicas de espectrometria de massa (MALDI-TOF). Adicionalmente, são apresentados os resultados e discussões dos dados referentes a quinze ciclos de operação de unidade de coqueamento retardado.

O capítulo 5 apresenta estratégias de análise de dados históricos da planta, de modo a detectar e eliminar erros grosseiros, corrigir erros sistemáticos e inconsistências devido a variação das condições operacionais, com a finalidade de construir uma base de dados consistente para calibração e validação do modelo matemático. Também são considerados, na análise, dados obtidos através de análises de laboratório.

No capítulo 6, é apresentado o desenvolvimento do modelo matemático do processo de coqueamento retardado para melhor avaliar influências das características das cargas residuais e das variáveis operacionais nos rendimentos dos produtos e na qualidade do coque verde produzido na unidade industrial. $\mathrm{O}$ modelo proposto é baseado na caracterização da carga e dos produtos em pseudocomponentes, modelos cinéticos de grupos e condições de equilíbrio liquido-vapor. São, também, 
apresentados os resultados e discussões da predição do modelo em comparação com os dados da operação da planta industrial.

O capítulo 7 apresenta a conclusão geral do trabalho. Neste capítulo, também são apresentadas sugestões para trabalhos posteriores.

Neste trabalho, foram desenvolvidos programas específicos para cada atividade: reconciliação de dados, análise das características da carga e produtos, qualidade do coque, modelo matemático, cálculo de equilíbrio líquido-vapor e propriedades físicas. Os programas foram desenvolvidos em linguagem FORTRAN, utilizando as bibliotecas IMSL (Fortran Numerical Library). 


\section{REVISÃO BIBLIOGRÁFICA}

Este capítulo apresenta uma revisão do estado da arte em modelagem do processo de coqueamento retardado, enfatizando os principais modelos cinéticos encontrados na literatura científica. Estes conceitos abrangem a modelagem do forno de coqueamento e o reator de coque.

\subsection{Modelos Cinéticos}

Ao longo dos anos, a estratégia para determinar a conversão e as propriedades do fluido no interior das serpentinas de fornos de coqueamento foi baseada em experiência e regras práticas. A situação desejada é obter um modelo matemático capaz de prever o rendimento e as características dos produtos ao longo da serpentina do forno, considerando as variáveis operacionais e as características da carga combinada.

Além disso, as reações de coqueamento são complexas e o desenvolvimento de um modelo cinético detalhado é uma tarefa desafiadora. A cinética das reações do processo de coqueamento envolve mecanismos de craqueamento térmico via radicais livres e a formação de coque através de policondensação de olefinas. Entretanto, bons resultados são reportados na literatura usando aproximações cinéticas de primeira e segunda ordem (MATEUS, 2008).

Como as reações químicas no processo de coqueamento ocorrem em dois equipamentos distintos, forno de coqueamento e reator de coque, são adotadas duas estratégias diferentes para desenvolvimento dos modelos cinéticos. Como os processos de coqueamento retardado e de viscorredução do tipo coil visbreaker são baseados em craqueamento térmico, os fornos têm um comportamento similar, com exceção do grau de severidade. Assim, o forno de coqueamento é similar ao processo de viscorredução, enquanto o reator de coque é similar ao reator de mistura. 
No processo de viscorredução, existem modelos capazes de prever o rendimento e a qualidade dos produtos, em função das variáveis operacionais e das características da carga. Como é extremamente difícil determinar as características da carga e descrever a cinética em nível molecular, o desenvolvimento dos modelos pode ser dividido em dois tipos: modelos empíricos e modelos de grupos.

A modelagem do forno de viscorredução e do processo de coqueamento retardado tem sido proposta por vários grupos de pesquisadores (Del BIANCO et al, 1993; MATEUS, 2008; REZA, MOHADDECY e SADICHI, 2011), utilizando agrupamentos de modo a simplificar o modelo. São consideradas porções de espécies agrupadas em classes equivalentes, chamada de técnica de grupos (lumping). Cada grupo é independente. As reações paralelas e as consecutivas podem caracterizar os modelos cinéticos de grupo. Estes modelos aproximados contêm dois, três, quatro, cinco e sete lumps.

Castellanos et al. (1991) representaram a carga e os produtos por um conjunto de pseudocomponentes discretos, que foram classificados conforme a quantidade do número de átomos de carbono presentes nos mesmos. Apenas a serpentina foi modelada, assumindo comportamento similar à do reator tubular.

Sugaya (1994) desenvolveu um modelo cinético do craqueamento térmico com reação irreversível de primeira ordem (carga $\rightarrow$ produto), sendo constituído por 16 agrupamentos e 24 pseudocomponentes, onde 10 são gases e 14 são cortes na faixa de $75^{\circ} \mathrm{C}$ a $550{ }^{\circ} \mathrm{C}^{+}$. Na modelagem cinética do forno de coqueamento, foi adotada uma simplificação que reduziu o modelo para cinco agrupamentos e cinco pseudocomponentes, visando minimizar a complexidade da modelagem. Dessa maneira, a caracterização do sistema reacional foi agrupada nos principais cortes industriais: gás, nafta $\left(\mathrm{C}_{5}-204^{\circ} \mathrm{C}\right)$, gasóleo leve $\left(204-350^{\circ} \mathrm{C}\right)$, gasóleo pesado (350 $\left.-550{ }^{\circ} \mathrm{C}\right)$ e resíduo $\left(550^{\circ} \mathrm{C}^{+}\right)$.

Carbonell e Guirardello (1997) realizaram simulações para estabelecer a hidrodinâmica (perda de pressão, distribuição radial de gás e de inventário de líquido, viscosidade e perfil de velocidade da fase líquida). Eles também supuseram reações de craqueamento térmico através de medidas radiais das variações das 
propriedades de transporte, de modo a prever a conversão de óleo pesado. Eles concluíram que o regime de escoamento de líquidos afeta fortemente os rendimentos de produtos. No entanto, a validação experimental não foi utilizada nestes modelos.

Mittal et al. (1999) desenvolveram a modelagem para serpentina-vaso de soaker como um reator tubular PFR juntamente com CSTR em série. A perda de pressão do forno foi estimada, utilizando a correlação Beggs e Brill (1973). A queda de pressão da serpentina, o perfil de temperatura e a conversão dos resíduos foram preditos dentro de uma faixa estreita de precisão. O modelo foi desenvolvido para uma carga e uma única reação de craqueamento, isto é, resíduo de vácuo convertendo em gás e nafta.

O principal problema com a modelagem de uma unidade de coqueamento retardado é a capacidade de caracterizar adequadamente a variedade de moléculas multifuncionais envolvidas. Xiao et al. (2002) desenvolveram modelos cinéticos de distribuição de produtos, onde as reações são consideradas de primeira ordem, os produtos não convertidos também não participam das reações secundárias.

Kataria et al. (2004) faz um levantamento bibliográfico e resume os dez modelos cinéticos publicados. As principais observações da pesquisa foram as seguintes:

A energia de ativação varia de acordo com as propriedades da carga, tais como: teores de saturados, polaridade dos aromáticos, teores de asfaltenos, resíduo de carbono Conradson, teores de enxofre e de metais. Para a energia de ativação das reações de craqueamento e de condensação, estima-se uma variação de 14 - 78 $\mathrm{kcal} / \mathrm{gmol}$ e 17 - $60 \mathrm{kcal} / \mathrm{gmol}$, respectivamente. Esta grande variação pode ser atribuída à grande variação da estrutura e da quantidade de grupos (lump). A composição do gás independe da severidade.

A facilidade de craqueamento térmico da carga é influenciada pelo grau de aromaticidade e o teor de asfaltenos. Durante o craqueamento térmico, as ligações carbono-carbono das parafinas se dividem, enquanto os asfaltenos continuam as reações de desalquilação. 
As tendências de não linearidade observadas para os destilados são provocadas pelas reações de condensação e pelo grau de severidade.

O peso molecular do gás combustível aumenta com o acréscimo do teor de asfalteno. A alta severidade provoca um leve aumento nas frações de $C_{3}, C_{4}$ e $C_{5}$. Isto indica que, em baixa severidade, ocorre primeiramente o craqueamento térmico das ramificações alquilas menores, possivelmente oriundas das moléculas de asfaltenos. Porém, com o aumento da severidade, é iniciado o craqueamento das ramificações das frações mais pesadas. Para uma dada carga, as proporções podem variar sensivelmente com o acréscimo de severidade em relação à operação da unidade. (KATARIA et al., 2004)

KATARIA et al. (2004) também propôs um modelo para obter os rendimentos de produtos com cinco grupos; diversos modelos cinéticos são de primeira ordem, como se pode observar na Figura 2.1.

Figura 2.1 - Proposta de modelo cinético com cinco grupos.

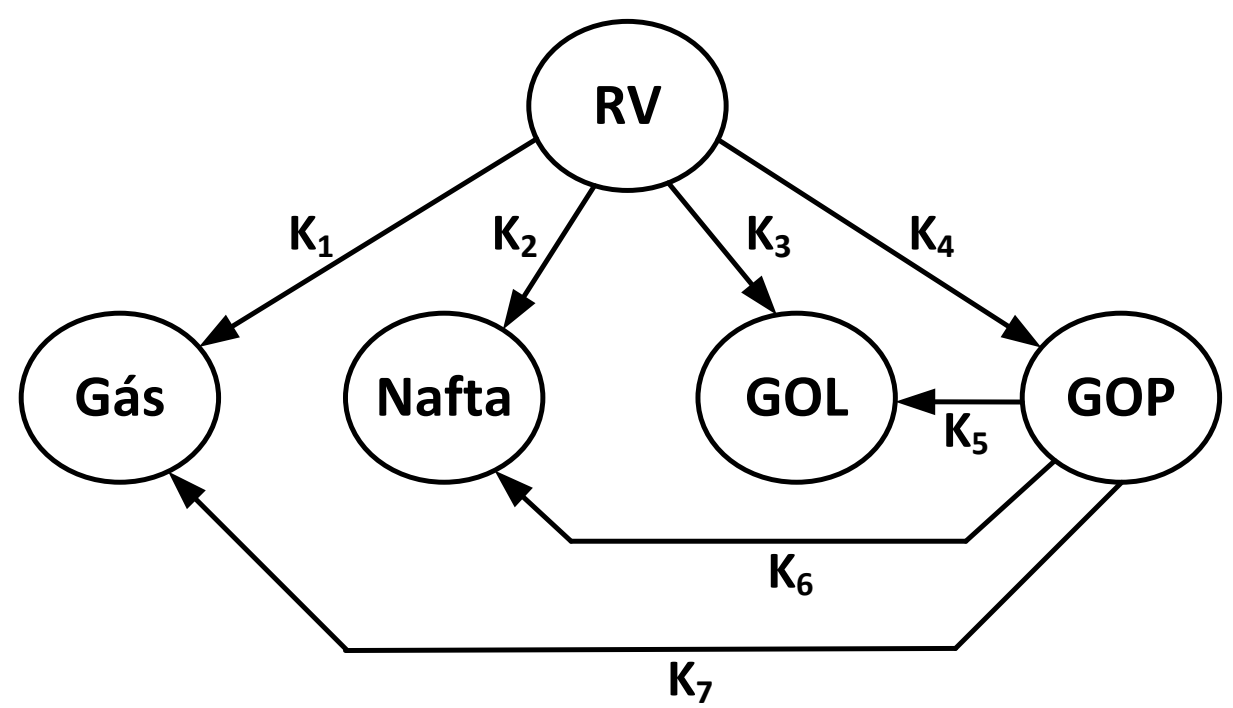

$\mathrm{Na}$ Tabela 2.1 são apresentados os quatros cortes (4 grupos) das frações de destilados. 
Tabela 2.1 - Faixa de temperatura dos cortes.

\begin{tabular}{cc}
\hline Cortes & Faixa \\
\hline Gás & $\mathrm{C}_{1}-\mathrm{C}_{5}$ \\
Nafta & $\mathrm{C}_{6}-150^{\circ} \mathrm{C}$ \\
Gasóleo leve & $150-350{ }^{\circ} \mathrm{C}$ \\
Gasóleo pesado & $350-500^{\circ} \mathrm{C}$ \\
\hline
\end{tabular}

Kulkarni (2005) modelou, em escala piloto, uma serpentina e um vaso de maturação do processo de viscorredução e tentou eliminar as diferenças entre os dados da planta piloto e de um reator em batelada. Ele multiplicou as constantes cinéticas dos reatores de batelada por um fator de escala. A serpentina foi assumida como sendo um reator tubular duplo, enquanto o vaso de maturação foi modelado como reator de mistura em série com interestágio de retro mistura.

Bozzano e Dente (2005) utilizaram uma abordagem mecanicista da pirólise em fase líquida de uma mistura de hidrocarbonetos para desenvolver modelos para o processo de coqueamento retardado. Inicialmente, um esquema cinético com cerca de 1600 reações com 450 componentes equivalentes foi preparado. Numa segunda etapa, as reações foram reduzidas a cerca de 700. Usando o conceito da estrutura orientada para a formação de agrupamentos (SOL - Structure Oriented Lumping). Tian, Shen e Liu (2012) descreveram os comportamentos das reações do processo de coqueamento retardado, considerando 92 tipos de moléculas single-core e 46 tipos de moléculas multicore para caracterizar o resíduo. Um total de 7004 tipos de agrupamentos de moléculas foram gerados para caracterizar a composição molecular dos resíduos. Estes exemplos mostram a complexidade da tarefa. Portanto, as técnicas empíricas de modelagem parecem ser a melhor abordagem para calcular os rendimentos do produto e, na prática, são preferíveis em processos de refino.

Zhou et al. (2007) propuseram um modelo cinético para o processo de coqueamento retardado com base em seis agrupamentos de composição da carga, incluindo saturados, aromáticos leves e pesados, bem como resinas e asfaltenos. O esquema de reação era composto por outras cinco espécies de produtos: gás, nafta, gasóleo 
leve, gasóleo pesado e coque. Os resultados revelaram que todos os parâmetros cinéticos foram invariantes com respeito à composição do resíduo de petróleo e, portanto, o modelo foi capaz de prever os rendimentos do produto para uma ampla variedade de carga e de valores das variáveis operacionais empregadas no teste.

Matheus (2008) desenvolveu a modelagem matemática e a simulação computacional de um forno para processos de conversão térmica de frações pesadas de petróleo. A modelagem foi baseada no modelo cinético das reações de conversão propostas por Sugaya (1993).

Zhou et al. (2010) apresentaram uma análise do efeito das principais variáveis de operação e o comportamento das reações durante todo o ciclo de enchimento de um reator de coque em três unidades industriais. Eles observaram que a temperatura das correntes de líquido e os rendimentos de nafta e gasóleo no reator permaneceram estáveis após algumas horas de operação.

Aguilar, Anchyeta e Trejo (2012) apresentou um modelo cinético de primeira ordem com cinco grupos para o processo de viscorredução, sendo seis reações secundárias. A constante cinética e a energia de ativação são determinadas com base no peso molecular do produto formado. Este modelo foi utilizado para simular um esquema de refino de fundo de barril baseado na rejeição de carbono. Uma estratégia similar pode ser utilizada no processo de coqueamento. $O$ coqueamento permite a polimerização ou a condensação até a formação de coque, proporcionando um acréscimo no teor de hidrogênio dos produtos líquidos por remoção de carbono, conhecido como "rejeição de carbono".

Rosal (2014) propôs um modelo matemático para um forno de coqueamento, baseado no modelo cinético de Singh (Singh et al., 2005), na caracterização da carga por agrupamentos e pseudocomponentes, no equilíbrio líquido-vapor e nos balanços de massa e energia.

Outros pesquisadores têm desenvolvido modelagem empírica para o processo de viscorredução e o processo de coqueamento retardado, utilizando correlações diferentes para determinar os rendimentos de produtos. Nas diversas publicações 
(KUO, 1984; MAPLES, 2000), a carga do forno é parcialmente craqueada em compostos leves, nafta e gasóleos. O coque formado é desprezado. A carga térmica fornecida no forno é para suprir o calor sensível, o calor de reação e o calor de vaporização.

Um exemplo foi apresentado por Maples (1993). O primeiro passo no desenvolvimento de suas correlações foi a determinação do rendimento de coque que utilizou o resíduo de carbono Conradson da carga. Os rendimentos dos outros produtos foram correlacionados mais satisfatoriamente com o rendimento de coque do que com o resíduo de carbono Conradson. Em seu modelo, Maples utilizou apenas $0^{\circ} \mathrm{API}$ da carga para o balanço material. Foi verificado que o resíduo de carbono foi o melhor parâmetro de ajuste, se comparado com $0^{\circ} \mathrm{API}$ da carga.

Castiglioni (1983) propôs um método gráfico para determinar os rendimentos do processo de coqueamento retardado em função de duas propriedades da carga ( ${ }^{\circ} \mathrm{API}$ e resíduo de carbono Conradson) e três variáveis operacionais (razão de reciclo, pressão e temperatura do topo do reator de coque). Os produtos do coqueamento são: gás combustível, nafta, gasóleo e coque. A corrente de gás é dividida em fração leve e propano, enquanto a corrente de nafta é dividida em butanos e na fração $\mathrm{C}_{5}-204{ }^{\circ} \mathrm{C}$. O método é dividido em três etapas. Na primeira etapa, a pressão de referência (0 psig) e a pressão real do reator são considerados para estimar o rendimento de coque, utilizando o teor de resíduo de carbono Conradson da carga e a temperatura de operação. Na segunda etapa, fatores de correção são determinados como função da razão de reciclo (CFR - Combined Feed Ratio). Na terceira etapa, uma segunda série de fatores de correção é obtida em função da razão de reciclo de operação. Finalmente, o fator de correção para nafta e o coque são obtidos em função do rendimento de gasolina e de coque, respectivamente.

Predel (1992) comparou várias abordagens para a modelagem empírica de unidades de coqueamento retardado. As condições operacionais também foram incluídas nas correlações. Além disso, verificou-se que a inclusão de análises da carga por HPLC (high performance liquid cromatography) melhora o modelo. $O$ rendimento de coque foi estimado dentro de faixa de $0,50 \%$, comparado com os valores medidos. 
Volk et al. (2002) propuseram um conjunto de correlações lineares para determinar os rendimentos de produto como função do resíduo microcarbon (MCR, em $\%$ massa), da temperatura ( $\mathrm{T}$, em $\left.{ }^{\circ} \mathrm{F}\right)$, da pressão ( $\mathrm{P}$, em psia), e da velocidade espacial de líquido (LSV, em $\left.\min ^{-1}\right)$. A faixa de condições operacionais usada para desenvolver as correlações foi $482-510{ }^{\circ} \mathrm{C}, 0,42$ - 2,80 bar, e MCR de 16 a $29 \%$ massa. Os autores afirmaram que as correlações não poderiam ser utilizadas para predizer rendimentos de coque em unidades industriais, por causa dos baixos rendimentos dos líquidos obtidos no micro reator, em comparação com os observados em refinarias. Além disso, as correlações incluem os efeitos de LSV, que têm um significado diferente para unidades industriais. Por estas razões, Ren et al. (2012) propuseram uma correção para derivar rendimentos de produto. Foi proposto que os rendimentos dos produtos do coqueamento retardado são dependentes de algumas propriedades da carga e das condições de operação, usando um polinômio quadrático com sete parâmetros.

Kataria et al. (2004) propôs um modelo para obtenção dos rendimentos dos produtos no forno, utilizando o índice de severidade e as propriedades da carga.

Smith et al (2006) propuseram correlações para determinar os rendimentos dos produtos, utilizando como base as correlações propostas por Gary, Handwerk e Kaiser (2007). As correlações foram baseadas no resíduo de carbono Conradson para estimar os rendimentos de coque, gás, nafta e gasóleos, considerando o efeito da pressão.

Sayles e Romero (2011) propôs um modelo cinético genérico simples para o processo de coqueamento que consiste de reações de craqueamento térmico e de polimerização.

\subsection{Considerações}

Diferentes modelos têm sido propostos para o forno de coqueamento e o reator de coque, levando em consideração o equilíbrio líquido-vapor com reações químicas, principalmente em fase líquida. 
O desenvolvimento dos modelos cinéticos baseia-se principalmente em técnicas de agrupamento, em que cada grupo é constituído por apenas um pseudocomponente: gás, nafta, gasóleo leve, gasóleo pesado e resíduo. Uma dificuldade apresentada nos modelos cinéticos por agrupamento é a faixa de ponto de ebulição diferente dos produtos para obter as constantes cinéticas propostas pelos pesquisadores. Isto dificulta a comparação dos parâmetros cinéticos e predição de rendimentos de produtos em outras faixas de cortes. Com o propósito de sobrepassar essa dificuldade, foi estabelecido no desenvolvimento do modelo proposto neste trabalho que cada agrupamento (gás, nafta, gasóleo leve, gasóleo pesado e resíduo) fosse constituído de diversos pseudo-componentes ou componentes puros. Isto tem a vantagem de permitir estabelecer outras faixas de cortes.

Vários pesquisadores têm considerado a serpentina do forno de coqueamento como um reator tubular e o reator de coque como reator CSTR (Continuous Stirred Tank Reactor).

A maioria dos modelos propostos para o forno de coqueamento despreza a formação de coque devido o curto tempo de residência.

A proposta desse trabalho foi realizar uma abordagem dos fenômenos físicoquímicos nos dois equipamentos do processo de coqueamento retardado, forno e reator. Enquanto diversas publicações disponíveis fazem uma abordagem dos equipamentos individualmente.

As principais contribuições foram caracterização dos asfaltenos por espectrometria de massa correlacionando com a viscosidade do resíduo de vácuo, estimativa da análise S.A.R.A. (Saturados, Aromáticos, Resinas e Asfaltenos), caracterização do vapor de topo do reator de coque, a influência do teor de asfalteno no atendimento a especificação do coque grau anodo. 


\section{PROCESSO DE COQUEAMENTO RETARDADO}

\subsection{Esquema básico de refino}

Basicamente, uma refinaria de petróleo pode ser considerada como uma rede complexa de unidades de processo integradas, cuja finalidade é produzir uma variedade de derivados de petróleo (Figura 3.1). Geralmente, é processada uma cesta de elenco de petróleo compatível com a produção de derivados desejados.

Figura 3.1 - Esquema básico de uma refinaria de petróleo (SPEIGHT, 1999).

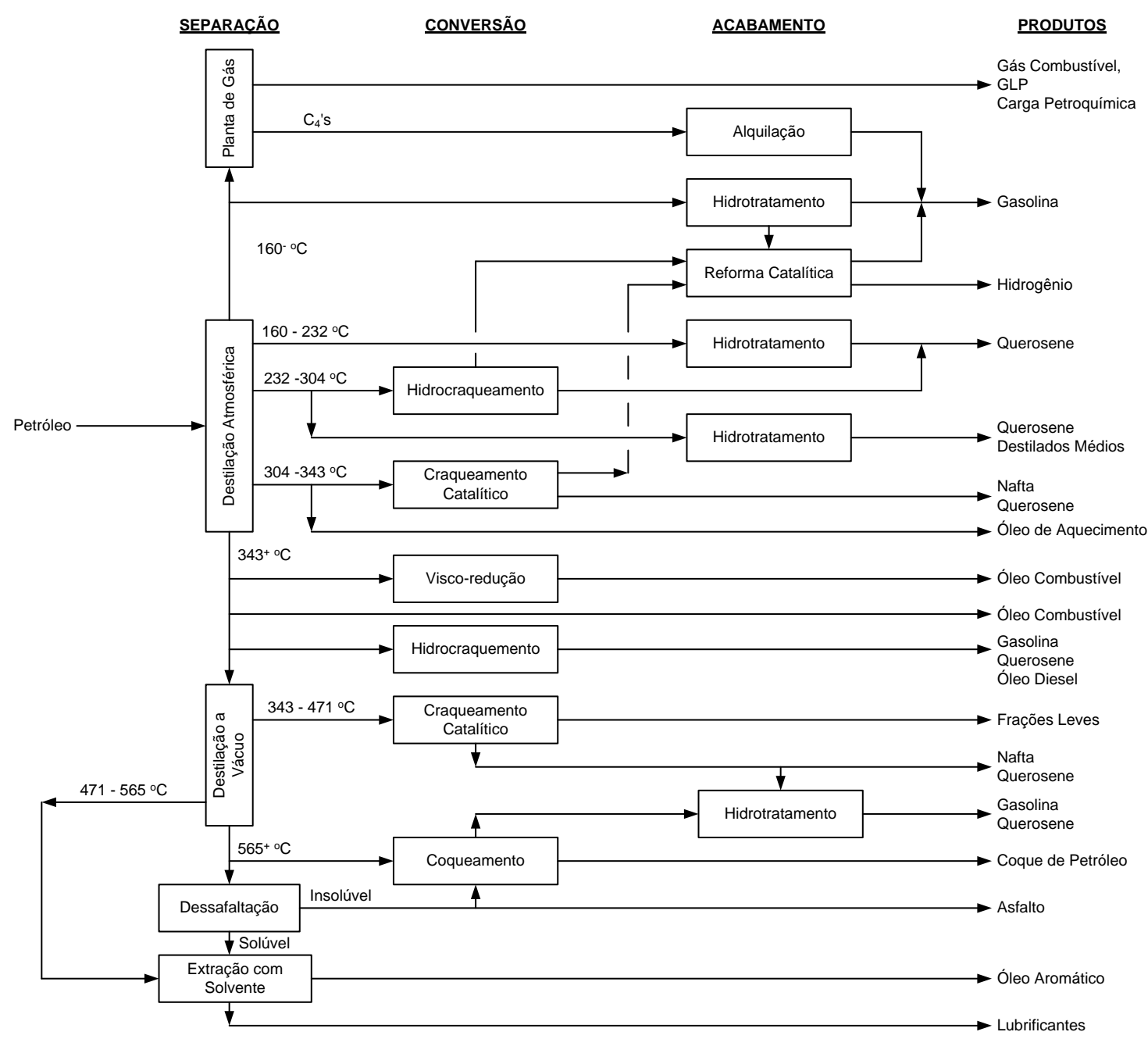

Os processos de uma refinaria podem ser divididos em três grupos principais: separação, conversão e acabamento. 
$\mathrm{Na}$ separação, ocorre o fracionamento do petróleo em várias frações através de destilação, que depende da natureza do elenco.

Essencialmente, os processos de conversão são responsáveis por modificar o número de átomos de carbono por molécula, alterando a relação molecular carbonohidrogênio ou a estrutura molecular sem afetar o número de átomos de carbono por molécula. Normalmente, estes processos proporcionam alta rentabilidade quando transformam frações de baixo valor comercial (gasóleos e óleos residuais) em outras de maiores valores (GLP - Gás Liquefeito de Petróleo, naftas, querosene e diesel) (BRASIL, 2014).

O acabamento de natureza química não tem a finalidade de provocar profundas mudanças nas frações; e sim, causar a melhoria da qualidade de cortes semiacabados através de uma variedade de processos, incluindo a remoção das impurezas presentes nos produtos, tais como: compostos sulfurosos e nitrogenados.

\subsection{Processo de coqueamento retardado}

\subsubsection{Histórico}

O primeiro coque de petróleo foi produzido nas refinarias de petróleo localizadas no noroeste da Pensilvânia, na década de 1860. Nas unidade primitivas de destilação, constituídas de pequenos vasos aquecidos no fundo por uma fornalha a lenha e a carvão, o petróleo era fervido para obter principalmente o querosene iluminante. Após o resfriamento dos vasos, os trabalhadores removiam manualmente o coque e o resíduo asfáltico com auxílio de pás e picaretas.

$\mathrm{Na}$ década de 1880 , este processo evoluiu para o uso de "vasos horizontais". Inicialmente, eram únicos, depois múltiplos e em série de onde eram obtidas outras frações de destilados. O coque era a primeira fração depositada. Os "destiladores" horizontais recebiam calor proveniente de carvão e, eventualmente, do próprio coque produzido. Com pás, barras de ferro e picaretas, o coque era removido a partir da abertura de uma extremidade do vaso. A espessura do coque formado 
nesses vasos horizontais (processo em batelada) era de 150 a $750 \mathrm{~mm}$. Possuía uma aparência brilhante e lustrosa. Os teores de matéria volátil e de cinzas eram da ordem de 8 e $1 \%$ massa, respectivamente. E também era caracterizado pela pequena geração de finos. (ELLIS e PAUL, 1998)

Na década de 1920, um forno tubular e uma torre de destilação foram introduzidos ao processo. O petróleo era aquecido no forno e enviado para a torre de destilação. O produto de fundo (cru reduzido ou resíduo) da torre era carregado em tanques horizontais. Isto permitia produzir um volume máximo de gasóleo. Algumas dessas unidades permaneceram em operação após a Segunda Guerra Mundial e necessitavam do mesmo processo manual de descoqueamento. (ELLIS e PAUL, 1998)

A concepção de forno com torre de destilação abriu caminho para a construção da primeira unidade de coqueamento retardado pela companhia Standard Oil na cidade de Whiting (Indiana, Estados Unidos), em 1929. (ELLIS e PAUL, 1998)

O processo de coqueamento retardado combinava uma série de recursos e de melhorias oriundo do processo de craqueamento térmico de gasóleo, tais como: o uso de pressão, calor para o craqueamento, a separação entre o forno e o reator de coque e a utilização de dois reatores para que a unidade operasse em regime contínuo.

O número de unidades de coqueamento retardado entre 1929 e 1955 era pequeno, mas um crescimento ocorreu entre 1955 e 1975. (HECK, 1972).

$\mathrm{Na}$ década de 1950, foram desenvolvidas outras tecnologias de coqueamento, Fluid Coking e Flexicoking. Em 1954, foi construída a primeira unidade Fluid Coker (Billings, Montana). No final de 1950, muitos pensavam que todas as novas unidades construídas seriam de Fluid Cokers. Porém, em função do menor investimento, a unidade de coqueamento retardado ainda era a preferida dos refinadores. (GARY, HANDWERK e KAISER, 2007; GRAY, 2015) 
Atualmente, a unidade de coqueamento retardado é o único processo semicontínuo em uma refinaria.

\subsubsection{Descrição do processo}

A Figura 3.2 ilustra um desenho simplificado de fluxo do processo de coqueamento retardado. A carga de resíduo de vácuo flui para seção inferior da torre fracionadora (ou torre combinada). A seção inferior da torre funciona como um vaso acumulador de carga destinada ao forno de coqueamento e também uma região de troca térmica entre o vapor de topo do reator e o resíduo de vácuo. Nesta seção, a fração pesada do vapor de topo do reator é condensada e incorporada ao resíduo de vácuo, formando a carga combinada cujo destino é o forno. A fração condensada da corrente de topo do reator de coque é chamada de reciclo (GARY, HANDWERK e KAISER, 2007).

Figura 3.2 - Esquema simplificado do processo de coqueamento retardado.

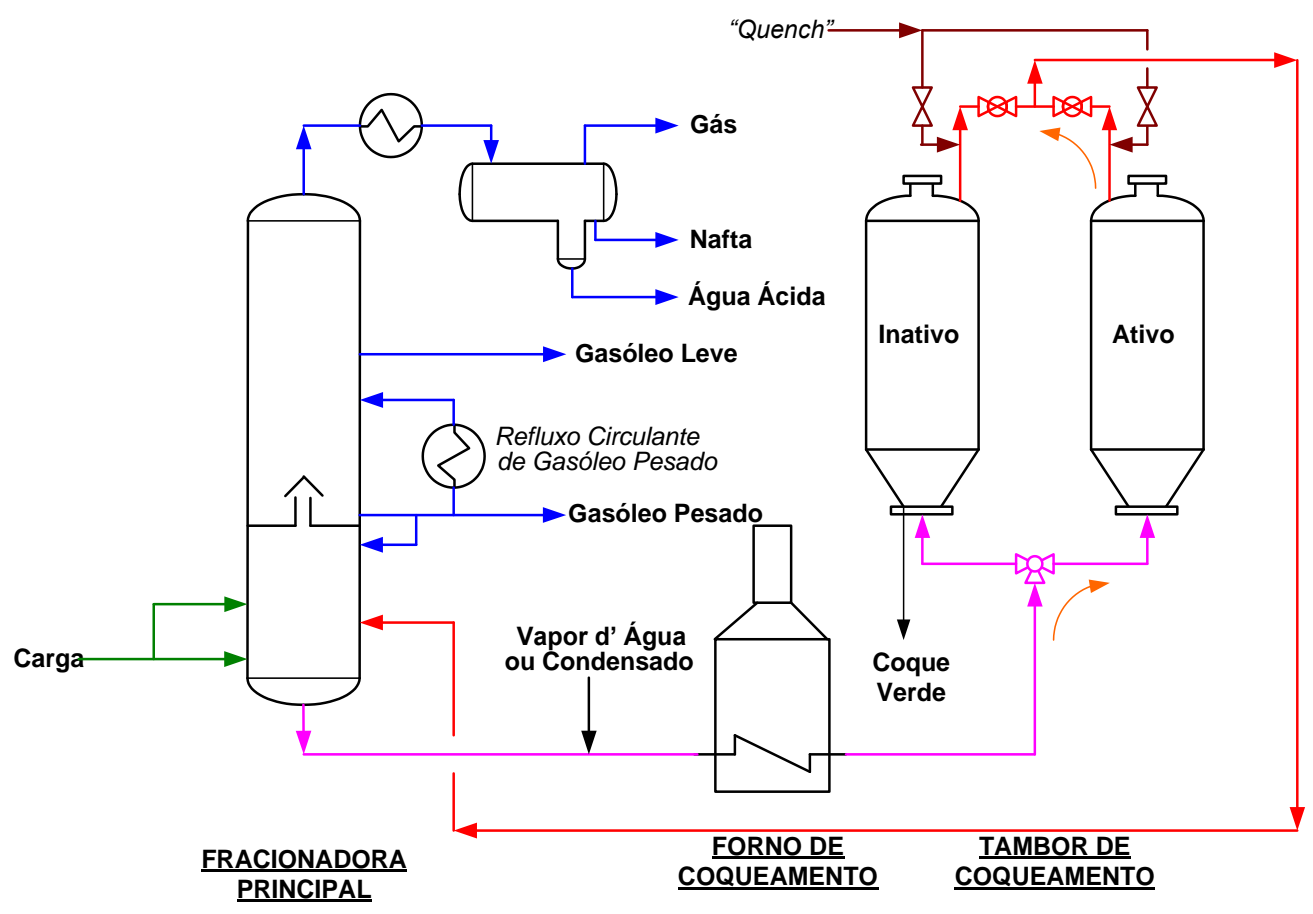

O forno de coqueamento aquece a carga combinada até $500^{\circ} \mathrm{C}$, aproximadamente. Ao ser aquecida nos passes do forno, a carga combinada alcança a temperatura de craqueamento térmico das cadeias pesadas, iniciando a conversão em gás, GLP, 
nafta e gasóleo. No forno, é mantido um curto tempo de residência nos tubos, visando retardar o coqueamento do fluido. Em seguida, a corrente produto de saída do forno flui através da linha de transferência até uma válvula especial de três vias, que direciona o fluxo para o fundo de um dos reatores de coque do par (PARKASH, 2003).

No reator ativo, ocorre um enchimento gradual do reator por um período de 18 a 24 horas e simultaneamente o produto de saída do forno é convertido em corrente gasoso e coque, resultantes das reações de craqueamento térmico e de coqueamento. A corrente gasosa, ao deixar o reator, recebe uma injeção de gasóleo para reduzir a temperatura em cerca de $15^{\circ} \mathrm{C}$, visando interromper as reações químicas em fase gasosa. Após o resfriamento, flui para a seção de fundo da torre fracionadora. As atividades de remoção do coque acumulado ao longo do ciclo permanecem em execução no outro reator (ELLIOTT, 1991).

Neste processo, os parâmetros chaves são uma combinação de tempo de residência e de temperatura para promover as reações de craqueamento térmico. Os principais parâmetros operacionais de processo de coqueamento são: razão de reciclo, perfil de temperatura, pressão, tempo de enchimento do reator e características da carga. Além disso, o processo de coqueamento retardado é endotérmico, sendo o forno a fonte de calor necessária para completar as reações químicas no reator de coque (ELLIOTT, 2003 e FAEGH e COLLINS, 2010).

$\mathrm{Na}$ torre fracionadora, os vapores gerado no reator, com base no ponto de ebulição, é condensado e separado em cinco frações desejadas: gás, nafta, gasóleo leve, gasóleo pesado e reciclo. Depois que o reator ativo está cheio de coque solidificado, a mistura quente do forno é encaminhada para o segundo reator. Enquanto o segundo reator está enchendo, o leito do reator cheio é retificado com vapor d' água para remover os hidrocarbonetos voláteis. Em seguida, é resfriado com água. Os flanges de topo e de fundo do reator são removidos, e o coque sólido é cortado com um jato de água em alta pressão. O coque cai num poço para drenagem e posterior armazenamento. 
O coque produzido pode apresentar três estruturas físicas distintas: shot-coke, esponja e agulha. As características de cada tipo de coque serão discutidas posteriormente (PARKASH, 2003; GARY, HANDWERK e KAISER, 2007).

\subsection{Fundamentos}

O petróleo é uma mistura complexa de hidrocarbonetos de diversos tamanhos e de ampla variedade de estruturas químicas. Após a destilação à vácuo, é formada uma corrente de resíduo de vácuo (Figura 3.3). Nela, concentram-se frações pesadas não voláteis, contendo macromoléculas de asfaltenos e de resinas.

Figura 3.3 - Curva de ponto de destilação verdadeiro para o petróleo (SPEIGHT, 2001).

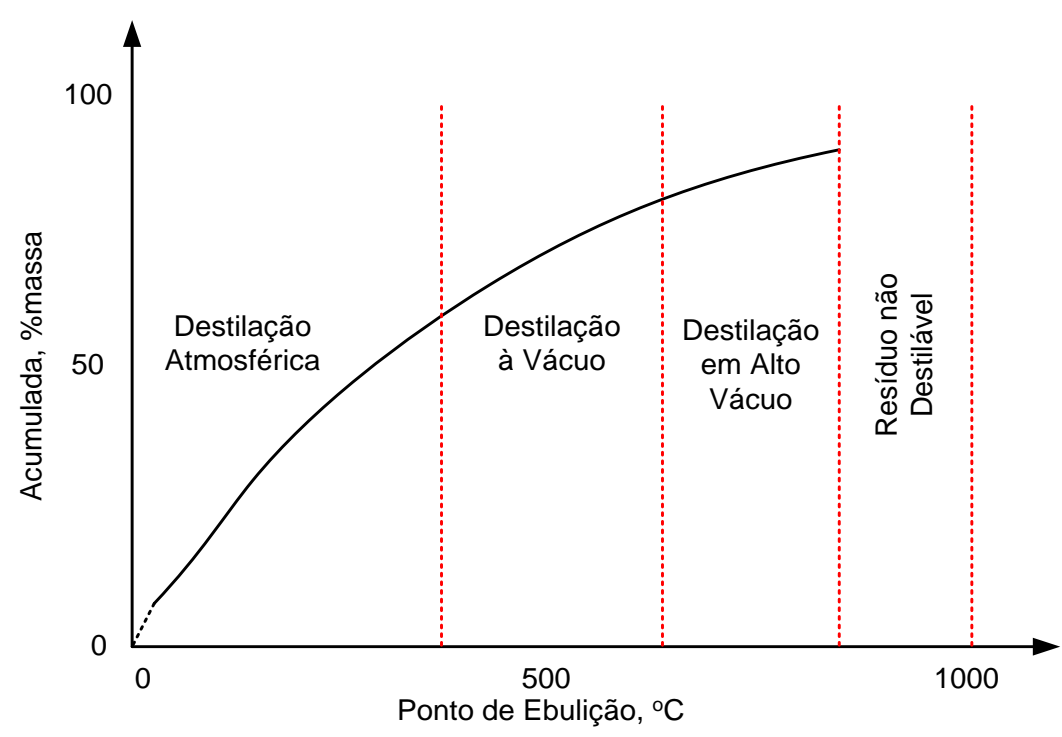

Os asfaltenos são macromoléculas complexas. Possuem forte caráter aromático e baixo teor de hidrogênio. Contêm heteroátomos de enxofre, de nitrogênio e de oxigênio, de metais (níquel e vanádio) e cadeias laterais alifáticas. Eles formam micelas com a fração de maltenos (saturados + aromáticos + resinas) presente no resíduo de vácuo. 
Em um óleo estável, todas as forças de atração entre as moléculas de asfaltenos e de resinas estão saturadas, levando as micelas a estabelecer um equilíbrio físico com a fase oleosa vizinha. Logo, os asfaltenos estão emulsionados (HUS, 1981).

As resinas são macromoléculas polares com alto peso molecular. São insolúveis em propano líquido, mas solúveis em n-heptano. No petróleo, o teor de resinas é superior ao de asfaltenos.

$\mathrm{Na}$ Figura 3.4, é representado um diagrama triangular de fase com três componentes: asfaltenos, saturados e aromáticos. Uma área de imiscibilidade existe entre os asfaltenos e os saturados. (HUS, 1981) Vários fatores podem perturbar o equilíbrio líquido-líquido, tais como: aumento de temperatura e adição de hidrocarbonetos alifáticos.

Figura 3.4 - Estabilidade de resíduo (HUS, 1981).

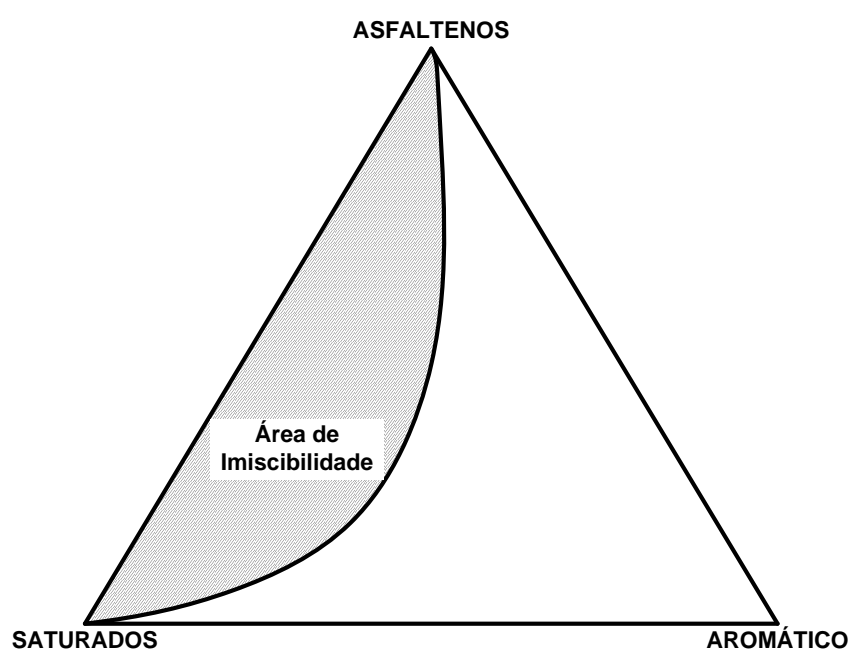

A temperatura alta favorece o rápido craqueamento das ramificações das cadeias alifáticas que constituem os núcleos de asfaltenos. Há, com isto, o aumento do parâmetro de solubilidade dos asfaltenos em relação ao restante dos hidrocarbonetos apolares. Consequentemente, favorece-se a separação dos asfaltenos devido à maior área superficial de partícula (ALLA et al., 1983; SPEIGHT, 1998). 


\subsubsection{Forno de coqueamento}

No forno de coqueamento, ocorre o craqueamento térmico das moléculas da fase oleosa contínua. Uma nova molécula de asfalteno é formada a partir das moléculas de maltenos, modificando o caráter da fase contínua de maltenos a medida que altera sua composição. O desenvolvimento da reação afeta o equilíbrio entre asfaltenos e maltenos, podendo alcançar o ponto de floculação dos asfaltenos. Neste ponto, o resíduo craqueado torna-se instável.

De acordo com Elliot (2009), o mecanismo exato de coqueamento retardado é tão complexo que não é possível determinar todas as ocorrências de reações químicas. Mas, é possível distinguir três etapas:

- $\quad$ vaporização parcial e craqueamento térmico moderado da carga combinada durante o escoamento do fluido através do forno;

- $\quad$ craqueamento térmico da fase vapor no interior do reator;

- craqueamento térmico sucessivo e polimerização do líquido pesado contido no interior do reator até a conversão em vapor e coque.

Sayles e Romero (2011) propôs um modelo cinético genérico simples para o processo de coqueamento que consiste de reações de craqueamento térmico e de polimerização conforme ilustrado na Figura 3.5. 
Figura 3.5 - Mecanismo para o coqueamento (SAYLES e ROMERO, 2011).

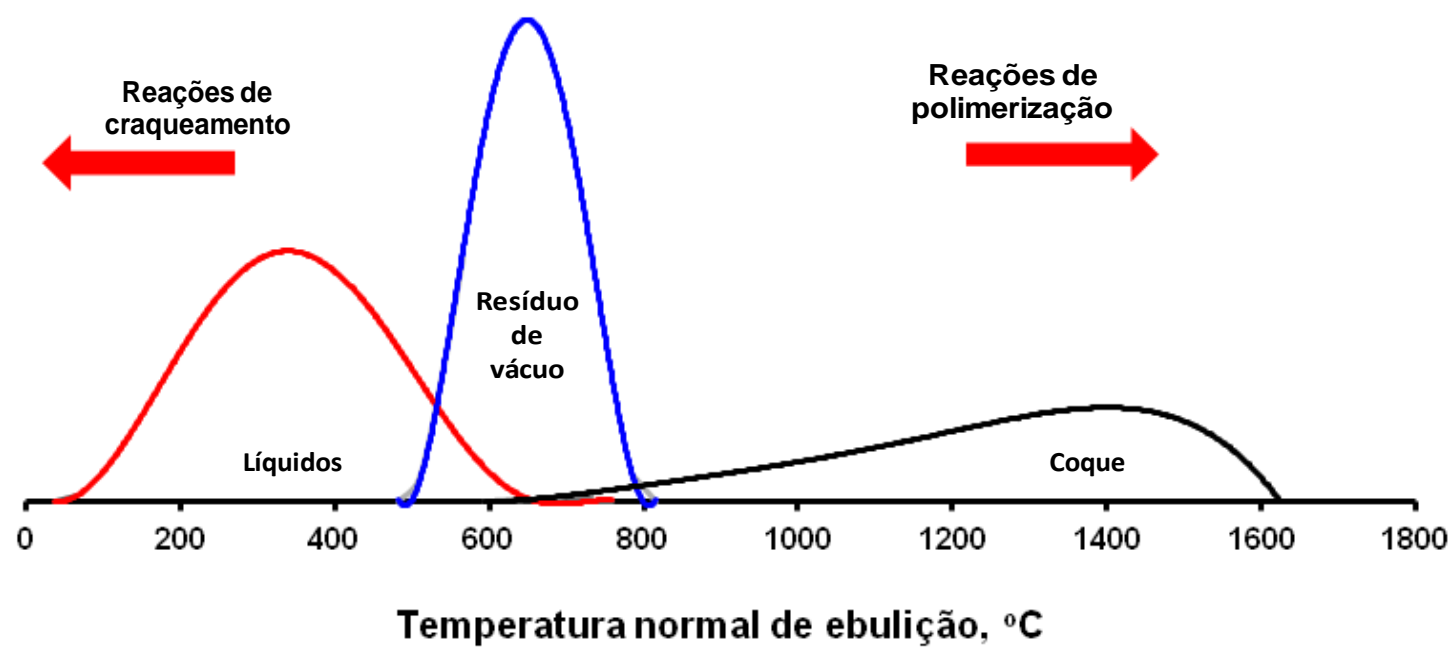

A reatividade de craqueamento dos diversos hidrocarbonetos para as várias famílias decresce na seguinte ordem:

n-parafinas $>$ iso-parafinas $>$ ciclo parafinas $>$ naftênicos $>$ aromáticos

No processo de viscorredução, a severidade do craqueamento ou da conversão é limitada pela estabilidade do óleo residual final. A severidade pode ser definida conforme as seguintes considerações: estabilidade do óleo residual produzido, redução da viscosidade do produto e formação de produtos leves da conversão (HUS, 1981; McKETTA, 1992; KATARIA et al., 2004).

No forno, podem ocorrer as seguintes principais reações:

- Quebra das ramificações laterais das moléculas de parafinas, o que reduz o ponto de fluidez;

- Craqueamento dos anéis de naftenos ocorre a partir de $482{ }^{\circ} \mathrm{C}$, aproximadamente; 
- Formação de coque pode ser por polimerização, policondensação, hidrogenação e desalquilação;

- Craqueamento térmico, favorecendo a precipitação do asfalteno e do coque na fase líquida.

A reação de craqueamento térmico dos hidrocarbonetos pode ser representada por um mecanismo de reações monomoleculares, resultante de radicais livres. A cinética pode ser escrita como de primeira ordem (NELSON, 1958 e HUS, 1981):

$$
\ln \frac{1}{1-x}=k \cdot t
$$

onde: $x$ - fração convertida

$\mathrm{k}$ - constante cinética

$\mathrm{t}$ - tempo.

A constante de velocidade cinética depende dos seguintes fatores:

- $\quad$ Tipo de hidrocarboneto

- Peso molecular e ponto de ebulição dos componentes

- Constante de Arrenhius:

$$
\ln K=\ln A-\frac{E}{R \cdot T}
$$

A energia de ativação é da ordem de $40 \mathrm{kcal} / \mathrm{gmol}$ e $50 \mathrm{kcal} / \mathrm{gmol}$ para componentes com 40 e 15 carbonos (gasóleo), respectivamente. As reações de policondensação de asfaltenos e a formação de coque têm uma energia de ativação de 60 a 90 $\mathrm{kcal} / \mathrm{gmol}$. Em temperatura alta, a reação de condensação torna-se relativamente mais importante do que em baixa temperatura. (HUS, 1981) 
Boashi et al.(2012) realizou uma investigação experimental das reações secundárias intermediárias no processo de coqueamento retardado. Os resultados mostraram um baixo craqueamento térmico na fração nafta e gasóleo leve, enquanto o gasóleo pesado favorece a conversão em gás, frações líquidas e coque.

O forno de coqueamento é dividido em duas seções distintas: pré-aquecimento e reação. $\mathrm{Na}$ seção de preaquecimento, aquece-se o fluido até $427{ }^{\circ} \mathrm{C}$, aproximadamente. Na seção de reação, fornecem-se calor e tempo de residência necessário para as reações de craqueamento térmico. Na Figura 3.6, é ilustrado o comportamento do fluido ao longo da serpentina do forno.

Mekler e Fairall (1959) propõe um critério para determinar a temperatura da zona crítica de decomposição, no interior da serpentina, em função da natureza química da carga, como representado pela Figura 3.7. A área entre os limites inferior e superior indica a região onde é iniciado o craqueamento térmico. Abaixo da curva de limite inferior, o resíduo torna-se instável, e ocorre apenas a precipitação de sedimentos, quando armazenado.

Heck (1972) menciona várias características de projeto a serem consideradas em um forno de coqueamento, tais como: mínimo tempo de residência na seção de reação; fluxo de calor cujo mínimo efeito de má distribuição é baseado na área periférica do tubo; múltiplas injeções de vapor d' água em cada passe do forno e alta velocidade do fluido no interior no tubo (BARLETA, 2002). O rápido coqueamento de um forno é causado pela combinação da temperatura de filme, pelo tempo de residência e pela instabilidade térmica do óleo. Akbar e Geelen (1981) propôs valores de tempo de residência do óleo no interior da serpentina do forno em função da temperatura de filme conforme apresentado na Figura 3.8. 
Figura 3.6 - Perfil típico numa serpentina do forno de coqueamento (ROSE, 1971).

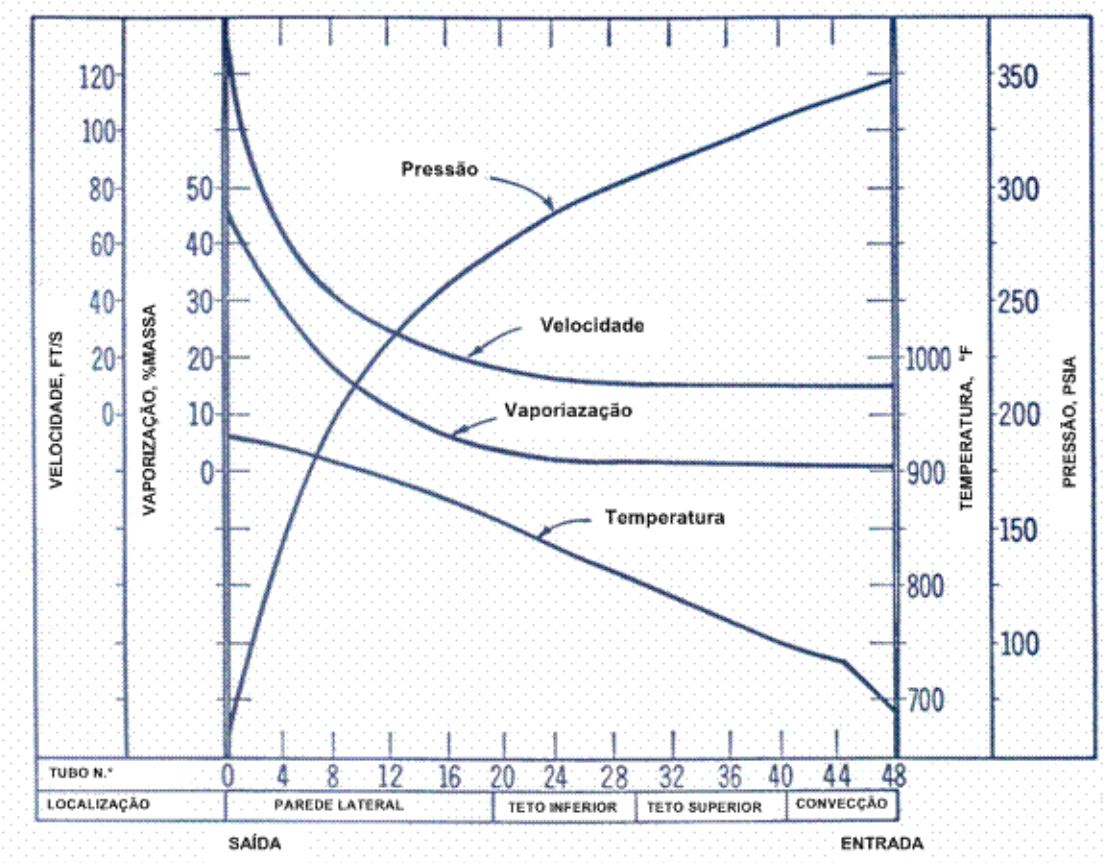

Derakhshesh (2013) estudou a influência dos asfaltenos sobre as incrustações em fornos de coqueamento, identificando que os efeitos mais severos ocorreram com as misturas de asfaltenos instáveis.

No projeto de forno são considerados dois parâmetros relevantes: fluxo mássico e fluxo de calor. Elliot (2003) propõe um fluxo mássico entre 1700 e $2200 \mathrm{~kg} /\left(\mathrm{m}^{2} . \mathrm{s}\right)$, para aumentar a turbulência e obter um coeficiente de película interno máximo. $\mathrm{O}$ benefício é o decréscimo da taxa de formação de coque sobre a parede do tubo. 
Figura 3.7 - Início do craqueamento térmico incipiente (MEKLER, 1950).

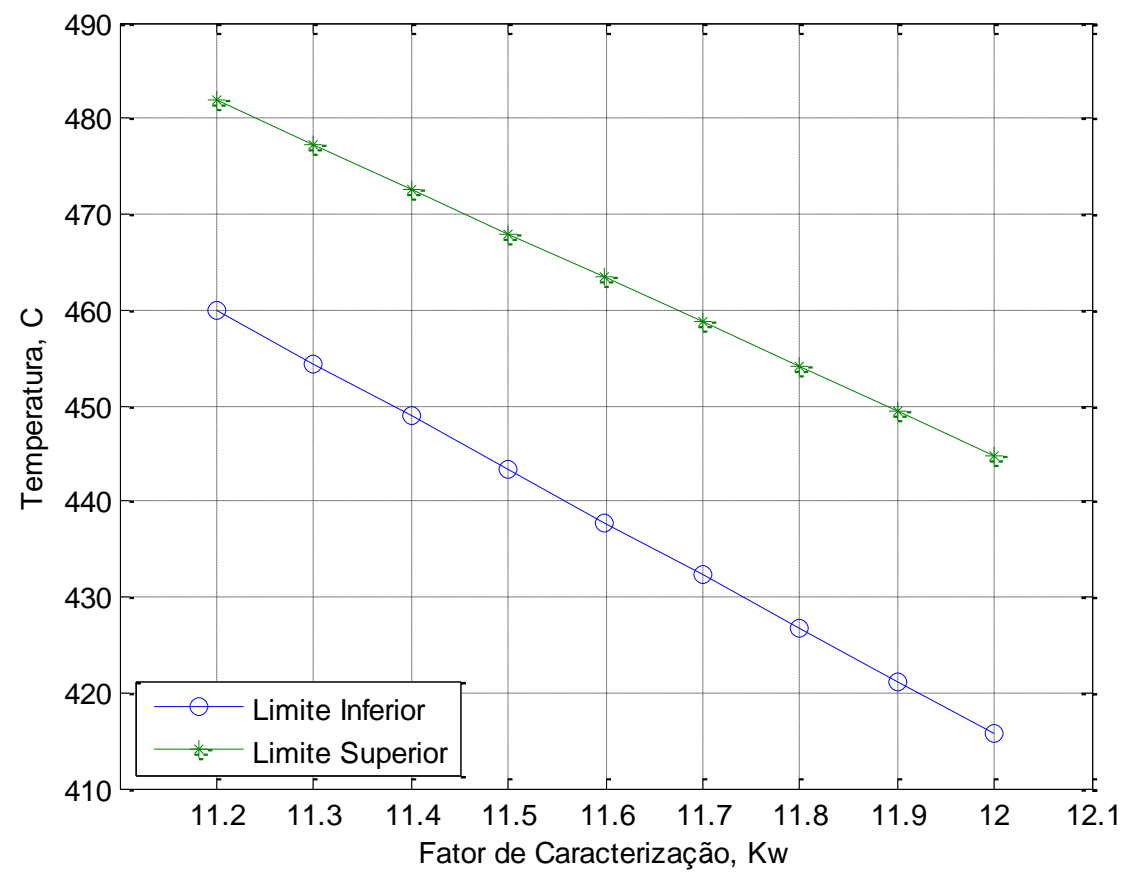

Figura 3.8 - Tempo de residência do óleo com temperatura (AKBAR e GEELEN, 1981).

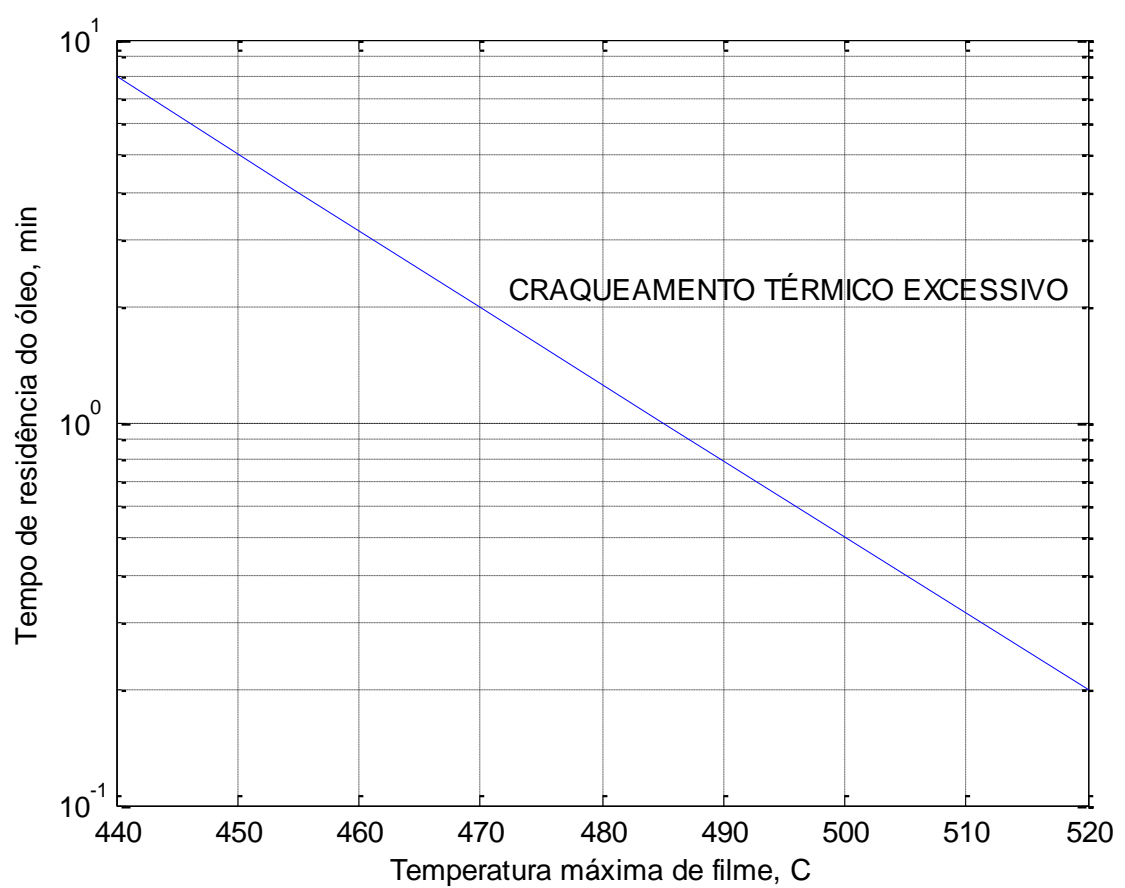

A experiência de diversos autores tem mostrado que à medida que aumenta o fluxo de calor, o tempo de campanha do forno é reduzido, dependendo da sensibilidade 
térmica da carga (LIEBERMAN, 1991). Romero (2010) faz uma comparação entre um forno single fired e um forno double fired e conclui que é possível aumentar o fluxo médio de calor, mantendo o mesmo fluxo máximo. A Tabela 3.1 apresenta valores típicos de fluxo de calor na seção de reação. Em projetos recentes, tem sido utilizado double fired quando é processada carga pesada e rica em asfaltenos. (ELLIOTT, 2003)

Tabela 3.1 - Valores típicos de fluxo de calor na seção de reação.

\begin{tabular}{lcc}
\hline Tipo de forno & Fluxo médio, $\mathrm{kW} / \mathrm{m}^{2}$ & Fluxo máximo, $\mathrm{kW} / \mathrm{m}^{2}$ \\
\hline Single fired & 31,545 & 56,782 \\
Double fired & 47,319 & 56,782 \\
\hline
\end{tabular}

Fonte: Romero (2010)

Heck (1972) propõe o critério de conversão por passe de 4 - 6 \%volume líquido, como $\mathrm{C}_{4}-204{ }^{\circ} \mathrm{C}$, e o calor absorvido do forno na faixa de 0,9 a $1,1 \mathrm{kcal} /(\mathrm{kg}$ carga $\mathrm{x}$ $\left.{ }^{\circ} \mathrm{C}\right)$. O software Visbreaker-Sim $\Theta$ também utiliza o critério de conversão por passe e um calor de reação de $2,22 \mathrm{kcal} / \mathrm{gmol} \mathrm{C}_{4}-204^{\circ} \mathrm{C}$. Outro aspecto a ser considerado é o regime de escoamento na seção de reação do forno. Duas diferentes fases estão presentes: fase vapor, resultante da vaporização das frações leves geradas pelas reações de craqueamento, e fase líquida. Ao longo da campanha, ocorre o coqueamento no interior do tubo, causando um acréscimo diário da temperatura de parede do tubo em cerca de 0,3 - 0,5 ${ }^{\circ} \mathrm{C} / \mathrm{dia}$. Quando o limite máximo da temperatura de parede é alcançado, é realizado um procedimento para descarbonização do forno. Nos fornos de viscorredução, com este regime de escoamento anular tem provocado um acréscimo no fenômeno de coqueamento, acelerando a taxa de evolução da temperatura de parede da serpentina. (AGORRETA, 2011)

Kern (1959) utiliza a equação de balanço de massa para descrever o fenômeno de acúmulo como mostrado na equação (3.3):

$$
\text { (acúmulo de depósito })=(\text { formação })-(\text { remoção })
$$


O termo da taxa de formação de depósitos depende da cinética de reação química, enquanto o de remoção é uma função da força de aderência do depósito e da tensão de cisalhamento do fluido. A diferença pode ser definida como taxa líquida de formação de depósito. Foram publicados diversos modelos de predição de taxa de acúmulo de depósito. Dentre eles, Polley (2005) propõe uma correlação em função dos Números de Reynolds e Prandtl, energia de ativação e temperatura de parede.

Wiehe (2006) propõe duas reações químicas em série para explicar o mecanismo de coqueamento da serpentina do forno.

- Reação n. ${ }^{\circ}$ 1: Os maltenos são convertidos em asfaltenos.

- $\quad$ - Reação n. ${ }^{\circ}$ 2: Os asfaltenos formam núcleos de asfaltenos.

A solubilidade destes núcleos de asfaltenos está sujeita à concentração máxima, precipitando o excesso.

\subsubsection{Reator de coque}

Mekler (1959) informa que a principal função do reator de coque é fornecer volume máximo para o acúmulo do coque produzido durante o enchimento normal de $24 \mathrm{~h}$. No projeto do reator de coque, também são necessários considerar a velocidade superficial máxima admissível, o nível máximo do leito de coque e as características da espuma. O reator, além de acumular o coque produzido, deve permitir um tempo de residência mínimo para concluir as reações de coqueamento. (WODNIK, 2005)

Até a década de 80 , as dimensões do reator de coque foram alteradas significativamente com 0 desenvolvimento da metalurgia e das técnicas de soldagem, conforme ilustradas na Tabela 3.2. A altura máxima foi limitada pela tecnologia de descoqueamento. (ROSE, 1971)

Ellis e Hardin (1993), em sua pesquisa sobre formação do leito de coque, identifica o desenvolvimento de um canal principal para o escoamento de uma mistura 
multifásica. A formação deste canal é iniciada quando o leito encontra-se no estado pastoso. Com o avanço do enchimento, são formados canais múltiplos de alimentação e a carga aquecida é distribuída. Na Figura 3.9, é ilustrado o desenvolvimento de um leito de coque.

Tabela 3.2 - Dimensões do reator de coque (SAWARKAR, 2007).

\begin{tabular}{ccc}
\hline Ano & Diâmetro, $m$ & Altura de flange-flange, $m$ \\
\hline Antes de 1940 & 3,0 & 12,2 \\
1946 & 5,2 & 20,7 \\
1952 & 6,1 & 25,6 \\
1967 & 7,3 & $>30,0$ \\
1980 & 8,2 & $>35,0$ \\
1999 & 8,5 & $>36,6$ \\
\hline
\end{tabular}

Fonte: Sawarkar, Pradit e Joshi (2009)

Figura 3.9 - Detalhes do enchimento do reator de coque (ELLIS, 1993).

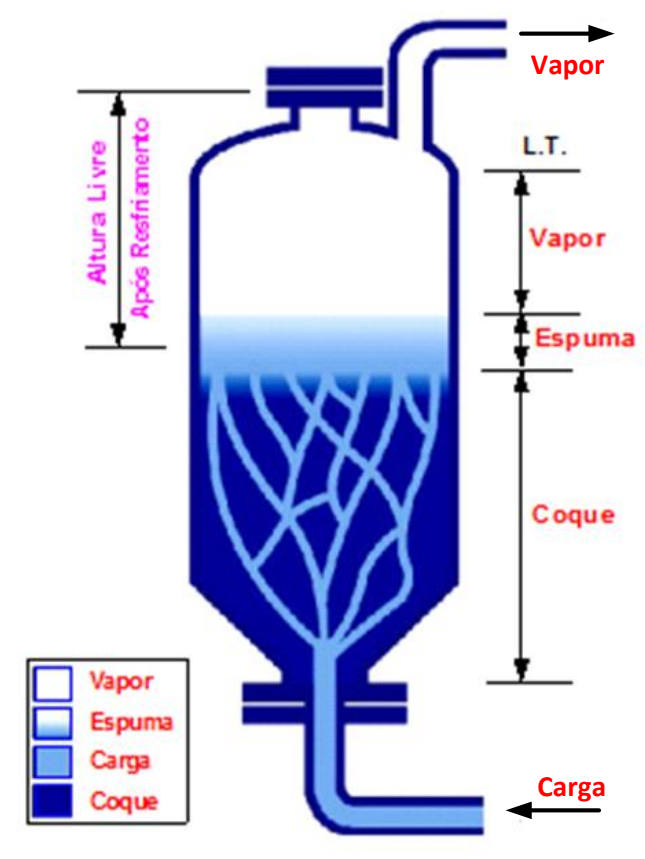

No interior do reator de coque, os asfaltenos são as primeiras partículas a aparecer na fase de hidrocarboneto líquido e podem agir como sementes para formação de coque. Inicialmente, estas partículas são pequenas, podendo ser facilmente arrastadas durante as etapas de alta velocidade ou na presença de espuma no interior do reator. (STEFANI, 1997). Com a finalidade de reduzir o arraste das 
partículas, é adotado um critério de velocidade máxima admissível de $0,15 \mathrm{~m} / \mathrm{s}$ dos vapores no interior do reator. (HECK, 1972)

Os parâmetros chave no processo de coqueamento são a combinação de tempo e de temperatura, para promover as reações de craqueamento térmico.

Um importante parâmetro de processo é a estratégia adotada para retardar a formação de coque na serpentina do forno, concentrando as reações térmicas no reator de coque.

O forno fornece toda a energia necessária para promover tais reações. Se a temperatura é muito baixa, a reação não ocorre o suficiente, levando a formação de piche e de leito de coque friável. Quando a temperatura é excessiva, ocorre a formação de um leito de coque com dureza excessiva, dificultando o descoqueamento hidráulico do leito.

Speight (1998) propôs um esquema de mecanismo de craqueamento térmico para as diferentes frações pesadas do petróleo conforme apresentado na Figura 3.10.

a) Inventário de líquido no reator

Como a carga entra no fundo do reator, ela flui ascendentemente através do leito de coque na forma líquida, formando espuma na fase de hidrocarbonetos. Simultaneamente, ocorre a precipitação dos asfaltenos, craqueamento dos hidrocarbonetos e vaporização ou polimerização das cargas e do produto craqueado. $O$ coque resultante da precipitação de asfaltenos tende a ser amorfo e de baixa qualidade, enquanto o coque formado da polimerização de hidrocarbonetos tende a ser mais cristalino. Logo após o início do ciclo de enchimento, estes eventos estão em equilíbrio com a entrada da carga (ELLIS e PAUL, 1998).

A quantidade de inventário de líquido e de espuma no interior do reator é afetada pela temperatura e pressão. Um acréscimo na pressão aumenta a retenção de líquido para reagir. 
Figura 3.10 - Produtos de coqueamento a partir de frações de petróleo. (SPEIGHT, 1998).

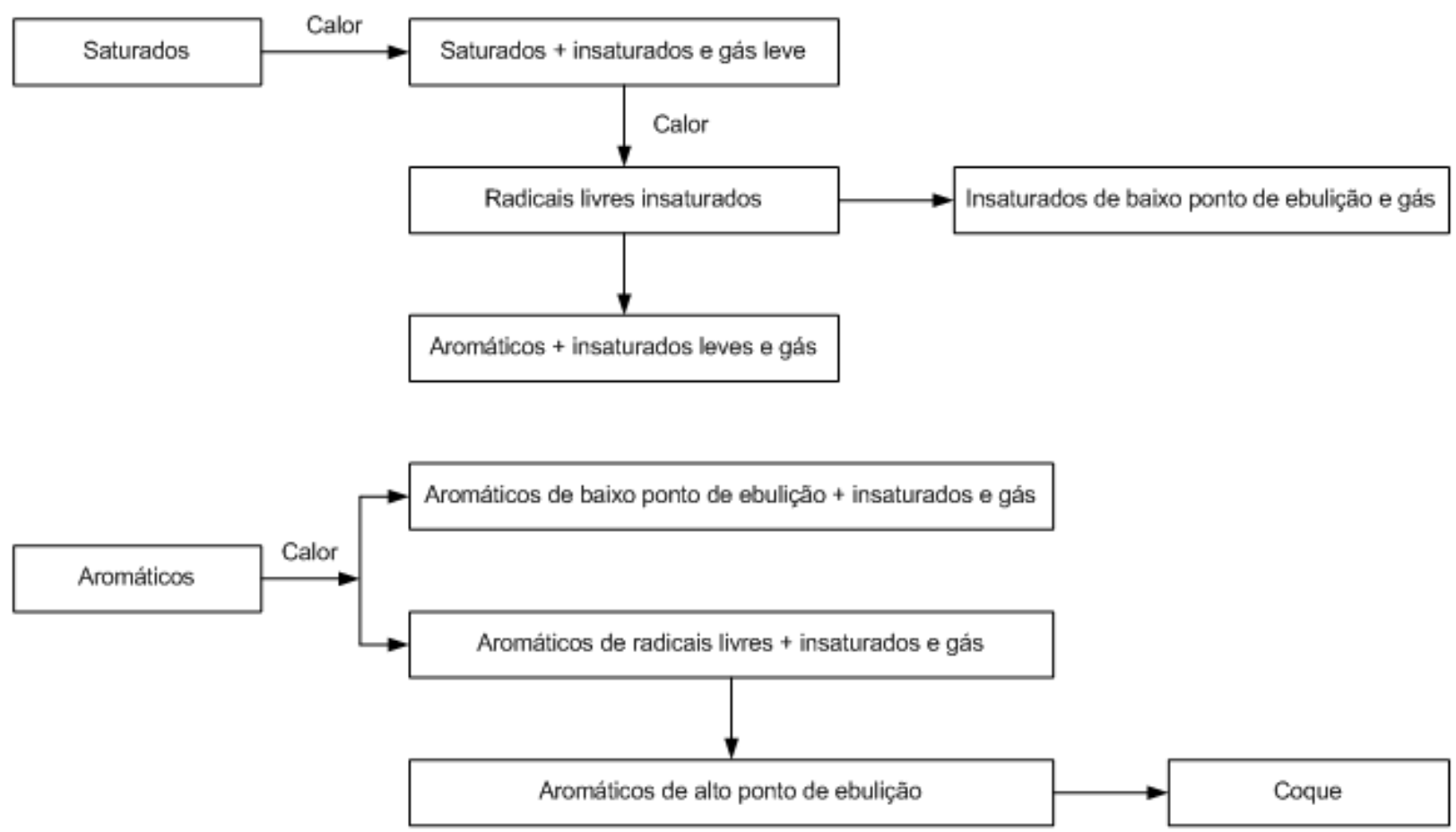

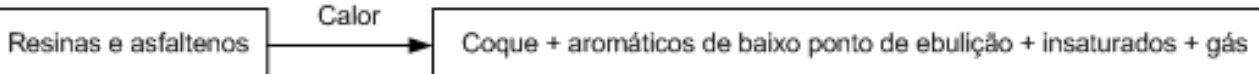

Uma segunda fase semilíquida, conhecida como mesofase, é observada durante o processamento de coqueamento de frações residuais pesadas. A mesofase não participa do equilíbrio líquido-vapor. (BOZZANO e DENTE, 2005). A reologia da mesofase controla o coalescência do meio, sendo influenciada pela composição química dos asfaltenos e sua capacidade de transferência de hidrogênio para os radicais livres responsáveis por manter a baixa viscosidade da mesofase. Isto favorece a produção de um coque de melhor qualidade e formação de diferentes morfologias. (HERNÁNDEZ, HURTADO e AGREDA, 2008).

O coque formado a partir da condensação de aromáticos polinucleares tem uma relação H/C de 0,73 (HSU e ROBINSON, 2006). Enquanto o coque formado por meio de outras reações pode variar a relação $\mathrm{H} / \mathrm{C}$ de 0,20 a 0,80 . 
b) Fase vapor do reator

Uma pequena quantidade adicional de craqueamento ocorre na fase vapor do reator. A proporção desta reação é modificada ao longo do ciclo de enchimento do reator, pois o espaço disponível decresce.

\subsubsection{Torre fracionadora}

Na Figura 3.11, é apresentado um esquema da seção de fundo da torre fracionadora com chicanas.

Como o reciclo de óleo formado na chicana não é separado como uma corrente de produto, a composição do reciclo não é de fácil determinação. Xinxue e Ruisen (2001) propõe uma metodologia para determinar a composição do reciclo, bem como a conversão em coque encontrado na unidade de coqueamento retardado.

Figura 3.11 - Esquema simplificado do fundo da torre fracionadora.

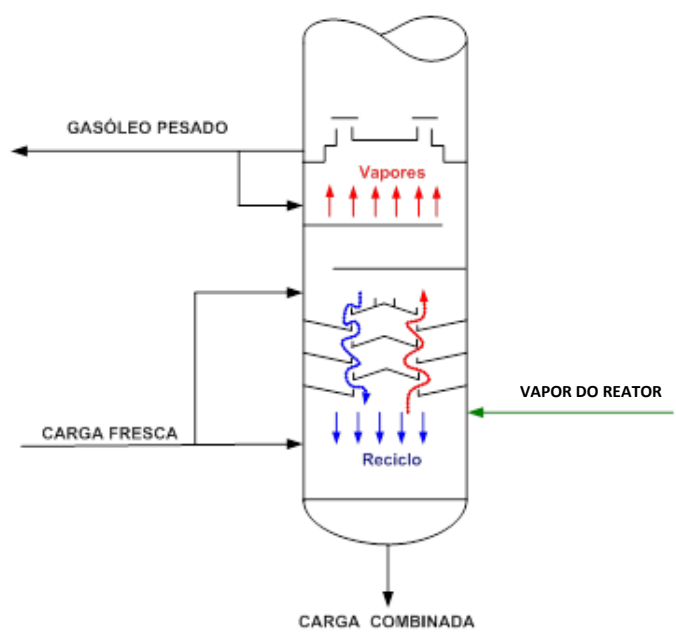

\subsection{Variáveis operacionais}

Geralmente, a maior rentabilidade do processo de coqueamento é obtida através da máxima produção de correntes líquidas de alta valorização e do mínimo rendimento 
de coque de menor valorização. Os principais parâmetros operacionais de processo de coqueamento são: razão de reciclo, perfil de temperatura, pressão e características da carga.

A rentabilidade dos produtos segue os modelos clássicos de predição que são baseados no resíduo de carbono. (NELSON, 1958) Um modelo mais complexo foi proposto por Castiglioni (1983), no qual a temperatura, a pressão, a razão de reciclo e o resíduo de carbono são considerados. Speight (1997) propõe um modelo de estimativa de rendimentos com base no teor de asfaltenos.

$\mathrm{Na}$ Tabela 3.3, são apresentadas as faixas de condições operacionais típicas de unidades industriais para produção de diferentes tipos de coques.

Tabela 3.3 - Condições operacionais típicas para produção de diferentes coques.

\begin{tabular}{lccc}
\hline \multirow{2}{*}{ Variáveis operacionais } & \multicolumn{3}{c}{ Tipo de coque } \\
\cline { 2 - 4 } & Combustível & Grau Anodo & Agulha \\
\hline Pressão de operação, bar man. & $1,0-1,5$ & $1,5-3,0$ & $4,0-7,0$ \\
Razão de reciclo, \%vol. & $5-10$ & $25-30$ & $50-80$ \\
Temperatura de coqueamento, ${ }^{\circ} \mathrm{C}$ & $435-440$ & $440-445$ & $440-445$ \\
\hline
\end{tabular}

Fonte: Motghi, Shree e Krishnamuthy (2010).

\subsubsection{Razão de reciclo}

O reciclo é formado pela condensação de componentes de alto ponto de ebulição vaporizada e é arrastado do interior com os vapores do reator de coque. $\mathrm{O}$ reciclo é um produto gerado no tambor de coque, sendo mais refratário ao coqueamento do que a carga. Esta última informação pode ser melhor compreendida, quando se considera os componentes mais aptos a sofrer coqueamento, como os asfaltenos, tendem prontamente a ser eliminados dos vapores de topo do reator. $\mathrm{O}$ reciclo tem um efeito similar ao efeito da pressão e distribuição dos produtos (ELLIOT, 2003).

O reciclo tem alto teor de resíduo de carbono e componentes insolúveis em 
n-heptano, que podem causar impacto nas unidades de hidrotratmento e catalíticas (ELLIOTT, 2003).

No processo, a corrente de reciclo é reinjetada na carga fresca e retorna ao processo de coqueamento, visando converter os componentes pesados em leves e em coque. O reciclo é utilizado para controlar o ponto final do gasóleo pesado, do resíduo de carbono e dos metais.

Quando a unidade opera com alta razão de reciclo, o teor de resíduo de carbono Conradson e os metais na corrente de gasóleo pesado são reduzidos. Eles também dependem da velocidade dos vapores no interior da seção de fundo da torre fracionadora e dos parâmetros operacionais de controle. Na Tabela 3.4, é mostrada a sua influência no processo.

Tabela 3.4 - Influência da razão de reciclo no gasóleo pesado.

\begin{tabular}{|c|c|c|}
\hline Propriedades & Caso 01 & Caso 02 \\
\hline Razão de Reciclo, \%vol. & $<5$ & 0 \\
\hline${ }^{\circ} \mathrm{API}$ & 17,78 & 11,55 \\
\hline Enxofre, \%massa & 2,58 & 2,55 \\
\hline Nitrogênio, ppm & 5303 & 5087 \\
\hline Resíduo de Carbono Conradson, \%massa & 0,53 & 2,43 \\
\hline Insolúveis em n- $C_{7}$, ppm & 432 & 2000 \\
\hline Teores de metais (níquel + vanádio), ppm & 1,0 & 3,8 \\
\hline Curva de destilação HT750 & \multicolumn{2}{|c|}{ Temperatura, ${ }^{\circ} \mathrm{C}$} \\
\hline $10 \%$ vol. & 387 & 390 \\
\hline $50 \%$ vol. & 462 & 478 \\
\hline $100 \%$ vol. & 578 & 616 \\
\hline Fator de Caracterização de Watson & 11,13 & 11,12 \\
\hline
\end{tabular}

Fonte: Elliott (2003)

Comparando os dois casos de operação apresentados na Tabela 3.4, observa que o decréscimo de $5 \%$ vol. na razão de reciclo provocou uma deterioração na qualidade da corrente de gasóleo pesado. Os teores de insolúveis em n- $\mathrm{C}_{7}$ (asfaltenos), de resíduo de carbono aumentaram $460 \%$ e $458 \%$, respectivamente.

A redução de reciclo provoca um decréscimo no rendimento de coque e um 
acréscimo de produtos líquidos, segundo Jansen e Leaman (1984). Geralmente, um valor de razão de reciclo é estabelecido em função das características da carga e das condições do forno de coqueamento. $O$ aumento da razão de reciclo favorece a redução no teor de matéria volátil no coque verde produzido. O reciclo age como fluido térmico, transferindo calor do forno para o reator de coque.

\subsubsection{Temperatura do topo do reator}

A temperatura é uma variável utilizada para controlar o teor de matéria volátil e o grau de dureza do coque verde produzido (PARKASH, 2003).

Mantendo constante a pressão e a razão de reciclo, o rendimento do coque verde decresce, enquanto há o aumento da temperatura (JANSEN e LEAMAN, 1984). Com este aumento, os hidrocarbonetos pesados são convertidos em frações intermediárias, são vaporizados e transformados em vapor do reator. Consequentemente, os voláteis são removidos do leito do coque. Em temperaturas baixas, os hidrocarbonetos pesados, no interior do reator, permanecem na fase líquida. Adicionalmente, a temperatura influencia na viscosidade, na taxa de craqueamento e na de polimerização do inventário de líquido.

Na Figura 3.12, é mostrada a influência da temperatura sobre o teor de matéria volátil. (JAKOB, 1971) 
Figura 3.12 - Efeito da temperatura no reator de coque sobre o teor de matéria volátil (JAKOB, 1971).

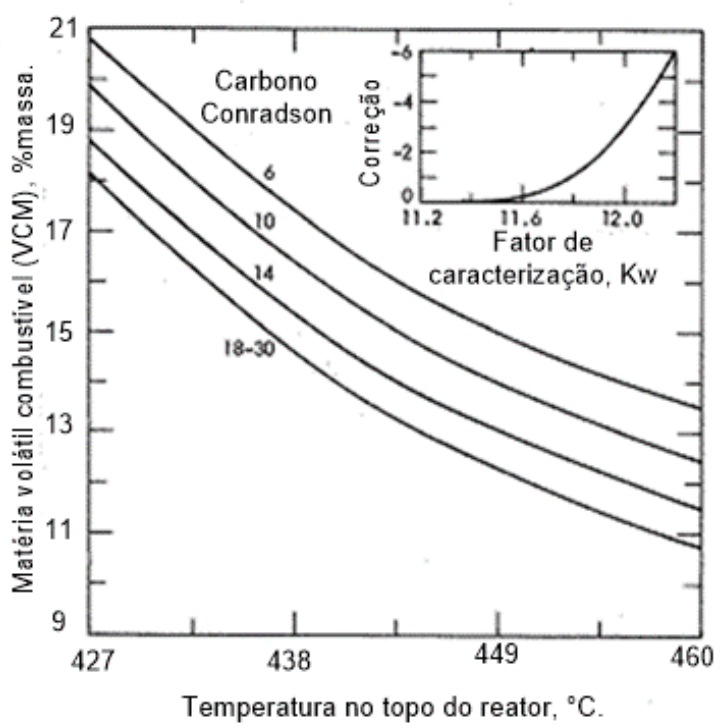

Existe uma faixa mínima dentro da qual se deve operar o tambor de coque: entre 427 e $443^{\circ} \mathrm{C}$. Atenção especial deve ser dada ao isolamento térmico do reator, visando garantir a mínima perda de calor para o ambiente.

\subsubsection{Pressão}

Sob condições de temperatura constante, há um acréscimo na pressão de operação do reator, o que provoca a retenção de hidrocarbonetos pesados no interior do reator. Isto aumenta o rendimento de coque e há um pequeno acréscimo no rendimento de gás.

$\mathrm{Na}$ Tabela 3.5, é apresentado o efeito do decréscimo na pressão sobre os rendimentos dos produtos nem uma unidade de coqueamento retardado. 
Tabela 3.5 - Influência da pressão sobre os rendimentos.

\begin{tabular}{|c|c|c|}
\hline Origem & Bachaqueiro $537^{\circ} \mathrm{C}^{+}$ & \\
\hline${ }^{\circ} \mathrm{API}$ & 4,3 & \\
\hline Fator de Caracterização & 11,5 & \\
\hline Resíduo de Carbono Conradson & $23,5 \%$ massa & \\
\hline \multirow{2}{*}{ Produtos } & \multicolumn{2}{|c|}{ Pressão } \\
\hline & $2,10 \mathrm{kgf} / \mathrm{cm}^{2} \mathrm{man}$ & $1,40 \mathrm{kgf} / \mathrm{cm}^{2}$ man. \\
\hline $\mathrm{C}_{4}$ e Leves & 8,91 & 8,66 \\
\hline $\mathrm{C}_{5}-168^{\circ} \mathrm{C}$ & 10,14 & 9,68 \\
\hline $168-343^{\circ} \mathrm{C}$ & 25,31 & 24,61 \\
\hline $343^{\circ} \mathrm{C}^{+}$ & 21,05 & 23,16 \\
\hline Coque Verde & 34,59 & 33,89 \\
\hline
\end{tabular}

Fonte: Elliott (2003)

\subsection{Características da carga}

Os constituintes da carga podem ser classificados em quatro grupos de hidrocarbonetos: saturados, aromáticos, resinas e asfaltenos. A composição e as características destes constituintes afetam a morfologia e as propriedades do coque formado, além dos rendimentos dos produtos. (JAKOB, 1971)

Associando as características da carga com as variáveis operacionais, diferentes tipos de coque podem ser produzidos, tais como: shot-coke, agulha e grau anodo. (SISKIN et al., 2006). A estrutura química dos asfaltenos presentes no resíduo de vácuo influencia a morfologia do coque produzido nas unidades de coqueamento retardado (shot-coke vs. coque esponja).

A distribuição típica de enxofre e de nitrogênio nos produtos gerados no processo de coqueamento retardado é apresentada na Tabela 3.6 (GARY, HANDWERK e KAISER, 2007). O enxofre presente na carga é mais distribuído para corrente de gás e de coque, enquanto a maioria do nitrogênio permanece concentrado na corrente de coque. 
Tabela 3.6 - Distribuição do enxofre e nitrogênio nos produtos em relação a carga.

\begin{tabular}{lcc}
\hline Corrente & Enxofre, \%massa & Nitrogênio, \%massa \\
\hline Gás & 30,0 & - \\
Nafta Leve & 1,7 & - \\
Nafta Pesada & 3,3 & 1,0 \\
Gasóleo Leve & 15,4 & 2,0 \\
Gasóleo Pesado & 19,6 & 22,0 \\
Coque & 30,0 & 75,0 \\
\hline
\end{tabular}

Fonte: Gary, Handwerk e Kaiser (2007)

Os metais níquel e vanádio presentes na carga tendem a se concentrar no coque formado. (DeBIASE, 1982)

Na Tabela 3.7, é mostrada a análise do resíduo de vácuo do petróleo venezuelano Orinoco, a $510{ }^{\circ} \mathrm{C}$ (ELLIOTT, 2008). Comparando as características das frações de saturados, aromáticos, resinas e asfaltenos, observa que os asfaltenos apresentam a menor relação atômica $\mathrm{H} / \mathrm{C}$ e os maiores teores de contaminantes (enxofre, nitrogênio, vanádio e enxofre).

Tabela 3.7 - Características do resíduo de vácuo do petróleo venezuelano Orinoco.

\begin{tabular}{lccccc}
\hline & $\begin{array}{c}\text { Resíduo de } \\
\text { vácuo }\end{array}$ & Saturados & Aromáticos & Resinas & Asfaltenos \\
\hline Rendimento, \%massa & 100,0 & 12,1 & 23,0 & 40,5 & 24,4 \\
${ }^{\circ} \mathrm{API}$ & 2,8 & & & & \\
RCC, \%massa & 22,3 & & & & \\
Viscosidade @ 149 ${ }^{\circ} \mathrm{C}, \mathrm{cSt}$ & 988,9 & & & & \\
Viscosidade @ 177 ${ }^{\circ} \mathrm{C}, \mathrm{cSt}$ & 261,6 & & & & \\
Insolúveis, n-C 7 , \%massa & 21,2 & & & & \\
Análise Elementar & & & & & \\
Carbono, \%massa & 84,30 & 85,54 & 84,00 & 83,84 & 83,65 \\
Hidrogênio, \%massa & 10,40 & 12,83 & 11,11 & 9,00 & 8,23 \\
Enxofre, \%massa & 4,20 & 0,67 & 4,31 & 4,37 & 5,01 \\
Nitrogênio, \%massa & 1,01 & 0,69 & 0,20 & 1,11 & 1,85 \\
Vanádio, mg/kg & 677 & - & - & 503 & 1638 \\
Níquel, mg/kg & 198 & - & - & 135 & 449 \\
Relação H/C, atômica & 1,48 & 1,80 & 1,59 & 1,29 & 1,18 \\
Relação C/H, atômica & 8,1 & 6,7 & 7,6 & 9,3 & 10,2 \\
\hline
\end{tabular}

Fonte: Elliott (2008) 


\subsection{Tipos e parâmetros de qualidade do coque de petróleo}

São produzidos três tipos de coque verde, os quais são significativamente diferentes quanto à estrutura química e às propriedades: shot-coke, grau anodo e agulha. A estrutura física e suas propriedades químicas determinam a sua aplicação final como combustível e eletrodos para indústria metalúrgica, dentre outros.

\subsection{Shot-coke}

Para produzir shot-coke em uma unidade de coqueamento, são necessárias altas concentrações de asfaltenos na carga, alta turbulência do leito de coque e temperatura elevada no reator. A carga com um elevado teor de compostos de oxigenados também pode favorecer a formação de shot-coke. Quando a relação mássica entre o teor de asfalteno na carga e o resíduo de carbono Conradson é superior a 0,50, é muito provável a formação de "shot-coke" (GUO et al., 2012). Na Figura 3.13, é apresentada uma amostra de shot-coke.

Figura 3.13 - Amostra de shot-coke (ELLIOTT, 2008; FAEGH e COLLINS, 2010).
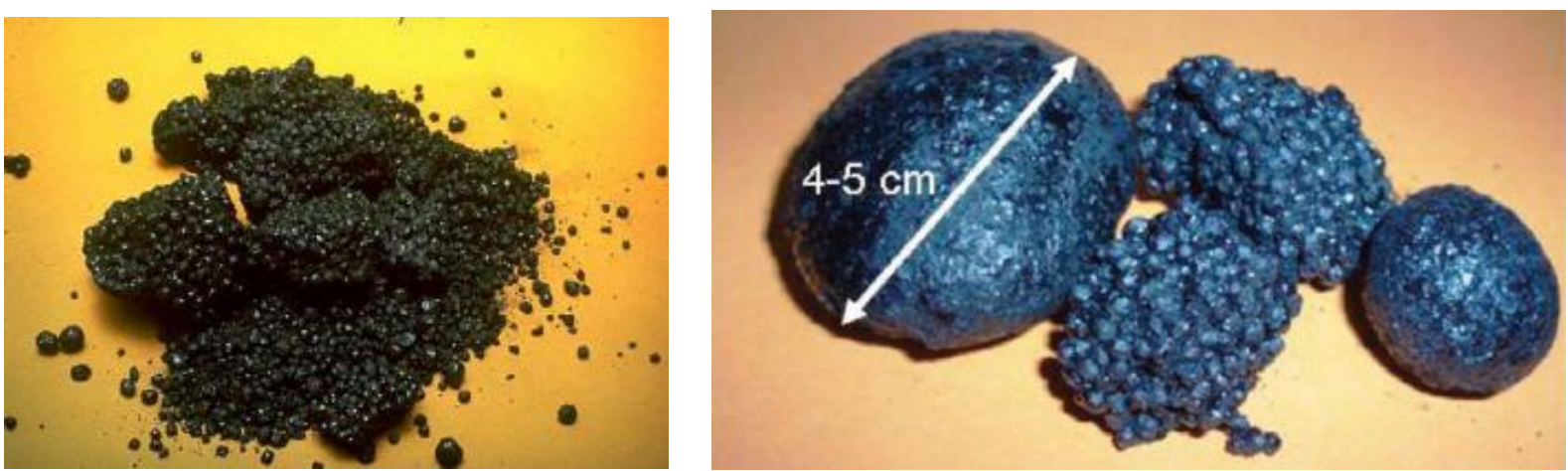

Ellis e Paull (2000) define shot-coke como um material muito duro, um tipo de coque preferido na fabricação de $\mathrm{TiO}_{2}$. Apresenta-se em forma de esferas rígidas e é produzido a partir da carga com alto teor de asfalteno e baixo ${ }^{\circ} \mathrm{API}$. Sua formação é influenciada pela concentração de compostos aromáticos polares acima de determinado massa molecular. Pode ser suprimido pelo acréscimo da pressão e da razão de reciclo. A adição de correntes aromáticas na carga fresca tende a reduzir a 
formação de shot-coke, aponta Elliott (2009). Quando a diretriz é maximizar o rendimento do produto líquido durante o processamento de carga extremamente pesada, a unidade de coqueamanto deve produzir shot-coke. (ELLIOTT, 2009)

O shot-coke é produzido no interior do reator em forma de um fluxo de óleo. Com a vaporização dos componentes leves, pequenas gotículas de piche pesado permanecem suspensas no fluxo. Estas esferas de piche rapidamente se convertem em esferas de coque, devido ao calor da reação exotérmica gerado na polimerização dos asfaltenos. O shot-coke é retirado do reator na forma de esferas discretas, de 2 - $5 \mathrm{~mm}$ de tamanho. No canal principal, formado ao longo do leito, há formação de grandes esferas, com até $25 \mathrm{~cm}$ de tamanho, as quais são constituídas de pequenas esferas aglomeradas. Normalmente, as pequenas esferas de shot-coke de diferentes unidades de coqueamento têm tamanho similar.

Todos os outros métodos para evitar a formação de shot-coke - como o decréscimo de temperatura, o aumento da pressão de operação do reator e o da razão de reciclo - favorecem o acréscimo do rendimento de coque produzido.

A camada externa da partícula de shot-coke tem baixo coeficiente de expansão térmica, enquanto na camada interna tem alto coeficiente de expansão térmica. No processo de calcinação, esta característica leva à produção de um coque calcinado inadequado para produção de anodo (fenômeno pop no calcinador).

\subsection{Coque esponja grau anodo}

O principal desafio das unidades produtoras de coque verde em grau anodo é o atendimento da especificação quanto ao teor de matéria volátil combustível (VCM). Os teores de metais e os de enxofre estão relacionados com os petróleos processados, mas o VCM é controlado pelo processo de coqueamento.

A temperatura no reator é o parâmetro mais crítico, juntamente com o tempo de coqueamento e a pressão operacional do reator. O tempo de residência prolongado e a temperatura adequada ajudam a reduzir o VCM. O acréscimo na vazão de 
reciclo pode aumentar a temperatura no reator. Outro item importante no processo é a minimização das perdas de energia na linha de transferência forno-reator, no isolamento do reator. (ELLIS e PAUL, 1998). Antes da produção de coque grau anodo, o coque verde tipo esponja é calcinado (Figura 3.14). A densidade do coque calcinado é um parâmetro crítico para a produção de bons ânodos de carbono. Quanto maior a densidade, maior será a quantidade de carbono a ser incorporado ao anodo, proporcionando um acréscimo na durabilidade do mesmo no processo. A densidade aparente (VBD - Vibrated bulk density) do coque calcinado deve ser $0,860 \mathrm{~g} / \mathrm{cm}^{3}$, no mínimo. Esta propriedade correlaciona satisfatoriamente $\mathrm{o}$ índice de moagem do coque verde (HGI - Hardgrove Grindability Index).

Normalmente, um coque verde com $\mathrm{HGl}<70$ pode produzir um coque calcinado com densidade aparente vibrada de $0,860 \mathrm{~g} / \mathrm{cm}^{3}$. A estrutura do coque verde é um indicativo para medir a tendência de calcinação. Um coque com baixo CTE (Coefficient of Thermal Expansion) tem maior VCM, que, comparado com um coque isotrópico, produzirá a mesma densidade. A porosidade do coque calcinado é função do teor de matéria volátil do coque verde. $\mathrm{E}$ a matéria volátil mantém correlação entre o coque verde e a estrutura do coque calcinado.

Figura 3.14 - Amostra de coque esponja (ELLIOTT, 2008).

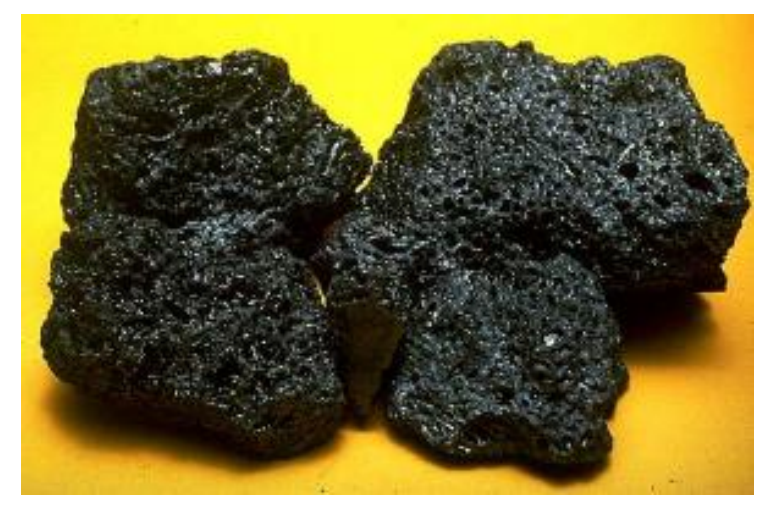

\subsection{Coque agulha}

O coque agulha é assim chamado devido a uma maior unidirecionalidade de sua estrutura cristalina com poros. É produzido a partir de uma carga especial, sem a presença de asfaltenos, por exemplo: óleo decantado de FCC (Fluidized Catalytic Cracking). Na Tabela 3.8, estão as características da carga para a produção desse 
tipo de coque. A Figura 3.15 apresenta uma amostra do coque tipo agulha (ELLIOT, 2008).

Tabela 3.8 - Características da carga para produção de coque agulha.

\begin{tabular}{lc}
\hline \multicolumn{1}{c}{ Item } & Valor \\
\hline Aromáticos, \% massa & 75 min \\
Enxofre, \% massa & 0,5 máx. \\
Asfalteno, \% massa & 1,0 máx. \\
Ponto de Ebulição, ${ }^{\circ} \mathrm{C}$ & $>427$ \\
$\mathrm{BMCl}$ & $95-130$ \\
\hline
\end{tabular}

Fonte: Petroleum Fuels Manufacturing Handbook.

O coque em questão é utilizado na fabricação de eletrodos de grafite de alta qualidade. Tem alto valor comercial. As condições operacionais do processo de coqueamento e de calcinação devem ser otimizadas, visando atender às propriedades requeridas.

Figura 3.15 - Amostra de coque agulha (ELLIOTT, 2008).

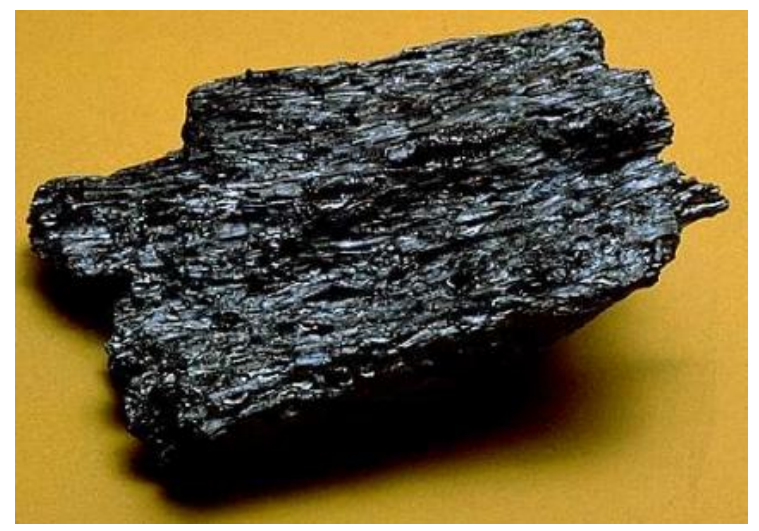

Shea (1956) apresentou uma descrição sobre a produção e a formação do coque agulha em sua patente US2775549. A maior parte de sua produção é oriunda do óleo decantado hidrodessulfurizado. A exigência do baixo teor de enxofre visa evitar a expansão e fragmentação da partícula de coque quando submetida a temperatura acima de $1300^{\circ} \mathrm{C}$, provocada pela liberação de compostos de enxofre (puffing).

O principal parâmetro de qualidade requerido para o coque agulha calcinado é o coeficiente de expansão térmica (CTE). Devido às tensões térmicas na fixação do 
eletrodo, ele deve possuir $\mathrm{CTE} \leq 2,0$, para evitar a fragmentação. Outros parâmetros fundamentais são os teores de enxofre e os de nitrogênio para evitar a ocorrência de puffing, durante o processo de grafitização a $2900^{\circ} \mathrm{C}$.

No processo de calcinação do coque agulha, há uma tendência de reverter a mesofase para líquido durante o aquecimento rápido. Quando a pirólise da matéria volátil começa a evoluir durante a calcinação, ocorre o crescimento da estrutura, deixando um coque calcinado com baixa densidade e alto coeficiente de expansão térmica. (ELLIS, 1998) Este coeficiente varia de 0 a $4 \times 10^{-7}{ }^{\circ} \mathrm{C}^{-1}$, enquanto o coque esponja calcinado varia de 8 a $18 \times 10^{-7}{ }^{\circ} \mathrm{C}^{-1}$. Já o shot-coke calcinado tem um coeficiente de expansão térmica da ordem de $20 \times 10^{-7}{ }^{\circ} \mathrm{C}^{-1}$.

As densidades aparente e real do coque agulha calcinado deverão ser, no mínimo, 0,780 e $2,13 \mathrm{~g} / \mathrm{cm}^{3}$, respectivamente.

\subsection{Qualidade do coque}

Fatores, como a característica da carga processada e o perfil de temperatura ao longo do processo, influenciam nos parâmetros de qualidade do coque verde produzido, por exemplo: teor de matéria volátil combustível (VCM - Volatile Combustible Materia), índice de moagem (HGI - Hardgrove Grindability Index), teores de enxofre e de metais. O tipo de coque produzido e seu valor econômico também dependem das características da carga e de variáveis operacionais.

\section{a) VCM - Teor de matéria volátil}

O coque verde de petróleo contém uma quantidade de hidrocarbonetos leves ligados à estrutura que está relacionada com o grau de severidade do processo e com as características da carga.

A variável de controle operacional para ajustar o VCM é a temperatura de coqueamento. Se todas as outras variáveis, incluindo a qualidade da carga, são 
constantes, a variável habitual de controle é a temperatura de saída do forno. (ELLIOTT, 2008)

A matéria volátil do coque verde afeta a densidade da partícula de coque e também pode afetar o desempenho do processo de calcinação. (ELLIS e PAUL, 1998)

b) $\mathrm{HGI}$ - Hardgrove Grindability Index

O HGI é uma medida de tendência do coque em gerar finos que podem causar problemas (segregação de partículas e emissão de particulados), durante as etapas de descoqueamento do reator e de manuseio do coque. A dureza do coque está relacionada com o teor de asfaltenos contidos na carga. Além disso, HGI é uma medida empírica e não uma propriedade física do coque. Trata-se de um ensaio padrão de repetibilidade.

O parâmetro HGl é influenciado pelo teor de matéria volátil e também pela estrutura do coque. $\mathrm{O} \mathrm{HGl}$ do coque verde do tipo shot-coke varia de 28 a 50, enquanto para o coque verde tipo agulha varia de 70 a 100. Este possui uma boa correlação com a densidade aparente do coque calcinado. Um coque verde com HGI de 75 a 85 produz um coque calcinado de excelente densidade aparente para indústria de alumínio. (ELLIS, 2000)

O processamento de carga com alto teor de asfalteno- por exemplo: $25 \%$ de massa de insolúveis em n-heptano - produz um coque verde cujos teores de VCM variam entre 8 e $9 \%$ de massa, em ciclos maiores de 18 horas, podendo resultar em $\mathrm{HGI}<30$. Este coque é indesejável para a comercialização como grau combustível. (ELLIOTT, 2008)

\section{a) CCR - Resíduo de carbono Conradson}

O resíduo de carbono Conradson (CCR) é uma medida experimental, cuja finalidade é determinar o potencial da quantidade de coque de petróleo formado por degradação térmica. $O$ resultado de rv é função direta da quantidade de material asfáltico presente na amostra. (NOEL, 1984) 


\section{CARACTERIZAÇÃO DE RESÍDUO DE VÁCUO E PRODUTOS}

Este capítulo apresenta os resultados e as discussões dos dados referentes a quinze ciclos de operação de unidade de coqueamento retardado, bem como as estratégias de caracterização do resíduo de vácuo por espectrometria de massa (MALDI-TOF) e dos produtos.

\subsection{Metodologia experimental}

Foram analisadas amostras de correntes de petróleo, resíduo atmosférico, resíduo de vácuo, nafta de coque, gasóleos de coque e coque verde nas unidades de processo da Refinaria Presidente Bernardes - Cubatão (RPBC - Petrobras). $\mathrm{Na}$ Figura 4.1, são identificados os pontos de coletas de amostras de petróleo, de resíduo atmosférico e resíduo de vácuo e produtos gerados na UCP1.

Figura 4.1 - Fluxograma com os pontos de coletas de amostras.

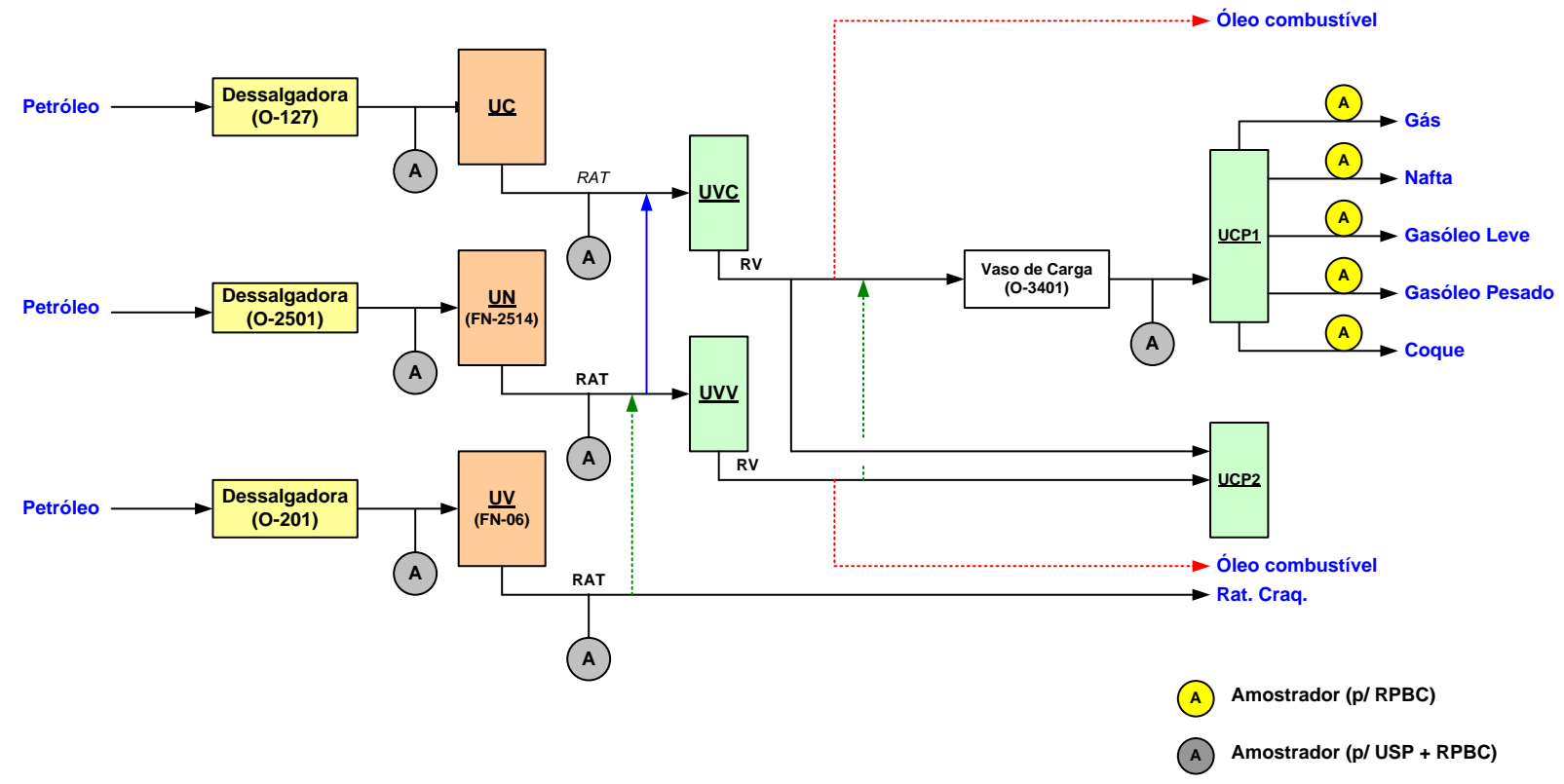

As amostras das correntes de petróleo, resíduo atmosférico e resíduo de vácuo foram analisadas no LSCP/PQI/POLI-SP, por espectrometria de massa, para caracterização da fração de asfalteno. As correntes de gás combustível de coque, nafta de coque, gasóleo leve e gasóleo pesado foram analisadas no laboratório de 
controle de qualidade da Refinaria. Enquanto o coque verde produzido foi analisado no laboratório da empresa calcinadora PETROCOQUE, Cubatão - SP.

\subsubsection{Técnicas analíticas}

As análises realizadas para cada corrente são:

- Resíduo de vácuo: densidade $\mathrm{D}_{20 / 4 C}$, resíduo de carbono, S.A.R.A. e asfaltenos como insolúveis em n-heptano;

- Gás combustível: cromatografia

- Nafta de coque: densidade $D_{20 / 4 C}$ e curva de destilação ASTM D-86;

- Gasóleo leve: densidade $\mathrm{D}_{20 / 4 \mathrm{C}}$ e curva de destilação ASTM D-86;

- Gasóleo pesado: densidade $\mathrm{D}_{20 / 4 C}$ e curva de destilação simulada HT750;

- Coque verde de petróleo: teor de matéria volátil (ASTM D-3175) e HGI - Hardgrove Grindability Index (ASTM D-409).

\subsubsection{Caracterização do resíduo de vácuo}

Para caracterizar sua estrutura molecular detalhada, o resíduo de vácuo é classificado em quatro frações: saturados, aromáticos, resinas e asfaltenos (S.A.R.A.). Geralmente, a fração saturada é composta por iso e cicloparafinas- e aromáticos têm relativamente elevada relação atômica $\mathrm{H} / \mathrm{C}$, baixos teores de heteroátomos e de metais comparados com as resinas e asfaltenos (Long, et al., 2011). Além disso, tem baixa tendência de coqueamento. Enquanto isso, os asfaltenos têm maior aromaticidade (baixa relação atômica $H / C$ ), de teores de heteroátomos ( $\mathrm{S}, \mathrm{N}$ e O) e de metais (principalmente vanádio e níquel).

Para Sabbah (2010), a distribuição da massa molecular da fração de asfaltenos de petróleo está rapidamente se tornando mais conhecida, mas a estrutura molecular ainda é pouco compreendida. Dois modelos têm sido propostos para descrever as 
estruturas das moléculas presentes nos asfaltenos: o modelo de "ilha" e de "arquipélago".

- Modelo "arquipélago": várias porções de aromáticos são ligadas através de pontes alifáticas que, potencialmente, contêm heteroátomos.

- Modelo "ilha": consiste num núcleo de poliaromáticos, com cadeias alifáticas ramificadas que podem conter heteroátomos similares contidos no modelo "arquipélago".

\subsubsection{Caracterização de asfaltenos por espectrometria de massa}

Numerosas técnicas têm sido utilizadas para medir o peso molecular dos asfaltenos. No entanto, existem muitas discrepâncias entre elas, por exemplo: 2.500 - 4.000 por ebuloscopia; $600-6.000$ por crioscopia; $900-2.000$ por viscometria; e $1.000-$ 5.000 por osometria de pressão de vapor. (SPEIGHT, 1999)

A técnica de espectrometria de massa tem sido utilizada nos estudos de determinação do peso molecular de asfaltenos. Boduszynski (1984) publicou os resultados de espectrometria de massa de campo-ionização (FIMS) em n-heptano asfaltenos: um peso molecular médio de 700 para o asfalteno, aproximadamente. Tal resultado está em desacordo com os dados até então apresentados, mostrandose questionável em dois pontos: a capacidade de obter fase gasosa de componentes de elevada massa molecular e a fragmentação possível. Posteriormente, a espectrometria de massa com laser de dessorção (LDMS) e de ionização a laser assistida por matriz de dessorção (MALDI - Matrix Assisted Laser Desorption/lonization) foram utilizados para estudar asfaltenos.

Os relatos na literatura variam de acordo com mais de um fator de 10 na massa molecular de asfaltenos. Alguns estudos obtiveram valores bastante próximos aos de Boduszynsky (1984), outros muito mais elevado. 
a) Preparação dos asfaltenos

Na Figura 4.2, é representado um diagrama do método S.A.R.A. que visa separar as frações de petróleo em quatro frações: saturados, aromáticos, resinas e asfaltenos.

Figura 4.2 - Separação do petróleo conforme a solubilidade em saturados, aromáticos, resinas e asfaltenos (Speight, 2006).

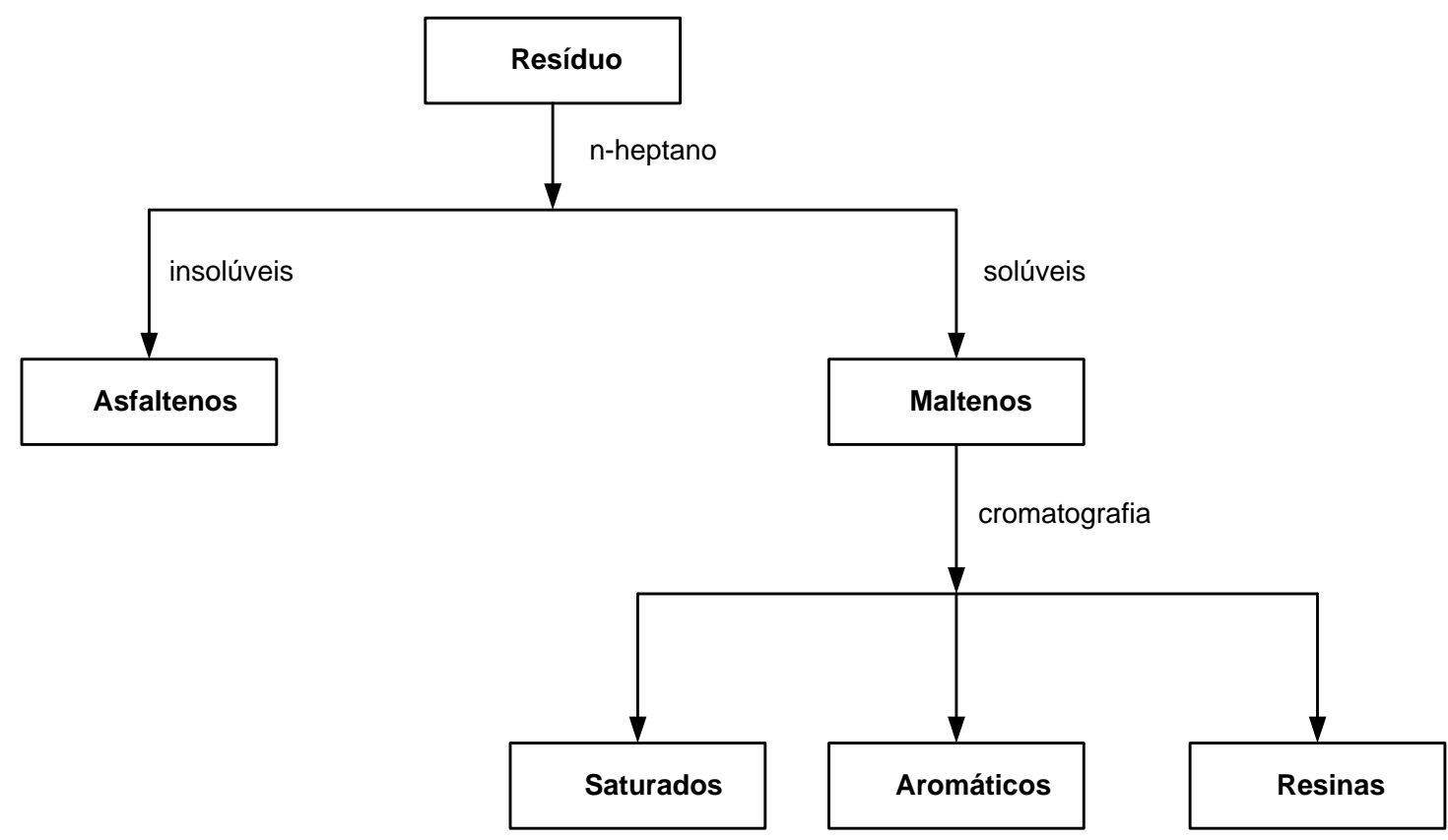

$\mathrm{Na}$ fração de asfaltenos separada, foi aplicada a técnica analítica de MALDI-TOF para determinar a distribuição de massa-carga. Os detalhes desta técnica estão descritos no Apêndice $A$.

A metodologia utilizada para separação das frações de asfaltenos e de maltenos (Saturados, Aromáticos e Resinas) das amostras foi utilizada por adição de nheptano na proporção de 40:1 como Jewel et al. (1972). A solução foi agitada e mantida por cerca de 24 horas em uma sala escura, a fim de evitar a degradação componentes. Este procedimento é mostrado na Figura 4.3.

O precipitado resultante, asfaltenos, foi removido por filtração a vácuo através de uma membrana de celulose de 0,45 $\mu \mathrm{m}$ e lavadas até a não observação de 
coloração escura no solvente de lavagem. O precipitado foi seco num dessecador a vácuo e pesados para se obter um peso constante.

Figura 4.3 - Procedimento utilizado para precipitar a fração de asfaltenos de uma inicial amostra (Mahdaoui et al, 2013).

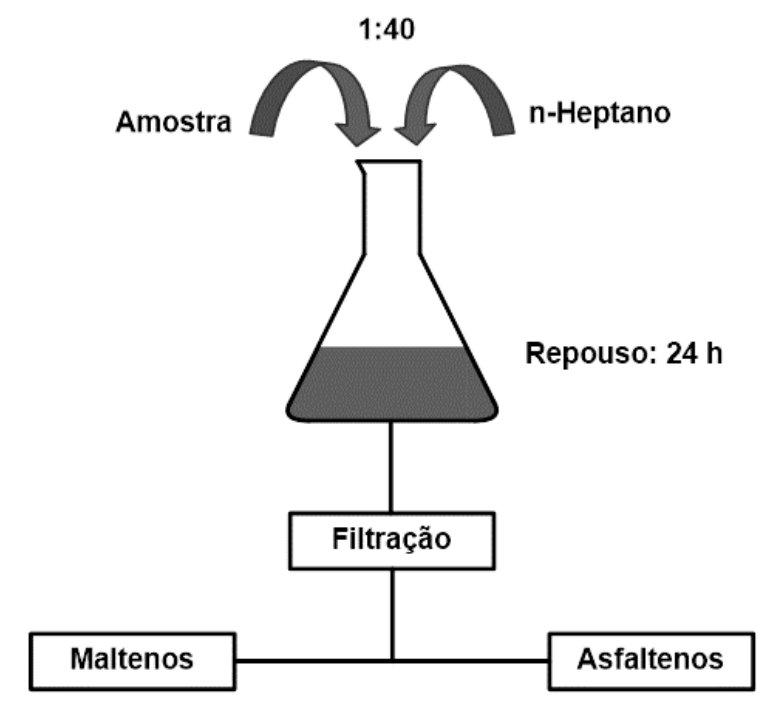

b) Espectrometria de massa por MALDI-TOF

A técnica analítica de espectrometria de massa MALDI TOF foi utilizada para determinar a distribuição de massa-carga das amostras de asfaltenos extraídos. Foi utilizado o espectrômetro de massa da Shimadzu Axima Confident, no modo "refectron", equipado com laser de nitrogênio (337 nm). Os espectros foram recolhidos em modo de extração retardado (50 ns) com intensidade do laser mantida a $70 \%$ da potência ou maior. Uma tensão de $10 \mathrm{kV}$ de extração foi empregada no modo de ionização positiva. O sinal da relação massa-carga abaixo de 100 foram suprimidas. As análises foram realizadas entre 100 - $1000 \mathrm{Da}$.

Uma análise preliminar foi realizada para estabelecer um padrão de matriz. Os melhores resultados foram obtidos para os espectros, fornecendo um desempenho semelhante, com outros estudos anteriores. Assim, a técnica pode ser chamada LDI TOF, desde que não foi utilizada qualquer matriz auxiliar na ionização por dessorção do analito. 
Os spots de amostra foram preparados, adicionando-se 1,0 $\mu \mathrm{L}$ de cada solução de amostra, (1,0 mg de sólido seco dissolvido em 1,0 ml de tolueno), no alvo MALDI. Os spots foram secos ao ar, antes da análise. Os espectros de MALDI-MS foram então recolhidos. Cada espectro foi gerado por uma média de 1000 disparos de laser por spots, em média.

\subsection{Resultados e discussão}

\subsubsection{Resíduo de vácuo}

\subsubsection{Resultados experimentais}

$\mathrm{Na}$ Tabela 4.1, estão os resultados das análises do resíduo de vácuo coletadas em oito ciclos de enchimento de reator e os seus rendimentos de coque correspondentes.

Tabela 4.1 - Rendimento de coque verde e propriedades do resíduo de vácuo.

\begin{tabular}{|c|c|c|c|c|c|}
\hline \multirow{2}{*}{ Amostra $\mathrm{N}^{\circ}$} & \multicolumn{4}{|c|}{ Propriedades } & \multirow{2}{*}{$\frac{\text { Rendimento }}{\mathrm{YCQ}}$} \\
\hline & ${ }^{\circ} \mathrm{API}$ & ASF & MCR & VIS & \\
\hline 1 & 10,19 & 5,72 & 17,38 & 2221 & 25,06 \\
\hline 2 & 9,85 & 4,47 & 16,40 & 2010 & 24,40 \\
\hline 3 & 11,58 & 3,80 & 15,40 & 1466 & 23,64 \\
\hline 4 & 8,71 & 6,27 & 18,36 & 3925 & 25,84 \\
\hline 5 & 8,83 & 6,72 & 18,31 & 3341 & 25,90 \\
\hline 6 & 8,92 & 6,00 & 18,13 & 3534 & 26,92 \\
\hline 7 & 8,10 & 6,81 & 19,12 & 5550 & 27,92 \\
\hline 8 & 8,04 & 6,98 & 18,95 & 5530 & 26,86 \\
\hline
\end{tabular}

ASF - Teor de asfaltenos, \%massa; MCR - Resíduo de carbono, \%massa;

VISC - Viscosidade a $100{ }^{\circ} \mathrm{C}, \mathrm{cSt}$; YCQ - Rendimento de coque verde, \%massa.

Com a finalidade de verificar a consistência do resíduo de carbono determinado nas amostras de resíduo de vácuo, foi elaborado um gráfico do rendimento de coque calculado. $O$ resultado obtido foi coerente, pois o rendimento mantém uma relação diretamente proporcional com resíduo de carbono, conforme mostrado na Figura 4.4. 
Diversos pesquisadores propuseram correlações para determinar o rendimento de coque a partir do resíduo de carbono. (NELSON, 1958; CASTIGLIONE, 1983; GARY, 2007).

A partir dos dados presente na Tabela 4.1 foi realizado o ajuste dos dados experimentais por mínimos quadrados. A reta de regressão é mostrada na equação (4.1):

$$
\begin{gathered}
Y_{\text {coque }}=1,0252 \cdot M C R+7,6143 \\
R=0,9325
\end{gathered}
$$

Figura 4.4 - Variação de rendimento de coque.

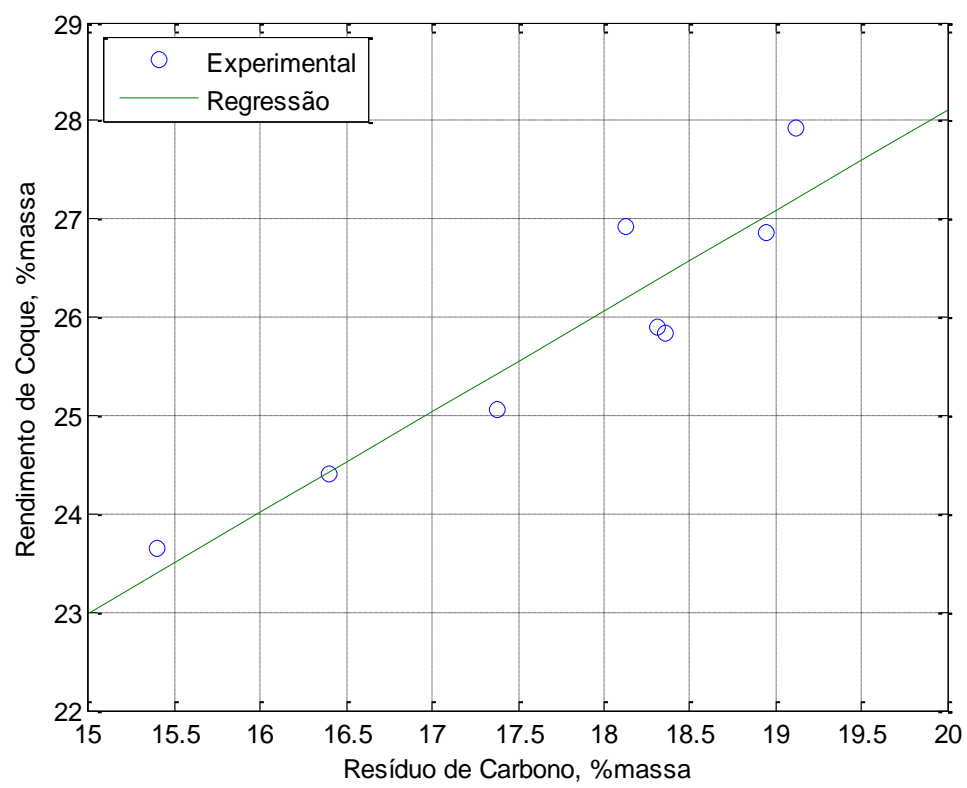

Observando os diversos pontos na Figura 4.4, é notado um aumento no desvio do rendimento de coque experimental em relação aos valores obtidos por regressão à medida que aumenta o valor do resíduo de carbono. Isto é um indicativo da existência de outros parâmetros (teor de asfalteno, temperatura de reação) que têm influência no rendimento de coque.

Na Figura 4.5, é apresentada uma curva de destilação simulada HT750 de uma amostra de resíduo de vácuo. 
Figura 4.5 - Curva de destilação simulada do resíduo HT750 de vácuo

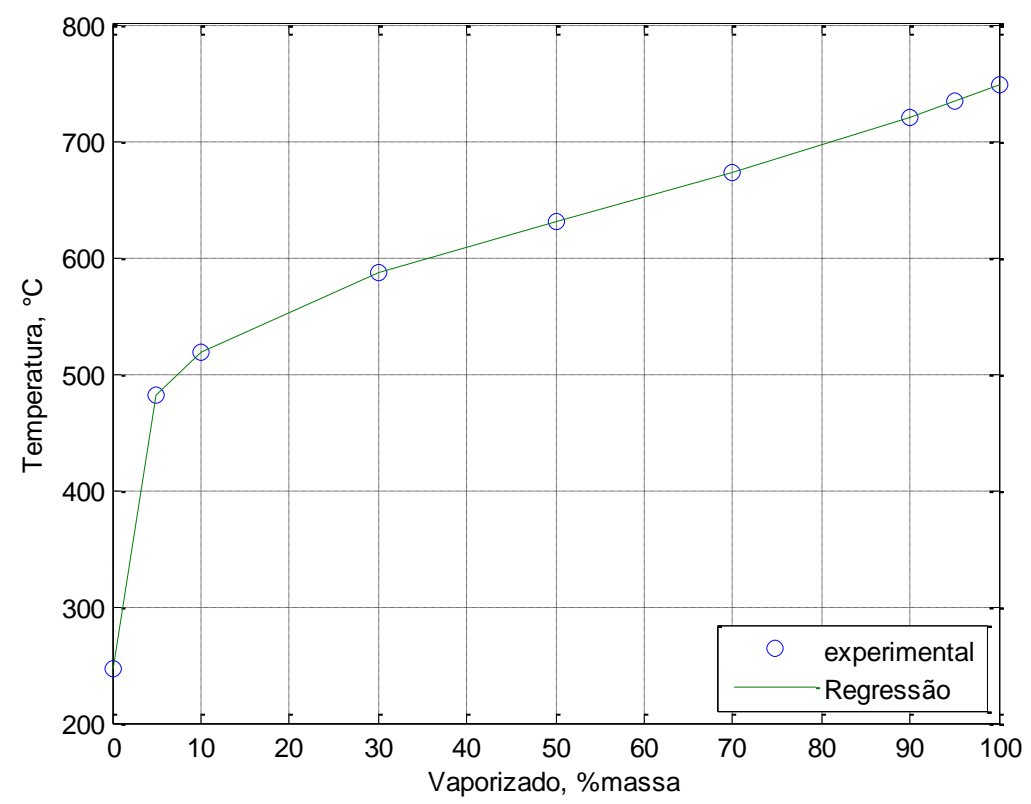

Com base na Figura 4.5, é observado um decréscimo acentuado na extremidade inicial da curva apresentada, que pode estar relacionado com a contaminação de fluido oriundo da selagem da bomba centrifuga responsável pela sua transferência ou da limpeza do amostrador. Aplicando o critério de correção da carta de probabilidade, é identificado um ponto inicial de ebulição da ordem de $450{ }^{\circ} \mathrm{C}$ conforme mostrado na Figura 4.6.

Figura 4.6 - Análise do comportamento da curva de destilação do resíduo de vácuo.

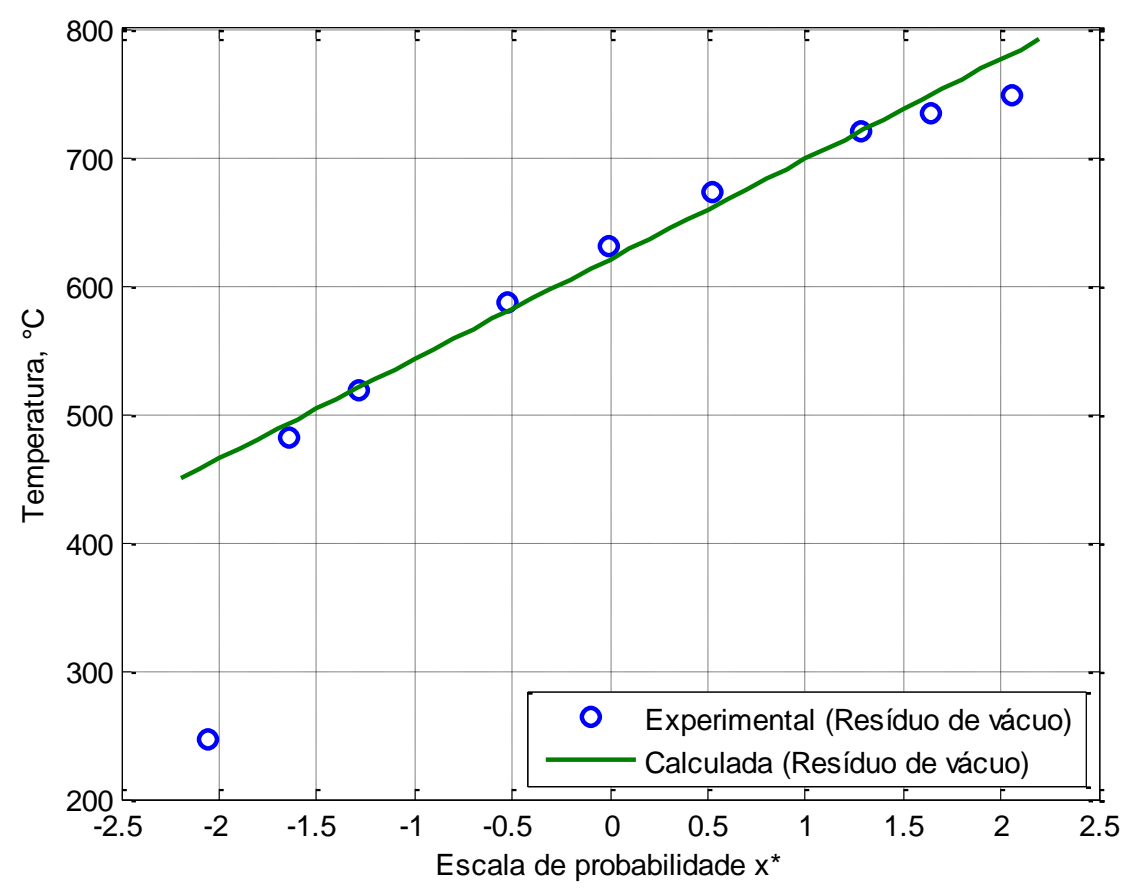




\subsubsection{Estimativa da análise S.A.R.A.}

A análise S.A.R.A. divide as frações pesadas não voláteis em quatro classes (Saturados (As), Aromáticos (Ar), Resinas (Re) e Asfaltenos (As)) de acordo com a sua polaridade e polarizabilidade através de técnicas analíticas. Este conceito pode ser definido pela equação de balanço de massa global (4.2).

$$
\mathrm{RV}=\mathrm{Sa}+\mathrm{Ar}+\mathrm{Re}+\mathrm{As}
$$

onde RV - resíduo de vácuo.

O método de ensaio de resíduo de Conradson (ASTM D-189) representa uma quantidade definida de amostra que é destilada até a sua decomposição térmica severa por período fixo. O resíduo remanescente é pesado e calculado como fração percentual da amostra original. Com base nesta definição, o resíduo de carbono Conradson pode ser representado pela equação (4.3).

$$
\mathrm{CCR}=\mathrm{a}_{0}+\mathrm{a}_{1} \cdot \operatorname{Ar}+\mathrm{a}_{2} \cdot \mathrm{Re}+\mathrm{a}_{3} \cdot \mathrm{As}
$$

Utilizando os resultados de análise S.A.R.A. e resíduo de carbono Conradson disponíveis em diversas fontes (GUO, 2008; ZHAO, 2005; YANG, 2012), foi determinada a contribuição de cada classe no resultado no resíduo através da equação (4.4).

$$
\begin{gathered}
C C R=0,1423 \cdot A r+0,2325 \cdot R e+0,6774 \cdot \text { As } \\
R=0,88073
\end{gathered}
$$

Considerando a mistura com quatros classes como uma mistura líquida ideal, a massa específica da mistura é obtida pelo somatório das multiplicações das massas específicas e frações mássicas de classe de acordo a equação (4.5). (AKBARZADEH, 2005; RIAZI, 2005) 


$$
\frac{1}{\rho}=\frac{\mathrm{Sa}}{\rho_{\mathrm{Sa}}}+\frac{\mathrm{Ar}}{\rho_{\mathrm{Ar}}}+\frac{\operatorname{Re}}{\rho_{\mathrm{Re}}}+\frac{\mathrm{As}}{\rho_{\mathrm{As}}}
$$

$\mathrm{Na}$ Tabela 4.2, estão mostrados os valores de massa específicos para as diferentes frações SARA, obtidos na literatura (LEÓN, PARRA, GROSSO, 2008; AKBARZADEH, et al, 2005).

Tabela 4.2 - Valores de massa específica, $\mathrm{kg} / \mathrm{m}^{3} @ 20^{\circ} \mathrm{C}$.

\begin{tabular}{lccc}
\hline Classe & Média & Máximo & Mínimo \\
\hline Saturados & 891 & 909 & 853 \\
Aromáticos & 986 & 1012 & 953 \\
Resinas & 1048 & 1114 & 1007 \\
Asfaltenos & 1135 & 1193 & 1075 \\
\hline
\end{tabular}

Através da solução simultânea das equações (4.3), (4.4) e (4.5), é determinado o S.A.R.A. do resíduo de vácuo.

a) Aromaticidade

$\mathrm{Na}$ Tabela 4.3, é apresentada a razão atômica $\mathrm{H} / \mathrm{C}$ para as quatro frações presentes no resíduo de vácuo (saturados, aromáticos, resinas e asfaltenos), obtidos na literatura (CHEN, et al., 2012; ZHAO, et al., 2010). A razão atômica H/C decresce na ordem: saturados $>$ aromáticos $>$ resinas $>$ asfaltenos.

Tabela 4.3 - Valores de razão atômica H/C para frações.

\begin{tabular}{ccccc}
\hline Classe & Saturados & Aromáticos & Resinas & Asfaltenos \\
\hline Média & 1,8657 & 1,4939 & 1,3844 & 1,1451 \\
Máximo & 1,9735 & 1,5950 & 1,4352 & 1,2343 \\
Mínimo & 1,7349 & 1,3678 & 1,3249 & 1,0873 \\
\hline
\end{tabular}

Para determinar a relação atômica média de H/C é aplicada uma regra simples de mistura conforme apresentado na equação (4. 6). 


$$
\left(\frac{\mathrm{H}}{\mathrm{C}}\right)_{\mathrm{RV}}=\left(\frac{\mathrm{H}}{\mathrm{C}}\right)_{\mathrm{SAT}} \cdot \mathrm{X}_{\mathrm{SAT}}+\left(\frac{\mathrm{H}}{\mathrm{C}}\right)_{\mathrm{ARO}} \cdot \mathrm{X}_{\mathrm{ARO}}+\left(\frac{\mathrm{H}}{\mathrm{C}}\right)_{\mathrm{RES}} \cdot \mathrm{X}_{\mathrm{RES}}+\left(\frac{\mathrm{H}}{\mathrm{C}}\right)_{\mathrm{ASF}} \cdot \mathrm{X}_{\mathrm{ASF}}
$$

Considerando os valores médios da relação atômica H/C para cada fração, como mostrado na Tabela 4.3, foi calculada a relação atômica $\mathrm{H} / \mathrm{C}$ do resíduo de vácuo, com equação (4.6) e as quantidades de saturados, aromáticos, resinas e asfaltenos presente em diversas amostras de resíduo de vácuo. Os resultados estão apresentados na Tabela 4.4 .

Tabela 4.4 - Valores de razão atômica H/C de vários resíduo de vácuo.

\begin{tabular}{|c|c|c|c|c|c|c|c|}
\hline \multirow{2}{*}{$\mathrm{N} .^{\circ}$} & \multicolumn{4}{|c|}{ Composição, \%massa } & \multicolumn{2}{|c|}{ Relação atômica H/C } & \multirow{2}{*}{ Diferença } \\
\hline & Saturados & Aromáticos & Resinas & Asfaltenos & Calculado & Experimental & \\
\hline 1 & 41,9 & 32,7 & 25,4 & 0,0 & 1,62 & 1,79 & 0,17 \\
\hline 2 & 16,1 & 30,6 & 51,1 & 2,2 & 1,49 & 1,58 & 0,09 \\
\hline 3 & 16,5 & 49,5 & 26,8 & 7,3 & 1,50 & 1,47 & $-0,03$ \\
\hline 4 & 15,9 & 40,0 & 33,7 & 9,3 & 1,47 & 1,51 & 0,04 \\
\hline 5 & 18,5 & 44,8 & 30,6 & 6,1 & 1,51 & 1,49 & $-0,02$ \\
\hline 6 & 12,6 & 46,6 & 29,9 & 10,8 & 1,47 & 1,44 & $-0,03$ \\
\hline 7 & 26,3 & 40,6 & 31,2 & 2,0 & 1,55 & 1,60 & 0,05 \\
\hline
\end{tabular}

Conforme a Tabela 4.4, as diferenças entre o valor experimental e o calculado é pequena. Com isso, a equação (4.6) mostrou-se satisfatório para determinar a relação atômica $\mathrm{H} / \mathrm{C}$.

O teor de hidrogênio e a razão atômica H/C são parâmetros importantes para o processamento de frações pesadas. Um elevado teor de hidrogênio ou alta razão atômica $\mathrm{H} / \mathrm{C}$ é tipicamente correlacionado com alto rendimento de líquido. (XU, et al., 2014).

Uma maneira simples de determinar o caráter aromático de uma fração de petróleo é utilizar a relação atômica H/C (WIEHE, 1992). Esta H/C tem uma forte correlação com o fator de aromaticidade, fa, mas tem correlação relativamente fraca com a estrutura molecular. A definição de fator de aromaticidade é apresentada na equação (4.7) (CORBETT, 1964). 


$$
\mathrm{fa}=\frac{\mathrm{Ca}}{\mathrm{C}_{\mathrm{T}}}
$$

onde:
fa - Fator de aromaticidade
$\mathrm{Ca}$ - Carbono aromático
$\mathrm{Ca} \quad$ - Carbono total

Com base em dados experimentais publicados na literatura (GUO, ZHANG e WANG, 2008; ZHAO, et al., 2005; YANG, et al., 2005; ROGEL e CARBOGNANI, 2003) foi obtida a Figura 4.7, na qual é apresentada uma relação entre aromaticidade e a relação atômica $\mathrm{H} / \mathrm{C}$.

Figura 4.7 - Fator de aromaticidade em função da relação atômica H/C.

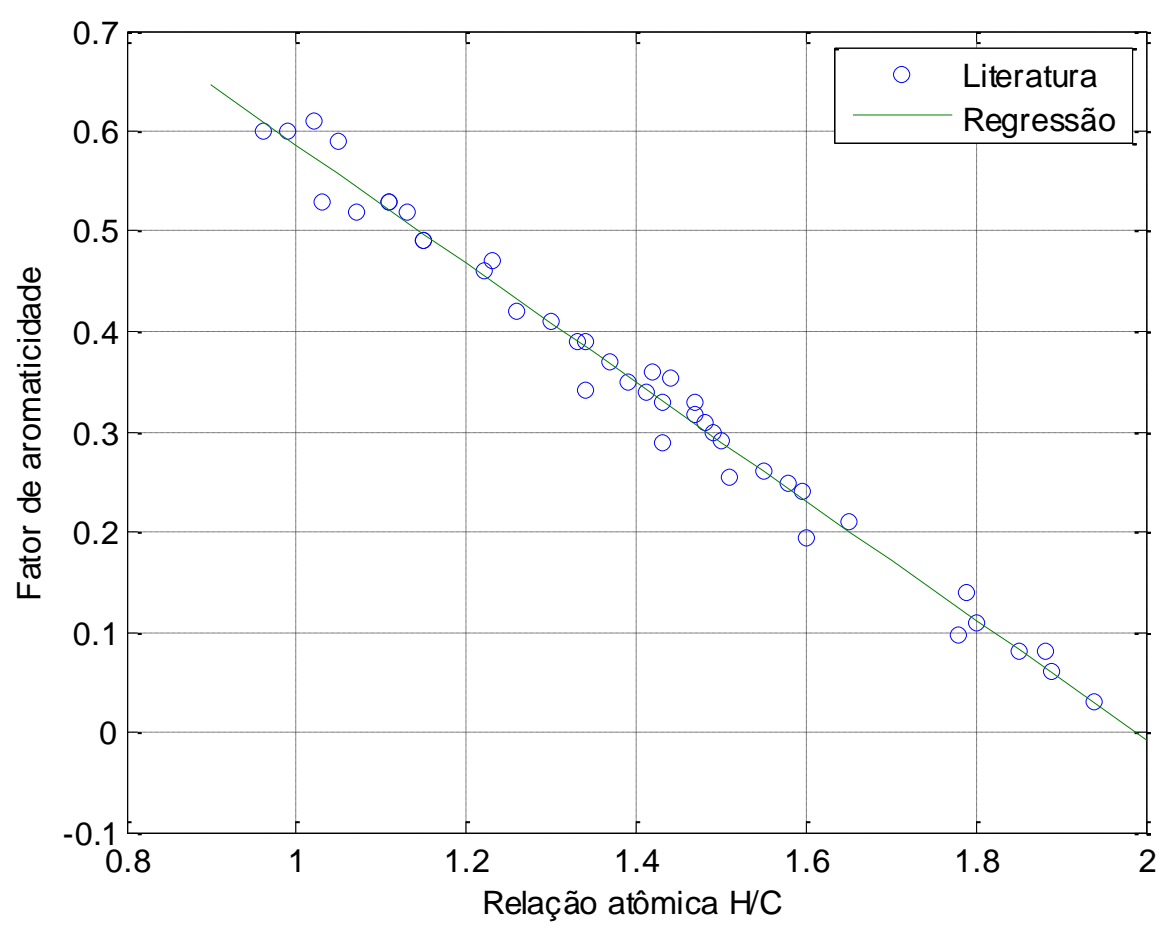

A regressão dos dados experimentais é apresentada na equação (4.8).

$$
\begin{gathered}
\mathrm{fa}=1,1810-0,5911 \cdot\left(\frac{\mathrm{H}}{\mathrm{C}}\right) \\
\mathrm{R}=-0,9930
\end{gathered}
$$


O teor de hidrogênio presente nas frações do SARA pode ser aferido através da equação (4.10) (GUO, et al., 2010).

$$
D_{20 / 4 \mathrm{C}}=1,4673-0,0431 \cdot \mathrm{H}
$$

Os teores de carbono aromático e de hidrogênio presentes na fração pesada podem ser determinados, utilizando-se as equações (4.11) e (4.12), respectivamente. (CHOUDHARY e MEIER, 2008).

$$
\begin{gathered}
C_{a}=292,1 \cdot S G-0,077 \cdot T_{50}-213,576 \\
H_{T}=-26,5 \cdot S G+0,00234 \cdot T_{50}+35,242
\end{gathered}
$$

onde:

$\mathrm{T}_{50} \quad$ - Temperatura de ebulição, ${ }^{\circ} \mathrm{C}$.

SG - Densidade da fração a $15,6 / 15,6^{\circ} \mathrm{C}$.

$\mathrm{Na}$ Tabela 4.5, são apresentados os resultados de S.A.R.A. e aromaticidade da

\begin{tabular}{|c|c|c|c|c|c|c|c|}
\hline \multirow{2}{*}{ Amostra N..$^{\circ}$} & \multicolumn{4}{|c|}{ S.A.R.A, \%massa } & \multirow{2}{*}{$\begin{array}{c}\mathrm{H} / \mathrm{C} \\
\text { atômica }\end{array}$} & \multirow{2}{*}{$\mathrm{fa}$} & \multirow{2}{*}{$\begin{array}{c}\mathrm{Ca} \\
\% \text { massa }\end{array}$} \\
\hline & Saturados & Aromáticos & Resinas & Asfaltenos & & & \\
\hline 1 & 23,23 & 23,94 & 47,68 & 5,15 & 1,5101 & 0,2884 & 0,3038 \\
\hline 2 & 25,34 & 24,47 & 45,27 & 4,92 & 1,5214 & 0,2817 & 0,3125 \\
\hline 3 & 27,25 & 24,98 & 43,60 & 4,18 & 1,5329 & 0,2749 & 0,2825 \\
\hline 4 & 18,07 & 40,17 & 34,86 & 6,90 & 1,4989 & 0,2950 & 0,3252 \\
\hline 5 & 19,44 & 35,77 & 37,40 & 7,39 & 1,4994 & 0,2947 & 0,3253 \\
\hline 6 & 18,95 & 38,06 & 36,39 & 6,60 & 1,5015 & 0,2935 & 0,3225 \\
\hline 7 & 17,43 & 36,28 & 38,79 & 7,49 & 1,4901 & 0,3002 & 0,3326 \\
\hline 8 & 17,94 & 36,27 & 38,12 & 7,68 & 1,4921 & 0,2990 & 0,3339 \\
\hline
\end{tabular}
corrente de resíduo de vácuo.

Tabela 4.5 - Resultados de SARA e aromaticidade do resíduo de vácuo.

Utilizando os dados da Tabela 4.1, foram estimados os valores de saturados, de aromáticos e de resinas a partir das equações (4.2), (4.4) e (4.5), enquanto a relação atômica de H/C foi obtida através da equação (4.6). Comparando o fator de 
aromaticidade com o rendimento de coque, verifica-se um acréscimo no rendimento de coque com aromaticidade (deficiência de hidrogênio) do resíduo de vácuo.

\subsubsection{Espectrometria de massa}

Como há uma biblioteca de compostos baseada em probabilidade (PBM Probability Based Matching) para frações pesadas de petróleo, foi desenvolvida uma estratégia para interpretar e compreender o espectrograma de massas dos resultados das diversas amostras analisadas. As etapas da estratégia são: interconversão e discretização dos resultados.

A interconversão dos resultados da razão massa-carga $(\mathrm{m} / \mathrm{z})$ e da abundância de espécies de íons obtida a partir da análise de amostra de asfaltenos por espectrometria de massas em fração acumulada de intensidade das espécies e $\mathrm{m} / \mathrm{z}$, apresenta um comportamento de curva sigmoidal. Na faixa de composição acumulada entre 0,10 e 0,90, a curva é uma reta (4.13) quando o envelope de distribuição de intensidade e relação $(\mathrm{m} / \mathrm{z})$ se aproxima de uma distribuição normal (distribuição simetria).

$$
\left(\frac{m}{z}\right)=a \cdot x+b
$$

Quando a curva apresenta um afastamento deste comportamento linear, a mistura apresenta mais de uma distribuição normal ou uma distribuição assimétrica.

Empregando esta metodologia na interpretação do espectrograma, foram determinadas as curvas de distribuição $\mathrm{m} / \mathrm{z}$ para cada amostra de asfalteno extraído do resíduo de vácuo, como se pode observar nas Figuras 4.8aำh.

As Figuras 4.8a-e, apresentam comportamento de espectros semelhantes à distribuição normal, enquanto as Figuras 4.8f-h apresentam um achatamento e duas regiões de concentração de intensidade.

\footnotetext{
${ }^{1}$ Com objetivo de comparar as curvas de distribuição de m/z, a Figura 4.8 se subdivide em oito.
} 
Figura 4.8 - Espectro de massa e curva de distribuição de m/z
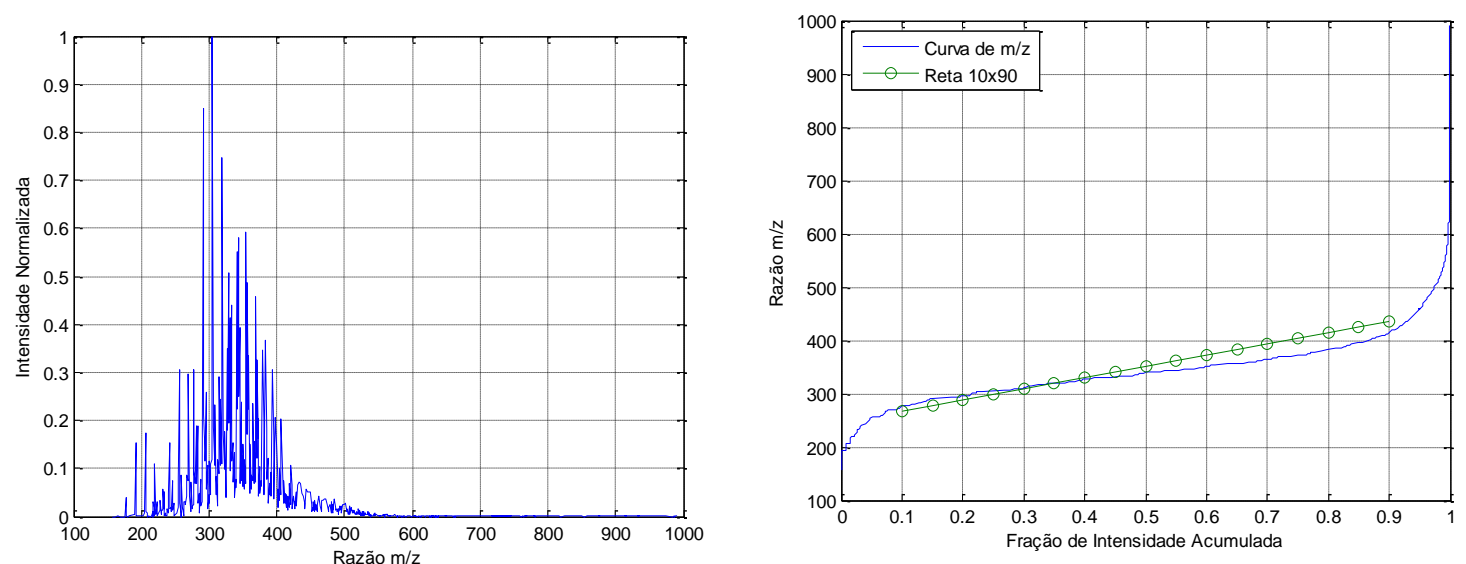

a) amostra 1
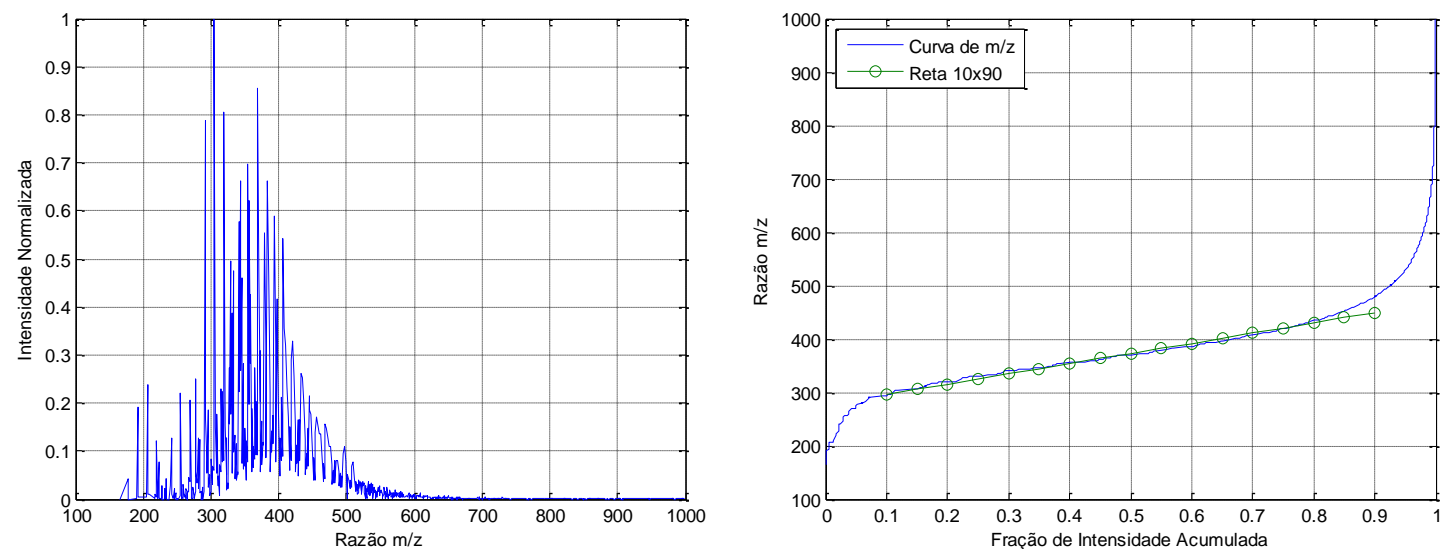

b) amostra 2
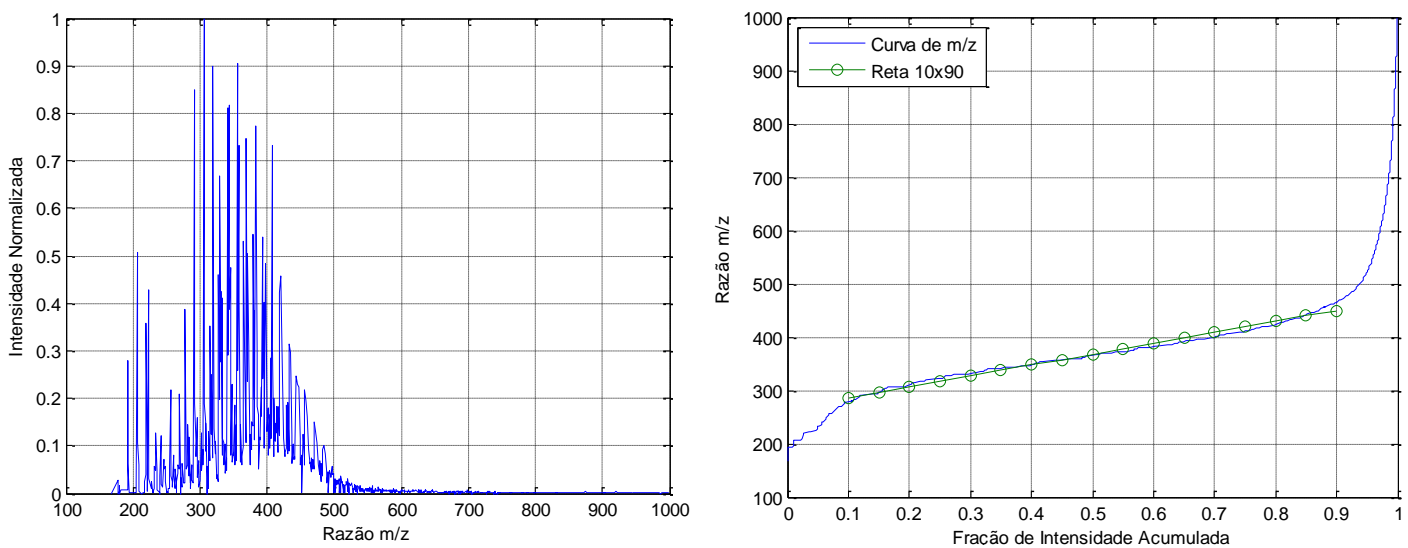

c) amostra 3 
Figura 4.8 - Espectro de massa e curva de distribuição de m/z (cont.)
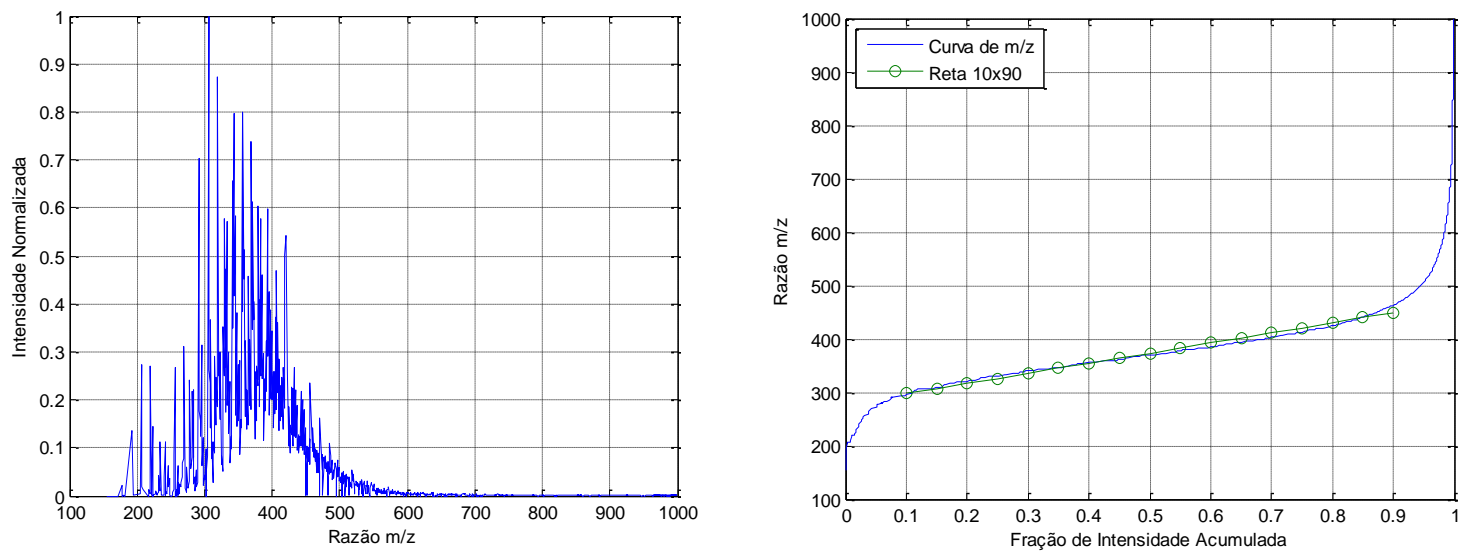

d) amostra 4
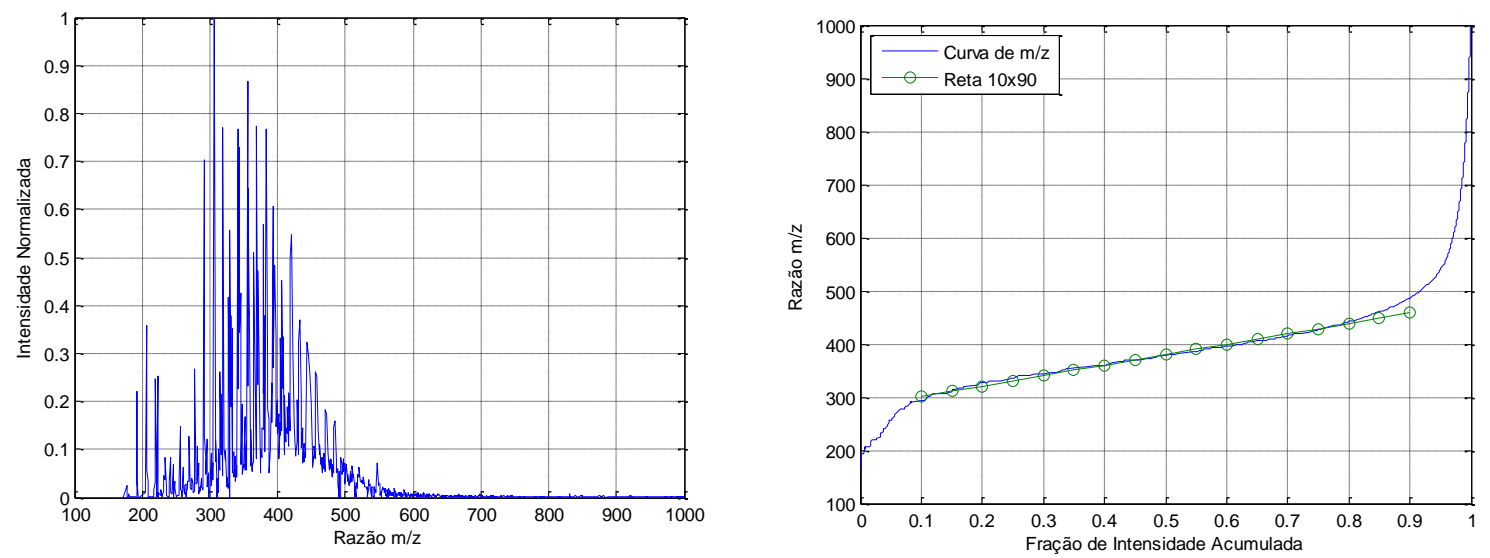

e) amostra 5
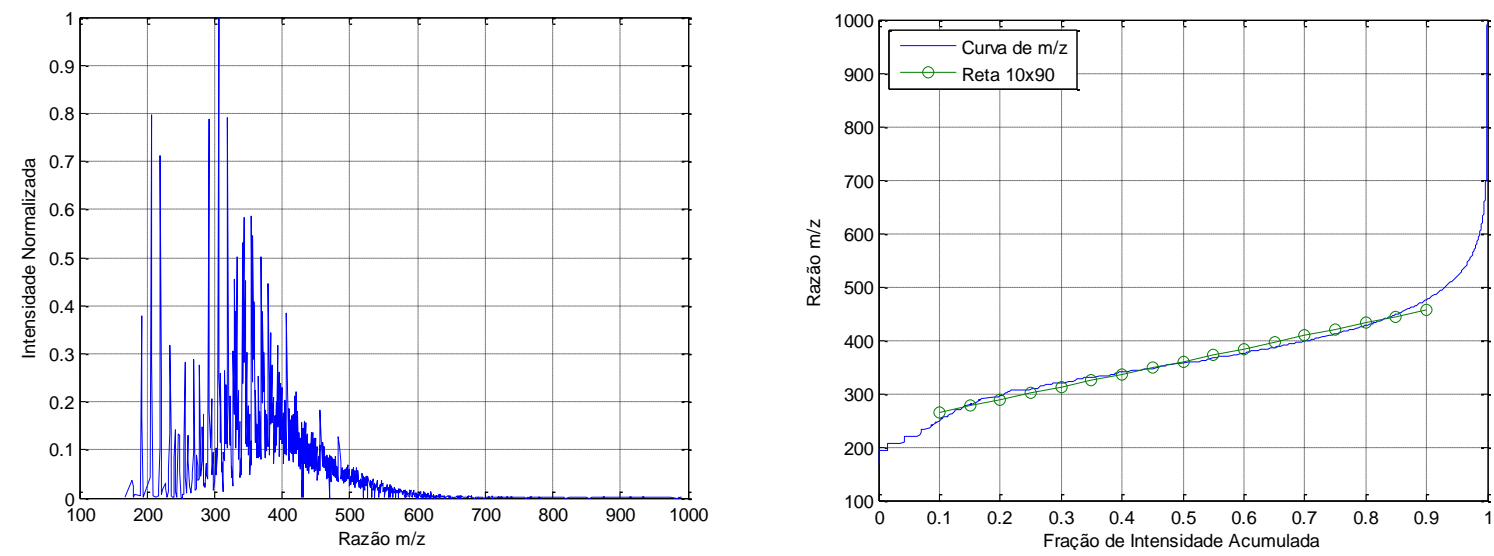

f) amostra 6 
Figura 4.8 - Espectro de massa e curva de distribuição de $\mathrm{m} / \mathrm{z}$ (cont.)
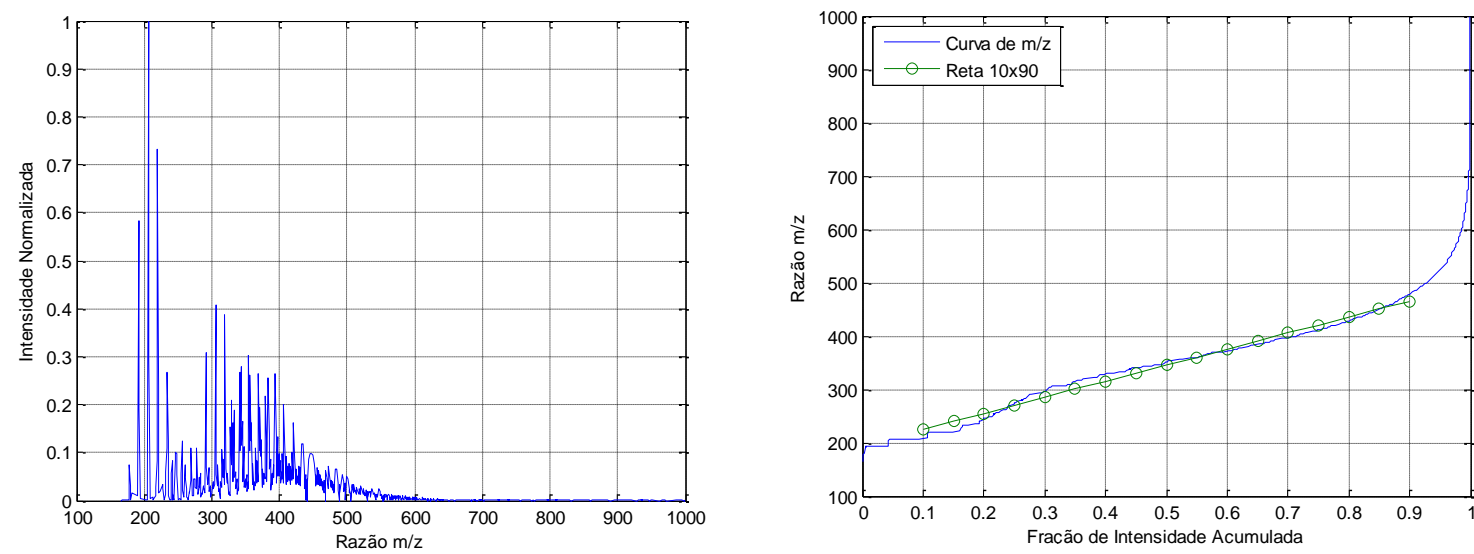

g) amostra 7
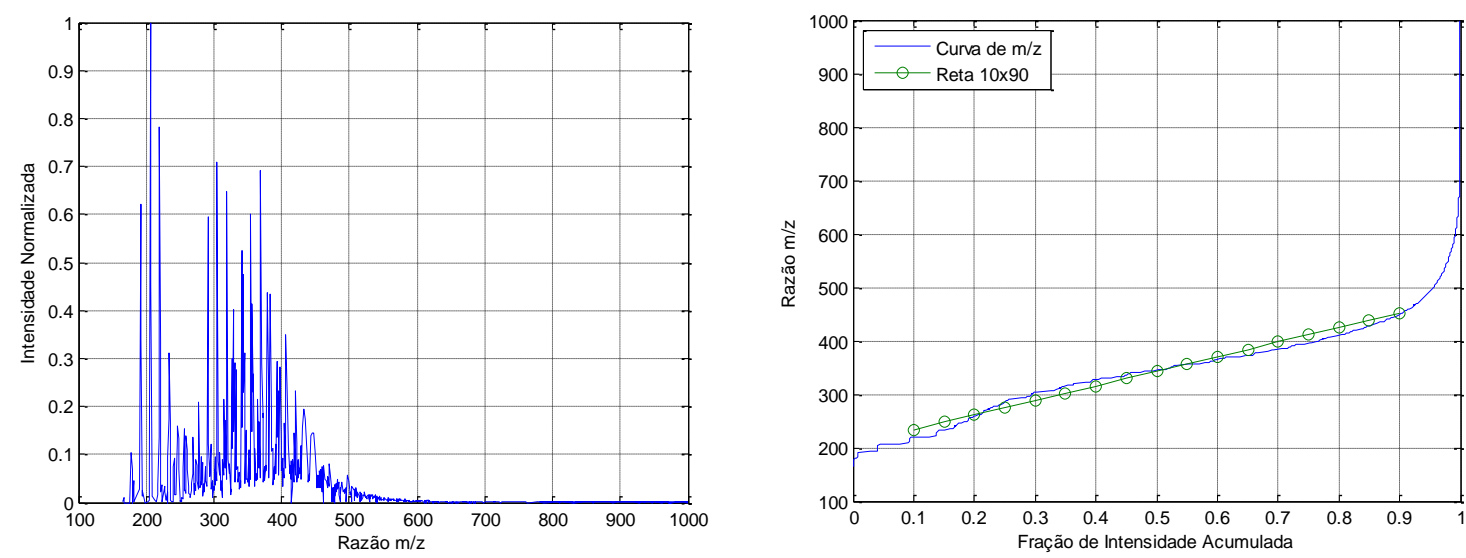

h) amostra 8

Comparando o comportamento das curvas de distribuição $\mathrm{m} / \mathrm{z}$ em relação à reta $10 \mathrm{x}$ 90, observa-se uma leve inflexão ao longo do intervalo para as Figura 4.8f, 4.8g e 4.8h. Esta inflexão é um indicativo de que a mistura foi realizada com grupos de petróleos cujas características são atribuídas a asfaltenos diferentes. A partir dos espectros destas amostras, foram identificadas duas regiões com diferentes intensidades.

Com a finalidade de identificar a existência da participação de um ou mais grupos de petróleo responsáveis por provocar a formação destas duas regiões de intensidades diferentes, as amostras de resíduos de vácuo de petróleo foram agrupadas em seis classes de viscosidade a $100{ }^{\circ} \mathrm{C}$ (<1100 cSt; $1100-1330$ cSt; $1330-3100$ cSt; 31007800 cSt; 7800-11000 cSt e >11000 cSt), em função da distribuição em insolúveis em n-C $C_{7}$ (asfaltenos). Estes agrupamentos estão representados na Figura 4.9. 
Figura 4.9 - Agrupamento dos diferentes resíduos em função da viscosidade.

Amostra 1

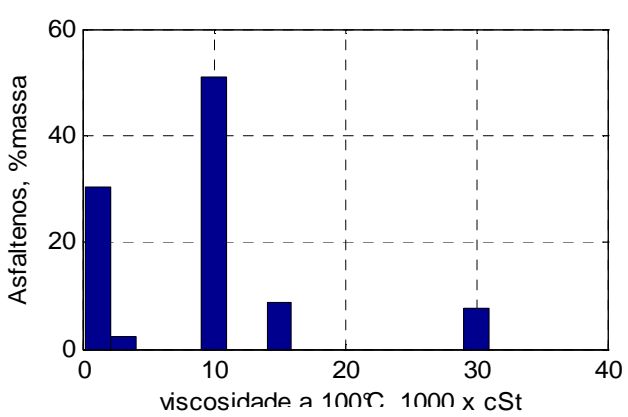

Amostra 3

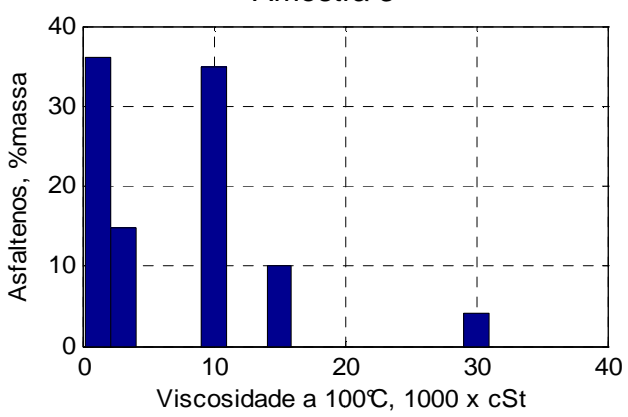

Amostra 5

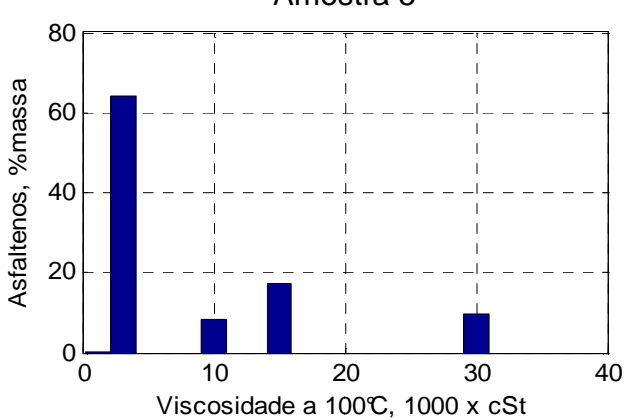

Amostra 7

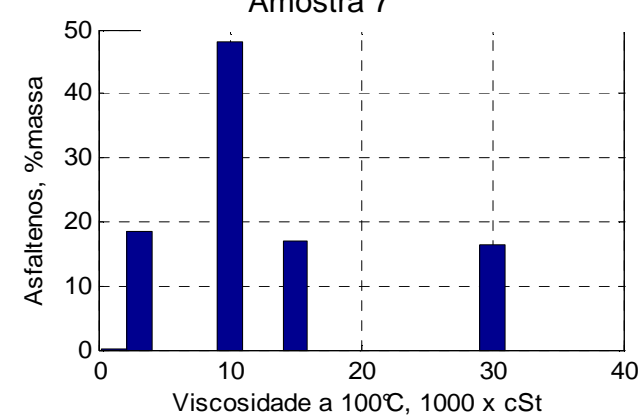

Amostra 2

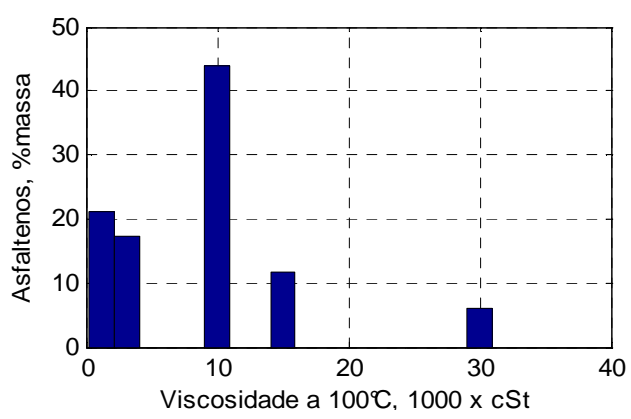

Amostra 4

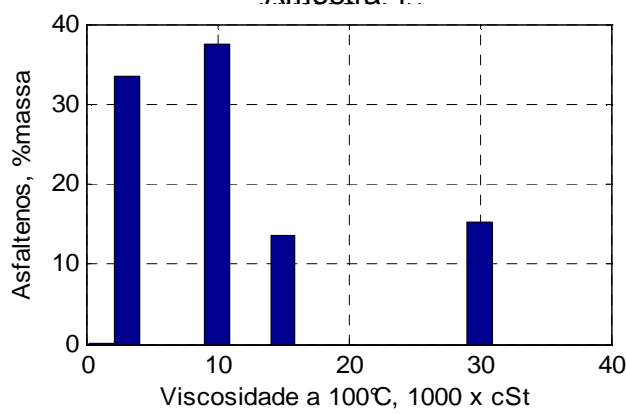

Amostra 6

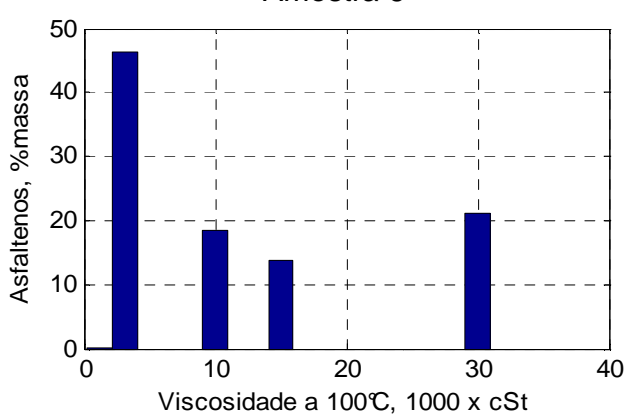

Amostra 8

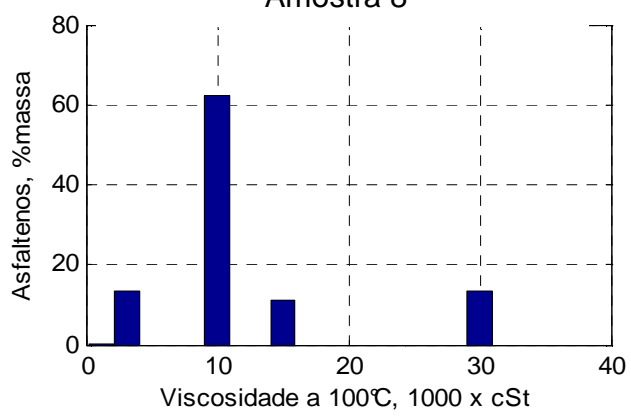

Nas amostras 1, 3 e 4, existem duas classes de resíduos com mais de 30\% de asfaltenos: uma classe com viscosidade baixa e outra alta. Isto é uma evidência de que o tamanho das moléculas de asfaltenos é diferente.

Classificando os resíduos de vácuo de petróleos com participação acima de $10 \%$ volume na mistura na constituição das amostras 1, 3 e 4, foram identificadas quatro, cinco e três fontes diferentes, respectivamente. Estas amostras foram 
formadas a partir da mistura de resíduos de vácuo com a relação MCR/ASF e com valores distintos, indicando que a natureza química é bastante diferente.

$\mathrm{Na}$ Tabela 4.6, estão apresentadas as características obtidas a partir dos espectros e das curvas de distribuição m/z.

Tabela 4.6 - Principais resíduos de vácuo presentes no petróleo.

\begin{tabular}{cccccc}
\hline Resíduo & MCR/ASF & $\begin{array}{c}\text { Viscosidade @ } \\
100^{\circ} \mathrm{C}, \mathrm{cSt} .\end{array}$ & Amostra 1 & Amostra 3 & Amostra 4 \\
\hline R3 & 3,36 & 1010 & 8,9 & 10,6 & \\
R4 & 2,18 & 3040 & & & 27,3 \\
R12 & 8,37 & 356 & & 8,6 & \\
R14 & & 10842 & & 9,6 & \\
R18 & 2,41 & 3145 & 25,9 & & 27,6 \\
R19 & 3,66 & 8911 & 9,2 & 15,3 & \\
R24 & & 26780 & & & 12,1 \\
R25 & 6,28 & 1277 & & 9,5 & 10,4 \\
R27 & & 7137 & 10,4 & 9,1 & \\
R29 & 3,44 & 1214 & 18,7 & 16,5 & \\
\hline
\end{tabular}

Através da interconversão, pode-se discretizar em cortes com base na razão $\mathrm{m} / \mathrm{z}$, utilizando o método da integral. Assim, esta metodologia permite comparar, numericamente, os resultados das diversas amostras, como apresentado na Tabela 4.7.

Considerando as moléculas formadas por carbono e hidrogênio presentes na fração de petróleo e agrupadas em peso molecular múltiplos de 13, pode-se estimar a fórmula química dos constituintes da mistura $(\mathrm{CH})_{n}$ para cada amostra de asfalteno extraído do resíduo de vácuo. A Tabela 4.9 apresenta a estimativa do número de carbono em cada corte citado na Tabela 4.8. 
Tabela 4.7 - Valores dos coeficientes da reta 10 × 90 de cada amostra.

\begin{tabular}{ccccl}
\hline $\begin{array}{c}\text { Amostra } \\
\text { N. }^{\circ}\end{array}$ & $a$ & $b$ & $\left(\frac{m}{z}\right)_{\text {máximo }}$ & \multicolumn{1}{c}{$\begin{array}{c}\text { Características dos asfaltenos na } \\
\text { mistura de petróleos }\end{array}$} \\
\hline 1 & 238,5965 & 240,9280 & 230,3725 & Dois grupos de petróleos distintos. \\
2 & 209,6387 & 246,1839 & 367,1477 & Grupos de petróleos similares \\
3 & 300,5091 & 195,1250 & 408,6323 & Dois grupos de petróleos distintos. \\
4 & 272,9806 & 206,4875 & 267,6497 & Dois grupos de petróleos distintos. \\
5 & 192,2343 & 276,7069 & 209,7395 & Grupos de petróleos similares \\
6 & 204,7276 & 265,6215 & 188,0902 & Grupos de petróleos similares \\
7 & 190,0608 & 278,4346 & 169,5229 & Grupos de petróleos similares \\
8 & 195,5746 & 281,9215 & 173,7730 & Grupos de petróleos similares \\
\hline
\end{tabular}

Tabela 4.8 - Curva da relação $(\mathrm{m} / \mathrm{z})$ para os cortes.

\begin{tabular}{ccccccccc}
\hline Corte & \multicolumn{7}{c}{ Amostra N. } \\
\cline { 2 - 8 }.$^{\circ}$ & 1 & 2 & 3 & 4 & 5 & 6 & 7 & 8 \\
\hline 1 & 182.0 & 213.2 & 180.4 & 180.8 & 216.1 & 183.6 & 221.4 & 196.9 \\
2 & 252.3 & 284.1 & 239.0 & 243.7 & 313.4 & 281.4 & 320.1 & 301.7 \\
3 & 278.3 & 300.4 & 258.5 & 262.5 & 335.7 & 304.5 & 338.1 & 326.9 \\
4 & 282.7 & 291.3 & 260.3 & 261.5 & 322.1 & 293.4 & 318.5 & 314.6 \\
5 & 280.9 & 276.8 & 258.7 & 257.3 & 300.0 & 275.7 & 291.2 & 293.8 \\
6 & 282.7 & 269.0 & 262.5 & 259.7 & 286.1 & 268.0 & 274.3 & 282.2 \\
7 & 292.7 & 273.9 & 275.6 & 273.0 & 288.7 & 278.1 & 276.9 & 288.4 \\
8 & 311.7 & 291.9 & 298.2 & 297.1 & 309.2 & 306.1 & 299.9 & 313.5 \\
9 & 337.7 & 319.9 & 327.5 & 328.8 & 343.9 & 347.3 & 338.9 & 353.0 \\
10 & 366.7 & 352.3 & 359.4 & 362.8 & 385.7 & 393.4 & 385.7 & 398.8 \\
11 & 393.7 & 382.3 & 388.6 & 393.1 & 425.8 & 434.6 & 430.3 & 441.4 \\
12 & 414.0 & 403.2 & 410.5 & 414.0 & 455.4 & 461.7 & 462.6 & 471.2 \\
13 & 424.3 & 410.1 & 421.5 & 421.4 & 467.6 & 467.6 & 474.9 & 481.0 \\
14 & 423.1 & 400.8 & 420.5 & 413.8 & 459.1 & 449.5 & 463.1 & 467.6 \\
15 & 412.3 & 377.2 & 409.5 & 393.7 & 431.7 & 411.1 & 429.3 & 433.6 \\
16 & 398.0 & 347.0 & 394.9 & 368.6 & 394.4 & 363.5 & 383.4 & 389.6 \\
17 & 391.8 & 324.6 & 388.6 & 352.3 & 364.6 & 328.3 & 344.8 & 356.2 \\
18 & 411.1 & 332.6 & 408.6 & 366.0 & 370.6 & 338.7 & 344.9 & 365.3 \\
19 & 481.1 & 403.3 & 480.3 & 439.7 & 452.4 & 441.8 & 428.7 & 462.7 \\
20 & 634.9 & 579.7 & 637.5 & 612.8 & 664.3 & 700.0 & 656.4 & 709.7 \\
\hline
\end{tabular}

Dados obtidos a partir dos picos dos espectogramas. 
Tabela 4.9 - Estimativa da quantidade de $(\mathrm{CH})_{n}$ em cada corte.

\begin{tabular}{|c|c|c|c|c|c|c|c|c|}
\hline \multirow{2}{*}{$\begin{array}{c}\text { Corte } \\
\mathrm{N} .^{\circ}\end{array}$} & \multicolumn{8}{|c|}{ Amostra } \\
\hline & 1 & 2 & 3 & 4 & 5 & 6 & 7 & 8 \\
\hline 1 & 14 & 16 & 14 & 14 & 16 & 14 & 17 & 15 \\
\hline 2 & 19 & 22 & 18 & 19 & 24 & 21 & 25 & 23 \\
\hline 3 & 21 & 23 & 20 & 20 & 26 & 23 & 26 & 25 \\
\hline 4 & 22 & 22 & 20 & 20 & 25 & 22 & 24 & 24 \\
\hline 5 & 21 & 21 & 20 & 20 & 23 & 21 & 22 & 22 \\
\hline 6 & 22 & 21 & 20 & 20 & 22 & 20 & 21 & 22 \\
\hline 7 & 22 & 21 & 21 & 21 & 22 & 21 & 21 & 22 \\
\hline 8 & 24 & 22 & 23 & 23 & 24 & 23 & 23 & 24 \\
\hline 9 & 26 & 24 & 25 & 25 & 26 & 27 & 26 & 27 \\
\hline 10 & 28 & 27 & 28 & 28 & 30 & 30 & 30 & 31 \\
\hline 11 & 30 & 29 & 30 & 30 & 33 & 33 & 33 & 34 \\
\hline 12 & 32 & 31 & 32 & 32 & 35 & 36 & 36 & 36 \\
\hline 13 & 33 & 32 & 32 & 32 & 36 & 36 & 37 & 37 \\
\hline 14 & 33 & 31 & 32 & 32 & 35 & 35 & 36 & 36 \\
\hline 15 & 32 & 29 & 31 & 30 & 33 & 32 & 33 & 33 \\
\hline 16 & 31 & 27 & 30 & 28 & 30 & 28 & 29 & 30 \\
\hline 17 & 30 & 25 & 30 & 27 & 28 & 25 & 26 & 27 \\
\hline 18 & 32 & 25 & 31 & 28 & 28 & 26 & 26 & 28 \\
\hline 19 & 37 & 31 & 37 & 34 & 35 & 34 & 33 & 36 \\
\hline 20 & 49 & 45 & 49 & 47 & 51 & 54 & 51 & 55 \\
\hline
\end{tabular}

Conforme a Tabela 4.9, as estimativas das quantidades de $(\mathrm{CH})_{n}$ variam de 14 a 55 , indicando que os resultados obtidos por ionização a laser assistida por matriz (MALDI) para os asfaltenos foram diferentes daqueles obtidos por outras técnicas analíticas. (SPEIGHT, 1999). Isso pode ser explicado pelo fato de que, nas medidas de peso molecular através de técnicas clássicas, necessita-se uma concentração de asfaltenos muito elevada, o que favorece a agregação de moléculas e, consequetemente, determina-se o peso molecular de uma associação de moléculas.

\subsubsection{Características dos produtos}

Os resultados das análises das correntes de gás, nafta, gasóleo leve, gasóleo pesado, resíduo de vácuo e coque verde foram utilizadas para determinar as 
propriedades físicas necessárias para o balanço de massa (massa específica e fator de caracterização). Na Tabela 4.10, estão os resultados de três produtos num ciclo de operação.

Tabela 4.10 - Resultado de análise de produtos num ciclo de operação.

\begin{tabular}{|c|c|c|c|c|}
\hline & & \multicolumn{3}{|c|}{ Temperatura, ${ }^{\circ} \mathrm{C}$} \\
\hline & & Nafta & Gasóleo Leve & Gasóleo Pesado \\
\hline \multicolumn{2}{|c|}{ Volume, \%vol. líq. } & ASTM D-86 & ASTM D-86 & Simulada HT-750 \\
\hline \multicolumn{2}{|r|}{0} & 58,7 & 196,7 & 169,2 \\
\hline \multicolumn{2}{|r|}{5} & 87,3 & 224,7 & 266,0 \\
\hline \multicolumn{2}{|r|}{10} & 97,5 & 233,1 & 294,6 \\
\hline \multicolumn{2}{|r|}{30} & 124,4 & 250,9 & 345,8 \\
\hline \multicolumn{2}{|r|}{50} & 147,4 & 267,9 & 380,4 \\
\hline \multicolumn{2}{|r|}{70} & 170,1 & 291,4 & 414,2 \\
\hline \multicolumn{2}{|r|}{90} & 196,2 & 330,7 & 476,8 \\
\hline \multicolumn{2}{|r|}{95} & 211,0 & 348,3 & 563,8 \\
\hline \multicolumn{2}{|r|}{100} & 223,4 & 368,3 & 721,4 \\
\hline \multirow[t]{2}{*}{ Viscosidade } & a $50{ }^{\circ} \mathrm{C}$ & & 2,39 & 19,9 \\
\hline & a $60^{\circ} \mathrm{C}$ & & 2,19 & 14,6 \\
\hline \multicolumn{2}{|c|}{ Resíduo de Carbono, \%massa. } & - & - & 1,87 \\
\hline \multicolumn{2}{|c|}{ Densidade, $d_{20 / 4^{\circ} \mathrm{C}}$} & 0,7652 & 0,8757 & 0,9362 \\
\hline
\end{tabular}

Fonte: Amostra coletada em 23/03/2011 na Unidade de Coqueamento Retardado (UCP1).

As amostras de gasóleo pesado apresentaram um teor médio de resíduo de carbono de $1,90 \%$ de massa. Além disso, a sua temperatura inicial está abaixo do gasóleo leve, sendo necessária uma correção desse valor. O critério utilizado foi a carta de probabilidade.

Analisando-se as três curvas de destilação da Tabela 4.10, observa-se um overlap nos fracionamentos das correntes de produtos.

Para minimizar os erros durante o processo de caracterização de produtos em pseudocomponentes, foi adotada a estratégia de efetuar os cortes em cada corrente e depois a mistura é realizada por aditividade de pseudocomponentes. 


\subsubsection{Qualidade de coque verde}

\subsubsection{Teor de matéria volátil}

A matéria volátil combustível (VCM) é um parâmetro chave para o sucesso da qualidade do coque verde, pois tem influência no comportamento do processo de calcinação e as propriedades de coque calcinado. Os coques verdes com alta VCM ( $>12 \%$ massa) são mais difíceis de calcinar, resultando em coque calcinado de maior porosidade e menor densidade (HON, et al., 2012).

A determinação do teor de matéria volátil fornece informações valiosas para o refinador, calcinador e "aluminium smelter". O refinador utiliza os resultados de VCM para avaliar a severidade do processo de coqueamento para determinar a quantidade de frações líquidas não recuperadas. Um alto valor de VCM significa que menos produtos líquidos foram recuperados. Em alguns casos, esta pode ser a escolha econômica de preferência da refinaria. Geralmente, uma unidade de coqueamento é gargalo na refinaria. A operação com menor severidade no processo de coqueamento proporciona a refinaria maior capacidade de processamento de óleos residuais ou maiores rendimentos. Quando aumenta a vazão de carga, a corrente de óleo residual é aquecida no forno para temperatura mais baixa. Como as reações endotérmicas de coqueamento ocorrem em severidades mais baixas, resultam num aumento no teor de VCM no coque verde.

Bacha propôs que o teor de matéria volátil total comumente medido e composto de três distintos tipos de VCM, conhecido como VCM primário, VCM secundário e VCM terciário (BACHA e GORMANO, 1987).

a) VCM primário $\left(\mathrm{VCM}_{1}\right)$ : É o produto gerado por reações de craqueamento térmico das espécies não destiláveis e não extraíveis acima de $500{ }^{\circ} \mathrm{C}$, aproximadamente. É constituída predominantemente por metano e hidrogênio gasoso gerado durante a mudança da estrutura do coque em desenvolvimento.

b) VCM secundário $\left(\mathrm{VCM}_{2}\right)$ : É o produto gerado por reações de craqueamento térmico das espécies não destiláveis e não extraíveis que são apenas fracamente 
ligadas quimicamente à estrutura do coque em desenvolvimento. Tal VCM também aparece na análise de TGA abaixo de $500^{\circ} \mathrm{C}$ e, também consiste em grande parte de hidrocarbonetos líquidos.

c) VCM terciário $\left(\mathrm{VCM}_{3}\right)$ : São emissões geradas pelas reações de craqueamento térmico (ou destilação) de frações do resíduo de vácuo e/ou componentes extraíveis com solventes do coque verde. Este tipo de VCM está associado principalmente com coque verde de elevado teor de matéria volátil (> $10 \%$ massa por TGA ou $>12 \%$ massa por método padrão). Ele aparece na análise TGA abaixo de $500{ }^{\circ} \mathrm{C}$ e provavelmente, consiste em grande parte de hidrocarbonetos líquidos.

$$
\begin{aligned}
& \mathrm{VCM}_{\mathrm{T}}=\mathrm{VCM}_{1}+\mathrm{VCM}_{2}+\mathrm{VCM}_{3} \\
& \mathrm{VCM}_{\mathrm{T}}=\frac{\mathrm{MV}}{\mathrm{MV}+\mathrm{CF}+\text { Cinza }} \cdot 100
\end{aligned}
$$

O leito de coque é retificado durante cerca de três horas ou até a matéria volátil combustível (VCM), em percentagem mássica atinja a faixa de 8,0 a 29,5 e de preferência na faixa de 9,5 - 11,0.

$$
\left(\frac{\mathrm{H}}{\mathrm{C}}\right)_{\text {ATÔMICA }}=\frac{11,9147}{\left(\frac{\mathrm{C}}{\mathrm{H}}\right)_{\text {MASSICA }}} \cdot 100
$$

Carbono não volátil:

$$
\mathrm{CF}=100-\left(\mathrm{VCM}_{\mathrm{T}}+\text { Cinzas }\right)
$$

Tipicamente, o teor de matéria volátil varia de 8,0 a 14,0 \%massa.

\subsubsection{Massa específica de coque verde}

Os valores de massa específica real do coque verde de petróleo ficam em torno de 
$1,36 \mathrm{~g} / \mathrm{cm}^{3}$ e do coque calcinado de 2,04 a $2,08 \mathrm{~g} / \mathrm{cm}^{3}$. Speight (1994) mostra a massa especifica real do coque em função do teor de carbono fixo, como mostrado na Tabela 4.11 e Figura 4.9.

Tabela 4.11 - Massa específica do coque verde de petróleo. (SPEIGHT, 1994)

\begin{tabular}{ccc}
\hline & \multicolumn{2}{c}{ Massa específica real, $\mathrm{g} / \mathrm{cm}^{3}$} \\
\hline Carbono Fixo, \%massa & Limite inferior & Limite superior \\
\hline 50 & 1,486 & 1,571 \\
60 & 1,416 & 1,500 \\
70 & 1,342 & 1,414 \\
80 & 1,271 & 1,342 \\
85 & 1,243 & 1,300 \\
90 & 1,257 & 1,343 \\
93 & - & 1,443 \\
95 & 1,443 & 1,614 \\
100 & 1,929 & 2,257 \\
\hline
\end{tabular}

Figura 4.9 - Variação da massa específica com o teor de carbono fixo.

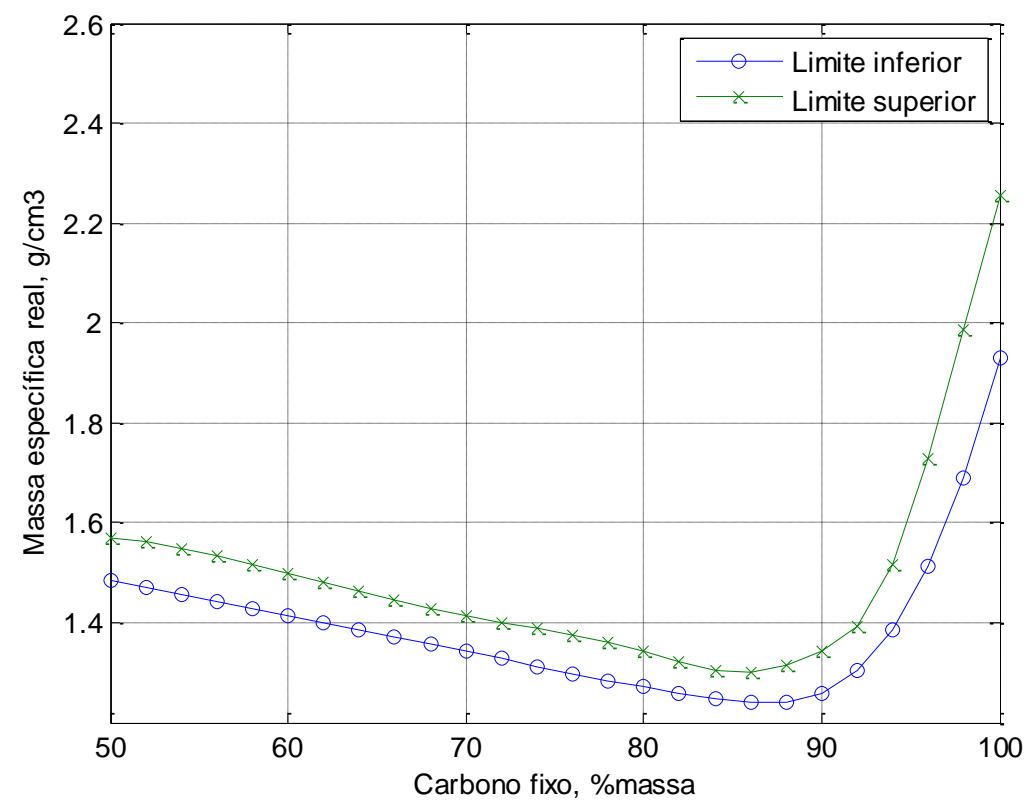

A porosidade do leito de coque pode ser definida pela equação 4.18 . 


$$
\varepsilon=\frac{\text { Volume de vazio }}{\text { Volume total }}
$$

A porosidade pode ser calculada a partir da massa específica "bulk" e real.

$$
\varepsilon=1-\frac{\rho_{\text {BULK }}}{\rho_{\text {REAL }}}
$$

A massa específica real do coque verde e calcinado é determinada conforme o método ASTM D-2638-70, por picnometria de gás hélio. É uma propriedade do coque que caracteriza a sua textura.

$$
\rho_{\mathrm{REAL}}=\frac{\text { massa }}{(\text { Volume total })-(\text { Volume de vazio })}
$$

A Tabela 4.12 apresenta as características do coque verde.

Tabela 4.12 - Características do coque verde.

\begin{tabular}{lcc}
\hline Tipo de coque & Massa específica, $\mathrm{kg} / \mathrm{m}^{3}$ & Tamanho, $\mathrm{mm}$ \\
\hline Esponja & $737-834$ & 10,0 \\
Shot-coke & $834-1041$ & 1,0 \\
Coque fluido & $1009-1153$ & 0,1 \\
\hline
\end{tabular}

\subsubsection{Hardgrove grindability index (HGI)}

O HGI foi desenvolvido nos anos 1930 por R. Hardgrove para medir empiricamente a relativa dificuldade de trituração de carvão para o tamanho de partícula necessário para a combustão completa numa fornalha de carvão pulverizado. Atualmente, o valor de HGI é utilizado para avaliar a especificação de coque verde de petróleo.

O valor do HGI é influenciado pela morfologia e granulometria do coque (Figura 4.10), bem como: teor de matéria volátil, teor de carbono, de hidrogênio e impurezas. Isto tem influência na dureza, onde o coque macio tem elevado valor de HGI, 
enquanto o duro tem alto valor de HGI (JOSHI, 1979). Geralmente, a dureza e a densidade do coque verde aumentam com o decréscimo na relação de aromático com parafina e naftênico na carga.

Figura 4.10 - Efeito da morfologia do coque de petróleo no VCM.

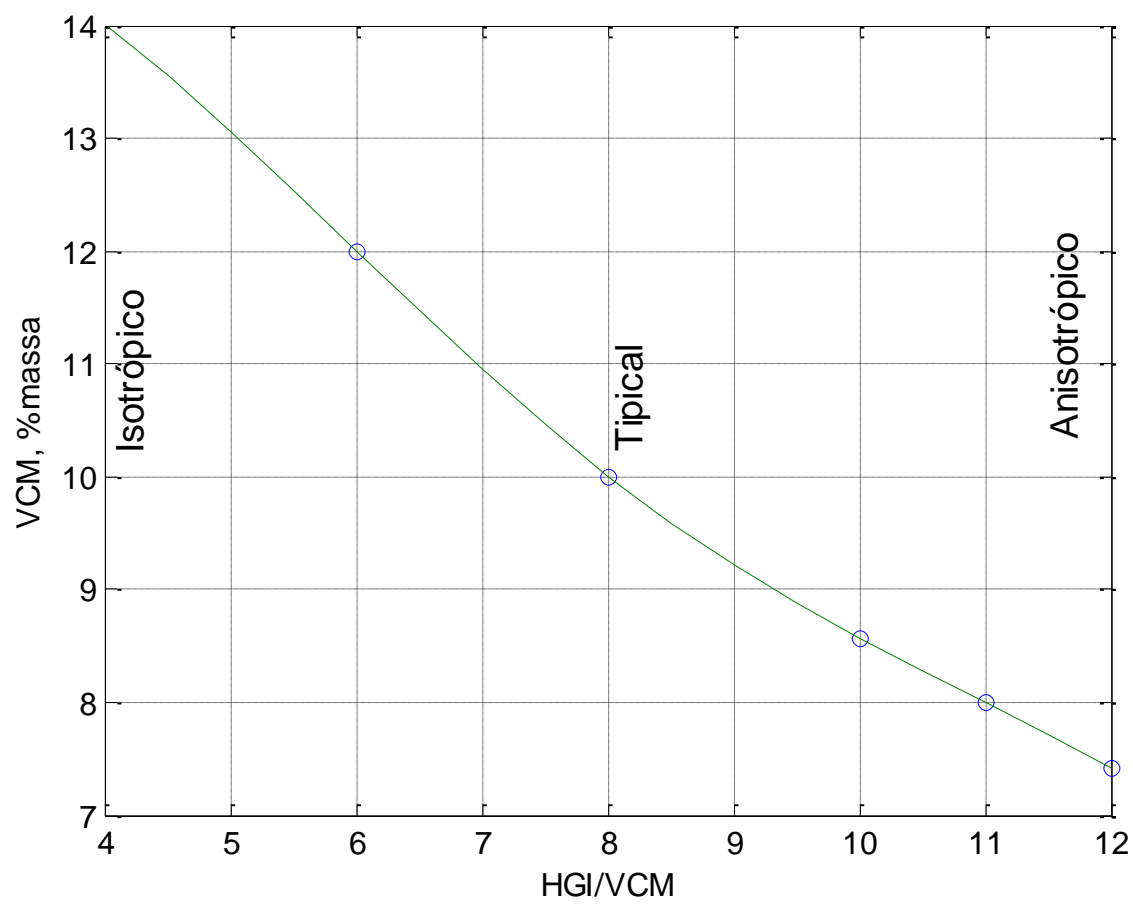

O método para predição do HGI é descrito na Norma ASTM D-409 Standard Test Method for Grindability of Coal by the Hardgrove-Machine Method (ASTM 2006).

Perruchoud (1998) afirma que o valor de HGI varia de 40 a 120 para o coque verde. Tipicamente, para o coque verde grau anodo, a razão HGI/VCM é igual 8, para um dado ciclo. Quando o ciclo é curto, o VCM médio do coque aumenta principalmente devido um drástico acréscimo de VCM no topo do reator. A Figura 4.11 apresenta os resultados da estimativa do HGI em função da razão HGI/VCM.

$$
\left(\frac{\mathrm{HGI}}{\mathrm{VCM}}\right)=12,0-16,0 \cdot\left(\frac{\text { Asfaltenos }}{\mathrm{CCR}}\right)
$$


Figura 4.11 - Estimativa do HGI (Hardgrove Grindability Index). (PERRUCHOUD, 1998)

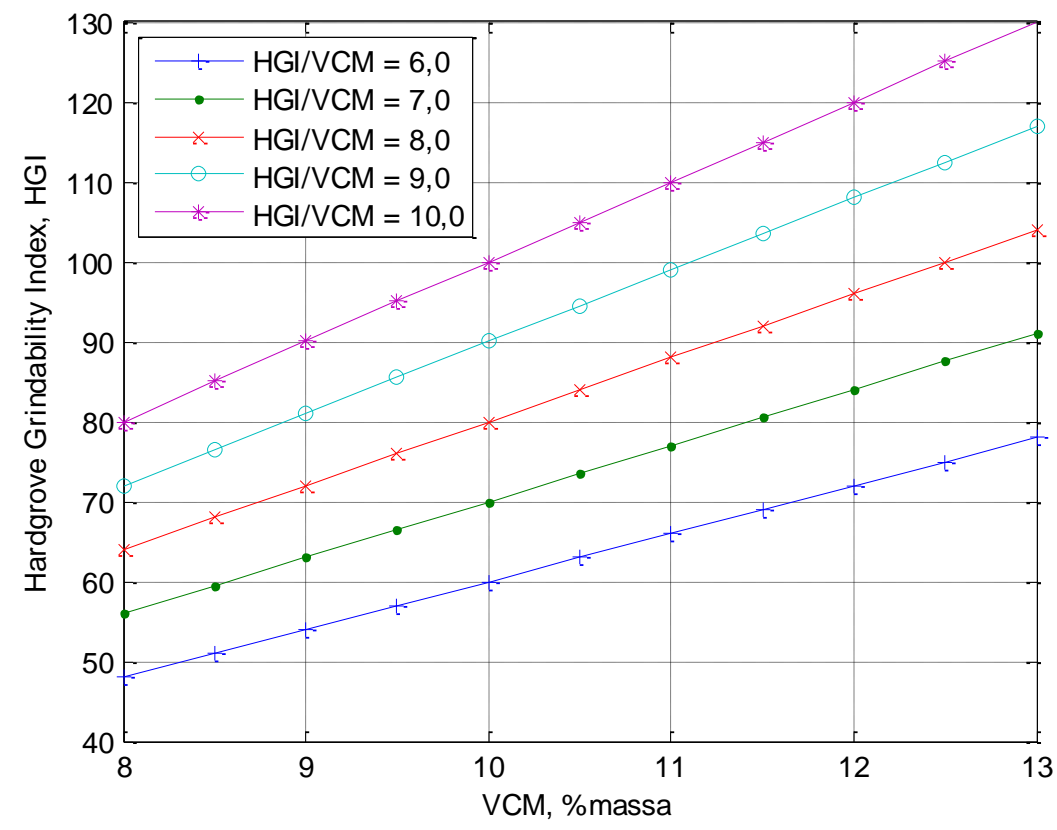

$\mathrm{Na}$ Figura 4.12, é mostrado o comportamento dos dados experimentais de VCM e HGI obtidos das amostras de coque verde. A partir do ajuste de mínimos quadrados, estes dados foram ajustados a uma equação de uma reta.

Figura 4.12 - Qualidade do coque verde dos testes de corridas.

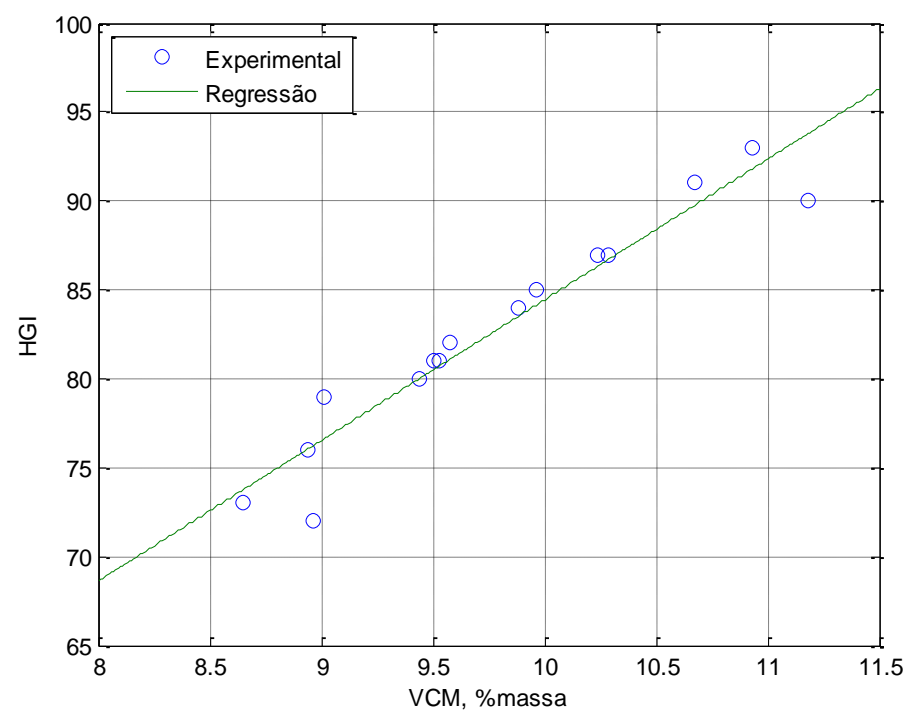


Conforme a curva da Figura 4.13, o HGI mantém relação direta com o teor de matéria volátil do coque verde. A reta de regressão dos dados experimentais é apresentada na equação (4.22).

$$
\begin{gathered}
H G I=7,9107 \cdot V C M+5,3348 \\
R=0,9594
\end{gathered}
$$

$\mathrm{Na}$ especificação do coque calcinado grau anodo existe um parâmetro conhecido como densidade aparente (VBD - Vibrated Bulk Density) que está relacionado com a morfologia do coque verde. Esta morfologia pode ser aferida através do $\mathrm{HGl}$ do coque verde obtido da Tabela 4.1 e calcinada numa unidade industrial conforme ilustrado na Figura 4.13.

Figura 4.13 - Influência do HGI do coque verde na densidade aparente.

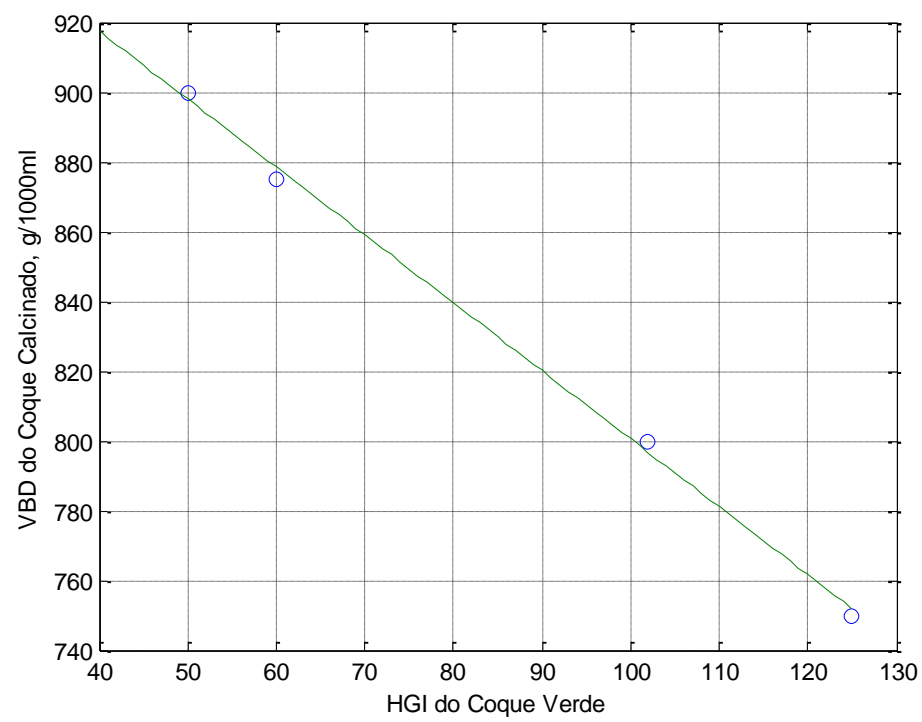




\section{RECONCILIAÇÃO DE DADOS}

O objetivo deste capítulo é apresentar um panorama sobre o procedimento de retificação e tratamento dos dados. O procedimento é constituído basicamente de três etapas principais: aquisição, validação e reconciliação dos dados.

\subsection{Introdução}

Medidas em um processo químico, como vazão volumétrica, temperatura e pressão, estão sujeitas a erros, tanto aleatórios quanto grosseiros, fazendo com que as leis de conservação da massa e energia não sejam devidamente atendidas. Em geral, os dados têm origem a partir de medições efetuadas em diferentes partes do processo de uma unidade industrial. (CROWE, 1996; ROMAGNOLI e SCHANCHEZ, 2000).

Geralmente, os erros que afetam os dados medidos podem ser classificados como erros aleatórios e erros grosseiros. Os erros aleatórios são normalmente distribuídos com média zero e matriz covariância conchecida (KIM, et al., 1997). Este tipo de erro é geralmente atribuído a não reprodutibilidade do instrumento de medição (LIEBMAN, et al., 1992).

Um erro grosseiro é uma medida que não pode ser explicada pela distribuição estatística da amostra de dados. Os erros grosseiros podem ser divididos em duas classes: (a) erro sistemático e (b) dados anômalos (outliers). O erro sistemático ocorre quando o instrumento de medição fornece valores que apresentam um desvio constante em relação ao valor real esperado (Liebman, et al., 1992). Outliers podem ser considerados observações com uma combinação única de características identificáveis como distintamente diferentes das outras observações. Erros grosseiros podem surgir devido a: variações nas condições de operação da unidade, erros na operação dos instrumentos de medidas, amostragem não representativa, ou simplesmente erros no registro da informação, os quais podem contaminar os dados válidos. (CHEN, et al., 1998;. ALVES e NASCIMENTO, 2002). 
O procedimento de reconciliação de dados é utilizado para reduzir os erros de um conjunto de dados brutos medidos com base em um estado confiável do processo. Com a finalidade de obter um balanço de massa preciso, a reconciliação de dados produz um único conjunto de dados consistente que representa a operação do processo mais provável. Isto faz com que as restrições das leis de conservação de massa e energia em toda a planta sejam satisfeitas. A quantidade de ajustes realizados para as medições é minimizada, uma vez que se espera que o erro aleatório nas medições seja pequeno. A reconciliação de dados requer a ausência de erros grosseiros porque sua presença invalida a base estatística (LING, et al., 2006).

Reconciliação de dados é uma etapa importante no desenvolvimento de modelos matemáticos, uma vez que a qualidade dos dados afeta diretamente a qualidade do ajuste do modelo.

Na Figura 5.1, é apresentada a sequência de operações e procedimento de reconciliação de dados.

\subsection{Seleção de variáveis e coleta de dados}

As variáveis de interesse foram definidas, considerando os dados de processo disponíveis e sua importância no processo e operação da planta. Então, foram identificados os valores máximos e mínimos de cada variável, bem como suas respectivas faixas de operação, com base nos dados de projeto e conhecimento prévio da operação da unidade.

Os dados de processo foram coletados na forma de séries temporais ao longo do ciclo de enchimento do reator de coque, com frequência de 15 minutos. O interesse era obter informações sobre a unidade baseada na distribuição de valores dessas variáveis ao longo do tempo. 
Figura 5.1 - Sequência de operações e o procedimento de reconciliação.

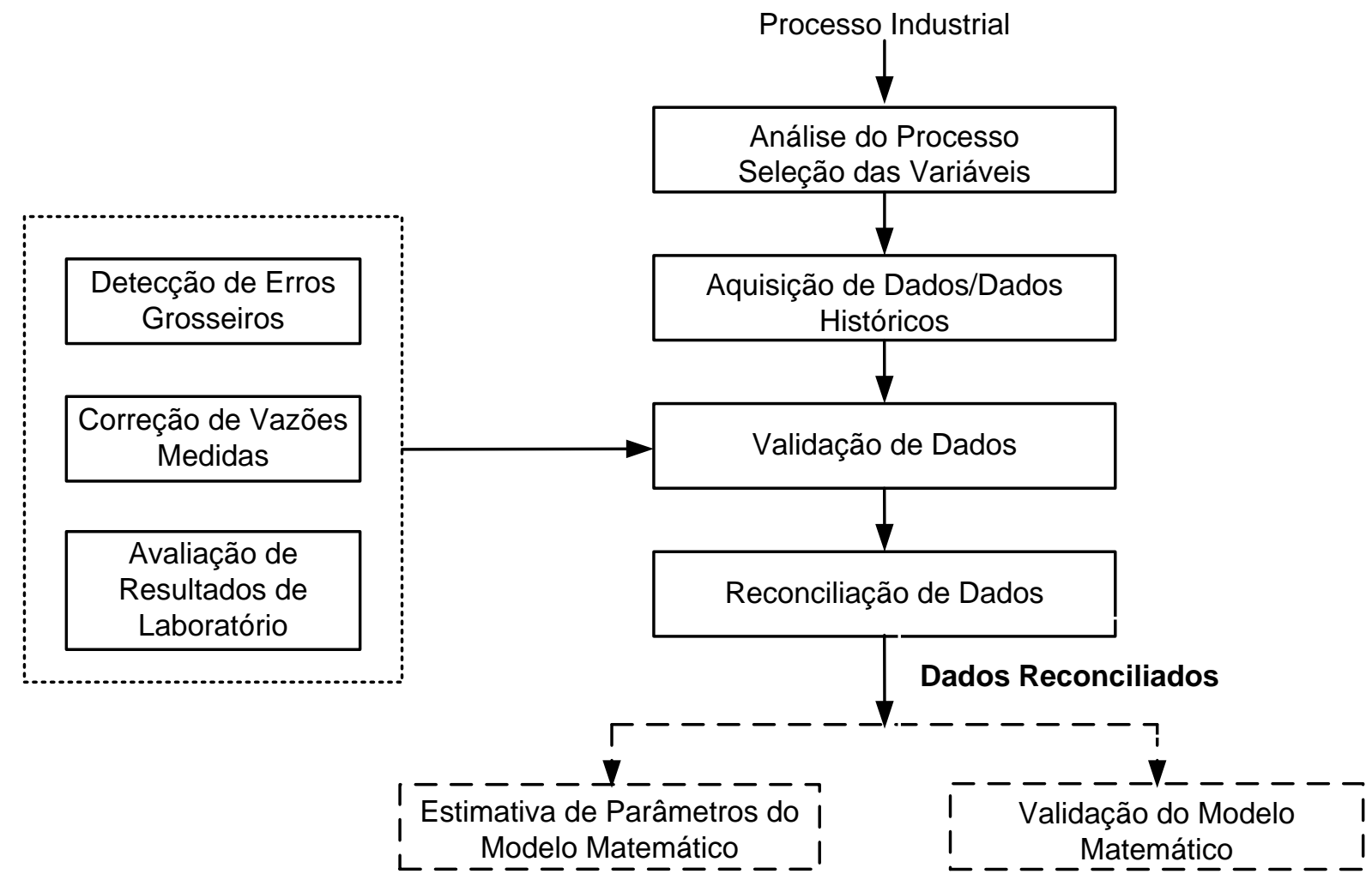

$\mathrm{Na}$ Tabela 5.1, encontram-se as informações sobre dois ciclos de enchimento do reator. O tempo típico de ciclo varia de 22 a $24 \mathrm{~h}$.

Tabela 5.1 - Informações sobre os ciclos de enchimento do reator de coque.

\begin{tabular}{cccccc}
\hline $\mathrm{N}^{\circ}$ & Ciclo N. $^{\circ}$ & Início & Final & Duração, h & Reator \\
\hline 1 & $297 / 2010$ & $21 / 10 / 105: 30$ & $22 / 10 / 1016: 15$ & 34,75 & $\mathrm{~A}$ \\
2 & $298 / 2010$ & $22 / 10 / 1016: 15$ & $24 / 10 / 100: 30$ & 32,25 & $\mathrm{~B}$ \\
3 & $303 / 2010$ & $28 / 10 / 105: 30$ & $29 / 10 / 105: 30$ & 24,00 & $\mathrm{~A}$ \\
4 & $039 / 2011$ & $6 / 2 / 1113: 30$ & $7 / 2 / 1112: 30$ & 23,00 & $\mathrm{~A}$ \\
5 & $040 / 2011$ & $7 / 2 / 1112: 30$ & $8 / 2 / 1112: 30$ & 24,00 & $\mathrm{~B}$ \\
6 & $058 / 2011$ & $25 / 2 / 117: 30$ & $26 / 2 / 115: 30$ & 22,00 & $\mathrm{~B}$ \\
7 & $062 / 2011$ & $28 / 2 / 1123: 30$ & $2 / 3 / 110: 30$ & 25,00 & $\mathrm{~B}$ \\
8 & $063 / 2011$ & $2 / 3 / 110: 30$ & $2 / 3 / 1123: 30$ & 23,00 & $\mathrm{~A}$ \\
9 & $076 / 2011$ & $14 / 3 / 1119: 30$ & $15 / 3 / 1119: 30$ & 24,00 & $\mathrm{~B}$ \\
10 & $22 / 03 / 2011$ & $23 / 3 / 1119: 30$ & $24 / 3 / 1119: 30$ & 24,00 & $\mathrm{~B}$ \\
11 & $085 / 2011$ & $23 / 3 / 1119: 30$ & $24 / 3 / 1119: 30$ & 24,00 & $\mathrm{~A}$ \\
12 & $089 / 2011$ & $27 / 3 / 1119: 00$ & $28 / 3 / 1119: 00$ & 24,00 & $\mathrm{~A}$ \\
13 & $090 / 2011$ & $28 / 3 / 1119: 00$ & $29 / 3 / 1119: 00$ & 24,00 & $\mathrm{~B}$ \\
14 & $099 / 2011$ & $6 / 4 / 115: 00$ & $7 / 4 / 113: 00$ & 22,00 & $\mathrm{~B}$ \\
\hline
\end{tabular}


A Figura 5.2 mostra dados de vazões de cargas e produtos medidos ao longo do tempo. Como o processo de coqueamento retardado é semi-contínuo, está sujeito a várias perturbações ao longo do ciclo de enchimento do reator. Os dados apresentados correspondem ao ciclo $\mathrm{N} .^{\circ}$. 1, para o qual o tempo de ciclo é $34 \mathrm{~h} 75$, acima dos valores típicos, e ao ciclo N. ${ }^{\circ} 10$.

Figura 5.2 - Vazões de carga e produtos ao longo do tempo.

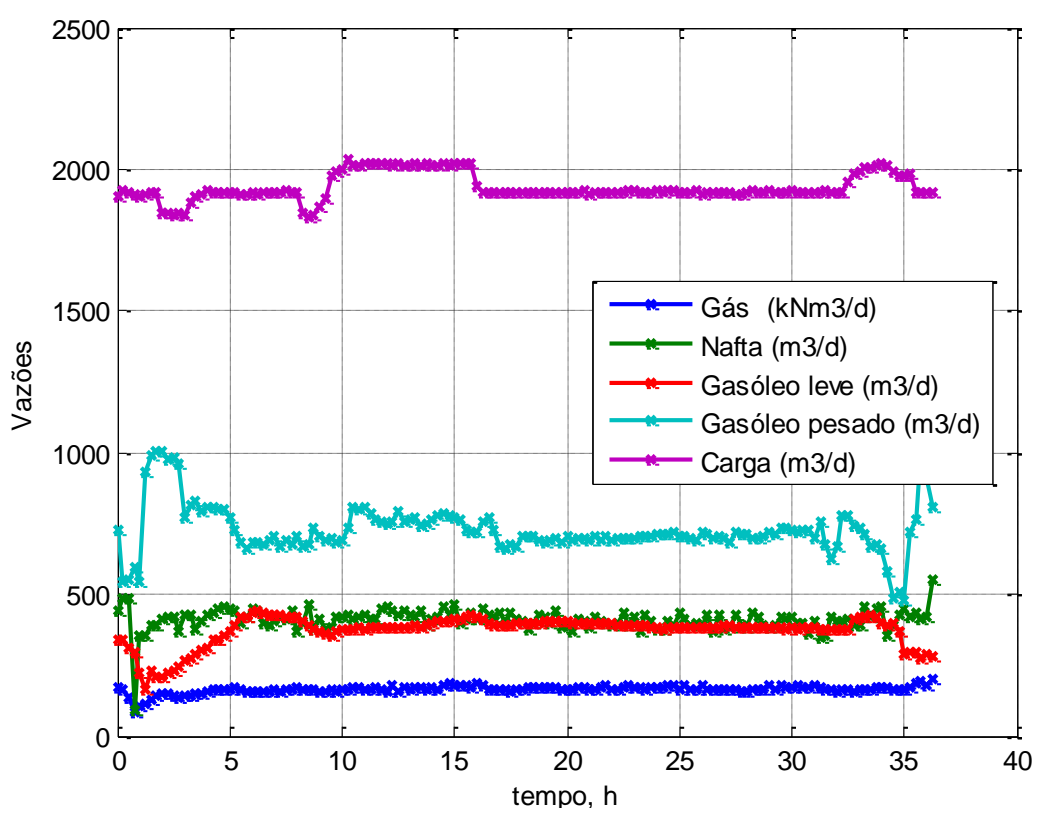

(a) Ciclo N. ${ }^{\circ} 1$

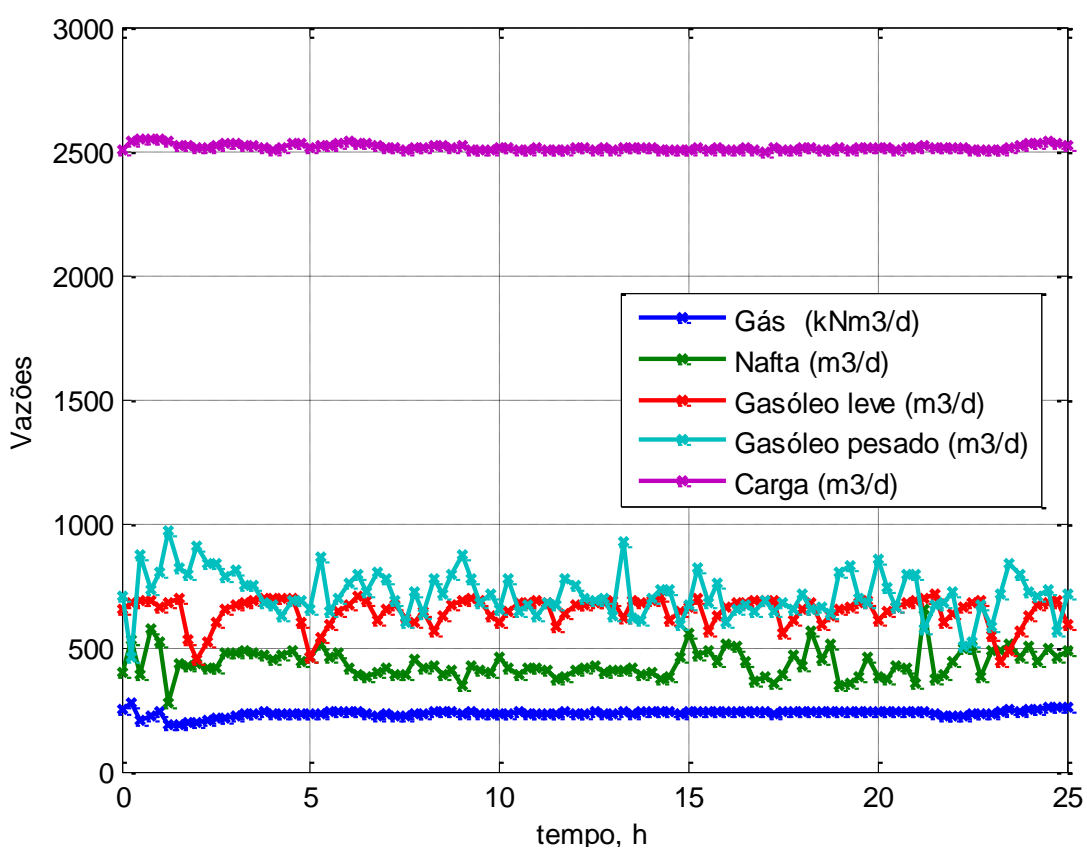

(b) Ciclo N. ${ }^{\circ} 10$ 


\subsection{Validação dos dados}

A validação dos dados é um procedimento para verificar a qualidade da informação medida e as incertezas dos instrumentos antes do processo de reconciliação de dados. Este procedimento consiste em realizar um pré-tratamento dos dados através da análise de cartas de controle, contendo valores das variáveis medidas em função do tempo, detecção e eliminação de erros grosseiros. Se o dados permitirem, um tratamento pode fornecer estimativas precisas e próximo do valor verdadeiro, com baixa variância e livre de erros grosseiros.

Analisando a Figura 5.2, observa-se um comportamento consistente das vazões de carga e produtos ao longo do tempo. Isto é um indicativo que não há um erro sistemático de medição. Com a finalidade de confirmar a ausência de erros sistemáticos nas vazões, foram gerados histogramas dessas variáveis, conforme mostrado nas Figuras 5.3 e 5.4 .

As vazões de gás, de nafta, de gasóleo leve e de gasóleo pesado têm um comportamento que aproxima da distribuição normal. A vazão de carga é um pouco assimétrica, mas este comportamento está relacionado com o distúrbio do processo durante a etapa de aquecimento e de purga do leito de coque que necessita da variável para ajustar o processo.

Para efetuar uma análise mais detalhadas dos erros de balanço de massa, foi determinada a matriz de correlações das vazões, onde os valores são apresentados na Tabela 5.2 e Tabela 5.3.

Tabela 5.2 - Matriz de correlação (Ciclo N. ${ }^{\circ}$ ).

\begin{tabular}{cccccc}
\hline & Carga & $\begin{array}{c}\text { Gasóleo } \\
\text { pesado }\end{array}$ & $\begin{array}{c}\text { Gasóleo } \\
\text { leve }\end{array}$ & Nafta & Gás \\
\hline Carga & 1,00 & $-0,11$ & 0,34 & 0,19 & 0,30 \\
Gasóleo pesado & $-0,11$ & 1,00 & $-0,53$ & 0,08 & $-0,08$ \\
Gasóleo leve & 0,34 & $-0,53$ & 1,00 & 0,10 & 0,52 \\
Nafta & 0,19 & 0,08 & 0,10 & 1,00 & 0,46 \\
Gás & 0,30 & $-0,08$ & 0,52 & 0,46 & 1,00 \\
\hline
\end{tabular}

Critério: $p<0,05$. 
Tabela 5.3 - Matriz de correlação (Ciclo N. ${ }^{\circ}$ 10).

\begin{tabular}{lccccc}
\hline Corrente & Carga & $\begin{array}{c}\text { Gasóleo } \\
\text { pesado }\end{array}$ & Gasóleo leve & Nafta & Gás \\
\hline Carga & 1,00 & 0,29 & 0,06 & 0,23 & $-0,11$ \\
Gasóleo pesado & 0,29 & 1,00 & $-0,21$ & $-0,34$ & $-0,43$ \\
Gasóleo leve & 0,06 & $-0,21$ & 1,00 & $-0,11$ & 0,14 \\
Nafta & 0,23 & $-0,34$ & $-0,11$ & 1,00 & 0,26 \\
Gás & $-0,11$ & $-0,43$ & 0,14 & 0,26 & 1,00 \\
\hline
\end{tabular}

Critério: $p<0,05$.

\subsubsection{Erros grosseiros}

A presença de erros grosseiros invalida a base estatística normalmente utilizada para construir os procedimentos de reconciliação de dados. Assim, é essencial um tratamento apropriado dos dados (ABU-EL-ZEET, et al., 2002). Em geral, o tratamento de erros grosseiros pode ser dividido em três fases. Na primeira fase, as técnicas de detecção de erros grosseiros são utilizadas para verificar se esses erros estão presentes nas medições. Se confirmada a presença de erros grosseiros, a próxima etapa é a identificação adequada das fontes de esses erros. A fase final é a eliminação das medidas corrompidas por erros grosseiros do conjunto de medidas experimentais.

Detetar outliers em um sistema multivariável não é uma tarefa simples. Em alguns casos, outilers podem ser facilmente detetados, mas em outros, não é tão óbvio. Adicionalmente, um outlier pode simplesmente ser um valor extremo em uma distribuição de probabilidades para uma variável randômica, que ocorre naturalmente mas não frequentemente e, portanto, não pode ser rejeitado. Se a origem de um valor anormal é conhecido, este valor pode ser imediatamente descartado. Por outro lado, se um erro ou uma observação extrema não pode ser justificada com segurança, o julgamento em descartar tal valor deve ser baseado em algum tipo de análise estatística (ALVES e NASCIMENTO, 2002, 2007). Assim, para rejeitar uma dada informação, deve-se verificar se a probabilidade das diferenças observadas devem-se apenas a erros de amostragem randômicos. Esta tarefa torna- 
se especialmente dificultada para processos complexos. Os parâmetros de influência podem ser diretamente acessíveis ou grandes desvios estocásticos podem levar a uma dispersão considerável nos dados medidos. (ALVES e NASCIMENTO, 2002).

Figura 5.3 - Histograma das vazões de cargas e produtos (Ciclo N. ${ }^{\circ}$ ).

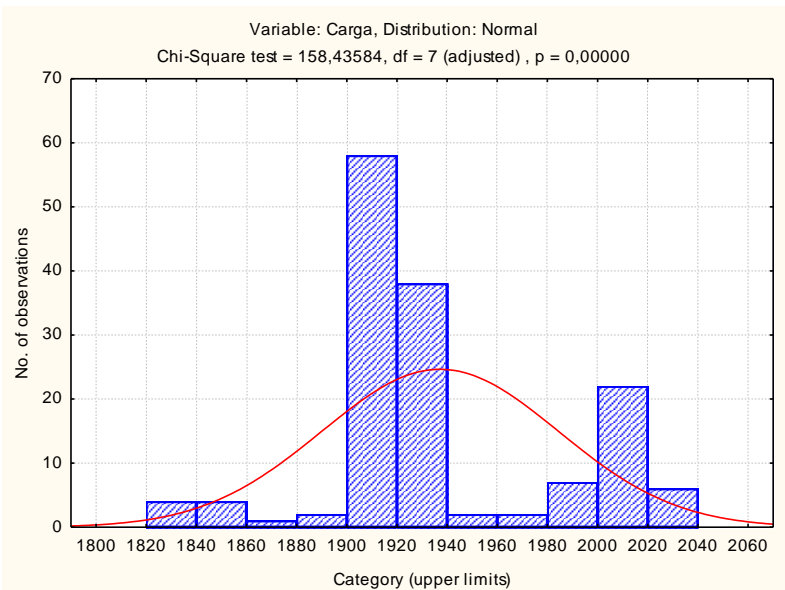

a) Vazão de resíduo de vácuo

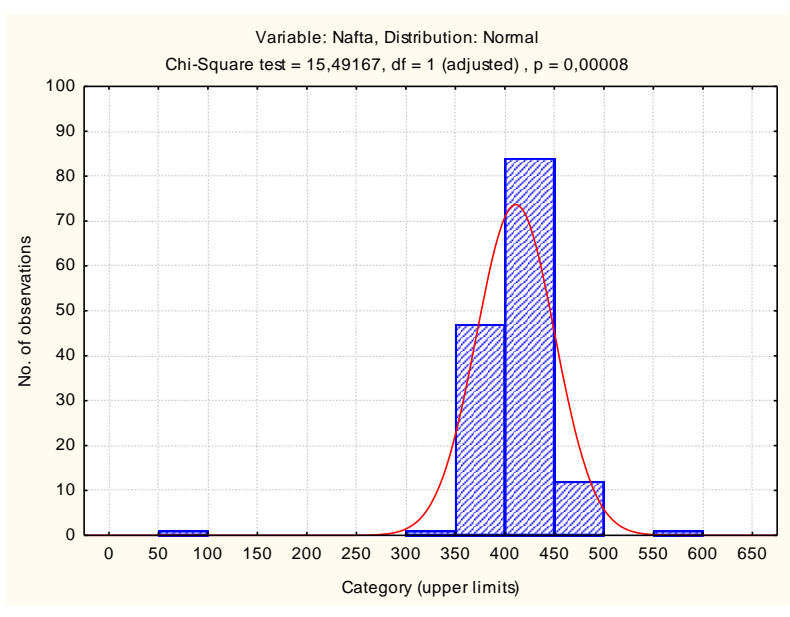

c) Vazão de nafta

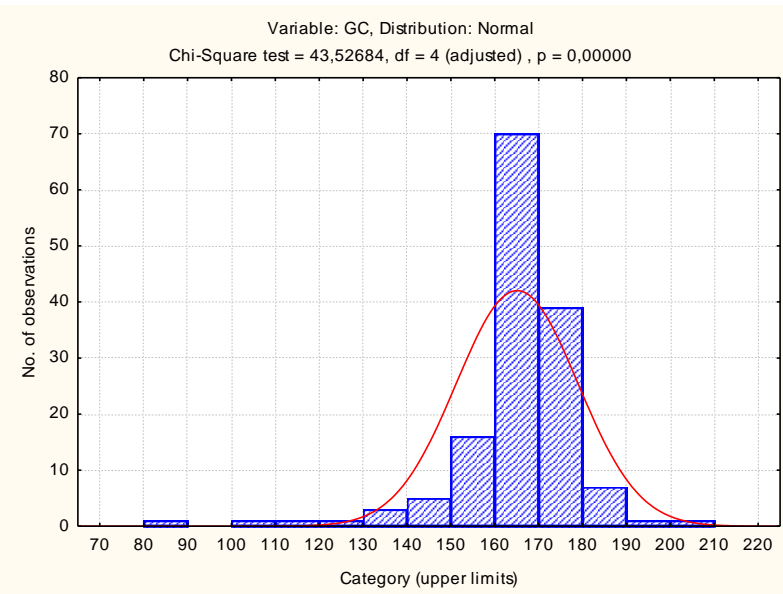

b) Vazão de gás combustível

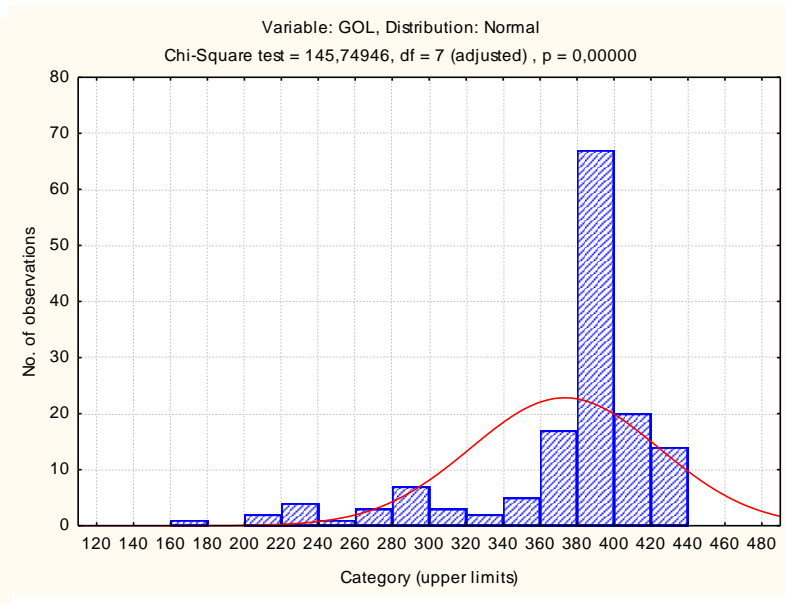

d) Vazão de gasóleo leve

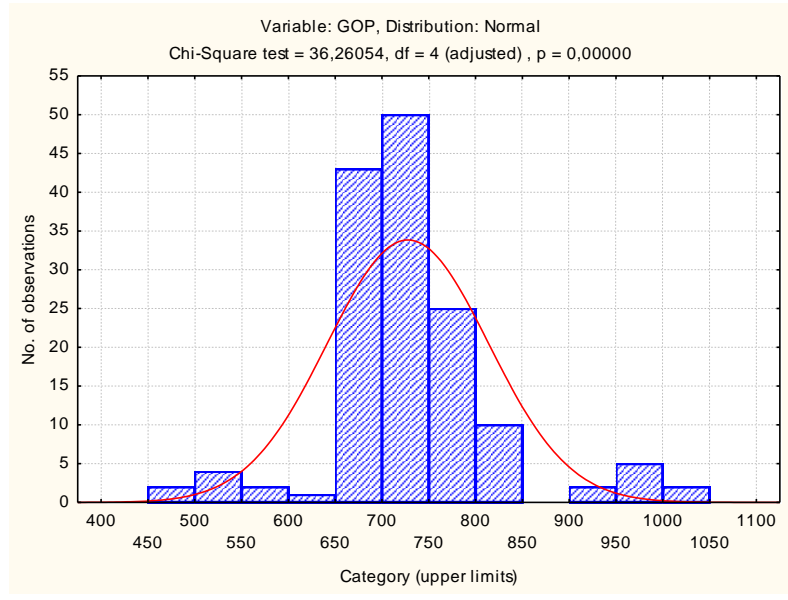

e) Vazão de gasóleo pesado 
Figura 5.4 - Histograma das vazões de cargas e produtos (Ciclo N. ${ }^{\circ} 10$ ).

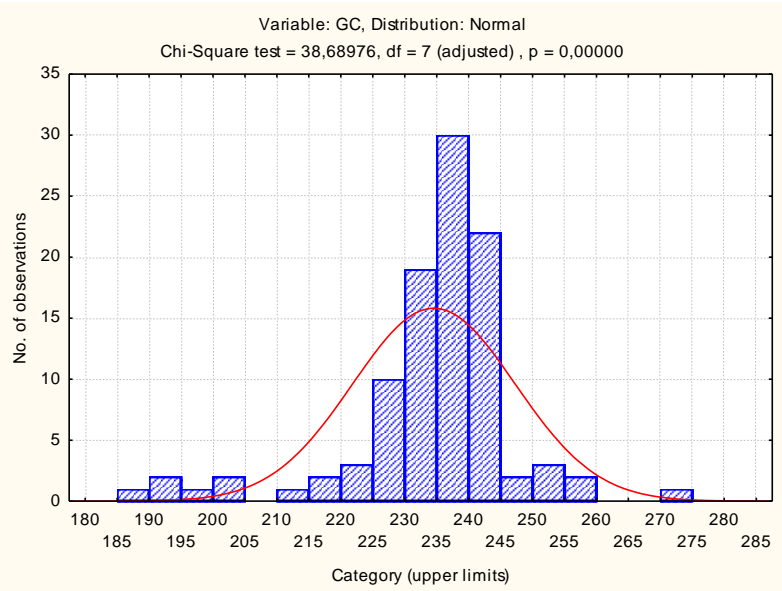

a) Vazão de resíduo de vácuo

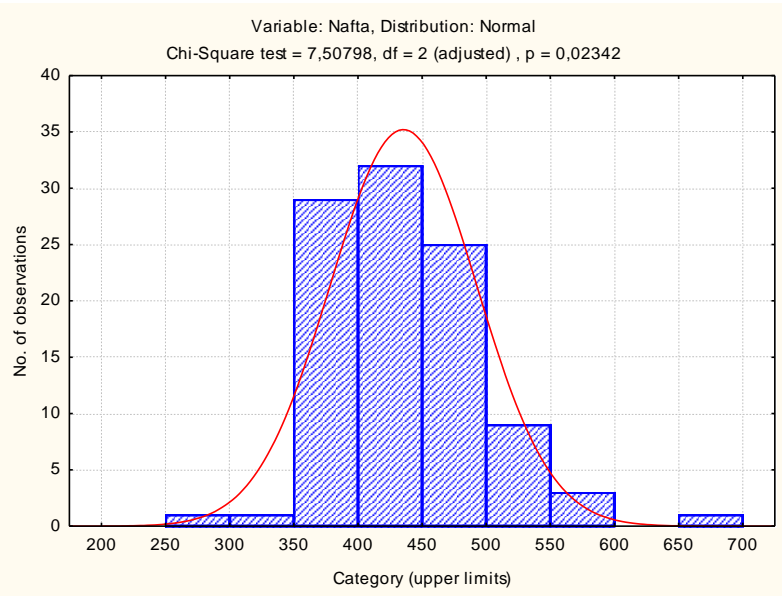

c) Vazão de nafta

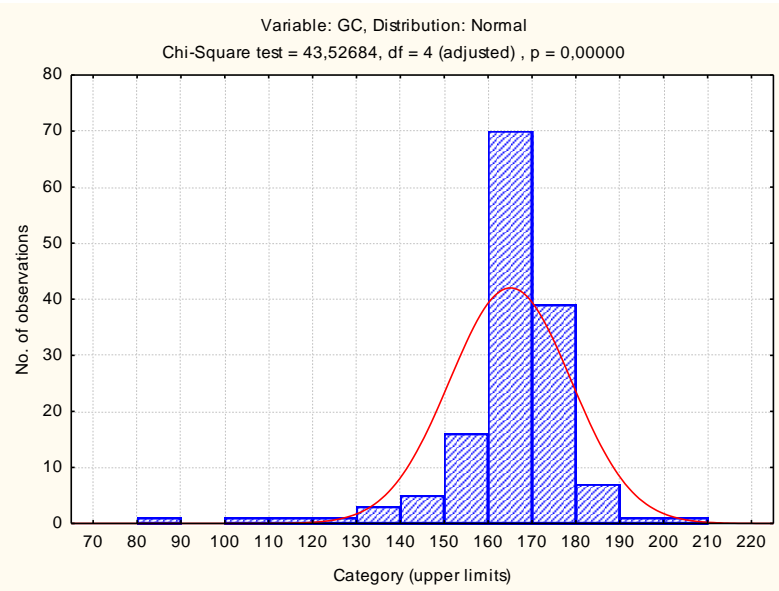

b) Vazão de gás combustível

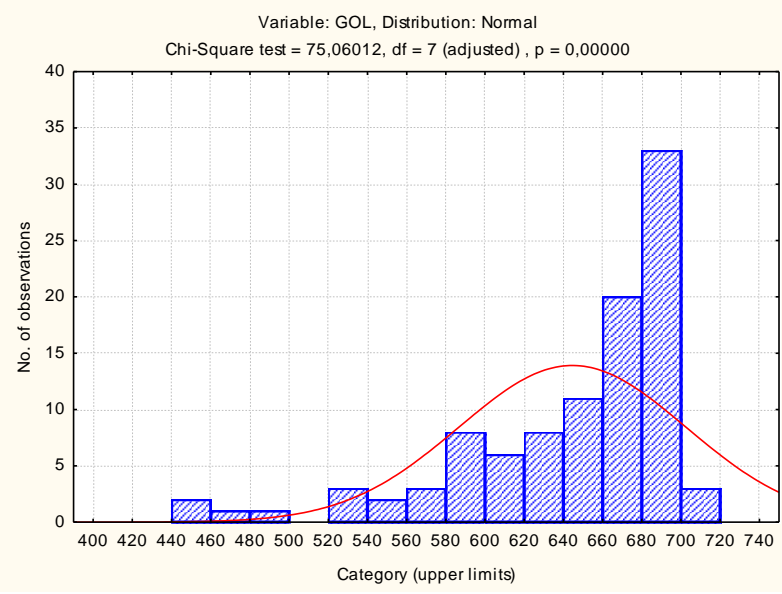

d) Vazão de gasóleo leve

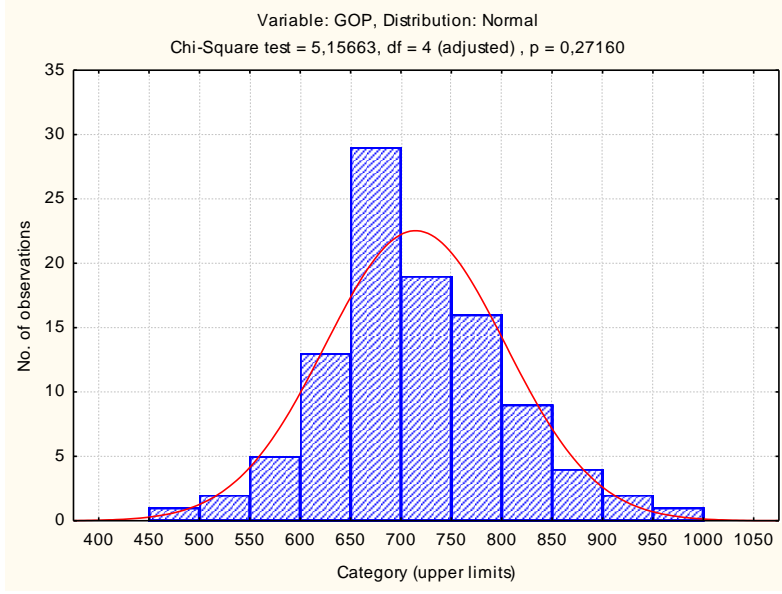

e) Vazão de gasóleo pesado

Vários investigadores têm estudado o desenvolvimento de métodos para identificar e eliminar erros grosseiros (McBRAYER, et al., 1995;. CHEN, et al., 1998;. ABU-EL- 
ZEET, et al., 2002; ALVES e NASCIMENTO, 2002, 2007). Abordagens comumente empregadas são baseadas em análise estatística ou equações de primeiro princípio. Entre os métodos para a validação dos resultados, estão os testes de hipóteses estatísticas para avaliar a confiabilidade dos valores reconciliados, verificando se existem erros grosseiros no conjunto dos valores medidos. Estes testes podem ser, por exemplo: o teste do qui-quadrado (teste global) e teste de restrições individuais (ROMANGNOLI e SCHACHEZ, 2000).

Nesta etapa, foi realizada uma análise preliminar dos valores anormais. Então, os seguintes dados foram avaliados e eliminados: valores nulos e negativos, valores constantes em um período de tempo, valores no fundo de escala dos instrumentos e variações abruptas ao longo da linha do tempo. Esta análise foi realizada através da observação das cartas de controle das variáveis. O conhecimento a priori do processo também permitiu a eliminação de informações consideradas anômalas, com base em possíveis valores de processo ou faixa de operação aceitável para a variável correspondente.

\subsubsection{Correção de vazão medida por placa de orifício}

Durante a operação da unidade industrial, a vazão volumétrica das correntes são medidas utilizando uma placa de orifício, a qual é calibrada com base em uma temperatura de referência. No entanto, a condição real de operação pode ser diferente desta condição de referência. Além disso, estas informações são expressas em uma condição padrão (Tpadrão $=20^{\circ} \mathrm{C}$ ). Portanto, as taxas de fluxo medidas devem ser corrigidas para levar em conta as condições reais do processo antes de ser usado em cálculos de balanço de massa.

A vazão de fluido através da placa de orifício pode ser dada equação geral (5.1), citada por Martins (1998).

$$
Q_{m}=\alpha \cdot \gamma \cdot F_{h} \cdot A \cdot \beta^{2} \cdot \sqrt{2 \cdot \rho_{1} \cdot \Delta P}
$$

onde: 
$\mathrm{Q}_{\mathrm{m}} \quad$ - $\quad$ Vazão mássica.

a $\quad$ - Coeficiente de vazão.

$\gamma \quad$ - Fator de expansão para fluidos compressíveis.

$\mathrm{F}_{\mathrm{h}} \quad$ - $\quad$ Fator de correção do orifício de drenagem.

A $\quad$ - Área do orifício em condições de operação

$\rho_{1} \quad$ - Massa específica do fluido nas condições de operação antes da placa de orifício.

B $\quad$ - $\quad$ Razão entre o diâmetro do orifício e o diâmetro da tubulação.

$\Delta \mathrm{P} \quad$ - $\quad$ Diferença de pressão medida pelo elemento primário.

Rearranjando a equação geral da placa de orifício, tem-se:

$$
\mathrm{Q}=\mathrm{K} \cdot \sqrt{\rho_{1}} \cdot \sqrt{\Delta \mathrm{P}}
$$

Onde

$$
K=\left(\alpha \cdot \varepsilon \cdot F \cdot A \cdot \beta^{2} \cdot \sqrt{2}\right)
$$

Desprezando o efeito da temperatura nos parâmetros geométricos e no coeficiente de fluxo, (a), a equação (5.3) pode ser arranjada como segue, de acordo com o estado físico da corrente:

a) Líquido:

Para líquidos considerados como fluidos incompressíveis $(\gamma=1)$, a vazão volumétrica a $20^{\circ} \mathrm{C}$ é dada por:

$$
Q_{\text {std }}=\frac{Q_{m}}{\rho_{\text {std }}}
$$

Substituindo a equação (5.4) na equação (5.3):

$$
\Delta \mathrm{P}=\left(\frac{\mathrm{Q} \cdot \rho_{\text {std }}}{\mathrm{K} \cdot \sqrt{\rho}}\right)^{2}
$$


A diferença de pressão através da placa de orifício é independente da variação de temperatura e da massa específica utilizada na sua calibração.

$$
\Delta \mathrm{P}^{\mathrm{REAL}}=\Delta \mathrm{P}^{\mathrm{CAL}}
$$

Então, equação (5.7) é obtida.

$$
\left(\frac{\mathrm{Q}_{\text {std }}^{\mathrm{REAL}} \cdot \rho_{\text {std }}^{\mathrm{REAL}}}{\mathrm{K} \cdot \sqrt{\rho^{\mathrm{REAL}}}}\right)^{2}=\left(\frac{\mathrm{Q}^{\mathrm{CAL}} \cdot \rho_{\text {std }}^{\mathrm{CAL}}}{\mathrm{K} \cdot \sqrt{\rho^{\mathrm{CAL}}}}\right)^{2}
$$

Assim, através da equação (5.7) é possível calcular a vazão líquida real nas condições de referência, com base nos dados de calibração e a condição real.

Para líquidos considerados como fluidos incompressíveis $(\gamma=1)$, a vazão volumétrica a $20^{\circ} \mathrm{C}$ é dada por:

$$
Q^{\mathrm{REAL}}=Q^{\mathrm{CAL}} \cdot \sqrt{\left(\frac{\rho^{\mathrm{REAL}}}{\rho^{\mathrm{CAL}}}\right)} \cdot\left(\frac{\rho^{\mathrm{CAL}}}{\rho^{\mathrm{REAL}}}\right)
$$

b) Gás:

Para vazão de gás ou vapor, o fator de expansão é considerado como fluidos compressíveis $(\gamma \neq 1)$. O fator de expansão é função do coeficiente isoentrópico $(\lambda)$ da mistura gasosa, da relação entre o diâmetro da placa de orifício e o diâmetro interno da tubulação e da relação entre a pressão à montante e à jusante. O fator de expansão aplicado para escoamento de fluido compressível através de uma placa de orifício pode ser determinado através da equação (5.9), proposta por Buckingham (MARTINS, 1998).

$$
\gamma=1-f(\beta) \cdot\left(\frac{1}{\lambda}\right) \cdot\left(\frac{\Delta P}{P}\right)
$$


$\mathrm{Na}$ equação (5.8), o fator de expansão aproxima-se de um valor unitário quando a relação $\Delta \mathrm{P} / \mathrm{P}$ é muito baixa, o que, usualmente, ocorre durante a medida de vazão através de placa de orifício.

A massa específica de uma mistura gasosa pode ser obtida através da equação (5.10).

$$
\rho=\frac{P \cdot M W}{Z \cdot R \cdot T}
$$

onde:

P $\quad$ - Pressão de operação absoluta da corrente gasosa.

MW - Peso molecular.

Z $\quad$ - Fator de compressibilidade.

R - - Constante universal dos gases.

T $\quad$ - Temperatura de operação.

Substituindo a massa específica da mistura gasosa da equação (5.10) e incluindo o fator de expansão na equação (5.7), é possível obter a vazão volumétrica real corrigida na condição padrão através da equação (5.11). A vazão corrigida é usada para avaliar o balanço de massa da unidade de processo.

$$
Q_{\text {std }}^{\text {REAL }}=Q_{\text {std }}^{\text {CAL }} \cdot \sqrt{\left(\frac{P^{\text {REAL }}}{P^{\text {CAL }}}\right) \cdot\left(\frac{M W^{\text {CAL }}}{M W^{\text {REAL }}}\right) \cdot\left(\frac{T^{\text {CAL }}}{T^{\text {REAL }}}\right) \cdot\left(\frac{Z^{\text {CAL }}}{Z^{\text {REAL }}}\right)}
$$

Para correntes gasosas, a condição de referência é a definida pela C.N.T.P. (Condição Normal de Temperatura e Pressão), dada por 273,15 K, $1.013 \times 10^{5} \mathrm{~Pa}$ e 22,4 litros por mol.

\subsubsection{Avaliação das análises de laboratório}

De acordo com o procedimento descrito anteriormente, verifica-se a necessidade de análises de laboratório para a correção da densidade na condição real de operação e na condição padrão a $20{ }^{\circ} \mathrm{C}$. No entanto, análises de laboratório podem estar 
sujeitas a erros desde a etapa de coleta de amostra até os inerentes ao próprio método analítico. Portanto, uma correção adequada para composição e propriedades físicas pode ser aplicada, utilizando-se as restrições da lei de conservação da massa e cálculos de equilíbrio vapor-líquido. Além disso, a fim de se obter dados de processo realistas, uma análise prévia da estabilidade operacional é realizada.

\section{- Frações leves}

A fracionadora opera a pressão acima da atmosférica e temperatura de $40{ }^{\circ} \mathrm{C}$. A corrente de nafta perde componentes leves (etano, propano e butano) dissolvidos na amostra durante a sua coleta em recipiente a pressão atmosférica e no manuseio durante a preparação para análise. De modo a mitigar este efeito, o recipiente coletor da amostra deve ser resfriado.

Além disso, o peso molecular de uma amostra de corrente de gás calculado a partir de sua composição obtida por cromatografia é menor do que o valor real. Isto porque os componentes pesados permanecem no interior do recipiente durante a injeção da amostra no cromatógrafo.

A Figura 5.5 apresenta a configuração do vaso de topo da torre fracionadora principal.

A Figura 5.6 apresenta a estratégia proposta para ajustar a composição da corrente de gás e a temperatura inicial da curva de destilação ASTM D-86 da corrente de nafta, de modo a satisfazer a condição de equilíbrio vapor-líquido no vaso de topo da torre. A corrente de alimentação do vaso de topo é simulada, utilizando o modelo de flash P-T, como uma mistura das correntes dos produtos, para as quais são conhecidos dados de análise cromatográfica. Assim, existem dois pontos a ser verificados:

a) A curva de destilação deve ser monotônica. Descontinuidades ou flutuações na curva sugerem que os dados de entrada estão incorretos. Se for o caso, deve-se avaliar criticamente os balanços de massa ou a análise do produto. 
b) Uma diferença significativa na qualidade entre a corrente de alimentação simulada e as correntes dos produtos sugere uma inconsistência nos dados de entrada.

Figura 5.5 - Vaso de topo da fracionadora principal.

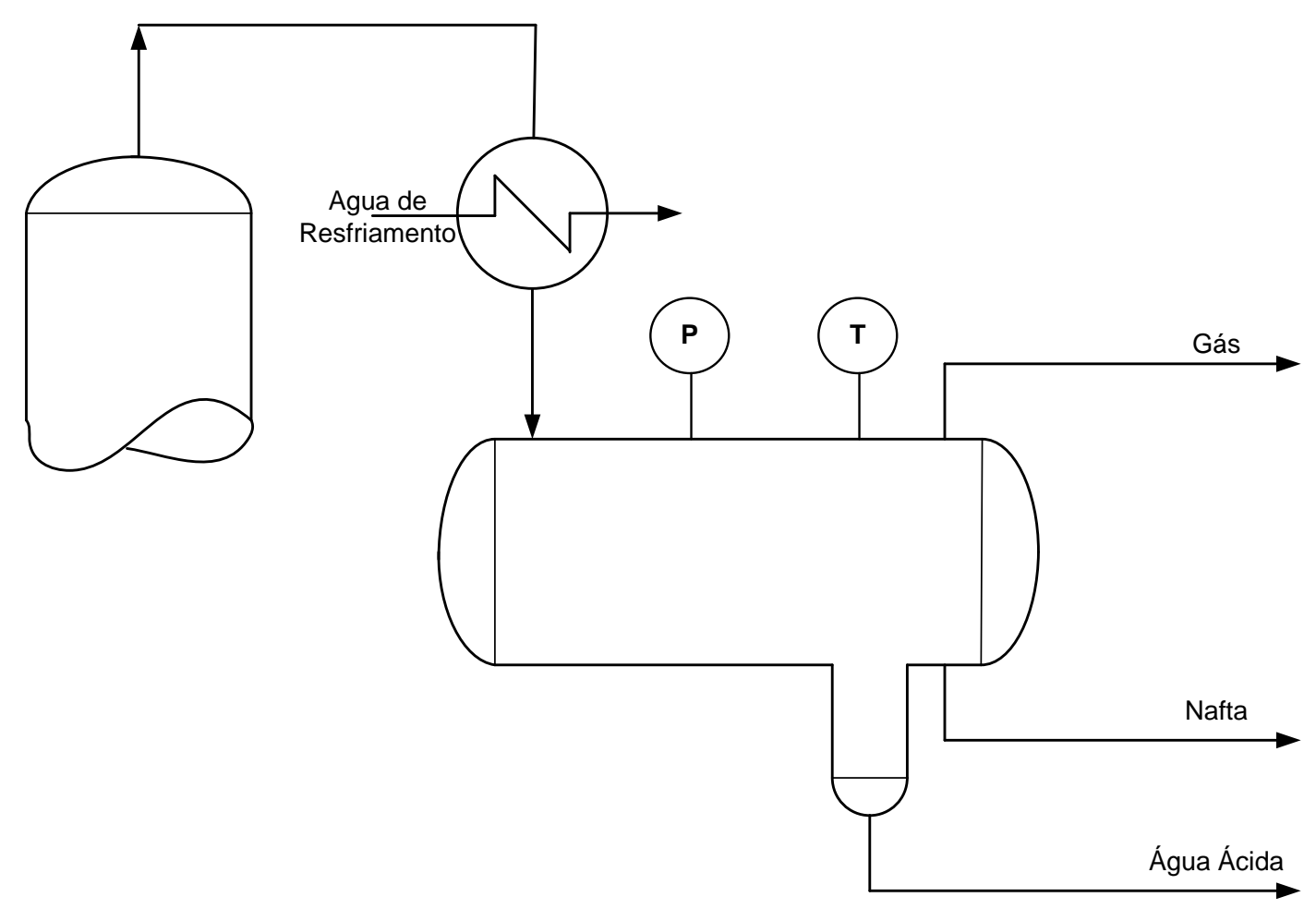

Figura 5.6 - Esquema de simulação.

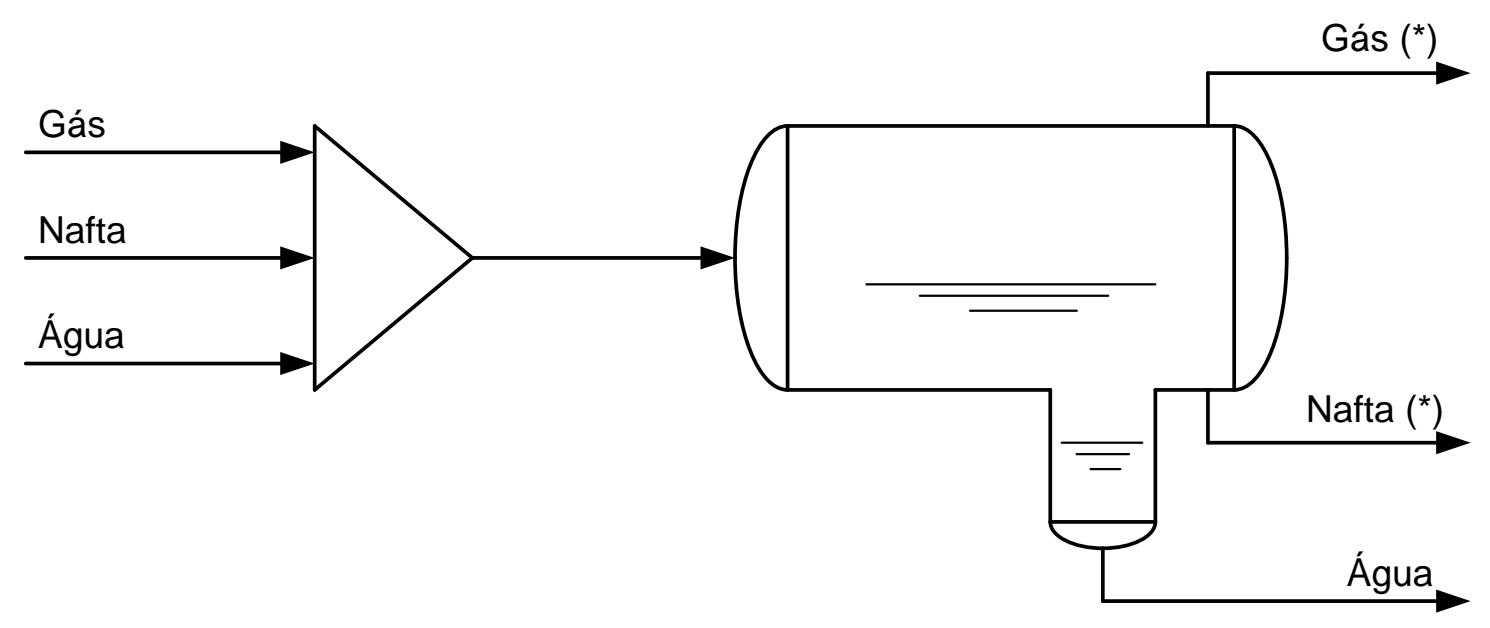

Misturador

Flash P \& 
Para cálculo do flash P-T foi utilizada a equação de estado de Peng-Robinson (SANDLER, 1999) para predizer as condições de equilíbrio líquido-vapor da mistura multicomponente. A fase aquosa foi considerada como líquido imiscível. Para resolver o sistema de equações não lineares do cálculo do misturador e do flash P-T, foi utilizada o subprograma NEQEF da IMSL (Fortran Numerical Library), versão 5.0. A composição corrigida $\left(^{*}\right)$ da corrente de gás combustível e a curva de destilação ASTM D-86 corrigida $\left(^{*}\right)$ da corrente de nafta também foi calculada.

Nas Tabelas 5.4 e 5.5 são apresentados os dados experimentais e os corrigidos para as correntes de gás e de nafta.

Tabela 5.4 - Composição do gás.

\begin{tabular}{lccc}
\hline \multicolumn{1}{c}{ Componente } & Experimental & Corrigido & Diferença \\
\hline Água & - & 3,12 & 3,12 \\
Hidrogênio & 10,47 & 10,08 & $-0,39$ \\
Nitrogênio & 2,30 & 2,22 & $-0,08$ \\
Oxigênio & 0,58 & 0,56 & $-0,02$ \\
Monóxido de carbono & 0,40 & 0,39 & $-0,01$ \\
Dióxido de carbono & 0,28 & 0,26 & $-0,02$ \\
Sulfeto de hidrogênio & 1,48 & 1,39 & $-0,09$ \\
Metano & 45,81 & 43,99 & $-1,82$ \\
Eteno & 1,86 & 1,77 & $-0,09$ \\
Etano & 14,71 & 13,93 & $-0,78$ \\
Propeno & 3,62 & 3,32 & $-0,30$ \\
Propano & 8,39 & 7,64 & $-0,75$ \\
i-Butano & 0,93 & 0,78 & $-0,15$ \\
n-Butano & 2,58 & 2,08 & $-0,50$ \\
1,3-Butadieno & 0,72 & 0,59 & $-0,13$ \\
Butenos & 2,53 & 2,10 & $-0,43$ \\
i-Pentano & 0,54 & 0,36 & $-0,18$ \\
n-Pentano & 0,94 & 0,56 & $-0,38$ \\
C ${ }_{5}^{+}$ & 1,86 & 4,86 & 3,00 \\
\hline Peso Molecular & 25,82 & 26,68 & 0,86 \\
\hline
\end{tabular}

O peso molecular da corrente gasosa foi corrigido de 25,82 para 26,68 , sendo a diferença de 3,33\%. 
Tabela 5.5 - Propriedades da corrente de nafta.

\begin{tabular}{ccc}
\hline \multicolumn{3}{c}{ Curva de destilação ASTM D-86. } \\
\cline { 2 - 3 } Vaporizado, \%vol. líquido & \multicolumn{2}{c}{ Temperatura, ${ }^{\circ} \mathrm{C}$} \\
\cline { 2 - 3 } & Experimental & Corrigido \\
5 & 58,7 & $-15,9$ \\
10 & 87,3 & 70,7 \\
30 & 97,5 & 93,0 \\
50 & 124,4 & 124,6 \\
70 & 147,4 & 148,4 \\
90 & 170,1 & 171,1 \\
95 & 196,2 & 198,3 \\
100 & 211,0 & 211,0 \\
& 223,4 & 225,2 \\
\hline Massa específica à $20^{\circ} \mathrm{C}, \mathrm{kg} / \mathrm{m}^{3}$ & 765,2 & 755,0 \\
\hline
\end{tabular}

A Figura 5.7 apresenta uma comparação entre a curva de destilação ASTM D86 experimental e corrigida para a corrente de nafta, de acordo com o procedimento proposto. A correção foi realizada apenas na extremidade inicial da curva, enquanto o restante permaneceu similar.

Figura 5.7 - Curva de destilação ASTM D-86 corrigida da nafta.

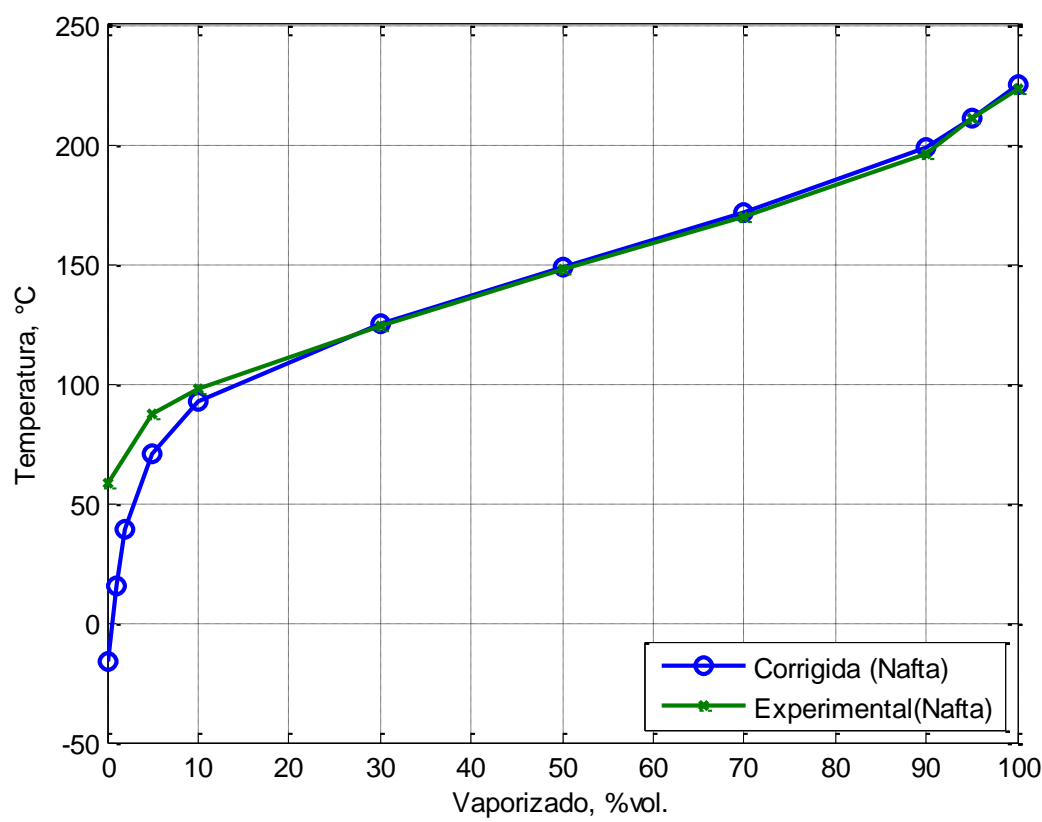


- Frações líquidas

Para identificar erros nos produtos da destilação, comparou-se os dados para todos os testes, traçando dados de temperatura em carta de probabilidade. Todas as curvas devem ser suaves e apresentar forma similar. A curva de destilação tem uma forma sigmoidal quando representada na forma de gráfico cartesiano. Quando esta curva de destilação é representada em carta de probabilidade, ela transforma-se em uma linha reta. Denchfield (1981) propôs uma equação para representar a curva de destilação em carta de probabilidade, convertendo a abcissa (volume) em uma escala de probabilidade.

Na Tabela 5.6 são apresentados os dados experimentais das correntes de gasóleo leve e de gasóleo pesado.

Tabela 5.6 - Propriedades das correntes de gasóleos.

\begin{tabular}{ccc}
\hline \multirow{2}{*}{ Vaporizado, \%vol. líquido } & \multicolumn{2}{c}{ Temperatura, ${ }^{\circ} \mathrm{C}$} \\
\cline { 2 - 3 } & $\begin{array}{c}\text { Gasóleo leve } \\
\text { ASTM D-86 }\end{array}$ & $\begin{array}{c}\text { Gasóleo pesado } \\
\text { Simulada HT750 }\end{array}$ \\
\hline 0 & 196,7 & 169,2 \\
\hline 5 & 224,7 & 266,0 \\
10 & 233,1 & 294,6 \\
30 & 250,9 & 345,8 \\
50 & 267,9 & 380,4 \\
70 & 291,4 & 414,2 \\
90 & 330,7 & 476,8 \\
95 & 348,3 & 563,8 \\
100 & 368,3 & 721,4 \\
\hline Massa específica à $20^{\circ} \mathrm{C}, \mathrm{kg} / \mathrm{m}^{3}$ & & 936,2 \\
\hline Viscosidade cinemática à $98,9^{\circ} \mathrm{C}, \mathrm{cSt}$ & & 5,14 \\
\hline
\end{tabular}

As Figuras 5.8 a 5.10 mostram o resultado desta comparação. As Figuras 5.8 e 5.9 indicam que os valores estão consistentes em toda faixa de destilação. 
A Figura 5.10 mostra um afastamento na extremidade final da curva, indicando um provável mau fracionamento na seção de fundo da torre. Portanto, foi utilizada uma curva de destilação corrigida para esta corrente. Foram, então, feitas as correções da curva de destilação ASTM D86 da corrente de nafta e do peso molecular da corrente de gás do ciclo N. ${ }^{\circ} 10$.

Figura 5.8 - Curva de destilação ASTM D-86 da nafta.

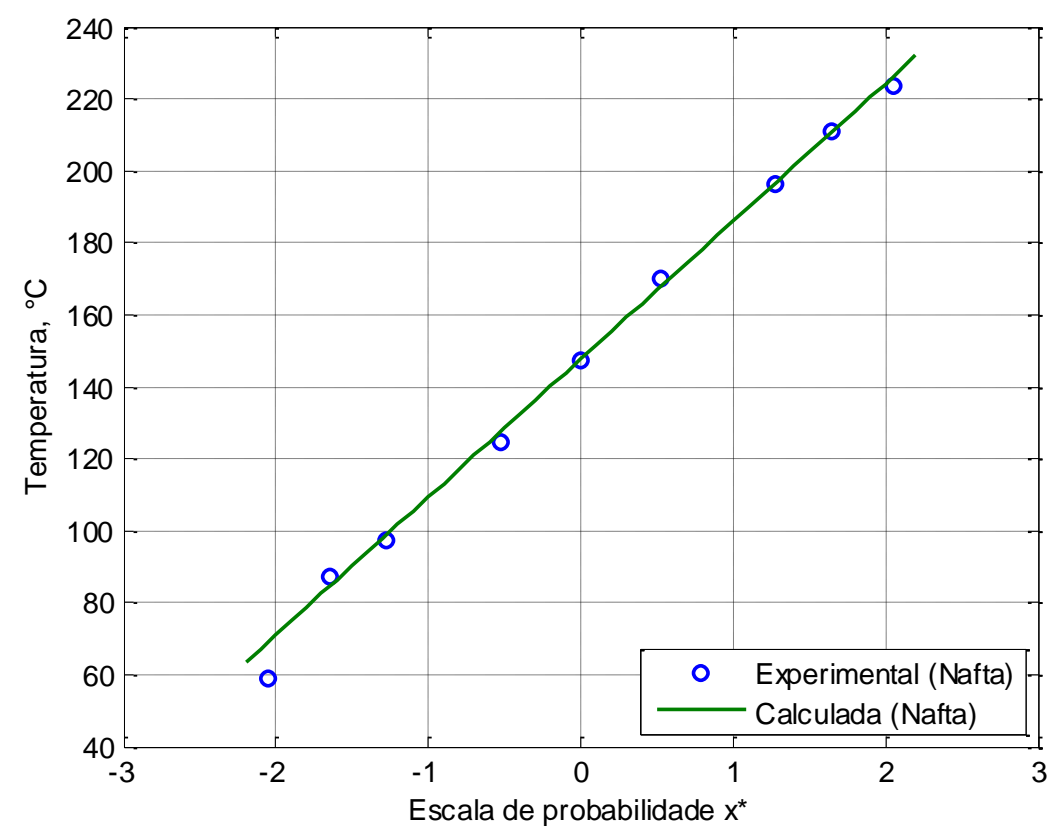

Figura 5.9 - - Curva de destilação ASTM D-86 do gasóleo leve.

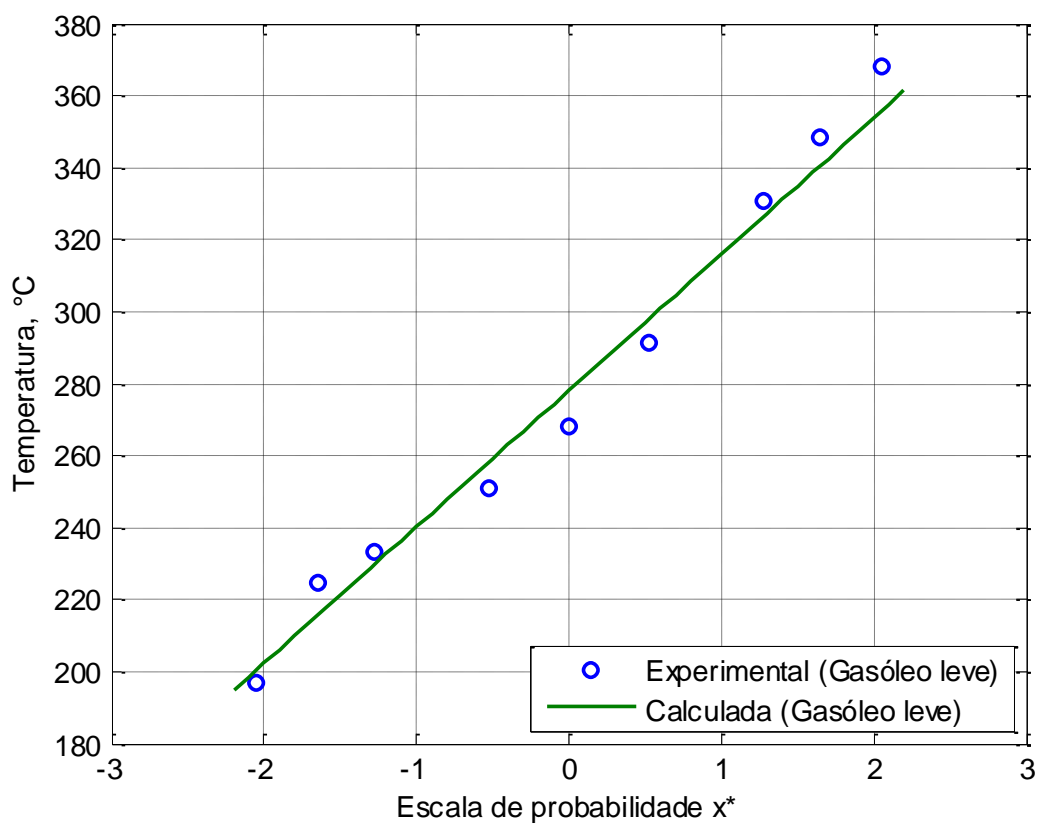


Figura 5.10 - Curva de destilação ASTM D-86 do gasóleo pesado.

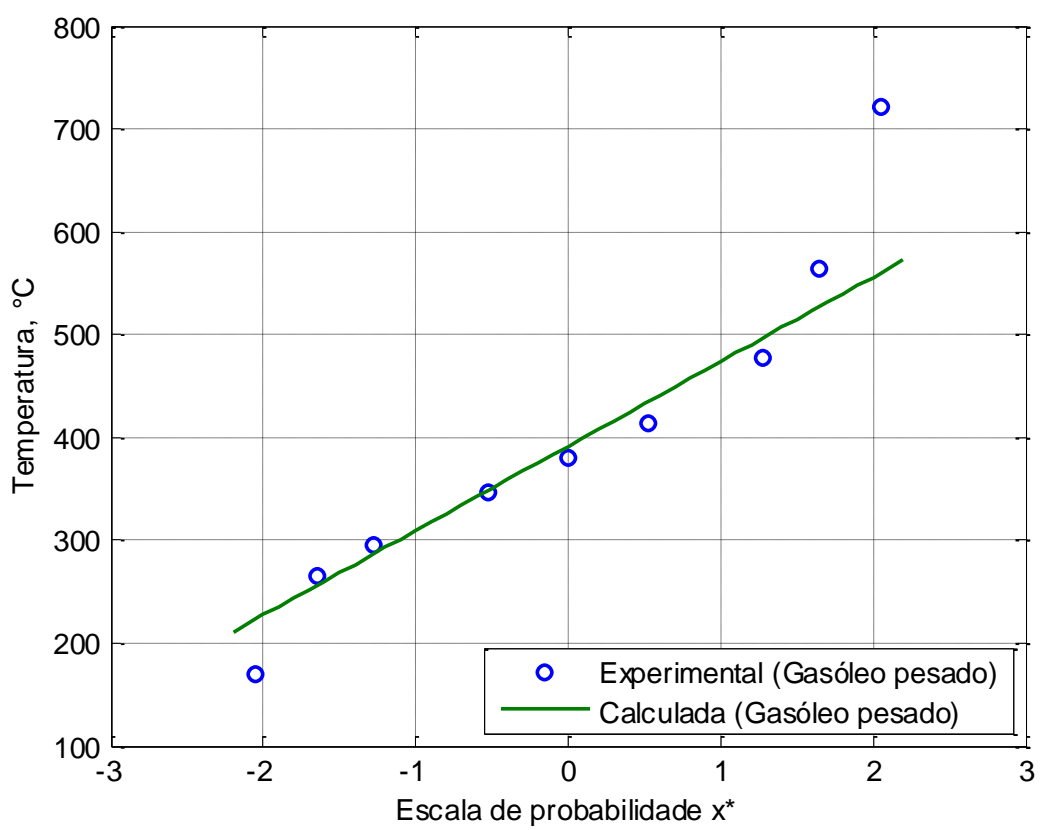

O fator de caracterização Watson foi, então, utilizado para verificar a consistência dos resultados experimentais da curva de destilação ASTM D-86 e as densidade das correntes de destilado. Nesta situação, o fator de Watson apresenta um leve decréscimo a partir da corrente de nafta até o gasóleo pesado.

O fator de caracterização Watson, $K_{W}$, de acordo com Riazi (2005), é

$$
\mathrm{K}_{\mathrm{w}}=\frac{\sqrt[3]{\mathrm{PEMe}}}{\mathrm{SG}}
$$

onde:

PEMe - Ponto de ebulição médio das frações de petróleo.

SG - Densidade a $60 / 60^{\circ} \mathrm{F}$.

Um procedimento alternativo para determinar o fator de caracterização Watson é obtido a partir da viscosidade cinemática a $210{ }^{\circ} \mathrm{F}$ em cSt, usando a equação proposta por Woodle (1980).

$$
K w=9,40+0,0825 \cdot A P I+0,73 \cdot \ln \left(\ln \left(v_{210 F}\right)\right)
$$


O procedimento descrito nesta seção ajuda na eliminação de dados anômalos dos resultados da amostragem e laboratoriais.

Com base nos dados experimentais apresentados na Tabela 5.5 e 5.6, foram determinados os valores do fator de caracterização de Watson, usando a equação (5.7), para as correntes de produtos (nafta, gasóleo leve e gasóleo pesado), de acordo com o procedimento proposto. Os resultados foram 11,72, 11,74 e 11,45, respectivamente. Estes valores confirmam a consistência dos resultados experimentais, porque a aromaticidade foi aumentada no sentido da corrente de nafta até de gasóleo pesado e sua variação foi mantida dentro da faixa normal.

\subsection{Reconciliação de dados}

Como a unidade de coqueamento é um processo semicontínuo, a massa de coque formada é acumulada no reator. Após o término do ciclo de enchimento do reator, é realizada a medição do volume de coque produzido. Assim, utiliza-se o tempo de ciclo de enchimento como base de cálculo do balanço material da unidade.

$\mathrm{Na}$ ausência de erros grosseiros, a relação entre a variável medida na planta industrial e o valor real pode ser representado pela equação:

$$
\underline{X}=\underline{\tilde{X}}+\underline{\varepsilon}
$$

onde:

$\begin{array}{lll}\tilde{X}_{i} & - & \text { Valor medido; } \\ \mathrm{X}_{\mathrm{i}} & - & \text { Valor real não conhecido; } \\ \varepsilon_{\mathrm{i}} & - & \text { Erros randômicos da medida. }\end{array}$

Quando erros grosseiros não estão presentes, assume-se que $\varepsilon$ é normalmente distribuído com média zero e matriz de covariância conhecida (LINKGKE, et al., 2006). 
O procedimento de reconciliação de dados convencional para processos em regime estacionário é baseado no critério de minimização de uma função objetivo, como mostrado na equação (5.15).

$$
\mathrm{FO}=\sum_{\mathrm{i}=1}^{\mathrm{n}}\left[\frac{\text { Valor Medido }- \text { Valor Reconciliado }}{\text { Incerteza }}\right]^{2}
$$

A dificuldade em usar a formulação típica é a necessidade de conhecer a variância dos dados experimentais. Em geral, as incertezas são escolhidas como o desvio padrão do instrumento de medida.

A reconciliação de dados de um balanço de massa em estado estacionário com todas as variáveis medidas é considerada um problema linear. Como, geralmente, assume-se que erros de medida seguem uma distribuição normal com uma matriz diagonal de covariância, a precisão de cada medida é caracterizada pelo seu desvio padrão $\sigma_{i}$.

O procedimento de reconciliação de dados pode, então, ser formulado como um problema de otimização de mínimos quadrados ponderado:

$$
\begin{aligned}
& \mathrm{FO}=(\underline{\mathrm{X}}-\underline{\hat{\mathrm{X}}})^{\top} \cdot \mathrm{V}^{-1} \cdot(\underline{\mathrm{X}}-\underline{\hat{\mathrm{X}}}) \\
& \min . F O=(\underline{X}-\underline{\hat{X}})^{\top} \cdot W^{-1} \cdot(\underline{X}-\underline{\hat{X}}) \\
& \mathrm{FO}=\left[\begin{array}{l}
\left(\mathrm{X}_{1}-\hat{\mathrm{X}}_{1}\right) \\
\left(\mathrm{X}_{2}-\hat{\mathrm{X}}_{2}\right. \\
\left(\mathrm{X}_{3}-\hat{\mathrm{X}}_{3}\right. \\
\left(\mathrm{X}_{4}-\hat{\mathrm{X}}_{4}\right) \\
\left(\mathrm{X}_{5}-\hat{\mathrm{X}}_{5}\right) \\
\left(\mathrm{X}_{6}-\hat{\mathrm{X}}_{6}\right)
\end{array}\right]^{\top} \cdot\left[\begin{array}{cccccc}
\sigma_{1}^{2} & 0 & 0 & 0 & 0 & 0 \\
0 & \sigma_{2}^{2} & 0 & 0 & 0 & 0 \\
0 & 0 & \sigma_{3}^{2} & 0 & 0 & 0 \\
0 & 0 & 0 & \sigma_{4}^{2} & 0 & 0 \\
0 & 0 & 0 & 0 & \sigma_{5}^{2} & 0 \\
0 & 0 & 0 & 0 & 0 & \sigma_{6}^{2}
\end{array}\right]^{-1} \cdot\left[\begin{array}{l}
\left(\mathrm{X}_{1}-\hat{\mathrm{X}}_{1}\right. \\
\mathrm{X}_{2}-\hat{\mathrm{X}}_{2} \\
\mathrm{X}_{3}-\hat{\mathrm{X}}_{3} \\
\left(\mathrm{X}_{4}-\hat{\mathrm{X}}_{4}\right) \\
\left(\mathrm{X}_{5}-\hat{\mathrm{X}}_{5}\right) \\
\left(\mathrm{X}_{6}-\hat{\mathrm{X}}_{6}\right)
\end{array}\right] \\
& \mathrm{FO}=\frac{\left(\mathrm{X}_{1}-\hat{\mathrm{X}}_{1}\right)^{2}}{\sigma_{1}^{2}}+\frac{\left(\mathrm{X}_{2}-\hat{\mathrm{X}}_{2}\right)^{2}}{\sigma_{2}^{2}}+\frac{\left(\mathrm{X}_{3}-\hat{\mathrm{X}}_{3}\right)^{2}}{\sigma_{3}^{2}}+\frac{\left(\mathrm{X}_{4}-\hat{\mathrm{X}}_{4}\right)^{2}}{\sigma_{4}^{2}}+\frac{\left(\mathrm{X}_{5}-\hat{\mathrm{X}}_{5}\right)^{2}}{\sigma_{5}^{2}}+\frac{\left(\mathrm{X}_{6}-\hat{\mathrm{X}}_{6}\right)^{2}}{\sigma_{6}^{2}}
\end{aligned}
$$


As restrições são:

- Balanço global de massa:

$X_{2}+X_{3}+X_{4}+X_{5}+X_{6}-X_{1}=0$

- Não negatividade:

$$
\begin{array}{lll}
X_{1} \geq 0 & X_{2} \geq 0 & X_{3} \geq 0 \\
X_{4} \geq 0 & X_{5} \geq 0 & X_{6} \geq 0
\end{array}
$$

Para resolver o problema de reconciliação de balanço de massa global, foi desenvolvido um programa em linguagem FORTRAN, utilizando o subprograma NCONF da biblioteca IMSL (Fortran Numerical Library) de modo a minimizar a função objetiva.

\subsection{Balanço de massa global}

A Figura 5.11 ilustra o sistema no qual balanço de massa será aplicado.

Figura 5.11 - Desenho esquemático do sistema.

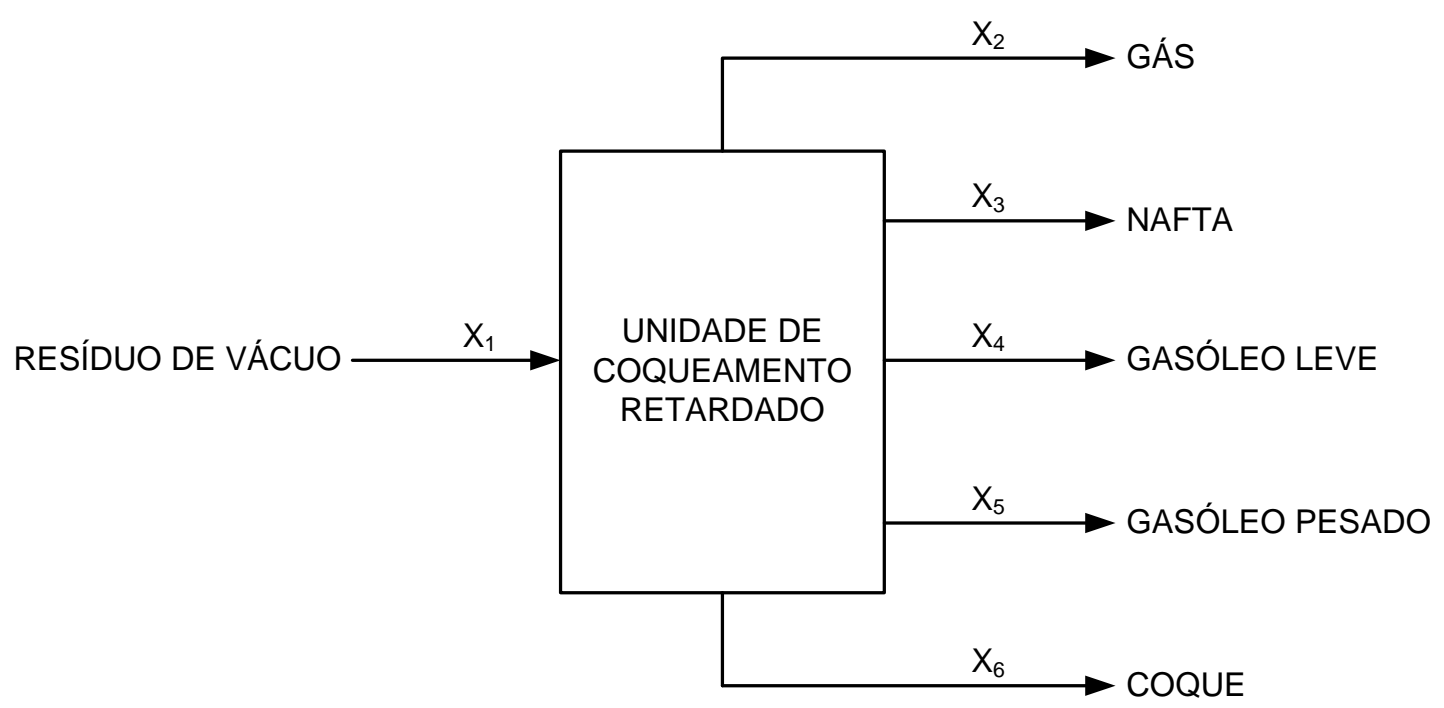


Considerando o intervalo de tempo igual ao ciclo de enchimento, o acúmulo é igual ao coque produzido, tornando a equação de balanço de massa igual à equação (5.20).

Os valores de vazões lidas no P\&I para correntes de gás, de nafta, de gasóleo leve e pesado foram corrigidos antes de serem utilizados no balanço de massa, visando minimizar as incertezas de medição.

$\mathrm{Na}$ Tabela 5.7, encontram-se os valores das vazões medidas dos produtos em três diferentes ciclos de operação da unidade de coqueamento retardado e a diferença entre os valores medidos e reconciliados.

Comparando-se os valores de vazões medidas e reconciliadas, são observadas apenas diferenças pequenas. Isto é um indicativo que a qualidade das informações é boa.

Tabela 5.7 - Vazões de correntes medidas em diferentes ciclos.

\begin{tabular}{cccc}
\hline Corrente & Medido & Reconciliado & Diferença \\
\hline Resíduo de vácuo & 2410,9 & 2457,1 & 46,2 \\
& 2505,5 & 2538,6 & 33,1 \\
& 2301,7 & 2309,6 & 7,9 \\
\hline Gás & 227,4 & 226,9 & $-0,5$ \\
& 238,7 & 238,3 & $-0,4$ \\
Nafta & 211,2 & 211,1 & $-0,1$ \\
& 313,8 & 312,9 & $-0,9$ \\
& 332,9 & 332,3 & $-0,6$ \\
Gasóleo leve & 321,8 & 321,5 & $-0,3$ \\
& 549,6 & 547,0 & $-2,6$ \\
& 545,0 & 543,4 & $-1,6$ \\
& 548,6 & 548,1 & $-0,5$ \\
\hline Gasóleo pesado & 752,4 & 747,6 & $-4,8$ \\
& 772,7 & 769,5 & $-3,2$ \\
& 639,1 & 638,3 & $-0,8$ \\
\hline Coque & 635,8 & 622,6 & $-13,2$ \\
& 664,4 & 655,2 & $-9,2$ \\
& 593,0 & 590,6 & $-2,4$ \\
\hline
\end{tabular}

Fonte: Unidade de Coqueamento Retardado (UCP1).

Na Tabela 5.8, estão apresentados os rendimentos mássicos dos produtos após a 
reconciliação de dados de quinze ciclos diferentes de operação.

Tabela 5.8 - Resultados reconciliação de dados.

\begin{tabular}{cccccc}
\hline & \multicolumn{5}{c}{ Rendimento, \%massa } \\
\cline { 2 - 6 } N. $^{\circ}$ & Gás & Nafta & GOL & GOP & Coque \\
\hline 1 & 8,46 & 16,02 & 17,81 & 34,07 & 23,64 \\
2 & 8,76 & 15,23 & 17,05 & 34,56 & 24,40 \\
3 & 9,84 & 16,29 & 16,17 & 32,63 & 25,06 \\
4 & 9,23 & 12,73 & 22,26 & 30,43 & 25,34 \\
5 & 9,39 & 13,09 & 21,41 & 30,31 & 25,81 \\
6 & 9,14 & 13,92 & 23,73 & 27,64 & 25,57 \\
7 & 9,52 & 13,35 & 24,57 & 26,66 & 25,90 \\
8 & 9,28 & 13,14 & 23,84 & 27,01 & 26,74 \\
9 & 9,65 & 12,90 & 23,18 & 26,82 & 27,44 \\
10 & 9,67 & 13,10 & 23,54 & 26,49 & 27,20 \\
11 & 9,62 & 12,99 & 23,52 & 27,00 & 26,87 \\
12 & 9,52 & 13,41 & 22,71 & 26,44 & 27,92 \\
13 & 9,53 & 13,43 & 22,72 & 26,72 & 27,60 \\
14 & 9,46 & 13,29 & 25,32 & 25,02 & 26,92 \\
15 & 8,98 & 12,87 & 23,13 & 27,98 & 27,04 \\
\hline
\end{tabular}

Conforme os valores de rendimentos de coque apresentados na Tabela 5.8, é observado uma variação de 23,64 a 27,92 . Isto é um indicativo de variação no teor de resíduo de carbono do resíduo de vácuo (Vide Figura 4.4).

\subsection{Determinação da composição elementar dos produtos}

Os principais elementos presentes na fração de petróleo são: carbono, hidrogênio, enxofre e nitrogênio. Os outros elementos - oxigênio e metais - estão em pequenas quantidades, podendo ser desprezados, sem causar erro significativo no balanço de massa elementar.

Com base nestas considerações, o balanço de massa elementar dos componentes de carbono $(\mathrm{C})$, hidrogênio $(\mathrm{H})$, enxofre $(\mathrm{S})$ e nitrogênio $(\mathrm{N})$, em cada corrente de produto, são representados na equação (5.22) e (5.23):

$$
\% \mathrm{C}+\% \mathrm{H}+\% \mathrm{~S}+\% \mathrm{~N}=100
$$




$$
\frac{\% \mathrm{C}}{\% \mathrm{H}}=\mathrm{CH}
$$

Resolvendo simultaneamente as duas equações e assumindo que os teores de enxofre e de nitrogênio são conhecidos, as seguintes relações podem ser obtidas para hidrogênio e carbono.

$$
\begin{gathered}
\% \mathrm{H}=\frac{100-\% \mathrm{~S}-\% \mathrm{~N}}{1+\mathrm{CH}} \\
\% \mathrm{C}=\left(\frac{\mathrm{CH}}{1+\mathrm{CH}}\right) \cdot(100-\% \mathrm{~S}-\% \mathrm{~N})
\end{gathered}
$$

Os valores de $\mathrm{CH}$ podem ser determinados pelos seguintes métodos:

- $\quad$ Correntes de nafta e de gasóleos

Uma relação entre carbono e hidrogênio, em massa, foi proposta por Moura (1987), em função da densidade e do fator de caracterização, conforme a equação (5.26). (MONTGOMERY, 1988)

$$
\begin{gathered}
\left(\frac{\mathrm{C}}{\mathrm{H}}\right)=\mathrm{a} \cdot(\mathrm{SG})^{\mathrm{b}} \\
\mathrm{a}=\exp (3,07536-0,0834254 \cdot \mathrm{Kw}) \\
\mathrm{b}=4,3214893-0,57975478 \cdot \mathrm{Kw}+0,026987742 \cdot(\mathrm{Kw})^{2}
\end{gathered}
$$

- Determinação da composição elementar do coque verde

$$
(M)_{\text {Coque }}=(M)_{\text {Carbono }}+(M)_{\text {Hidrogênio }}+(M)_{\text {Enxofre }}+(M)_{\text {Nitrogênio }}+(M)_{\text {Oxigênio }}
$$

Com o teor de matéria volátil no coque verde, pode ser utilizada a equação empírica de Goutel para determinar o poder calorífico superior (GOMIDE, 1984). 


$$
\begin{aligned}
& \mathrm{PCS}=82 \cdot \mathrm{CF}+\alpha \cdot \mathrm{VCM} \\
& \mathrm{VCM}^{*}=\frac{\mathrm{VCM}}{\mathrm{VCM}+\mathrm{CF}} \cdot 100 \\
& \mathrm{CF}=100-\mathrm{VCM}-\text { Ash }
\end{aligned}
$$

O coeficiente $\alpha$ da equação (5.30) é função do teor de matéria volátil em base seca e isenta de cinzas, sendo determinado através da equação (5.33):

$$
\alpha=-0,0011111 \cdot\left(\mathrm{VCM}^{*}\right)^{3}+0,11381 \cdot\left(\mathrm{VCM}^{*}\right)^{2}-4,67460 \cdot\left(\mathrm{VCM}^{*}\right)+165,8571
$$

A equação empírica de Seyler relaciona o poder calorífico superior em base seca e isenta de cinza com a porcentagem de hidrogênio e com a matéria volátil em base seca e isenta de cinza (GOMIDE, 1984).

$$
\begin{gathered}
H=0,069 \cdot\left(\frac{\mathrm{PCS}^{*}}{100}+\mathrm{VCM}^{*}\right)-2,87 \\
\mathrm{PCS}^{*}=\frac{\mathrm{PCS}}{\mathrm{VCM}+\mathrm{CF}} \cdot 100
\end{gathered}
$$

Utilizando as propriedades do coque verde para determinar o teor de carbono a partir dos teores de matéria volátil (VCM), cinzas (Ash), enxofre (S) e carbono fixo (CF), obtém-se a equação (5.36). (LEE et al., 1998).

$$
\mathrm{C}=0,9571601 \cdot \mathrm{CF}+0,6646875 \cdot(\mathrm{VCM}-\mathrm{Ash})-0,5360022 \cdot \mathrm{S}
$$

A equação de balanço de massa global é:

$$
(\mathrm{M})_{\mathrm{RV}}=(\mathrm{M})_{\mathrm{gas}}+(\mathrm{M})_{\mathrm{nafta}}+(\mathrm{M})_{\mathrm{gol}}+(\mathrm{M})_{\mathrm{gop}}+(\mathrm{M})_{\mathrm{coque}}
$$

As equações de balanços materiais por elementos são:

$$
\mathrm{C}_{\mathrm{RV}}=\mathrm{C}_{\text {gas }}+\mathrm{C}_{\text {nafta }}+\mathrm{C}_{\text {gol }}+\mathrm{C}_{\text {gop }}+\mathrm{C}_{\text {coque }}
$$




$$
\begin{aligned}
& \mathrm{H}_{\mathrm{RV}}=\mathrm{H}_{\text {gas }}+\mathrm{H}_{\text {nafta }}+\mathrm{H}_{\text {gol }}+\mathrm{H}_{\text {gop }}+\mathrm{H}_{\text {coque }} \\
& \mathrm{S}_{\mathrm{RV}}=\mathrm{S}_{\text {gas }}+\mathrm{S}_{\text {nafta }}+\mathrm{S}_{\text {gol }}+\mathrm{S}_{\text {gop }}+\mathrm{S}_{\text {coque }} \\
& \mathrm{N}_{\mathrm{RV}}=\mathrm{N}_{\text {gas }}+\mathrm{N}_{\text {nafta }}+\mathrm{N}_{\text {gol }}+\mathrm{N}_{\text {gop }}+\mathrm{N}_{\text {coque }}
\end{aligned}
$$

De modo que:

$$
\begin{gathered}
(\mathrm{M})_{\mathrm{RV}}=(\mathrm{C})_{\mathrm{RV}}+(\mathrm{H})_{\mathrm{RV}}+(\mathrm{S})_{\mathrm{RV}}+(\mathrm{N})_{\mathrm{RV}} \\
(\mathrm{M})_{\mathrm{gas}}=(\mathrm{C})_{\mathrm{gas}}+(\mathrm{H})_{\mathrm{gas}}+(\mathrm{S})_{\mathrm{gas}}+(\mathrm{N})_{\mathrm{gas}} \\
(\mathrm{M})_{\text {nafta }}=(\mathrm{C})_{\mathrm{nafta}}+(\mathrm{H})_{\mathrm{rafta}}+(\mathrm{S})_{\mathrm{rafta}}+(\mathrm{N})_{\mathrm{rafta}} \\
(\mathrm{M})_{\mathrm{gol}}=(\mathrm{C})_{\mathrm{gol}}+(\mathrm{H})_{\mathrm{gol}}+(\mathrm{S})_{\mathrm{gol}}+(\mathrm{N})_{\mathrm{gol}} \\
(\mathrm{M})_{\mathrm{gop}}=(\mathrm{C})_{\mathrm{gop}}+(\mathrm{H})_{\mathrm{gop}}+(\mathrm{S})_{\mathrm{gop}}+(\mathrm{N})_{\mathrm{gop}} \\
(\mathrm{M})_{\text {coque }}=(\mathrm{C})_{\text {coque }}+(\mathrm{H})_{\mathrm{coque}}+(\mathrm{S})_{\text {coque }}+(\mathrm{N})_{\text {coque }}
\end{gathered}
$$

Para resolução das equações, são aplicados os critérios de reconciliação de balanço de massa, visando atender à conservação de massa da quantidade de cada componente presente nas correntes. Os resultados dos balanços de massa dos componentes proporcionaram a determinação da composição elementar CHSN, permitindo obter uma fórmula química empírica equivalente das correntes. Esta fórmula é representada pela equação (5.48).

$$
\mathrm{C}_{\mathrm{a}} \mathrm{H}_{\mathrm{b}} \mathrm{S}_{\mathrm{c}} \mathrm{H}_{\mathrm{d}}
$$

Como não foram realizados ensaios dos teores de enxofre e de nitrogênio nas correntes, foram utilizados os valores típicos destes componentes em cada corrente, conforme mostrado na Tabela 5.9: 
Tabela 5.9 - Valores típicos de enxofre e de nitrogênio nos produtos.

\begin{tabular}{ccc}
\hline Corrente & Enxofre total, \%massa $^{(a)}$ & Nitrogênio total, \%massa $^{(\mathrm{a}) .}$ \\
\hline Resíduo de vácuo & 0,90 & 1,00 \\
Gás combustível & 1,50 & 0,50 \\
Nafta & 0,43 & 0,04 \\
GOL & 0,58 & 0,27 \\
GOP & 0,68 & 0,68 \\
Coque & 1,00 & $2,63^{(\mathrm{b})}$ \\
\hline
\end{tabular}

Fonte: (a) Dados médios obtidos na Unidade de Coque de Petróleo (UCP1).

Para resolver o problema de reconciliação de balanço de massa global, foi desenvolvido um programa na linguagem FORTRAN, utilizando o subprograma NCONF da biblioteca IMSL (Fortran Numerical Library) de modo a minimizar a função objetiva.

Os resultados do programa para o ciclo N ${ }^{\circ} 4$ estão mencionados nas Tabelas $5.10 \mathrm{e}$ 5.11. Os demais ciclos apresentaram valores similares.

Tabela 5.10 - Resultado do balanço de massa dos componentes.

\begin{tabular}{lcccc}
\hline & Carbono, \%massa & Hidrogênio, \%massa & Enxofre, \%massa & Nitrogênio, \%massa \\
\hline RV & 84,83 & 12,51 & 1,18 & 1,48 \\
Gás & 75,77 & 21,28 & 2,25 & 0,70 \\
Nafta & 82,51 & 16,83 & 0,61 & 0,05 \\
GOL & 84,27 & 14,46 & 0,87 & 0,40 \\
GOP & 84,64 & 13,31 & 1,02 & 1,03 \\
Coque & 90,09 & 4,46 & 1,50 & 3,94 \\
\hline
\end{tabular}

Tabela 5.11 - Coeficiente de relação atômica da fórmula empírica $\mathrm{C}_{\mathrm{a}} \mathrm{H}_{\mathrm{b}} \mathrm{S}_{\mathrm{c}} \mathrm{N}_{\mathrm{d}}$.

\begin{tabular}{lcccc}
\hline & a, adimensional & b, adimensional & c, adimensional & d, adimensional \\
\hline RV & 1,00 & 1,7572 & 0,0052 & 0,0149 \\
Gás & 1,00 & 3,3470 & 0,0111 & 0,0079 \\
Nafta & 1,00 & 2,4302 & 0,0028 & 0,0006 \\
GOL & 1,00 & 2,0447 & 0,0039 & 0,0040 \\
GOP & 1,00 & 1,8748 & 0,0045 & 0,0104 \\
Coque & 1,00 & 0,5906 & 0,0062 & 0,0375 \\
\hline
\end{tabular}


Com base na comparação dos teores de enxofre e nitrogênio apresentados na Tabelas 5.10 e 5.10, foi observado que a reconciliação do balanço de massa elementar desempenha um papel importante nos ajustes dos seus teores por serem fortemente sensíveis aos erros. Como o processo de coqueamento estão sujeitas as variações de vazões e de qualidade dos produtos ao longo do ciclo, os teores de enxofre e de nitrogênio presente nas correntes de produtos da torre fracionadora são afetadas pelo horário de coletada de amostra. $\mathrm{O}$ erro pode ser em torno de 10 $20 \%$.

\subsection{Caracterização do resíduo de vácuo}

\subsubsection{Propriedades físico-químicas}

Na Tabela 5.12, estão os resultados das análises do resíduo de vácuo coletadas em oito ciclo de enchimento de reator e os seus rendimentos de coque correspondentes.

Tabela 5.12 - Rendimento de coque verde e propriedades do resíduo de vácuo.

\begin{tabular}{cccccc}
\hline Amostra N $^{\circ}$ & ${ }^{\circ}$ API & ASF & MCR & VIS & YCQ \\
\hline 1 & 10,19 & 5,72 & 17,38 & 2221 & 25,06 \\
2 & 9,85 & 4,47 & 16,40 & 2010 & 24,40 \\
3 & 11,58 & 3,80 & 15,40 & 1466 & 23,64 \\
4 & 8,71 & 6,27 & 18,36 & 3925 & 25,84 \\
5 & 8,83 & 6,72 & 18,31 & 3341 & 25,90 \\
6 & 8,92 & 6,00 & 18,13 & 3534 & 26,92 \\
7 & 8,10 & 6,81 & 19,12 & 5550 & 27,92 \\
8 & 8,04 & 6,98 & 18,95 & 5530 & 26,86 \\
\hline
\end{tabular}

ASF - Asfaltenos; MCR - Micro-resíduo de carbono; VIS - Viscosidade; YCQ - Coque.

Conforme a Tabela 5.12, a razão ASF/MCR é inferior a 0,50. Isto é um indicativo que o resíduo de vácuo não tem tendência para produção de shot-coke. (GUO A. et al, 2012). 


\section{MODELAGEM MATEMÁTICA}

Neste capítulo, encontra-se descrita a metodologia utilizada no desenvolvimento da modelagem matemática e simulação do forno e do reator da unidade de coqueamento, bem como as discussões dos resultados.

$\mathrm{Na}$ Figura 6.1, é apresentada a sequência do procedimento da modelagem matemática.

Figura 6.1 - Metodologia para modelagem matemática.

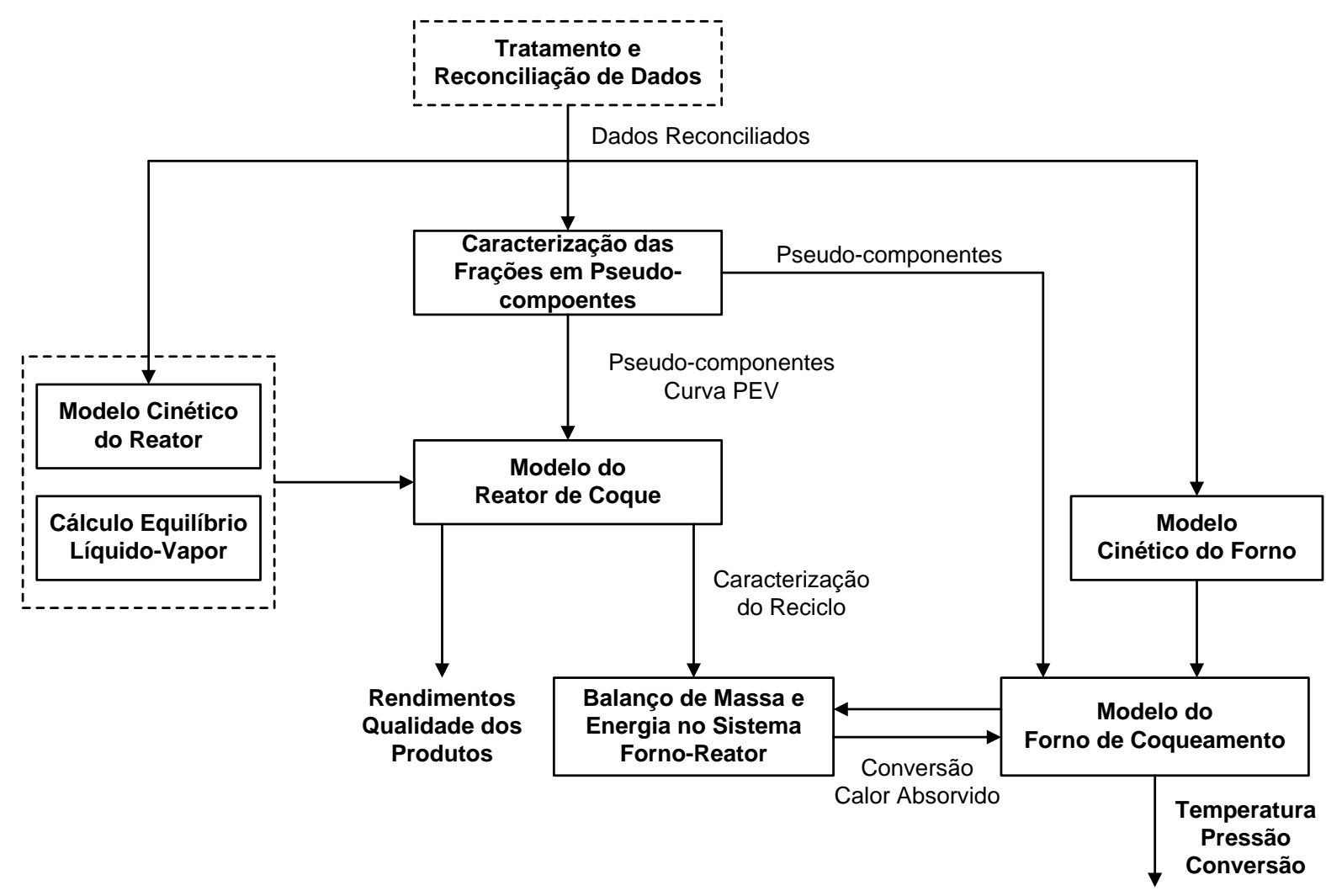

\subsection{Caracterização das frações em pseudo-componentes}

As frações de petróleo foram caracterizadas como uma mistura de pseudocomponentes discretos com faixas de ponto normal de ebulição definidas na curva de destilação de ponto de ebulição verdadeiro (PEV) ou similar. Cada pseudocomponente corresponde a vários compostos reais desconhecidos que tem 
temperatura de ebulição dentro da faixa. Geralmente, cada pseudo-componente é caracterizado por um ponto de ebulição normal médio, pela densidade e pelo peso molecular, sendo que as duas primeiras propriedades são obtidas experimentalmente a partir da curva de destilação de ponto ebulição verdadeiro em função do \%volume líquido acumulado e da densidade média da fração.

a) Correntes de nafta e gasóleo leve: foi realizada a interconversão da curva de destilação ASTM D-86 experimental para curva de destilação de ponto de ebulição verdadeiro (PEV), conforme proposto por Daubert (1994), a partir da qual obtêm-se os pseudo-componentes.

b) Correntes de resíduo de vácuo (carga) e gasóleo pesado: os pseudocomponentes foram gerados a partir da curva de destilação simulada experimental.

Os pseudo-componentes gerados foram ordenados em ordem crescente de valores da temperatura normal de ebulição de modo a. evitar perda de precisão devido ao mau fracionamento no interior da fracionadora principal.

Considerando o fator de caracterização de Watson constante para as correntes de nafta, gasóleo leve e pesado, foram determinadas as densidades de cada pseudocomponente. Conhecido a temperatura normal de ebulição e a densidade 60/60 ${ }^{\circ} \mathrm{F}$ de cada pseudo-componente, foram determinadas as propriedades críticas, peso molecular e fator acêntrico de cada um.

Para caracterizar as frações de petróleo foram utilizados os métodos mencionados na Tabela 6.1.

Para determinar a massa específica, viscosidades, condutividade térmica e tensão superficial, foram utilizadas as equações relacionadas na Tabela 6.2. 
Para executar os cálculos, foi desenvolvido um programa na linguagem FORTRAN 90, sendo utilizado o subprograma CSIEZ da biblioteca IMSL (Fortran Numerical Library) para interpolação da curva PEV por spline cúbica.

Tabela 6.1- Quadro de correlações.

\begin{tabular}{lc}
\hline \multicolumn{1}{c}{ Parâmetro } & Método \\
\hline Interconversão de curva de destilação ASTM D-86 em & Daubert (1984) \\
ponto de ebulição verdadeiro & API TDB (1989) \\
Peso molecular & TWU \\
Temperatura crítica & TWU \\
Pressão crítica & TWU \\
Volume crítico & Lee-Kesler \\
Fator acêntrico & Lee-Kesler \\
Fator de compressibilidade crítico & Riazi \\
Relação carbono-hidrogênio & Rackett modificada por Spencer e \\
Volume molar de líquido & Danner (1973) \\
& COSTALD para corrigir o efeito da \\
& pressão. \\
\hline
\end{tabular}

Tabela 6.2 - Propriedades físicas de pseudocomponentes e fração de petróleo.

\begin{tabular}{lcc}
\hline & Líquido & Vapor \\
\hline Massa específica & API-TDB & Peng-Robinson \\
\hline Entalpia & Lee-Kesler & Lee-Kesler \\
& Peng-Robinson & Peng-Robinson \\
\hline Viscosidade & TWU (1985) & Lucas (1984) \\
& Walther (1931) para estimar a & Regra de mistura de Bromley e \\
& viscosidade em função da & Wilke (1951). \\
& temperatura. & Jossi-Stiel-Thodos para corrigir o \\
& & efeito da pressão \\
\hline Condutividade térmica & Procedimento 12A3.2 do API & Misic e Thodos (1963) \\
& TDB (1992). & Stiel-Thodos (1951) para corrigir \\
& & o efeito da pressão. \\
\hline Tensão superficial & Block-Bird & \\
\hline
\end{tabular}


Foram utilizados 78 componentes, sendo 22 puros e os demais pseudocomponentes. Estes pseudo-componentes serão utilizados nos cálculos de equilíbrio líquido-vapor, balanço de massa e energia.

\subsection{Caracterização do vapor de topo do reator de coque}

O vapor de topo do reator é constituído por produtos de reações de craqueamento térmico (gás, nafta, gasóleos leve e pesado) e o vapor d'água injetado no processo. No entanto, uma fração da saída do reator é constituída de óleo de reciclo interno proveniente da seção de fundo da fracionadora principal conforme mostrado na Figura 6.2.

Figura 6.2 - Curva de destilação de ponto de ebulição verdadeiro do vapor de topo do reator.

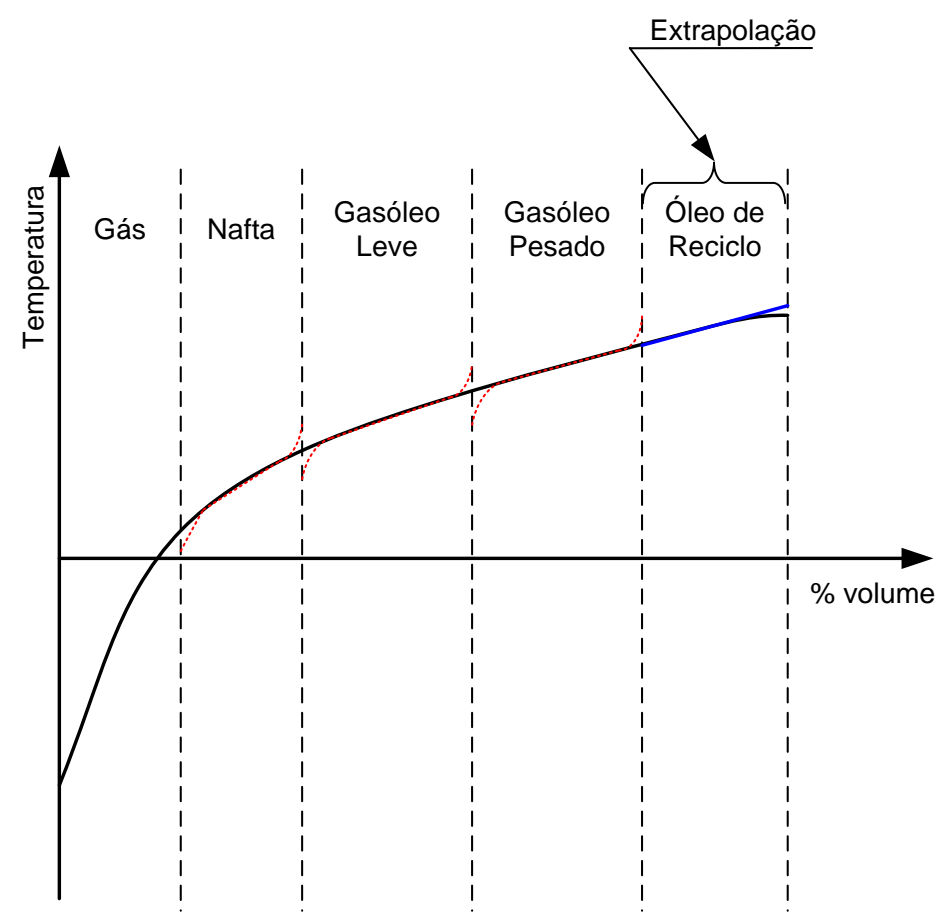

Todas as vazões das correntes e suas características são conhecidas, exceto a composição do óleo de reciclo. Como o reciclo não é separado do vapor de topo do 
reator, sua caracterização é desconhecida. A metodologia desenvolvida para determinar as suas características é baseada na extrapolação da curva de destilação verdadeira do vapor de topo, atendendo as equações de balanço de massa e de energia e a temperatura de ponto de orvalho no topo do reator.

A composição do óleo de reciclo é determinada por um processo de convergência sucessiva até os balanços de massa e energia serem satisfeitos, atendendo às restrições de equilíbrio líquido-vapor. Este procedimento é ilustrado na Figura 6.3.

Figura 6.3 - Estratégia para determinação do reciclo.

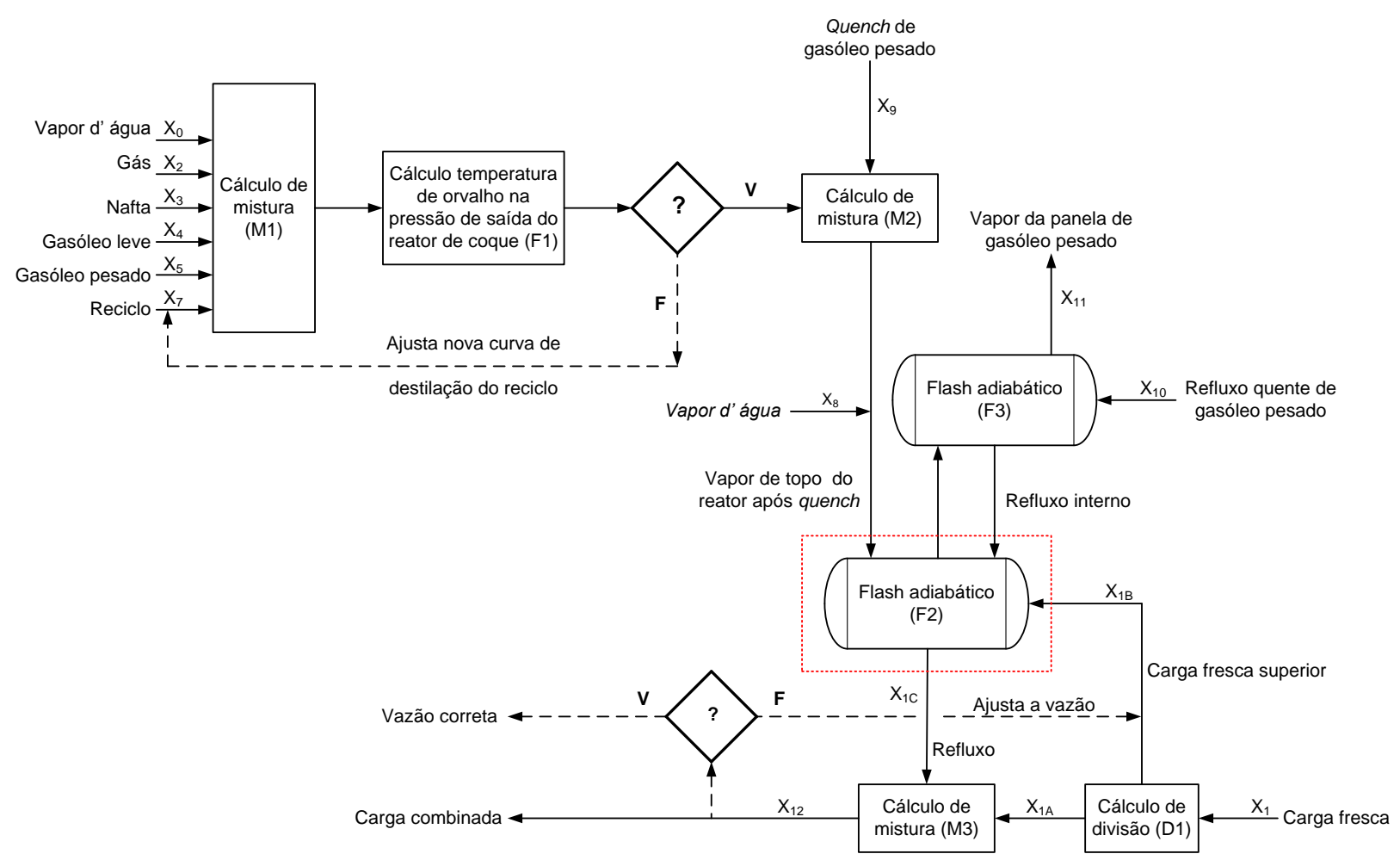

Como o óleo de reciclo foi obtido por extrapolação da curva de destilação PEV, considerando um acréscimo da temperatura normal de ebulição com o fator de caracterização de Watson constante, foram determinadas as propriedades críticas, peso molecular e fator acêntrico dos componentes do reciclo.

A temperatura de saída do reator de coque é difícil de medir com precisão. No entanto, podem-se aferir as características do óleo de reciclo, a partir do balanço de energia na seção de fundo da fracionadora. Posteriormente, é determinada a 
temperatura de orvalho do vapor de topo do reator na condição de pressão de topo do reator, antes da injeção do fluido de quench.

Como estratégia de modelagem, a seção de fundo da torre fracionadora principal pode ser dividida em três seções distintas:

- Seção de mistura entre carga fresca e óleo de reciclo;

- Seção de troca térmica e de lavagem do vapor de topo do reator com reciclo quente de gasóleo pesado;

- O líquido formado na zona de troca térmica.

O balanço de massa na seção de fundo da torre fracionadora pode ser utilizado para determinar a vazão de vapor de topo do reator acima da panela de gasóleo pesado.

$$
X_{11}=X_{0}+X_{2}+X_{3}+X_{4}+X_{5}+X_{8}+X_{9}+X_{10}
$$

Como as vazões e as composições de todas as correntes são conhecidas, determina-se diretamente a vazão e a composição do vapor na chaminé da panela de gasóleo pesado $\left(X_{11}\right)$. A pressão na seção de lavagem é conhecida e a temperatura da seção de lavagem é estimada através de cálculo do ponto de orvalho.

Uma corrente de refluxo de líquido é formada, com composição e vazão desconhecidas, é enviado para seção de mistura no fundo da fracionadora, onde é combinada com a carga fresca. A vazão de óleo de reciclo pode ser determinada através de medições de carga fresca e carga combinada (alimentação do forno).

Se a seção de lavagem é tratada como um estágio de equilíbrio líquido-vapor entre a corrente de vapor da chaminé e do líquido de fundo, a composição do óleo de reciclo é facilmente determinado: 


$$
X_{12}=X_{1 C}+X_{1 A}
$$

$\mathrm{Na}$ unidade industrial, determina-se a razão do óleo de reciclo (CFR) conforme descrito na equação (6.3).

$$
\mathrm{CFR}=\frac{\mathrm{X}_{12} \cdot \rho_{12}^{\mathrm{STD}}}{\mathrm{X}_{1} \cdot \rho_{1}^{\mathrm{STD}}}
$$

O cálculo da mistura (M1) é usado para determinar a vazão e a composição do vapor de topo reator de coque, incluindo o óleo de reciclo com sua composição ajustada em função da temperatura de orvalho na saída e balanço de energia na seção de fundo da torre fracionadora.

O quench de gasóleo pesado é misturado (M2) com o vapor de topo do reator de coque para controle de temperatura.

Na seção de fundo da torre fracionadora, a corrente de vapor de topo do reator é misturada com entrada de carga fresca superior, representado por um estágio de equilíbrio líquido-vapor (flash adiabático F2). Um controlador de temperatura de carga combinada utiliza como variável manipulada a vazão de carga superior de carga fresca.

A temperatura do vapor do flash adiabático (F3) deve atender a restrição de temperatura estabelecida.

A equação de estado de Peng-Robinson (SANDLER, 1999) é utilizada para predizer as condições de equilíbrio líquido-vapor da mistura. A composição inicial da fase líquida foi estimada através da constante de equilíbrio líquido-vapor para solução ideal proposta por Wilson (1968). Para estimativa inicial, como existem muitos componentes com propriedades físicas distintas, é necessário fazer a normalização da composição calculada. Caso contrário, a solução do sistema de equações apresenta problemas de convergência.

Foi desenvolvido um programa na linguagem FORTRAN 90, utilizando o subprograma NEQEF da biblioteca IMSL (Fortran Numerical Library). 


\subsection{Balanço de massa e energia do sistema forno-reator}

Para o cálculo do balanço de massa e energia do sistema forno -reator, é necessário o conhecimento prévio do modelo cinético das reações de craqueamento térmico que ocorrem no sistema. Para tanto, são assumidos cinco grupos discretos, como mostrados na Tabela 6.3. Estes produtos de agrupamentos foram selecionados com base nos cinco cortes principais do processamento de coqueamento.

Tabela 6.3 - Faixa de temperatura dos grupos do modelo proposto.

\begin{tabular}{lc}
\hline \multicolumn{1}{c}{ Grupos } & Faixa de corte \\
\hline Gás & $-\mathrm{C}_{4}$ \\
Nafta & $\mathrm{C}_{5}-200^{\circ} \mathrm{C}$ \\
Gasóleo leve & $200-370^{\circ} \mathrm{C}$ \\
Gasóleo pesado & $370-540^{\circ} \mathrm{C}$ \\
Resíduo & $>540^{\circ} \mathrm{C}$ \\
\hline
\end{tabular}

$\mathrm{Na}$ Figura 6.4, um diagrama de bloco do sistema forno-reator é apresentado, incluindo as correntes de produtos.

Figura 6.4 - Esquema no sistema forno-reator.

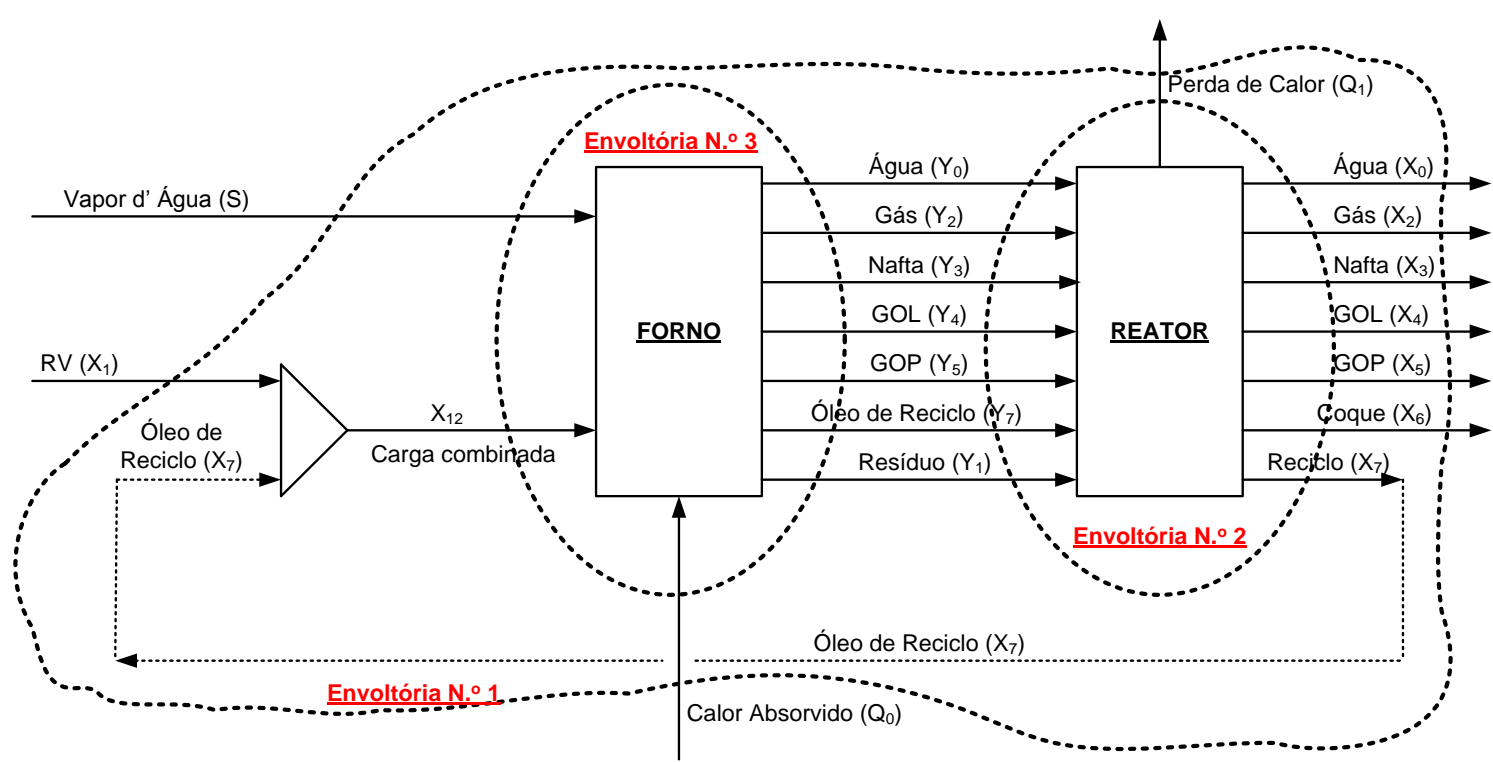


A seguir, estão relacionadas as principais equações de balanço de massa e de energia do sistema:

- $\quad$ Balanço de massa global do processo (Envoltória N.$^{\circ}$ 01):

$$
X_{1}+S=X_{0}+X_{2}+X_{3}+X_{4}+X_{5}+X_{6}
$$

- Balanço de massa global no forno de coqueamento (Envoltória N.$\left.^{\circ} 02\right)$ :

$$
\mathrm{X}_{1}+\mathrm{X}_{7}+\mathrm{S}=\mathrm{Y}_{0}+\mathrm{Y}_{2}+\mathrm{Y}_{3}+\mathrm{Y}_{4}+\mathrm{Y}_{5}+\mathrm{Y}_{6}+\mathrm{Y}_{7}
$$

- Vazão de cada agrupamento na saída do forno:

$$
\begin{gathered}
Y_{i}=\alpha_{i} \cdot X_{i} \quad(i=2, \ldots, 5) \\
Y_{1}=X_{1}-\left(Y_{2}+Y_{3}+Y_{4}+Y_{5}\right)
\end{gathered}
$$

- $\quad$ Balanço de massa no reator (Envoltória N. ${ }^{\circ}$ 03):

$$
\begin{gathered}
\Delta \mathrm{X}_{\mathrm{i}}=\left(1-\alpha_{\mathrm{i}}\right) \cdot \mathrm{X}_{\mathrm{i}} \quad(\mathrm{i}=2, \ldots, 5) \\
\Delta \mathrm{X}_{6}=\mathrm{X}_{6}
\end{gathered}
$$

- $\quad$ Balanço de energia global do processo (Envoltória N. ${ }^{\circ}$ 01):

$$
\begin{gathered}
(\Delta \mathrm{H})_{\text {ENTRADA }}+\mathrm{Q}_{0}=(\Delta \mathrm{H})_{\text {PRODUTO }}+(\Delta \mathrm{H})_{\text {REAÇÃO }}+\sum(\Delta \mathrm{H})_{\text {PERDAS }} \\
(\Delta \mathrm{H})_{\text {ENTRADA }}=\mathrm{X}_{1} \cdot \mathrm{H}_{1}+\mathrm{S} \cdot \mathrm{H}_{\mathrm{S}}+\mathrm{Q}_{0} \\
(\Delta \mathrm{H})_{\text {PRODUTO }}=\left(\begin{array}{l}
\left.\mathrm{X}_{0} \cdot \mathrm{H}_{0}+\mathrm{X}_{2} \cdot \mathrm{H}_{2}+\mathrm{X}_{3} \cdot \mathrm{H}_{3}+\mathrm{X}_{4} \cdot \mathrm{H}_{4}+\mathrm{X}_{5} \cdot \mathrm{H}_{5}+\mathrm{X}_{6} \cdot \mathrm{H}_{6}+\right) \\
\mathrm{X}_{7} \cdot \mathrm{H}_{7} \\
(\Delta \mathrm{H})_{\text {REAÇÃOO }}=\sum\left(\Delta \mathrm{H}_{\mathrm{f}}^{0}\right)_{\text {PRODUTO }}-\sum\left(\Delta \mathrm{H}_{\mathrm{f}}^{0}\right)_{\text {REAGENTE }}
\end{array}\right.
\end{gathered}
$$


- Balanço de energia no forno de coqueamento (Envoltória N..$^{\circ} 03$ ):

$$
\begin{aligned}
&(\Delta \mathrm{H})_{\text {ENTRADA }}+\mathrm{Q}_{0}=(\Delta \mathrm{H})_{\text {PRODUTO }}+(\Delta \mathrm{H})_{\text {REAÇÃO }}+\sum(\Delta \mathrm{H})_{\text {PERDA }} \\
&(\Delta \mathrm{H})_{\text {ENTRADA }}=\mathrm{X}_{1} \cdot \mathrm{H}_{1}+\mathrm{S} \cdot \mathrm{H}_{\mathrm{S}}+\mathrm{Q}_{0} \\
&(\Delta \mathrm{H})_{\text {PRODUTO }}= \mathrm{Y}_{0} \cdot \mathrm{H}_{0}+\mathrm{Y}_{2} \cdot \mathrm{H}_{2}+\mathrm{Y}_{3} \cdot \mathrm{H}_{3}+\mathrm{Y}_{4} \cdot \mathrm{H}_{4}+\mathrm{Y}_{5} \cdot \mathrm{H}_{5}+ \\
& \mathrm{Y}_{6} \cdot \mathrm{H}_{6}+\mathrm{Y}_{7 \mathrm{~B}} \cdot \mathrm{H}_{7}+\mathrm{Y}_{1} \cdot \mathrm{H}_{1}
\end{aligned}
$$

Os coeficientes de distribuição dos produtos na saída do forno de coqueamento $\left(\alpha_{i}\right)$ são determinados por um processo de convergência sucessiva de balanço de massa e de energia a ser satisfeito, atendendo às três envoltórias.

\subsection{Forno de coqueamento}

\subsubsection{Balanço de energia no forno de coqueamento - combustão}

No forno, o calor é liberado pelas reações de combustão de combustíveis em uma câmara e transferido para fluido no interior dos tubos que estão distribuídos ao longo da parede e do teto. $O$ calor é transferido por radiação direta e convecção, bem como reirradiação das paredes de refratário. Na Figura 6.5 é apresentado o esquema do forno de coqueamento.

O balanço de energia no forno pode ser realizado por duas metodologias diferentes: método do calor absorvido pelo fluido a ser aquecido (método direto) e das perdas (método indireto). O método indireto é baseado no cálculo de todas as entradas de energia e a partir destas sãos subtraídas as perdas através das paredes e dos gases exaustos, resultando no calor absorvido pelo processo. Enquanto o método do calor absorvido é determinado diretamente através da variação de entalpia entre a entrada e a saída da serpentina do forno (AL-HAJ IBRAHIM e AL-QASSIMI, 2008).

A seguir, é apresentada a metodologia de cálculo da eficiência térmica pelas duas 
metodologias:

Figura 6.5 - Esquema do forno de coqueamento.

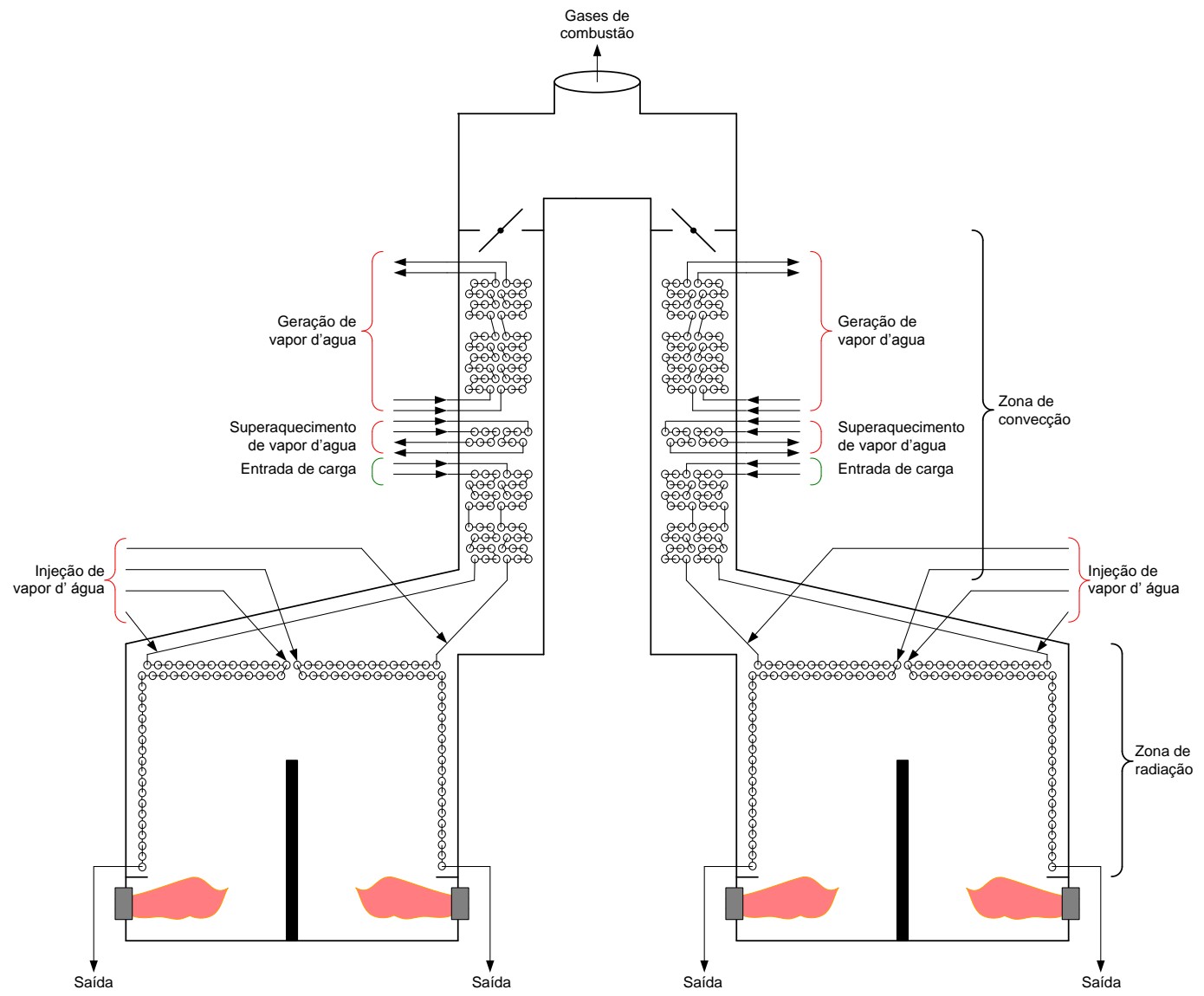

a) Método das perdas

$$
\eta=\frac{Q_{L I B}-\sum Q_{P E R D A}}{Q_{L I B}} \cdot 100=\left(1-\frac{\sum Q_{P E R D A}}{Q_{L I B}}\right) \cdot 100
$$

As principais perdas de calor são: paredes do forno, umidade do ar e gases de combustão.

b) Método do calor absorvido

$$
\eta=\frac{Q_{A B S}}{Q_{L I B}} \cdot 100
$$

Como no forno de coqueamento ocorrem aquecimento, reações químicas e 
vaporização de fluido, o calor absorvido é determinado por método indireto. Conhecendo esse calor absorvido, determina-se a conversão ao longo da serpentina do forno, a partir da variação de entalpia e de perda de carga.

A Figura 6.6 apresenta o esquema simplificado da fornalha para auxiliar no desenvolvimento do modelo matemático.

Figura 6.6 - Esquema simplificado de uma fornalha.

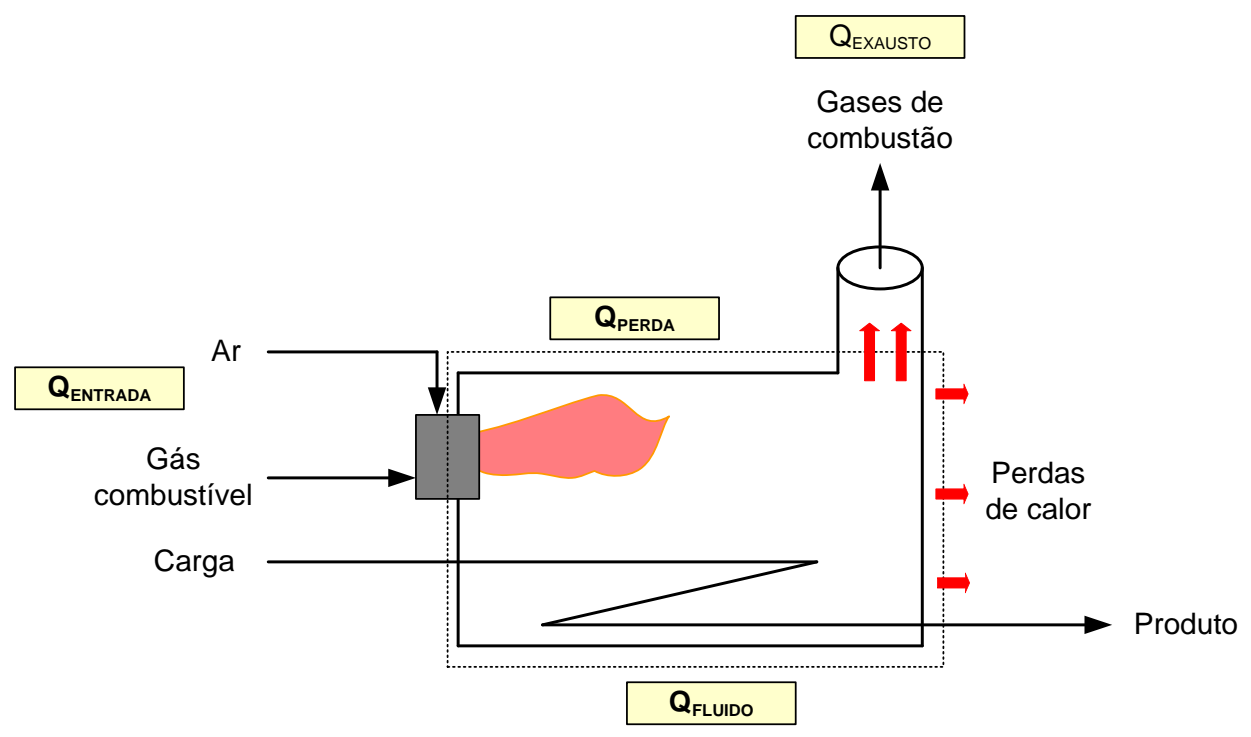

No método indireto, as fontes de entrada de calor para o aquecimento são: calor liberado pela combustão $\left(Q_{\text {LIBERADO }}\right)$, calor sensível do ar de combustão $\left(Q_{A R}\right)$ e calor sensível do gas combustível $\left(Q_{G C}\right)$. Enquanto as fontes de retiradas de calor são: calor transferido para os tubos da seção de radiação $\left(Q_{R A D}\right)$ e de conveção $\left(Q_{C O N V}\right)$, perda de calor através das paredes do forno $\left(Q_{P E R D A}\right)$ e calor perdido com os gases de combustão ( $Q_{\text {EXAUSTO}) \text {. }}$

O balanço global de energia é representado pela equação (6.19).

$$
Q_{L I B}=Q_{R A D}+Q_{P E R D A}+Q_{\text {EXAUSTO }}-Q_{A R}-Q_{G C}
$$

Através do cálculo de balanço de energia em estado estacionário, são determinados o calor transferido para o fluido no interior dos tubos e sua distribuição ao longo da serpentina do forno de coqueamento. 


\subsubsection{Determinação do fluxo de calor na seção de radiação}

a) Calor transferido na zona de radiação

$$
\frac{Q_{R A D}}{\alpha \cdot A_{R} \cdot \mathfrak{I}}=0,1730 \cdot\left[\left(\frac{T_{G}+460}{100}\right)^{4}-\left(\frac{T_{T}+460}{100}\right)^{4}\right]+7 \cdot\left(T_{G}-T_{S}\right)
$$

b) Balanço de energia na zona de radiação

$$
\frac{Q_{\text {RAD }}}{\alpha \cdot A_{R} \cdot \mathfrak{I}}=\frac{Q_{L I B}}{\alpha \cdot A_{R} \cdot \mathfrak{I}} \cdot\left(1+\frac{Q_{A R}}{Q_{L I B}}+\frac{Q_{G C}}{Q_{L I B}}-\frac{Q_{P E R D A}}{Q_{L I B}}-\frac{Q_{\text {EXAUSTO }}}{Q_{L I B}}\right)
$$

onde:

$\mathrm{Q}_{\mathrm{RAD}} \quad$ - Calor absorvido na seção de radiação, $B T U / h$

$Q_{A R} \quad$ - Calor sensível do ar alimentado para combustão acima de $60^{\circ} \mathrm{F}, \mathrm{BTU} / \mathrm{h}$.

$\mathrm{Q}_{\mathrm{GC}} \quad$ - Calor sensível do gás combustível acima de $60^{\circ} \mathrm{F}$, BTU/h.

$Q_{\text {PERDA }} \quad$ - Perda de calor para vizinhança, BTU/h.

$Q_{\text {EXAusto - }}$ - Calor dos gases de combustão deixando a seção de radiação, BTU/h.

$\mathrm{Q}_{\mathrm{LBB}} \quad$ - Calor total liberado pela combustão com base no poder calorífico inferior, BTU/h.

c) Fator de eficiência de uma superfície $(\alpha)$ :

Como a fileira de tubos não absorve totalmente o calor de radiação da superfície fria, Hottel (KERN, 1950) propôs um fator de absorvidade $(\alpha)$ para corrigir a área do plano frio em função do arranjo de tubos e espaçamento entre os tubos. Esse fator pode ser descrito pela equação (6.22), considerando uma fileira de tubos em frente à superfície de refratário. 


$$
\alpha=\frac{1}{C_{1} \cdot x+C_{2} \cdot x^{2}+C_{3} \cdot \exp (x)+\frac{C_{4}}{x}+C_{5} \cdot \exp \left(\frac{1}{x}\right)}
$$

$x=\frac{S_{\text {tubos }}}{D_{O}}$

$$
\begin{array}{lll}
C_{1}=0,582961 & C_{2}=-0,024535 & C_{3}=8,75478 \cdot 10^{-5} \\
C_{4}=2,039241 & C_{5}=-0,587105 & R=0,99969
\end{array}
$$

onde:

$\mathrm{S}_{\text {tubos }} \quad$ Espaçamento entre tubos da mesma fileira (centro-centro), $\mathrm{ft}$.

$\mathrm{D}_{0} \quad$ - Diâmetro externo do tubo, ft.

d) Área do plano frio equivalente (Acp):

Geralmente, a área de absorção de calor num forno é constituída por diversos tubos em paralelo. Para um forno com queima horizontal apenas de um lado dos tubos, a área do plano frio equivalente Acp é determinada por

$$
A_{C P}=N_{\text {tubos }} \cdot S_{\text {tubos }} \cdot L_{\text {tubos }}
$$

onde:

$\mathrm{N}_{\text {tubos }} \quad$ - Número de tubos na parede.

$S_{\text {tubos }} \quad$ - Espaçamento entre tubos da mesma fileira (centro - centro), ft.

$\mathrm{S}_{\text {tubos }}$ - Comprimento efetivo do tubo, $\mathrm{ft}$.

Quando o forno tem uma seção de shield que está recebendo radiação direta, o $\alpha . A_{C P}$ é calculada independentemente. 
A área total é a soma de todas as áreas de refratário da seção de radiação do forno, incluindo as paredes atrás dos tubos, piso, teto, paredes terminais e altar. Enquanto a área efetiva de refratário na seção de radiação é determinada pela equação (6.24).

$$
A_{R}=A_{T}-\left(\left(\alpha \cdot A_{C P}\right)_{\text {RAD }}+\left(\alpha \cdot A_{C P}\right)_{\text {SHELD }}\right)
$$

onde:
$A_{R}$
$\mathrm{A}_{\mathrm{T}} \quad$ - Área total das superfícies do forno, $\mathrm{ft}^{2}$.
$\left(\alpha \cdot A_{C P}\right)_{\text {RAD }}$ - Área plana equivalente da superfície fria dos tubos da
radiação, $\mathrm{ft}^{2}$.

Para tubos de aço com $9 \% \mathrm{Cr}$ e $1 \%$ Mo, a condutividade do metal é dada pela equação (6.25).

$$
\mathrm{K}_{\mathrm{METAL}}=15+0,0011 \cdot \mathrm{T}_{\text {fluido }}
$$

e) Emissividade dos gases de combustão:

A emissividade dos gases de combustão pode ser determinada pelas curvas apresentadas por Lobo e Evans (1939). Os constituintes presentes nos gases de combustão com emissividade significativa são as moléculas triatômicas, por exemplo: água e dióxido de carbono. A emissividade pode ser calculada, utilizando as dimensões do forno, a pressão parcial dos constituintes, temperatura de parede do tubo e dos gases de combustão. As variações de temperatura de parede do tubo entre 315 e 650 C, provocando um desvio inferior a $1 \%$ destas curvas.

A equação da pressão parcial dos componentes gasosos é:

$$
\begin{aligned}
& P_{\mathrm{CO} 2}=y_{\mathrm{CO} 2} \cdot P_{\mathrm{atm}} \\
& P_{\mathrm{H} 2 \mathrm{O}}=y_{\mathrm{H} 2 \mathrm{O}} \cdot P_{\mathrm{atm}}
\end{aligned}
$$




$$
\mathrm{P}=\mathrm{P}_{\mathrm{CO} 2}+\mathrm{P}_{\mathrm{H} 2 \mathrm{O}}
$$

A emissividade dos gases de combustão é dada por:

$$
\varepsilon_{G}=0,387587 \cdot \exp \left(0,140199-\frac{0,031266}{P \cdot M B L}+0,292215 \cdot \ln (P \cdot M B L)\right)-0,00016 \cdot T_{G}
$$

onde:

P - Pressão parcial de $\mathrm{CO}_{2}+\mathrm{H}_{2} \mathrm{O}$, ata.

$\mathrm{MBL} \quad$ - Comprimento médio de feixe, $\mathrm{ft}$.

$\mathrm{T}_{\mathrm{G}} \quad$ - Temperatura dos gases de combustão, ${ }^{\circ} \mathrm{C}$.

Para zona de combustão retangular, com dimensões de 1-1-1 a 1-1-3 e 1-2-1 a 1-2-4, de acordo com Wimpress (1963), pode ser utilizada a equação (6.30) proposta por Hottel (KERN, 1980).

$$
\mathrm{MBL}=\frac{2}{3} \cdot \sqrt[3]{\mathrm{L} \cdot \mathrm{W} \cdot \mathrm{H}}
$$

onde:

L $\quad$ - Comprimento da seção de radiação, ft.

W - Largura da seção de radiação, ft.

H - Altura da seção de radiação, ft.

f) Fator de forma global da fornalha (I):

Como os gases de combustão diferem bastante de um corpo negro e alguns dos seus componentes são transparentes à radiação térmica, Lobo e Evans propuseram um fator de correção na equação de transferência global de calor da fornalha conhecida como fator de forma global da fornalha. Este fator é função da emissividade dos gases de combustão, da razão entre a área do plano frio equivalente e área total de refratário da fornalha e da absorvidade dos tubos. 
Mekler e Fairall (1952) usaram diversas curvas para determinar o fator de troca global da fornalha em função da emissividade do gás de combustão e da razão entre a área do plano frio equivalente e da área total de refratário. A equação (6.31) representa as diversas curvas.

$$
\mathfrak{I}=\frac{1}{\left(\frac{1}{\varepsilon_{\mathrm{G}}}\right)+\left(\frac{1}{\varepsilon_{\mathrm{S}}}\right)-1}
$$

onde:

3 - Fator de troca global da fornalha, adimensional.

$\varepsilon_{G} \quad$ - Emissividade dos gases de combustão, adimensional.

$\varepsilon_{S} \quad-\quad$ Emissividade da superfície dos tubos (valor típico: $\varepsilon_{S}=0,80-0,90$ ), adimensional.

$\alpha \cdot \mathrm{A}_{\mathrm{CP}} \quad$ - Área plana equivalente da superfície fria dos tubos da radiação, $\mathrm{ft}^{2}$.

$\mathrm{A}_{\mathrm{R}} \quad$ - Área efetiva de refratário exposta na seção de radiação, $\mathrm{ft}^{2}$.

$\mathrm{F}_{\mathrm{RC}} \quad$ - Fração de radiação total proveniente da superfície fria.

A relação entre a emissividade do tubo e a emissividade dos gases é dada por:

$$
\begin{aligned}
& \varepsilon_{\mathrm{F}}=\varepsilon \cdot\left[1+\left(\frac{\mathrm{A}_{\mathrm{R}}}{\alpha \cdot \mathrm{A}_{\mathrm{CP}}}\right) \cdot \frac{1}{1+\left(\frac{\varepsilon_{\mathrm{G}}}{1-\varepsilon_{\mathrm{G}}}\right) \cdot \frac{1}{\mathrm{~F}_{\mathrm{RC}}}}\right] \\
& F_{R C}=\frac{\alpha \cdot A_{C P}}{A_{R}+\alpha \cdot A_{C P}} \quad \text { Quando } \quad \frac{A_{R}}{\alpha \cdot A_{C P}}=0 \quad \text { a } \quad 0,5 \\
& F_{R C}=\frac{\alpha \cdot A_{C P}}{A_{R}+\alpha \cdot A_{C P}} \quad \text { Quando } \quad \frac{A_{R}}{\alpha \cdot A_{C P}}=0 \quad \text { a } \quad 0,5
\end{aligned}
$$




$$
\begin{gathered}
\mathrm{F}_{\mathrm{RC}}=\frac{\alpha \cdot A_{\mathrm{CP}}}{\mathrm{A}_{\mathrm{R}}} \quad \text { Quando } \quad \frac{\mathrm{A}_{\mathrm{R}}}{\alpha \cdot A_{\mathrm{CP}}}=4 \text { a } 7 \\
\frac{1}{\mathrm{~F}_{\mathrm{RC}}}=\mathrm{C}_{0}+\mathrm{C}_{1} \cdot\left(\frac{\mathrm{A}_{\mathrm{R}}}{\alpha \cdot \mathrm{A}_{\mathrm{CP}}}\right)+\mathrm{C}_{2} \cdot\left(\frac{\mathrm{A}_{\mathrm{R}}}{\alpha \cdot \mathrm{A}_{\mathrm{CP}}}\right)^{2}+\mathrm{C}_{3} \cdot\left(\frac{\mathrm{A}_{\mathrm{R}}}{\alpha \cdot \mathrm{A}_{\mathrm{CP}}}\right)^{3}+\mathrm{C}_{4} \cdot \exp \left(\frac{\mathrm{A}_{\mathrm{R}}}{\alpha \cdot \mathrm{A}_{\mathrm{CP}}}\right)
\end{gathered}
$$

onde:

$$
\begin{aligned}
& C_{0}=0,9900515073 \\
& C_{1}=1,1234086550 \\
& C_{2}=-0,1932383912 \\
& C_{3}=0,02711500126 \\
& C_{4}=-0,001548881009
\end{aligned}
$$

O valor de $\mathfrak{I}$ deve ser determinado separadamente para a serpentina localizada na seção de radiação ou na seção de shock.

g) Perda de calor através da chaparia dos fornos:

Geralmente, é adotada de 2 a 3\% do calor liberado pelos queimadores como perdas de calor de calor através da chaparia do forno.

Outra maneira, é determinar as perdas de calor a partir da medição de temperatura de superfície e condições ambientais conforme a equação (6.37).

$$
\begin{aligned}
Q_{P E R D A}= & 0,173 \cdot \varepsilon_{p} \cdot\left[\left(\frac{T_{C H}+460}{100}\right)^{4}+\left(\frac{T_{A R}+460}{100}\right)^{4}\right]+ \\
& 0,25 \cdot\left(T_{C H}-T_{A R}\right)^{1,25} \cdot(1+0,30 \cdot v) \cdot f
\end{aligned}
$$

onde:

$\mathrm{Q}_{\text {PERDA }}$ - Fluxo de calor, BTU/h/ft ${ }^{2}$.

$\varepsilon_{\mathrm{p}} \quad-$ Emissividade da superfície $\left(\varepsilon_{\mathrm{p}}=0,82\right)$.

$\mathrm{T}_{\mathrm{CH}} \quad$ - Temperatura externa da parede, ${ }^{\circ} \mathrm{F}$. 
$\mathbf{T}_{\mathrm{AR}}$ - Temperatura do ar, ${ }^{\circ} \mathrm{F}$.

V $\quad$ - Velocidade do vento, milha/h.

f $\quad$ - Fator que depende da posição e da forma da superfície. Parede plana vertical: $f=1,0$

Parede plana horizontal: $f=0,64$ (piso) e $f=1,28$ (teto)

h) Temperatura efetiva dos gases na câmara de combustão $\left(T_{G}\right)$

Para uma seção de radiação que é considerada bem misturada, a temperatura é assumida ser igual a temperatura que deixa a seção, isto é a temperatura de bridgewall. Para maioria das aplicações, esta é uma aproximação aceitável.

No caso de um forno de temperatura elevada, com uma câmara de combustão alta e parede de queima, a temperatura $T_{G}$ controladora da transferência de calor por radiação pode ser aproximadamente de 90 a $150{ }^{\circ} \mathrm{C}$ superior a temperatura de saída dos gases. Para estes casos, é necessário dividir a radiação em zonas para cálculo.

$$
\left(T_{G}\right)=T_{B W}+22,2 \cdot\left(\frac{H}{V}\right)
$$

onde:

$T_{G} \quad$ - Temperatura efetiva dos gases na câmara de combustão, ${ }^{\circ} \mathrm{C}$

$\mathrm{T}_{\mathrm{BW}}$ - Temperatura de Bridgewall, ${ }^{\circ} \mathrm{C}$.

H - Altura da câmara de combustão, ft.

W - Largura da câmara de combustão, ft.

i) Temperatura de média de parede do tubo $\left(T_{\text {tubo }}\right)$

A temperatura média de parede do tubo na seção de radiação depende da temperatura do fluido de processo e o coeficiente de transferência de calor interna do tubo, a resistência térmica da parede, do fluxo de calor e das incrustações. $O$ cálculo desta temperatura é tratado na seção 6.2.3. 
A temperatura média de parede do tubo na seção de radiação pode ser estimada com base na temperatura de entrada e de saída do fluido conforme a equação (6.39).

$$
\left(T_{\text {tubo }}\right)=100+\left(\frac{T_{1}+T_{2}}{2}\right)
$$

\subsubsection{Temperatura máxima de parede do tubo}

O valor máximo de temperatura de parede do tubo é calculado com base no fluxo máximo de calor na seção de radiação, no coeficiente de transferência de calor e no perfil de temperatura do fluido. O API STD-530 (2003) propôs a equação (6.40) para determinar a temperatura máxima de parede.

$$
\begin{gathered}
\mathrm{T}_{\text {max }}=\mathrm{T}_{\text {fluido }}+\Delta \mathrm{T}_{\text {filme }}+\Delta \mathrm{T}_{\text {coque }}+\Delta \mathrm{T}_{\text {metal }} \\
\Delta \mathrm{T}_{\text {filme }}=\frac{\mathrm{q}_{\mathrm{MAX}}}{\mathrm{h}_{\mathrm{f}}} \cdot\left(\frac{\mathrm{D}_{0}}{\mathrm{D}_{\mathrm{i}}-2 \cdot \varepsilon_{\text {coque }}}\right) \\
\Delta \mathrm{T}_{\text {coque }}=\frac{\mathrm{q}_{\text {MAX }}}{\mathrm{K}_{\text {coque }}} \cdot \varepsilon_{\text {coque }} \cdot\left(\frac{\mathrm{D}_{0}}{\mathrm{D}_{\mathrm{i}}-\varepsilon_{\text {coque }}}\right) \\
\Delta \mathrm{T}_{\text {metal }}=\frac{\mathrm{q}_{\text {MAX }}}{\mathrm{K}_{\text {metal }}} \cdot \varepsilon_{\text {metal }} \cdot\left(\frac{\mathrm{D}_{0}}{\mathrm{D}_{0}-\varepsilon_{\text {metal }}}\right)
\end{gathered}
$$

O fluxo de calor máximo pode ser estimado com base na equação (6.41) descrita a seguir:

$$
\mathrm{q}_{\max }=\mathrm{F}_{\mathrm{C}} \cdot \mathrm{F}_{\mathrm{L}} \cdot \mathrm{F}_{\mathrm{T}} \cdot \mathrm{q}_{\mathrm{avg}}+\mathrm{q}_{\mathrm{conv}}
$$

onde:

$\mathrm{T}_{\max } \quad$ - Temperatura máxima de parede do tubo, ${ }^{\circ} \mathrm{F}$.

$\mathrm{T}_{\text {fluido }} \quad$ - Temperatura do fluido no interior do tubo, ${ }^{\circ} \mathrm{F}$

$\Delta \mathrm{T}_{\text {filme }} \quad$ - Diferença de temperatura através do filme de fluido, ${ }^{\circ} \mathrm{F}$ 


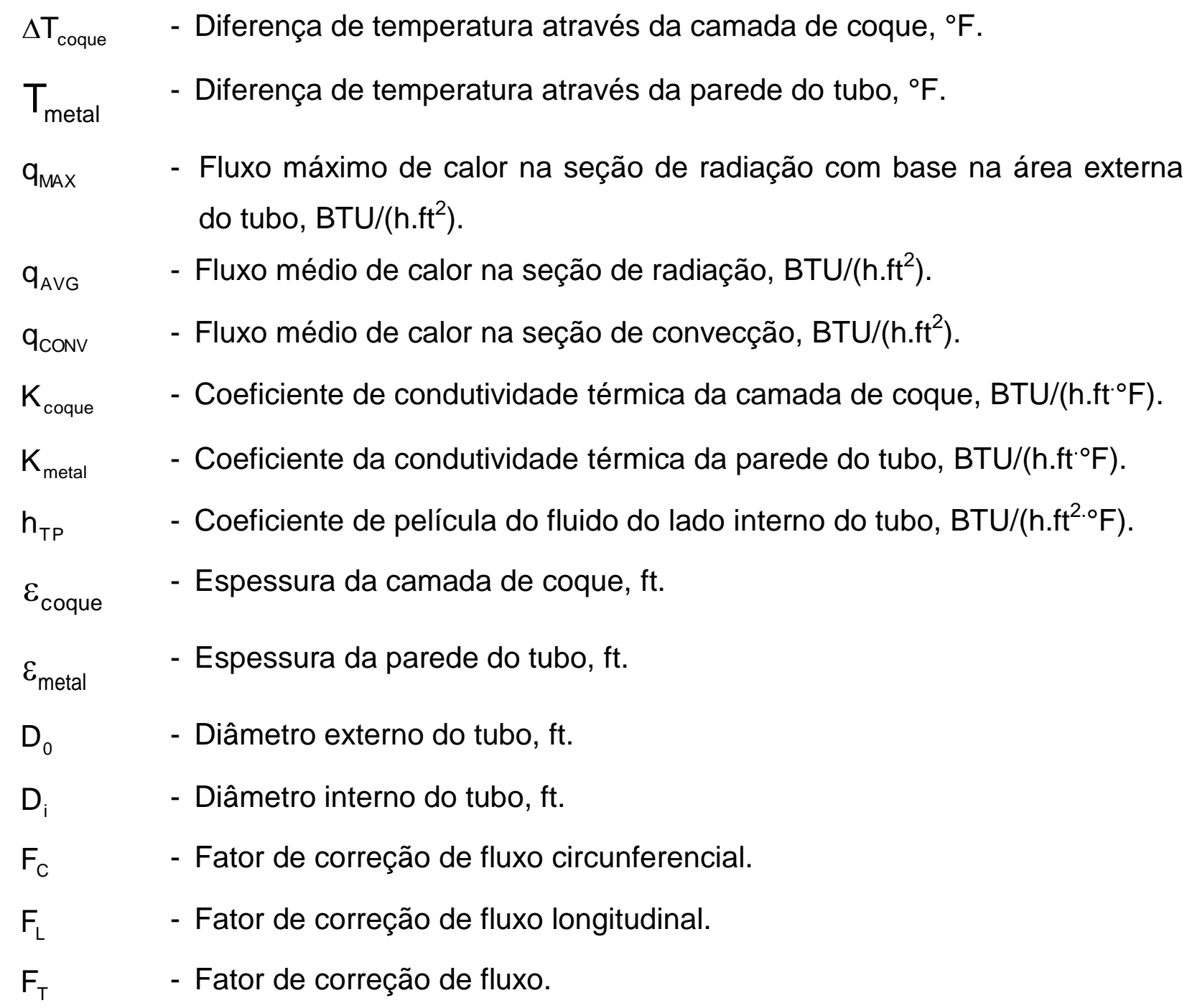

O coeficiente de película interna requerido para os cálculos de transferência de calor foi estimado através do método proposto no API STD 530 (2003).

Para escoamento turbulento de líquido com $R e>10.000$, pode-se utilizar as equações (6.42) e (6.43).

$$
h_{L}=0,023 \cdot\left(\frac{K_{\text {fluido }}}{D_{i}}\right) \cdot\left(\operatorname{Re}_{f}\right)^{0,80} \cdot\left(\operatorname{Pr}_{f}\right)^{0,33} \cdot\left(\frac{\mu_{b}}{\mu_{w}}\right)^{0,14}
$$

E para escoamento turbulento de vapor com $\operatorname{Re}>15.000$ :

$$
h_{v}=0,021 \cdot\left(\frac{K_{\text {flluido }}}{D_{i}}\right) \cdot\left(R_{f}\right)^{0,80} \cdot\left(\operatorname{Pr}_{f}\right)^{0,40} \cdot\left(\frac{T_{b}}{T_{w}}\right)^{0,50}
$$


Onde o número de Reynolds $(R e)$ e o número de Prandtl $(\operatorname{Pr})$ são dados por

$$
\begin{aligned}
& \operatorname{Re}_{f}=\frac{\rho \cdot v \cdot D_{i}}{\mu_{b}} \\
& \operatorname{Pr}_{f}=\frac{C p \cdot \mu_{b}}{K_{\text {fluido }}}
\end{aligned}
$$

Para escoamento bifásico, o coeficiente de transferência de calor por convecção pode ser aproximado por uma aditividade mássica conforme a equação (6.46).

$$
h_{T P}=w_{L} \cdot h_{L}+w_{V} \cdot h_{V}
$$

A partir equação (6.41) proposta pelo API STD 530 (2003), foram determinados os fatores de correção de fluxo de calor.

O fator de correção de fluxo de calor circunferencial $\left(F_{C}\right)$ tem a finalidade de corrigir as irregularidades de distribuição periférica nos tubos da serpentina do forno. Este fator é uma função do espaçamento entre tubos e a configuração dos tubos.

$$
\mathrm{F}_{\mathrm{C}}=\mathrm{C}_{0}+\frac{\mathrm{C}_{1}}{\mathrm{x}}+\frac{\mathrm{C}_{2}}{\mathrm{x}^{2}}
$$

Os coeficientes da equação são dados na Tabela 6.4.

Tabela 6.4 - Coeficientes da equação (6.47).

\begin{tabular}{ccccc}
\hline Curva N $^{\circ}$ & $C_{0}$ & $C_{1}$ & $C_{2}$ & $R$ \\
\hline 1 & 0,6573509054 & 4,5379521810 & 1,1791188782 & 0,9999365137 \\
2 & 1,0897969632 & 0,8137116567 & 1,2527223905 & 0,9999361941 \\
3 & 1,0242415706 & 0,9291305509 & 1,2043903243 & 0,9998914490 \\
4 & 1,0664081798 & 0,005503266836 & 0,4757414787 & 0,9994651678 \\
\hline
\end{tabular}

Curva $N .{ }^{\circ} 1$ - Fileira dupla contra parede com arranjo triangular.

Curva $N{ }^{\circ} 2$ - Fileira dupla com igual radiação de ambos os lados e dois diâmetros entre fileira, com espaçamento equilateral.

Curva $N{ }^{\circ} 3$ - fileira única contra a parede.

Curva $\mathrm{N}^{\circ} 4$ - Fileira única com radiação de ambos os lados. 
A Figura 6.6 apresenta dados do fator de correção do fluxo de calor, $F c$, em função da relação entre a distância dos tubos e o diâmetro externo do tubo, de acordo com a norma API STD-530 (2003) para uma única fileira de tubos contra a parede.

O fator de correção longitudinal $\left(F_{\mathrm{L}}\right)$ corrige alguma irregularidade de distribuição de calor na parte vertical e horizontal na seção de radiação do forno.

$$
F_{L}=0,910+0,0085 \cdot H+5,0 \cdot 10^{-5} \cdot H^{2}
$$

onde:

H - Altura da seção de radiação, ft.

Figura 6.7 - Fator de correção do fluxo de calor (API RP 530).

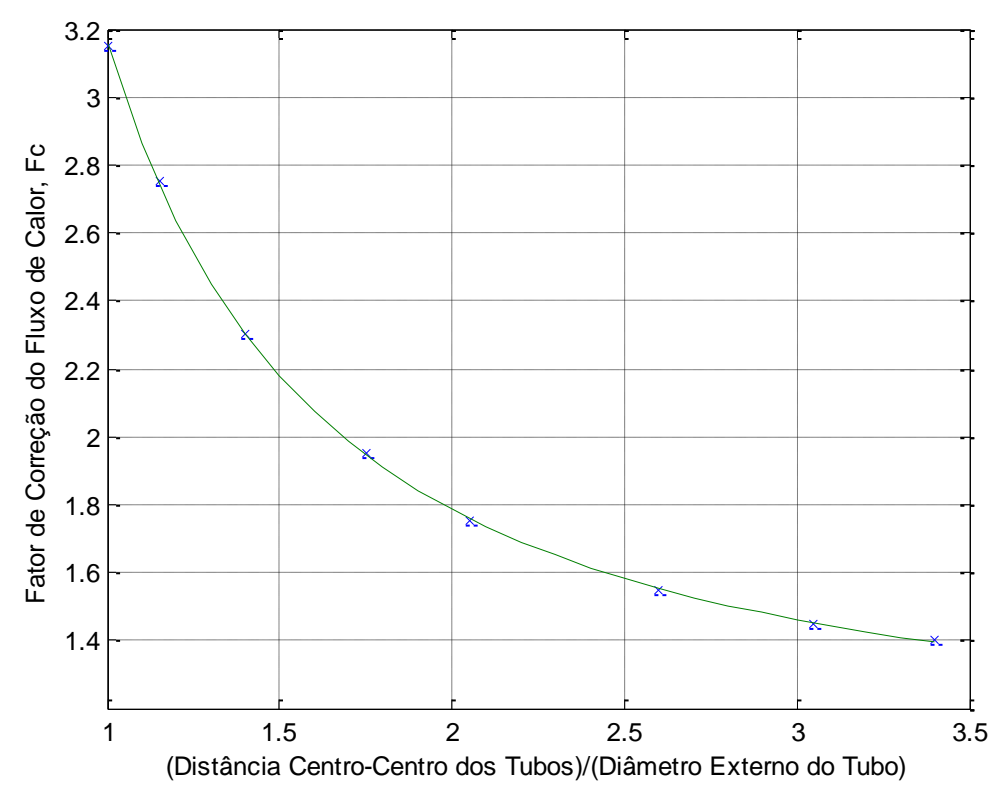

O fator de correção de má distribuição de fluxo de calor pelo efeito do tipo de chama formado no interior da seção de radiação do forno.

$$
F_{T}=\frac{T_{G}{ }^{4}-T_{W}{ }^{4}}{T_{G}{ }^{4}-\bar{T}_{G}{ }^{4}}
$$

onde: 
$T_{G}$ - Temperatura absoluta média dos gases de combustão na zona de radiação $T_{W} \quad$ - Temperatura absoluta de parede no ponto em estudo.

$\overline{\mathrm{T}}_{\mathrm{G}} \quad$ - Temperatura média dos gases de combustão na seção de radiação.

A Tabela 6.5 apresenta dados para o fator de correção de má distribuição de temperatura de parede em função do tipo de combustível e tipo de chama.

Tabela 6.5 - Fator de correção de má distribuição de temperatura de parede.

\begin{tabular}{ccc}
\hline Tipo de combustível & Tipo de chama & $\mathrm{F}_{\mathrm{T}}$ \\
\hline Gás & Não luminosa & 1,00 \\
Óleo & Luminosa & 1,06 \\
Óleo e gás & Combinada & 1,06 \\
\hline
\end{tabular}

\subsubsection{Cálculo do excesso de ar}

A combustão é um conjunto de reações químicas de uma ou mais substâncias com oxigênio, acarretando a liberação de energia e geração de produtos gasosos como $\mathrm{H}_{2} \mathrm{O}, \mathrm{CO}_{2}, \mathrm{CO}, \mathrm{NO}$ e $\mathrm{SO}_{2}$.

A maioria dos processos utiliza o ar como fonte de oxigênio $\left(79 \% \mathrm{~N}_{2}\right.$ e $\left.21 \% \mathrm{O}_{2}\right)$, onde ser desprezado os outros componentes presentes com teores inferiores a $1,0 \%$.

Apesar de uma pequena quantidade de $\mathrm{N}_{2}$ reagir durante o processo de combustão com oxigênio, sendo oxidado a $\mathrm{NO}$ e $\mathrm{NO}_{2}$ (chamado de $\mathrm{NOx}$, conhecidos como poluentes), a quantidade é tão pequena que pode ser tratado como inerte durante a etapa de combustão (BAUKAL, 2001).

O oxigênio teórico (requerido) é a mínima quantidade de oxigênio necessária para levar a queima à combustão completa.

$$
\mathrm{C}_{m} \mathrm{H}_{n}+\left(\mathrm{m}+\frac{\mathrm{n}}{4}\right) \cdot\left(\mathrm{O}_{2}+3,76 \cdot \mathrm{N}_{2}\right)=\mathrm{m} \cdot \mathrm{CO}_{2}+\frac{\mathrm{n}}{2} \cdot \mathrm{H}_{2} \mathrm{O}+3,76 \cdot\left(\mathrm{m}+\frac{\mathrm{n}}{4}\right) \cdot \mathrm{N}_{2}
$$




$$
\begin{gathered}
\mathrm{H}_{2}+\frac{1}{2} \cdot\left(\mathrm{O}_{2}+3,76 \cdot \mathrm{N}_{2}\right)=\mathrm{H}_{2} \mathrm{O}+3,76 \cdot\left(\frac{1}{2}\right) \cdot \mathrm{N}_{2} \\
\mathrm{H}_{2} \mathrm{~S}+\frac{3}{2} \cdot\left(\mathrm{O}_{2}+3,76 \cdot \mathrm{N}_{2}\right)=\mathrm{SO}_{2}+\mathrm{H}_{2} \mathrm{O}+3,76 \cdot\left(\frac{3}{2}\right) \cdot \mathrm{N}_{2} \\
\mathrm{NH}_{3}+\frac{5}{2} \cdot\left(\mathrm{O}_{2}+3,76 \cdot \mathrm{N}_{2}\right)=\mathrm{NO}+\frac{3}{2} \cdot \mathrm{H}_{2} \mathrm{O}+3,76 \cdot\left(\frac{5}{2}\right) \cdot \mathrm{N}_{2} \\
\mathrm{CO}+\frac{1}{2} \cdot\left(\mathrm{O}_{2}+3,76 \cdot \mathrm{N}_{2}\right)=\mathrm{CO}_{2}+3,76 \cdot\left(\frac{1}{2}\right) \cdot \mathrm{N}_{2}
\end{gathered}
$$

Para garantir a combustão completa, é alimentado um excesso de ar no processo de combustão conforme a equação (6.50).

$$
\text { \%Excesso de ar }=\frac{\mathrm{O}_{2} \text { alimentação }-\mathrm{O}_{2} \text { requerido }}{\mathrm{O}_{2} \text { requerido }} \cdot 100
$$

Através do balanço de massa em relação a $\% \mathrm{O}_{2}$, volume em base seca, é obtida a equação (6.51)

$$
\% \mathrm{O}_{2} \text { medido }=\frac{\mathrm{O}_{2}}{\sum\left(\mathrm{CO}_{2}+\mathrm{SO}_{2}+\mathrm{NO}+\mathrm{N}_{2}+\mathrm{O}_{2}\right)} \cdot 100
$$

O excesso de quantidade de ar presente nos gases de combustão que deixa a chaminé pode ser determinado com base no teor de oxigênio.

$$
\% \text { Excesso de } a r=\frac{\mathrm{O}_{2} \text { medido }}{0,21-\mathrm{O}_{2} \text { medido }} \cdot 100
$$

\subsubsection{Modelo matemático do forno de coqueamento}


Após a determinação dos coeficientes de distribuição dos produtos na saída do forno de coqueamento $\left(\alpha_{i}\right)$, é possível determinar o perfil de composição ao longo da serpentina para os diferentes agrupamentos, a partir do fluxo de calor, com base nos gases de combustão, temperatura de parede dos tubos, perfil de pressão e perfil de temperatura ao longo da serpentina.

O forno de coqueamento é dividido em duas seções distintas: pré-aquecimento e reação. Na Figura 6.8 é mostrado um desenho esquemático.

Figura 6.8 - Diagrama de bloco representando as seções do forno.

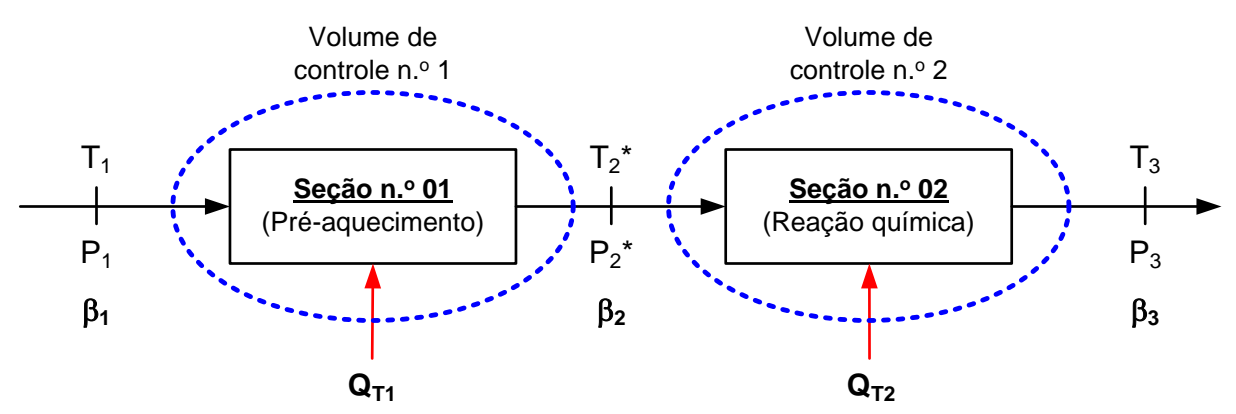

Os dados de temperatura do fluido no interior da serpentina do forno serão obtidos através de termopares na unidade industrial, localizados em diferentes comprimentos. Esses dados em função do comprimento de serpentina são utilizados para determinar os coeficientes da curva do perfil de temperatura conforme a Figura 6.7 , bem como os coeficientes da equação (6.53).

$$
T(z)=\alpha_{3} \cdot z^{3}+\alpha_{2} \cdot z^{2}+\alpha_{1} \cdot z+\alpha
$$

Com a temperatura calculada pela equação (3.61) é possível determinar as propriedades físicas do fluido em qualquer localização da serpentina.

O fluxo total de calor absorvido pelo processo é a soma dos fluxos absorvidos nas duas seções do forno de coqueamento.

$$
\dot{\mathrm{Q}}_{0}=\dot{\mathrm{Q}}_{\mathrm{T} 1}+\dot{\mathrm{Q}}_{\mathrm{T} 2}
$$


A seção de reação química do forno de coqueamento pode ser considerada como vários reatores de mistura em série, em estado estacionário, com escoamento bifásico (líquido e vapor). As equações de balanço de massa e energia, transferência de calor, escoamento de fluido e cálculo de equilíbrio líquido-vapor, incluindo a conversão química são descritas a seguir.

- $\quad$ Cálculo de variação de entalpia

Para calcular a entalpia da mistura na temperatura $T$ e pressão $P$, é utilizada a entalpia residual obtida a partir da equação de estado de Peng-Robinson, representada pela equação $(6.55)$.

$$
H(T, P, x)=\Delta H_{f}^{298 K}+\int_{298 K}^{T} C p^{0} \cdot d T+\left(\Delta H^{P R}\right)
$$

Através da variação de entalpia calculada pela equação (6.55), determina-se o calor absorvido pelo fluido.

- Cálculo de variação de entalpia por transferência de calor

A entalpia do fluido varia ao longo da serpentina em função do fluxo de calor. O fluxo de calor absorvido pelo fluido é resultado da transferência de calor da câmara de combustão, radiação e convecção.

$$
\frac{\mathrm{dH}(T, P, \underline{\mathrm{x}})}{\mathrm{dz}}=\pi \cdot \mathrm{D}_{0} \cdot \mathrm{U} \cdot\left(\mathrm{T}_{0}-\mathrm{T}\right)
$$

onde:

U - Coeficiente global de transferência de calor.

$D_{0}$ - Diâmetro externo do tubo.

$\mathrm{T}_{0}$ - Temperatura externa do tubo

$\mathrm{T}$ - Temperatura interna do tubo

- Mecânica dos fluidos 
A perda de carga global de um fluido no interior da serpentina é determinada pela equação (6.57):

$$
\Delta \mathrm{P}_{\text {TOTAL }}=\Delta \mathrm{P}_{\mathrm{F}}+\Delta \mathrm{P}_{\mathrm{K}}+\Delta \mathrm{P}_{\mathrm{A}}+\Delta \mathrm{P}_{\mathrm{C}}
$$

onde:

$$
\begin{aligned}
& \Delta P_{\text {TOTAL }} \text { - Perda de carga total } \\
& \Delta P_{F} \quad \text { - Perda de carga por atrito } \\
& \Delta P_{K} \quad-\text { Perda de carga por acidente } \\
& \Delta P_{A} \quad-\text { Perda de carga por aceleração } \\
& \Delta P_{C} \quad-\text { Perda de carga por elevação }
\end{aligned}
$$

A perda de pressão por atrito no interior da serpentina do forno é calculada conforme a equação de Darcy-Weisbach (6.58).

$$
\Delta P_{F}=f_{D} \cdot \frac{L}{D_{i}} \cdot \frac{G^{2}}{2 \cdot \rho_{A V G}}
$$

onde:
$f_{D} \quad$ - Fator de atrito de Darcy.
G - Fluxo mássico
L $\quad$ - Comprimento reto da serpentina.
$D_{i} \quad$ - Diâmetro interno do tubo.
$\rho_{\text {AVG }} \quad$ - Massa específica média.

As propriedades médias no segmento de tubo e acessórios são usadas para determinar a perda de pressão por comprimento para aplicação no comprimento global equivalente. A estimativa de cálculo da massa específica do fluido é com base na condição de entrada e saída do segmento conforme a equação (6.59).

$$
\rho_{\mathrm{AVG}}=\frac{\left(\rho_{2}-\rho_{1}\right)}{\ln \left(\frac{\rho_{2}}{\rho_{1}}\right)}
$$


onde:
$\rho_{\text {AVG }}$ - Massa específica média no segmento
$\rho_{2} \quad$ - Massa específica na saída do segmento
$\rho_{1} \quad$ - Massa específica na entrada do segmento

O fator de atrito de Darcy no interior da serpentina é determinado pela correlação proposta por CHURCHIL (1977) em função do número de Reynolds e rugosidade, sendo válida para todos os regimes de escoamento: laminar, transição e turbulento.

$$
\begin{gathered}
f_{D}=8 \cdot f \\
f=\left[\left(\frac{8}{R e_{f}}\right)^{12}+\frac{1}{(A+B)^{3 / 2}}\right]^{1 / 12} \\
A=\left[\begin{array}{c}
\left.2,457^{*} \ln \left(\frac{1}{\left(\frac{7}{R e_{f}}\right)^{0,90}+0,27 \cdot\left(\frac{\varepsilon}{D_{i}}\right)}\right)\right]^{16} \\
B=\left(\frac{37530}{R e_{f}}\right)^{16}
\end{array}\right.
\end{gathered}
$$

A perda de pressão por acidente no interior da serpentina do forno é calculada conforme a equação (6.64).

$$
\Delta P_{K}=K_{D} \cdot \frac{\rho \cdot v^{2}}{2 \cdot g}
$$

O coeficiente de perda de carga pode ser representado como um comprimento equivalente (Leq). Igualando-se as equações (6.57) e (6.58), chega-se a: 


$$
\begin{aligned}
K_{D} \cdot\left(\frac{\rho \cdot v^{2}}{2 \cdot g}\right) & =\left(f \cdot \frac{\text { Leq }}{D_{i}}\right) \cdot\left(\frac{\rho \cdot v^{2}}{2 \cdot g}\right) \\
\text { Leq } & =K_{D} \cdot \frac{D_{i}}{f}
\end{aligned}
$$

Os valores dos coeficientes de perda de carga $\left(\mathrm{K}_{\mathrm{D}}\right)$ para curva de $180^{\circ}$ e cabeçotes (plug type header) são 0,85 e 1,70, respectivamente, para tubo com diâmetro nominal de $100 \mathrm{~mm}$.

A perda de carga por atrito é dada pela equação (6.66)

$$
\Delta P_{F}=f_{D} \cdot \frac{(L+L e q)}{D_{i}} \cdot \frac{G^{2}}{2 \cdot \rho_{A V G}}
$$

Na Figura 6.9, é apresentado o escoamento de fluido através de um tubo com área da seção transversal constante, onde é esperada apenas perda de carga por atrito e aceleração.

Figura 6.9 - Escoamento de fluido no interior do tubo.

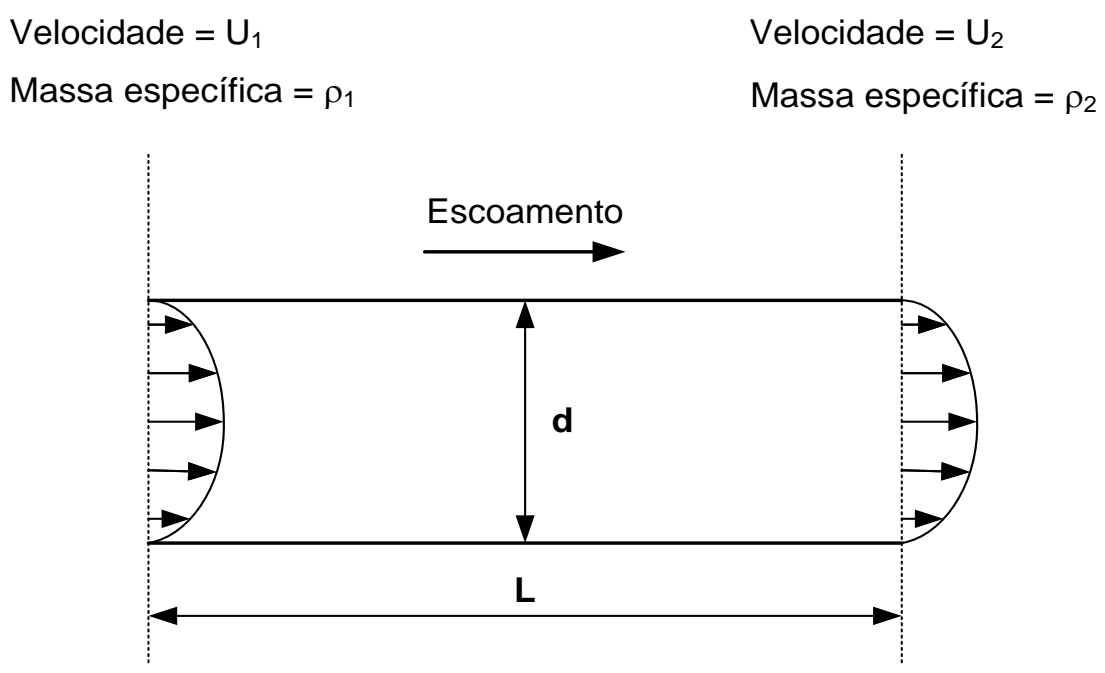

A perda de carga por aceleração do fluido é dada pela equação (6.67).

$$
\Delta P_{A}=G^{2} \cdot\left(\frac{1}{\rho_{2}}-\frac{1}{\rho_{1}}\right)
$$


O regime de escoamento no interior da serpentina da seção $n .^{\circ} 02$ será determinado pelo mapa de Baker (KERN, 1969). Neste mapa, utilizam-se os parâmetros $B x$ e $B y$, representados nas equações (6.68) e (6.69),

$$
\begin{gathered}
\mathrm{Bx}=531 \cdot\left(\frac{\mathrm{W}_{\mathrm{L}}}{\mathrm{W}_{\mathrm{V}}}\right) \cdot\left(\frac{\sqrt{\rho_{\mathrm{L}} \cdot \rho_{\mathrm{V}}}}{\left(\rho_{\mathrm{L}}\right)^{2 / 3}}\right) \cdot\left(\frac{\mu_{\mathrm{L}}{ }^{1 / 3}}{\sigma_{\mathrm{L}}}\right) \\
\mathrm{By}=2.16 \cdot\left(\frac{\mathrm{W}_{\mathrm{V}}}{\mathrm{A}}\right) \cdot \frac{1}{\sqrt{\rho_{\mathrm{L}} \cdot \rho_{\mathrm{V}}}}
\end{gathered}
$$

onde:
A - Área da seção transversal interna do tubo, $\mathrm{ft}^{2}$.
$\mathrm{W}_{\mathrm{V}}$ - Vazão mássica de gás, $\mathrm{lbm} / \mathrm{h}$
$\mathrm{W}_{\mathrm{L}} \quad$ - Vazão mássica de líquido, $\mathrm{lbm} / \mathrm{h}$
$\rho_{\mathrm{L}} \quad$ - Massa específica do líquido, $\mathrm{lbm} / \mathrm{ft}^{3}$.
$\rho_{V} \quad$ - Massa específica do vapor, lbm/ $/ \mathrm{tt}^{3}$.
$\mu_{\mathrm{L}} \quad$ - Viscosidade do líquido, $\mathrm{CP}$.
$\mu_{\mathrm{V}} \quad$ - Viscosidade do gás, cP.
$\sigma_{L} \quad$ - Tensão superficial do líquido, dina/cm.

O parâmetro $B x$ depende da relação das vazões mássicas e das propriedades físicas das fases líquida e vapor, sendo independente da dimensão do tubo. Com isso, ele varia somente com as propriedades do fluido e a fração vaporizada. Enquanto o parâmetro $B y$ depende da vazão mássica da fase vapor, massa específica das fases vapor e líquida e da área do tubo.

A interseção dos pontos $B x$ e By na Figura 6.10 determina o regime de escoamento em regime bifásico. 
Figura 6.10 - Mapa de Baker para escoamento em tubo horizontal.

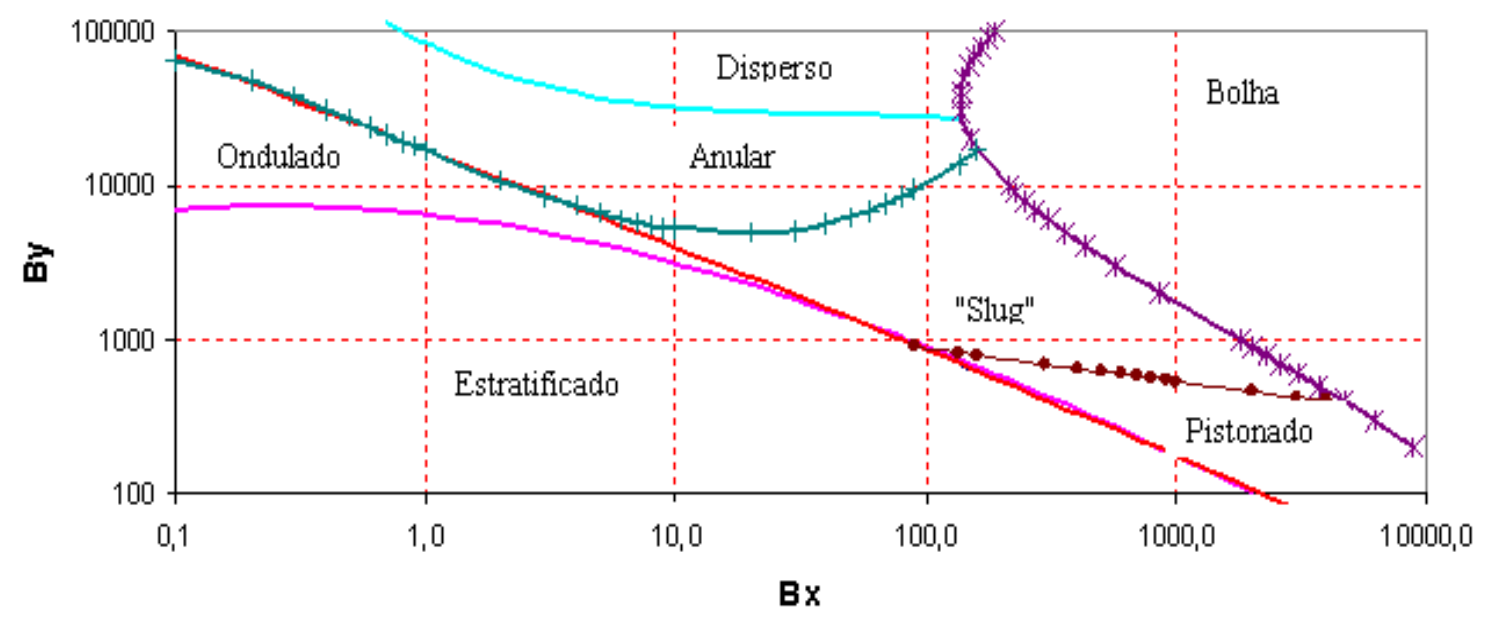

- Cálculo de equilíbrio líquido-vapor

A equação de estado de Peng-Robinson (SANDLER, 1999) é utilizada para predizer as condições de equilíbrio líquido-vapor da mistura multicomponentes ao longo da serpentina, através de sucessivos cálculos de flash.

Para resolver o sistema de equações não-lineares simultaneamente, foi utilizado o subprograma NEQEF da IMSL. Para estimativa inicial da composição, foi utilizada a equação proposta por Wilson (1968) para determinar as constantes de equilíbrio Ki.

- Modelo de craqueamento térmico

O modelo cinético de craqueamento térmico proposto para o forno é constituído por cinco grupos discretos como mostrado na Figura 6.11. O primeiro grupo representa a quantidade total do óleo craqueável do resíduo de vácuo (RV). Os outros quatro grupos discretos representam os produtos, os quais são progressivamente vaporizados no interior da serpentina do forno de coqueamento. A taxa de formação de coque no interior da serpentina do forno é considerada desprezível. 
Figura 6.11 - Esquema das reações com cinco grupos.

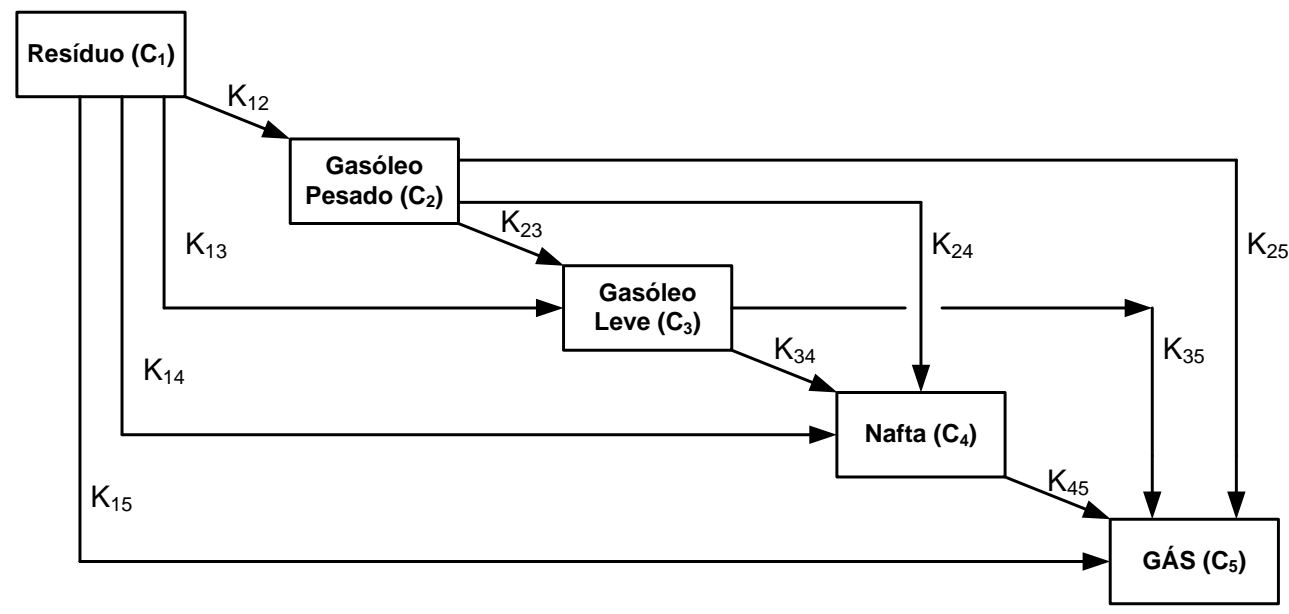

Em primeira instância, é assumido que as reações de craqueamento térmico são cinéticas de primeira ordem irreversíveis. As equações da taxa de reação para os cinco grupos representados na Figura 6.11 podem ser expressas como:

$$
\begin{gathered}
\left(\frac{\mathrm{d}\left[\mathrm{C}_{1}\right]}{\mathrm{dt}}\right)=-\left(\mathrm{K}_{12}+\mathrm{K}_{13}+\mathrm{K}_{14}+\mathrm{K}_{15}\right) \cdot\left[\mathrm{C}_{1}\right] \\
\left(\frac{\mathrm{d}\left[\mathrm{C}_{2}\right]}{\mathrm{dt}}\right)=\mathrm{K}_{12} \cdot\left[\mathrm{C}_{1}\right]-\left(\mathrm{K}_{23}+\mathrm{K}_{24}+\mathrm{K}_{25}\right) \cdot\left[\mathrm{C}_{2}\right] \\
\left(\frac{\mathrm{d}\left[\mathrm{C}_{3}\right]}{\mathrm{dt}}\right)=\mathrm{K}_{13} \cdot\left[\mathrm{C}_{1}\right]+\mathrm{K}_{23} \cdot\left[\mathrm{C}_{2}\right]-\left(\mathrm{K}_{34}+\mathrm{K}_{35}\right) \cdot\left[\mathrm{C}_{3}\right] \\
\left(\frac{\mathrm{d}\left[\mathrm{C}_{4}\right]}{\mathrm{dt}}\right)=\mathrm{K}_{14} \cdot\left[\mathrm{C}_{1}\right]+\mathrm{K}_{24} \cdot\left[\mathrm{C}_{2}\right]+\mathrm{K}_{34} \cdot\left[\mathrm{C}_{3}\right]-\mathrm{K}_{45} \cdot\left[\mathrm{C}_{4}\right] \\
\left(\frac{\mathrm{d}\left[\mathrm{C}_{5}\right]}{\mathrm{dt}}\right)=\mathrm{K}_{15} \cdot\left[\mathrm{C}_{1}\right]+\mathrm{K}_{25} \cdot\left[\mathrm{C}_{2}\right]+\mathrm{K}_{35} \cdot\left[\mathrm{C}_{3}\right]+\mathrm{K}_{45} \cdot\left[\mathrm{C}_{4}\right] \\
\mathrm{K}_{\mathrm{A}}=\mathrm{K}_{12}+\mathrm{K}_{13}+\mathrm{K}_{14}+\mathrm{K}_{15} \\
\mathrm{~K}_{\mathrm{B}}=\mathrm{K}_{23}+\mathrm{K}_{24}+\mathrm{K}_{25} \\
\mathrm{~K}_{\mathrm{C}}=\mathrm{K}_{34}+\mathrm{K}_{35}
\end{gathered}
$$


As condições iniciais para resolver as equações diferenciais são:

$$
C_{1}=C_{1,0} \quad C_{2,0}=C_{3,0}=C_{4,0}=C_{5,0}=0
$$

A conversão representa a fração de qualquer reagente convertido em qualquer outro componente. A seguir, é definida a conversão para o reagente 1:

$$
\begin{gathered}
X_{1}=1-\frac{C_{1}}{C_{1,0}} \\
X_{1}=1-\exp \left(-K_{A} \cdot t\right)
\end{gathered}
$$

A equação de Arrhenius é utilizada para descrever a dependência da constante da taxa da reação com a temperatura.

$$
\ln \left(K_{i j}\right)=\ln \left(A_{i j}\right)-\frac{E_{i j}}{R \cdot T}
$$

onde $A_{i j}$ e $E_{i j}$ são $o$ termo pré-exponencial e a energia de ativação, respectivamente.

Os dados experimentais das composições dos cinco agrupamentos obtidos a partir de balanço de massa e energia ao longo da serpentina do forno, juntamente com o perfil de temperatura, permitem determinar as constantes cinéticas do modelo proposto.

\subsection{Modelo matemático de craqueamento térmico no reator de coque}

O reator de coque é considerado como um reator de mistura perfeita em estado pseudo-estacionário. Quando a alimentação do reator é parcialmente convertida, a equação geral de balanço molar é a seguinte: 


$$
\frac{V}{\left(F_{i}\right)_{0}}=\frac{\left[\left(X_{i}\right)_{F}-\left(X_{i}\right)_{1}\right]}{\left( \pm r_{i}^{*}\right)_{F}}
$$

onde:

V - Volume do inventário do reator em processo reacional.

$\mathrm{F}_{\mathrm{i}} \quad$ - Vazão molar do agrupamento i.

$r_{i}^{*} \quad$ - Taxa da reação de craqueamento térmico no reator do grupo i.

$X_{i} \quad$ - Conversão do agrupamento i.

Com base na experiência operacional do processo de craqueamento térmico Eureka (TAKATSUKA, 1995), o tempo mínimo necessário para iniciar a formação de coque é da ordem de quatro horas. Com esta informação é possível determinar o volume do inventário no processo reacional.

$$
\tau=\frac{\mathrm{C}_{\mathrm{A} 0} \cdot \mathrm{V}}{\mathrm{F}_{\mathrm{A} 0}}=\frac{\mathrm{V}}{\mathrm{q}}
$$

A Figura 6.12 apresenta um reator de coque durante a etapa de enchimento com as suas diferentes fases. A Figura 6.13 mostra a estratégia de cálculo, na qual o interior do reator está dividido em três fases: vapor, líquido e sólida.

Figura 6.12 - Esquema do reator de coque

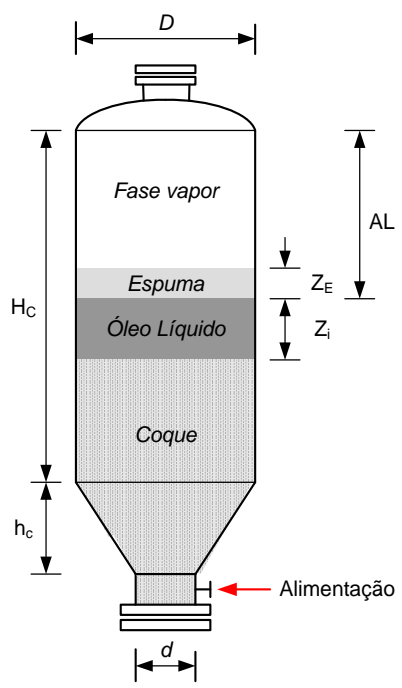


Figura 6.13 - Esquema do modelo proposto para o reator.

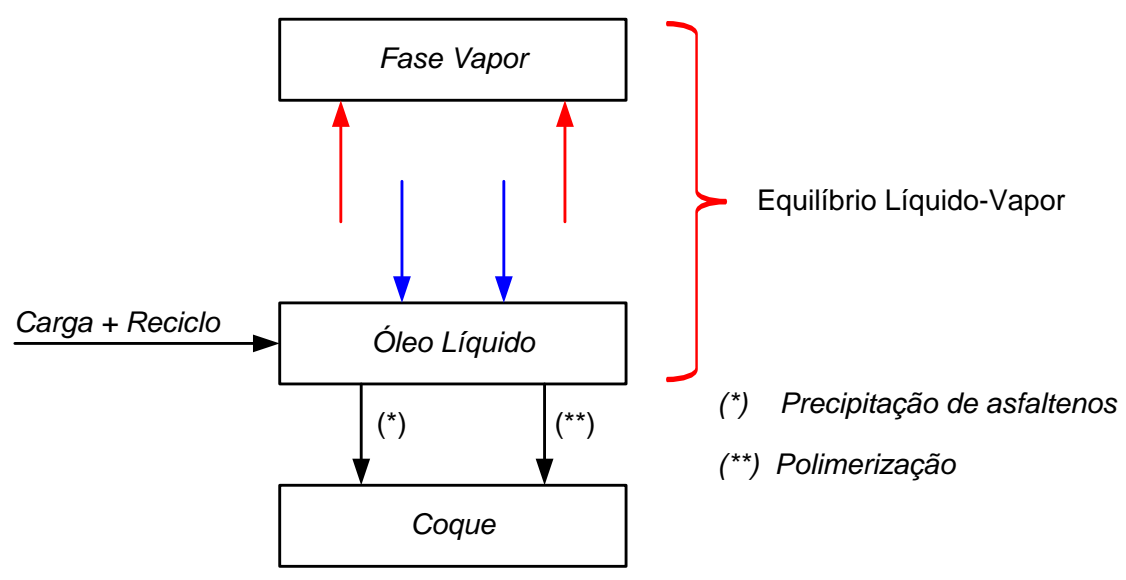

\subsection{Procedimento de cálculo}

A seguir, é apresentada uma descrição detalhada dos algoritmos propostos para caracterização do vapor de topo do reator de coque (item 6.2), balanços de massa e de energia no forno-reator (item 6.3) e no interior da serpentina (item 6.4).

\subsubsection{Caracterização das frações em pseudocomponentes}

6.6.2 Cálculos de equilíbrio líquido-vapor (ELV) de modo a caracterizar o vapor de topo (reciclo).

a) Mistura da carga caracterizada como pseudo-componentes com a corrente de gás combustível realizada a mistura com a corrente de gás combustível.

b) Determinação do ponto de orvalho da mistura no topo do reator de coque.

c) A composição do óleo do reciclo é determinada por um processo iterativo até que os balanços de massa e energia sejam satisfeitos, atendendo às restrições de ELV.

6.6.3 Cálculo dos balanços de massa e energia forno- reator 
a) Cálculo do balanço de massa no sistema forno-reator.

b) Determinação da entalpia do vapor de topo do reator de coque.

c) Determinação das perdas de calor do sistema forno-reator para o ambiente.

d) Determinação do calor absorvido pela corrente de óleo no interior da serpentina do forno.

e) Determinação do calor de reação de craqueamento térmico no sistema fornoreator de coque.

f) Determinação da conversão na saída do forno

Conhecida os valores da pressão e temperatura na saída do forno, determinase a conversão dos grupos, conforme Tabela 6.1, na saída forno de modo a atender o balanço de energia global e calor de reação do sistema forno-reator.

6.6.4 Cálculo de perfil de pressão e conversão no interior da serpentina do forno de coqueamento.

Para estimar a pressão no início da seção de reação no interior da serpentina, foi calculada a pressão nesse ponto com base no valor da pressão de entrada da serpentina conforme descrito a seguir:

a) Determinação da cinética das reações e estabelecer os cortes dos grupos (lumps), como mostrado na Tabela 6.1: gás, nafta, gasóleo leve, gasóleo pesado e resíduo. Os grupos são constituídos de diversos pseudocomponentes com características similares presente na corrente de vapor de saída do reator de coque, exceto os asfaltenos.

b) Determinação da temperatura de craqueamento térmico incipiente através da Figura 3.7 ou considera-se $427^{\circ} \mathrm{C}$, na seção de pré-aquecimento. 
c) Cálculo da perda de pressão

A sequência de cálculo da perda de pressão foi iniciada pela entrada da carga combinada no interior da serpentina, onde existe apenas fase líquida até a temperatura de início de craqueamento térmico incipiente. Nessa etapa, foi realizado o cálculo de perda de pressão tubo por tubo.

Foi considerada uma injeção de vapor d' água no interior da serpentina do forno de coqueamento. A partir desse ponto, foram consideradas duas fases, uma vapor e outra líquida.

Quando o ponto de craqueamento térmico incipiente é atingido, estimou-se o perfil de pressão no interior serpentina, localizada na seção de reação, com a finalidade de determinar as propriedades físicas de transportes.

Com base na condição de saída da serpentina do forno de coqueamento, foi realizado o cálculo da perda de pressão no sentido inverso até a entrada da serpentina.

A conversão de cada grupo foi determinada e, em seguida, calculou-se a perda de pressão carga e a fração vaporizada a partir do equilíbrio liquido-vapor.

d) Cálculo do perfil de temperatura e de conversão

A temperatura foi calculada por balanço de massa e energia absorvida pelo fluido no interior da serpentina.

O procedimento é sequencial, conforme mostrado na Figura 6.14.

e) O procedimento do item (i) é repetido até a entrada da serpentina. 
Figura 6.14 - Algoritmo usado na simulação do forno de coqueamento.

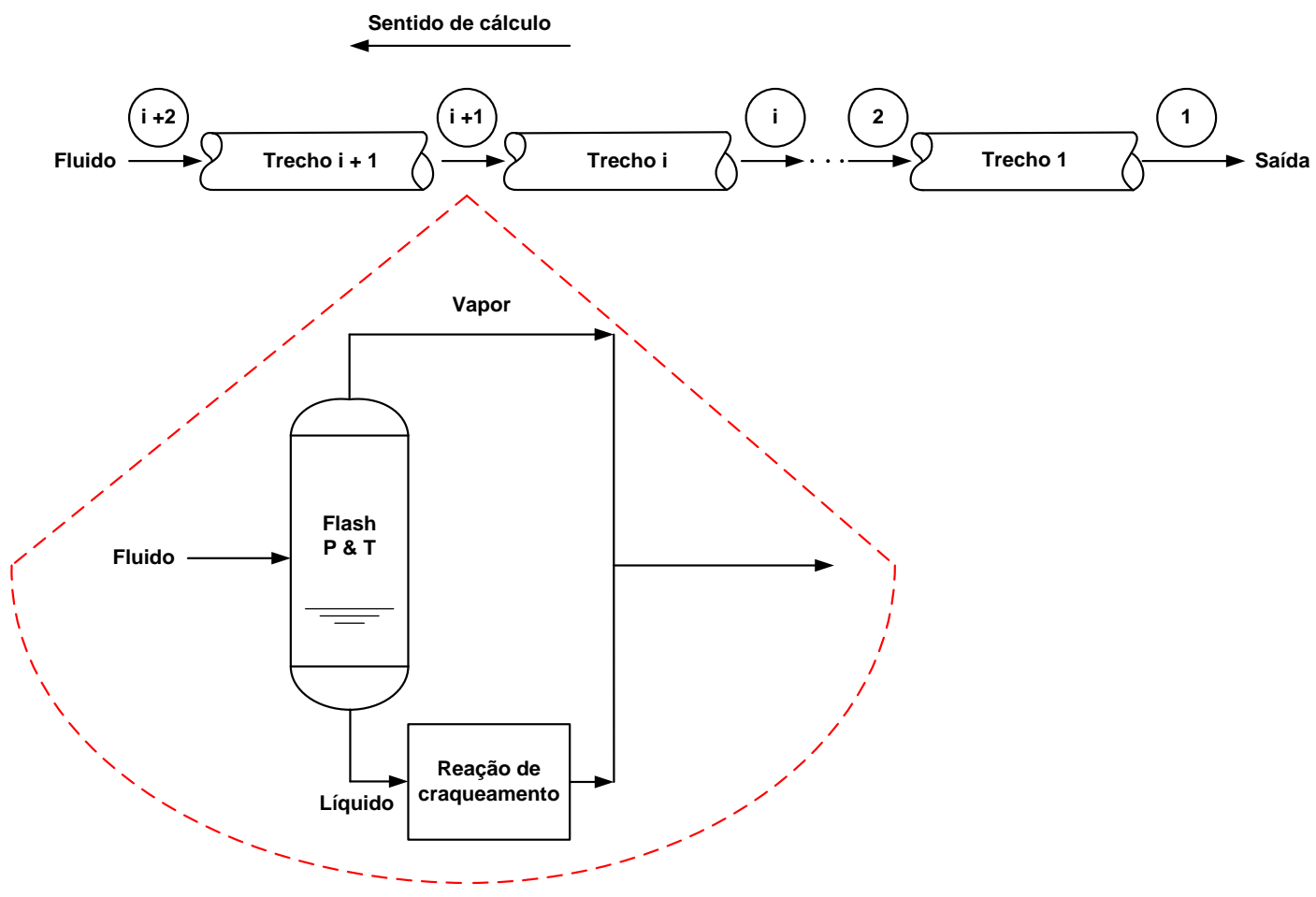

\subsection{Resultados e discussões}

\subsubsection{Determinação do vapor de topo do reator de coque}

A curva de destilação de ponto de ebulição verdadeira calculada para o vapor de saída do reator de coque é apresenta na Figura 6.15, enquanto a Figura 6.16 mostra a curva de destilação do reciclo. No cálculo, foram utilizados os valores de temperatura e de pressão no topo do reator de $445{ }^{\circ} \mathrm{C}$ e 3,76 bar abs., respectivamente.

\subsubsection{Forno de coqueamento}

A caracterização do óleo e a obtenção de algumas propriedades usadas na simulação do forno de coque foram obtidas através da caracterização do vapor de topo do reator de coque e o resíduo de vácuo, como mostrado, anteriormente, na Tabela 4.1, e da curva de destilação PEV da Figura 4.5. A partir da curva PEV foram 
divididos os cortes de interesse na modelagem cinética, sendo obtidos os valores de diversas propriedades para os grupos, os quais são apresentados na Tabela 6.6.

Figura 6.15 - Curva de destilação completa do vapor de topo do reator de coque.

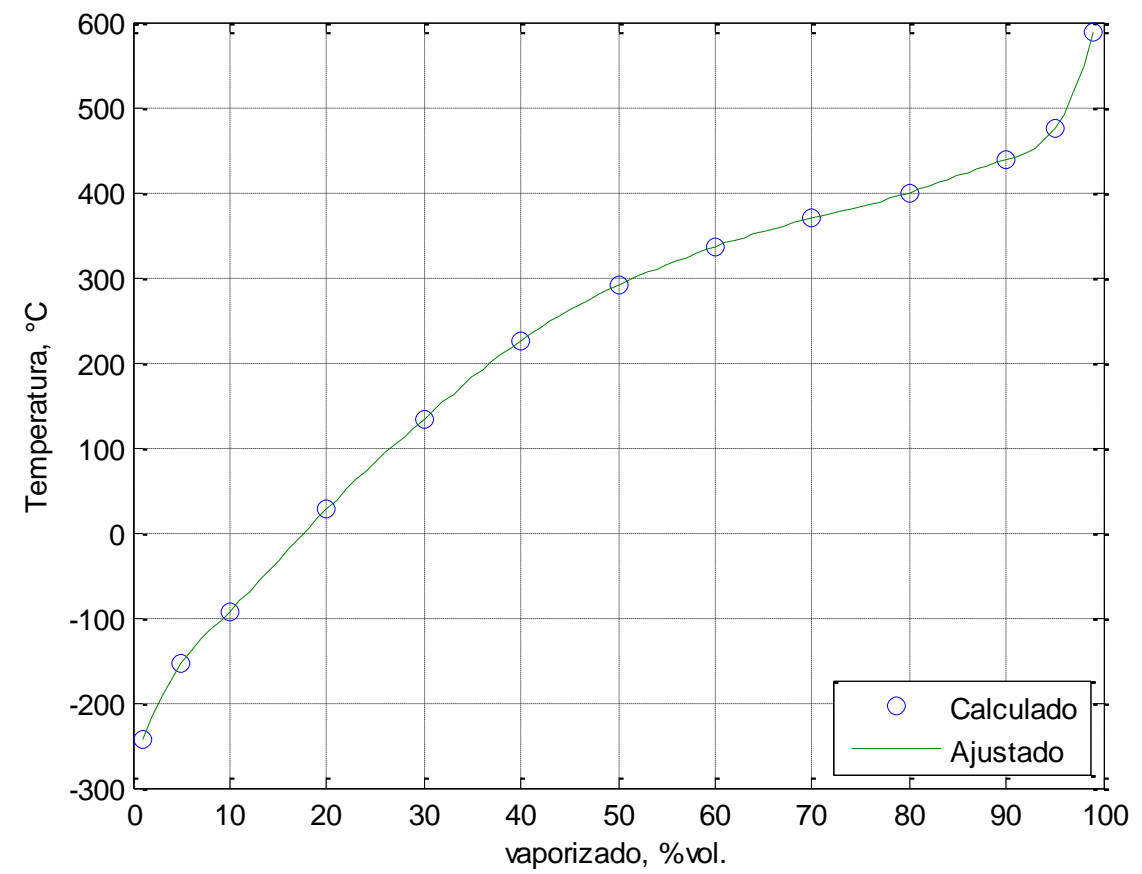

Figura 6.16 - Curva de destilação calculada completa do reciclo contido no vapor de topo do reator de coque.

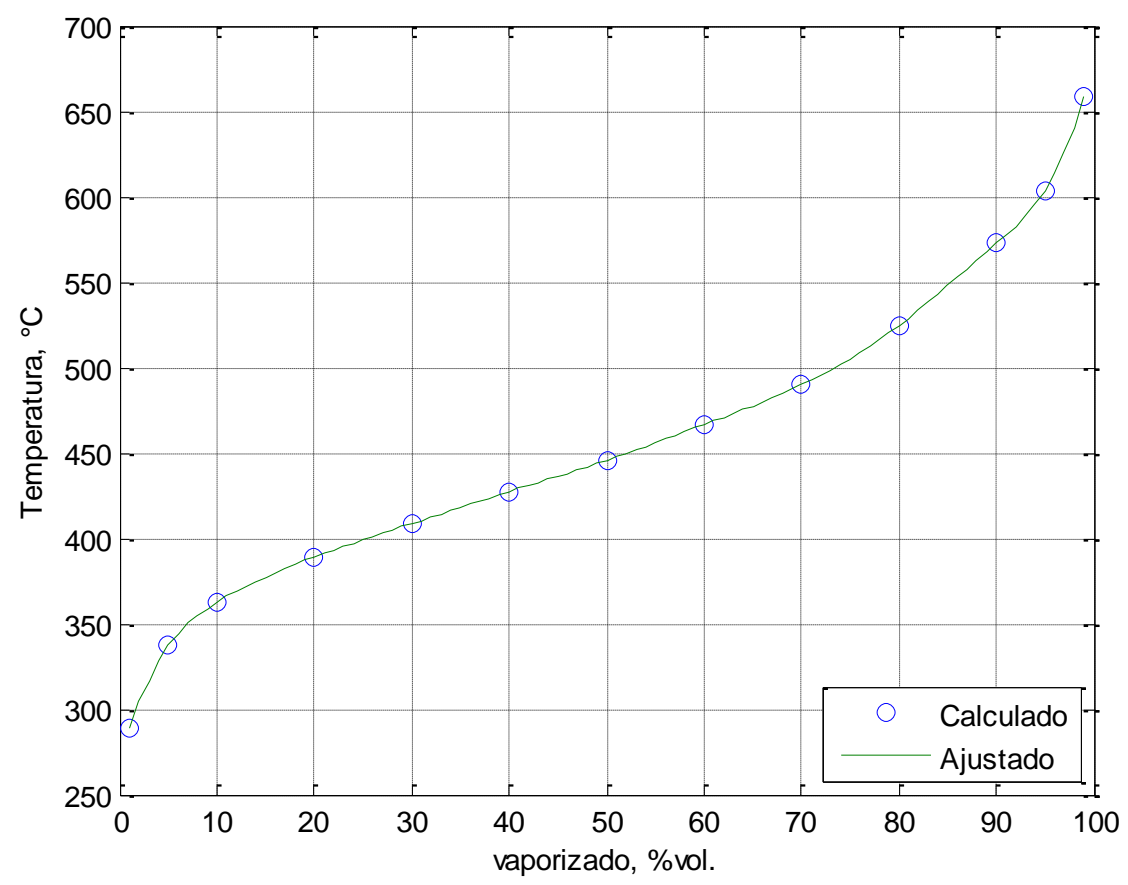


Tabela 6.6 - Composição de produto de saída do forno de coqueamento.

\begin{tabular}{lccc}
\hline Grupo & Faixa & ${ }^{\circ} \mathrm{API}$ & Vazão, kg/h \\
\hline Água & - & & 820,0 \\
Gás & $\mathrm{C}_{4}{ }^{-}$ & & 4632,8 \\
Nafta & $\mathrm{C}_{5}-204$ & 59,2 & 7229,8 \\
Gasóleo leve & $204-350$ & 36,2 & 16294,5 \\
Gasóleo pesado & $350-530$ & 21,3 & 12751,5 \\
Resíduo & $530^{+}$ & 7,2 & 85065,0 \\
\hline
\end{tabular}

$\mathrm{Na}$ Tabela 6.7, estão relacionados os principais parâmetros geométricos utilizados na simulação do forno de coqueamento.

Tabela 6.7 -Parâmetros geométricos utilizado na simulação.

\begin{tabular}{llc}
\hline Serpentina & Diâmetro externo & $101,6 \mathrm{~mm}$ \\
& Diâmetro interno & $85,4 \mathrm{~mm}$ \\
& Espessura do tubo & $8,1 \mathrm{~mm}$ \\
& Comprimento total & $12,20 \mathrm{~m}$ \\
& Distância centro-centro & $178 \mathrm{~mm}$ \\
& Número de tubos por passe & 70 \\
& Número de passes & 2 \\
\hline Câmera de combustão & Altura & $6,00 \mathrm{~m}$ \\
& Largura & $5,30 \mathrm{~m}$ \\
\hline
\end{tabular}

Com a finalidade de determinar o calor absorvido pela serpentina do forno, foi realizado o balanço de energia pelos métodos das perdas descrito no item 6.4.1.

$\mathrm{Na}$ Tabela 6.8, estão as informações utilizadas na simulação da serpentina do forno.

Tabela 6.8 - Informações do fluido no interior da serpentina.

\begin{tabular}{lll}
\hline Condição de entrada & Vazão de carga combinada & $130.000 \mathrm{~kg} / \mathrm{h}$ \\
& Injeção de vapor d' água & $820 \mathrm{~kg} / \mathrm{h}$ \\
& Pressão & $18,0 \mathrm{kgf} / \mathrm{cm}^{2}$ abs. \\
& Temperatura & $325^{\circ} \mathrm{C}$ \\
\hline Condição de saída & Pressão & $6,5 \mathrm{kgf} / \mathrm{cm}^{2}$ abs. \\
& Temperatura & $502^{\circ} \mathrm{C}$ \\
\hline
\end{tabular}


$\mathrm{Na}$ Figura 6.17, é apresentado o perfil de temperatura do fluido no interior da serpentina, obtido a partir da medição de temperatura no forno em operação e ajustado por regressão para os demais pontos desconhecidos.

Figura 6.17 - Perfil de temperatura ao longo da serpentina.

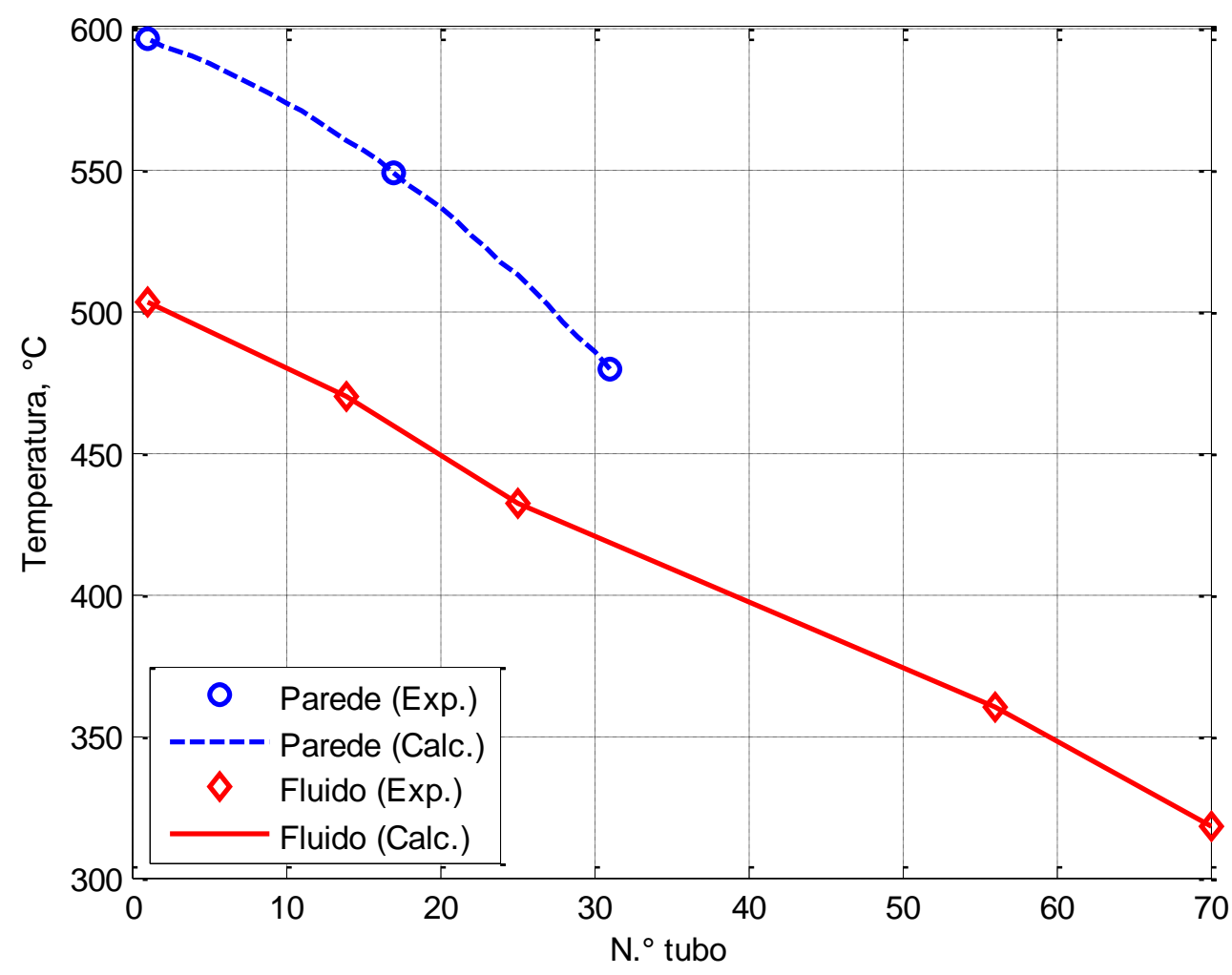

Foram utilizados os valores de temperatura de parede medido nos tubos $n .{ }^{\circ} 39,53 \mathrm{e}$ 70 para determinar a temperatura média de parede dos tubos da seção de radiação.

$\mathrm{Na}$ Figura 6.18, é apresentado o perfil da diferença de temperatura entre a temperatura de parede e a temperatura do fluido desde os tubos 39 até 70 , onde o comportamento é parabólico. 
Figura 6.18 - Perfil da diferença de temperatura entre a parede e o fluido.

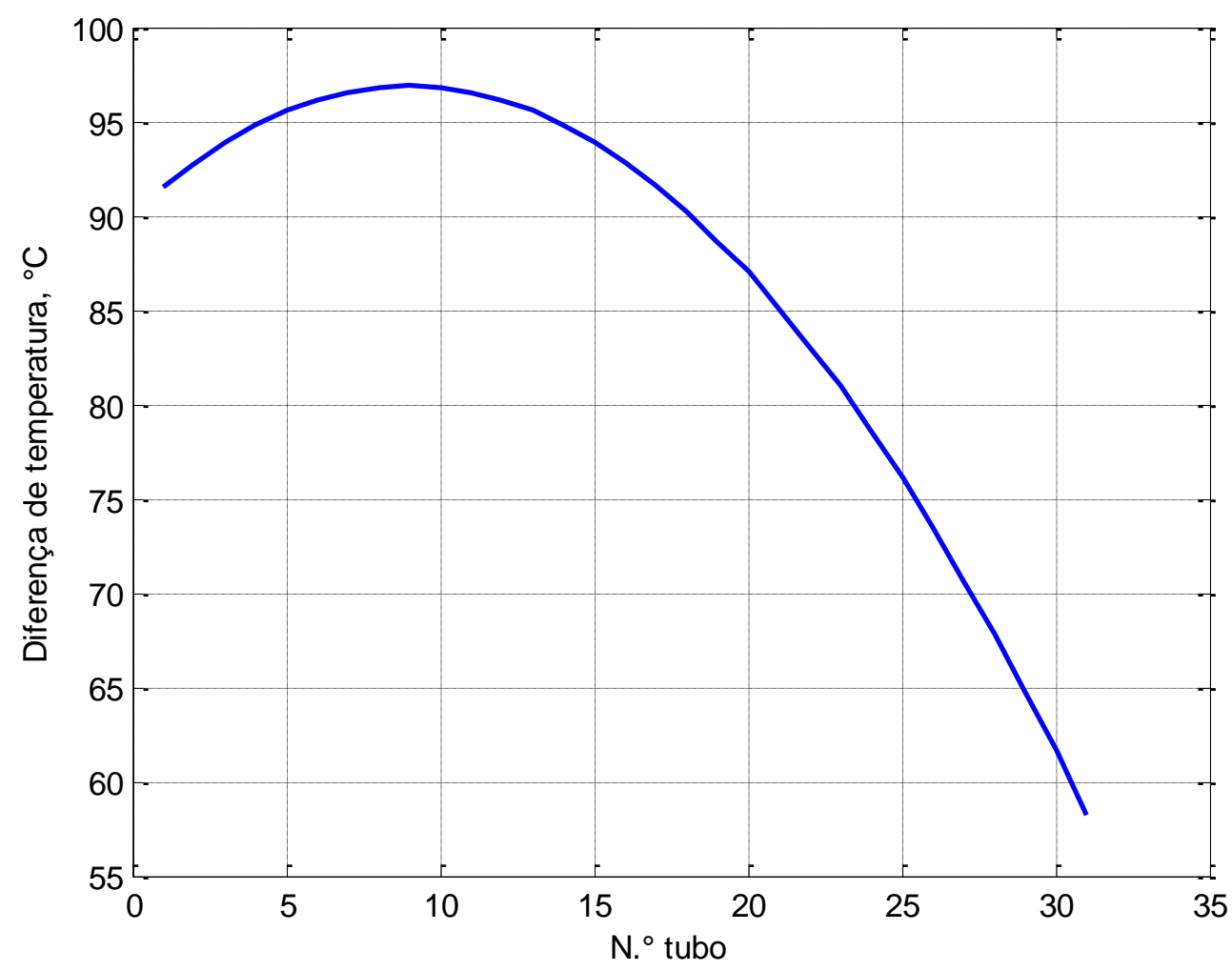

Como o perfil da diferença de temperatura apresentou um comportamento não linear, foi obtida a temperatura média de parede, com base na área do intervalo de tubos em análise. $\mathrm{O}$ valor obtido foi de $481,8^{\circ} \mathrm{C}$.

Na Tabela 6.9, estão as informações referentes à seção de convecção e de radiação do forno de coqueamento.

Tabela 6.9 - Informações sobre a seção de convecção e de radiação do forno.

\begin{tabular}{ccc}
\hline Item & Descrição & Valor \\
\hline Combustível & Vazão de gás combustível & $152,88 \mathrm{kgmol} / \mathrm{h}$ \\
& Excesso de $\mathrm{O}_{2}$ (base úmida) & $8,2 \% \mathrm{vol}$. \\
\hline & Temperatura na chaminé & $331^{\circ} \mathrm{C}$ \\
& Temperatura da zona radiação & $853^{\circ} \mathrm{C}$ \\
\hline
\end{tabular}

A estimativa do calor absorvido na seção de radiação foi de $18,74 \times 10^{6} \mathrm{kcal} / \mathrm{h}$, correspondendo a uma temperatura média da zona de radiação de $849,14{ }^{\circ} \mathrm{C}$. 
Com a finalidade de analisar o comportamento dos principais parâmetros de processo do forno: pressão, fração vaporizada e velocidade média do fluido, foram realizadas simulações do forno de coqueamento industrial, considerando os cinco grupos do modelo cinético. As Figuras 6.19 e 6.20 apresentam os resultados dos perfis de pressão, temperatura e fração vaporizada.

Figura 6.19 - Perfis de pressão e temperatura ao longo da serpentina.

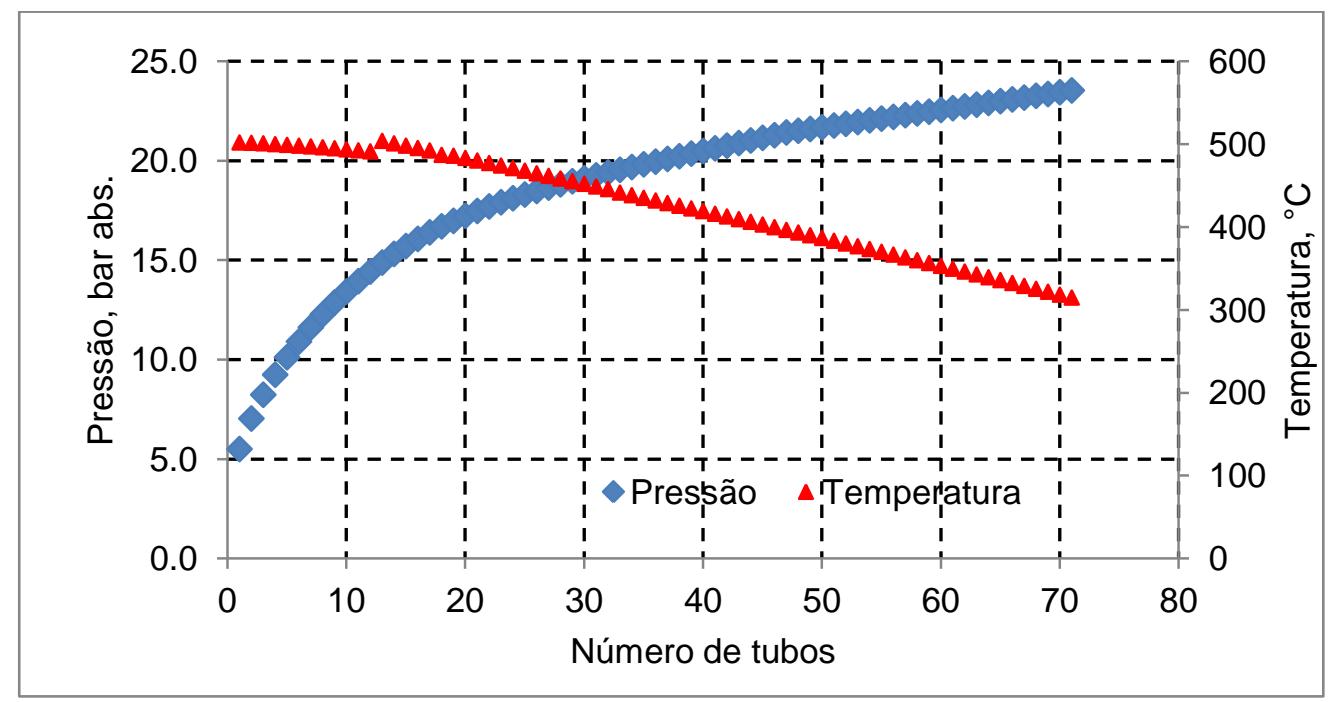

No início, o perfil de pressão do fluido ao longo da serpentina decresce linearmente devido o escoamento ser monofásico. A partir do tubo n. ${ }^{\circ} 24$, ocorre uma mudança no comportamento desse perfil.

A pressão calculada na entrada da serpentina do forno de coqueamento foi 23,53 bar abs. Enquanto o valor experimental médio entre os passes dos fornos era de 20,0 bar abs. No cálculo foi considerado uma espessura uniforme de coque no interior da serpentina de $3,0 \mathrm{~mm}$. Isto tem influência no resultado da perda de carga calculada de 3,53 bar.

De acordo com a Figura 6.20, observa-se a formação da fase vapor a partir do tubo n. ${ }^{\circ} 18$, chegando ao tubo de saída da serpentina com $50 \%$, em massa, vaporizado. A partir do tubo n. ${ }^{\circ} 18$ é iniciado o craqueamento térmico da carga combinada. A medida que a conversão avança, a velocidade média das fases aumenta ao longo da serpentina do forno. 
Figura 6.20 - Fração mássica vaporizada do fluido ao longo da serpentina.

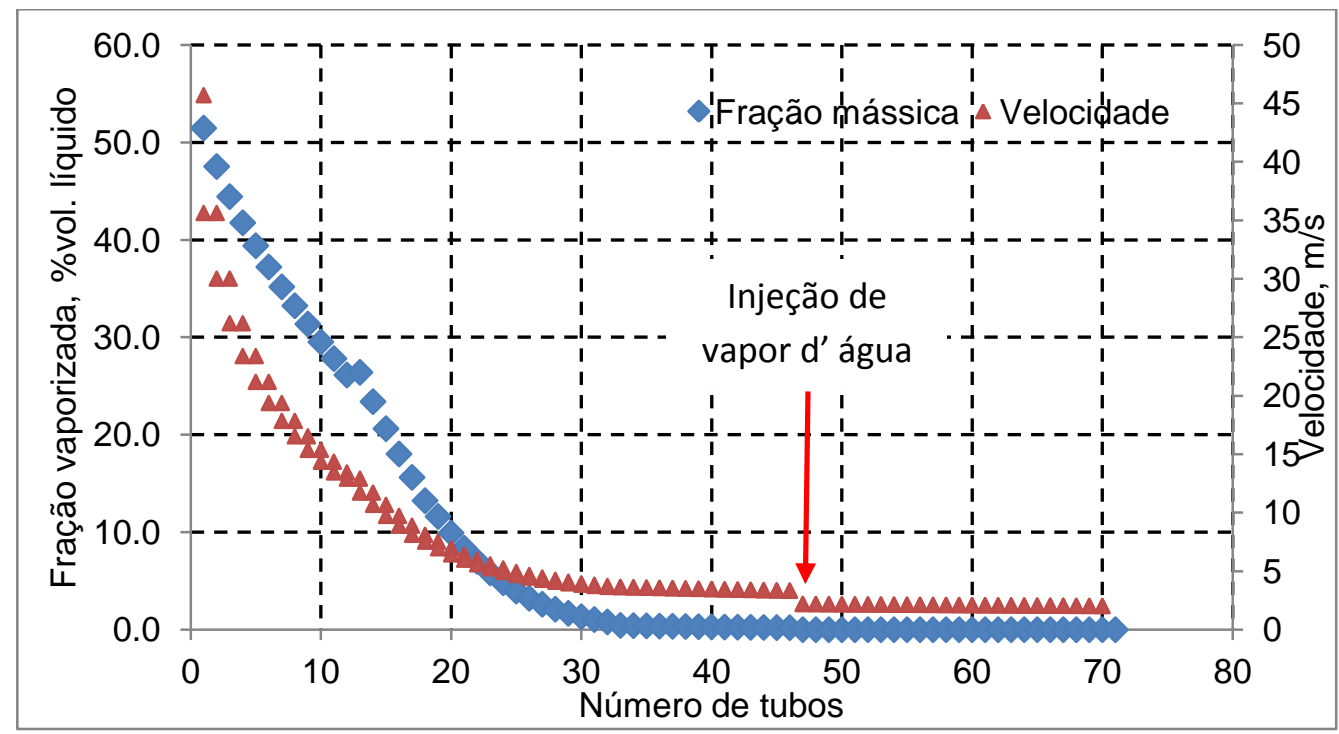

\subsubsection{Comparação de resultados}

a) Vapor de saída reator - cortes

A vazão do reciclo no fundo da seção de fundo da torre fracionadora foi de 16,25 $\mathrm{m}^{3} / \mathrm{h}$. Comparando com a faixa de corte citado na Tabela 6.10 , foi observada uma diferença de $12,67 \mathrm{~m}^{3} / \mathrm{h}$ que está compreendida na faixa de gasóleo pesado.

Tabela 6.10 - Produtos na saída do forno de coqueamento.

\begin{tabular}{lcccc}
\hline Grupo & Faixa & Vazão, $\mathrm{m}^{3} / \mathrm{h}$ & $\mathrm{PM}$ & $\rho, \mathrm{kg} / \mathrm{m}^{3}$ \\
\hline Água & - & 2,9936 & 18,01 & \\
Gás & $\mathrm{H}_{2}-\mathrm{C}_{2}{ }^{-}$ & 17,2819 & 18,13 & \\
GLP & $\mathrm{C}_{4}-\mathrm{C}_{3}$ & 4,8137 & 48,11 & 538,37 \\
Nafta & $\mathrm{C}_{5}-190$ & 15,1724 & 112,09 & 784,75 \\
Gasóleo leve & $190-350$ & 33,9255 & 209,28 & 872,05 \\
Gasóleo pesado & $350-530$ & 32,1918 & 370,97 & 948,29 \\
Reciclo & $530^{+}$ & 3,6813 & 668,49 & 1019,03 \\
\hline - Densidade à $60^{\circ} \mathrm{F}$. & & &
\end{tabular}

Na Tabela 6.11 são apresentados os valores de temperatura de orvalho do vapor de topo de reator de coque a pressão de 4,23 bar abs., aproximadamente. 
Tabela 6.11 - Comparação da temperatura de orvalho do vapor de topo do reator.

\begin{tabular}{ccc}
\hline \multirow{2}{*}{ Caso N. ${ }^{\circ}$} & \multicolumn{2}{c}{ Temperatura de orvalho, ${ }^{\circ} \mathrm{C}$} \\
\cline { 2 - 3 } & Experimental & Calculado \\
\hline 1 & 447,0 & 447,9 \\
2 & 441,0 & 441,4 \\
3 & 443,0 & 443,7 \\
\hline
\end{tabular}

Na Figura 6.21, é apresentada a curva de destilação do vapor de topo do reator para o caso $n .^{\circ} 01$, incluindo o reciclo obtido através do cálculo da temperatura do ponto de orvalho no topo do reator de coque.

Figura 6.21 - Curva de destilação de ponto de ebulição do vapor de topo do reator.

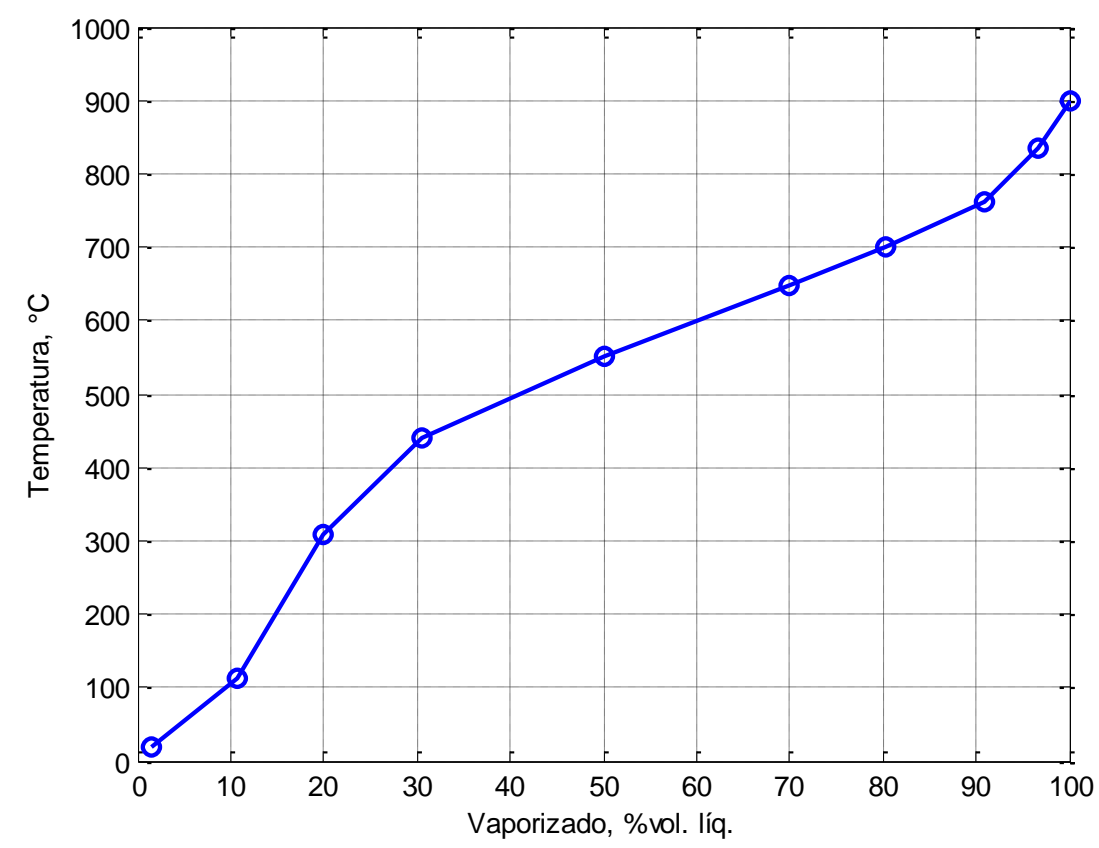

Com a finalidade de aferir se a determinação da curva de destilação de ponto de ebulição verdadeiro do vapor de topo do reator de coque, foi calculada a temperatura de orvalho sem o reciclo e comparado com a temperatura de vapor da chaminé da panela de gasóleo pesado da torre fracionadora (Figura 3.11). A temperatura de orvalho calculada sem o reciclo foi $375^{\circ} \mathrm{C}$ enquanto a temperatura experimental dos vapores da chaminé da panela era $385^{\circ} \mathrm{C}$. Esta diferença foi considerada aceitável, pois esta temperatura é bastante sensível a presença de água injetada no processo, sendo uma possível causa de explicação da diferença observada. 


\section{CONCLUSÕES}

\subsection{Caracterização de resíduo de vácuo e produtos}

Os resultados obtidos por ionização a laser assistida por matriz (MALDI) para os asfaltenos foram diferentes dos resultados obtidos por outros métodos (SPEIGHT, 1999). O valor de peso molecular médio determinado através da técnica MALDI foi inferior por fator de 10. Isso pode ser explicado devido ao fato de que medidas de peso molecular feitos através de técnicas clássicas uma concentração de asfaltenos necessária para a realização das medidas é muito elevada isso favorece a agregação de moléculas e consequentemente, é determinado o peso molecular de uma associação de moléculas. Enquanto na técnica MALDI TOF é utilizada uma concentração baixa que deixam as moléculas de asfaltenos livres de agregação, sendo determinado peso molecular de uma molécula.

A interconversão dos resultados de razão massa-carga $(\mathrm{m} / \mathrm{z})$ e abundância das espécies de íons obtida a partir do MALDI TOF permite determinar curvas de distribuição $\mathrm{m} / \mathrm{z}$. Quando a amostra era constituída por duas fontes de resíduos de vácuo com diferentes valores de viscosidade, houve o aparecimento de dois envelopes no espectro de massa.

Os dados experimentais de HGl (Hardgrove Grindability Index) mostraram uma relação direta com o teor de matéria volátil do coque verde. No coque calcinado, a tendência de sua densidade aparente (VBD - Vibrated Bulk Density) é aumentar com o decréscimo do valor de HGI do coque verde.

Conforme a equação (4.4), apenas os Aromáticos, as Resinas e os Asfaltenos têm contribuição significativa o resultado do resíduo de carbono Conradson, sendo a maior contribuição é dos asfaltenos. 


\subsection{Reconciliação de dados}

Neste trabalho, foi apresentada uma uma metodologia detalhada para a implementação do processo de reconciliação de dados em uma unidade de coqueamento retardado. No entanto, pode ser aplicada a outros processos de refinaria também.

Como variações de vazões são inerentes ao processo ao longo do ciclo (correntes de carga e de produtos), foi realizada a integração dos valores medidos considerando o mesmo intervalo de tempo do ciclo. Além disso, os erros grosseiros foram eliminados antes de reconciliação de dados para o sistema de estado estacionário, utilizando um procedimento de correção da vazão. Assim, a reconciliação de dados foi aplicado no sistema de estado estacionário com apenas erros aleatórios envolvidos.

O procedimento de correção da vazão proposto mostrou-se vantajoso, uma vez que os ajustes nas vazões medidas forma mínima durante a etapa de reconciliação de dados.

Embora, os teores dos elementos, tais como: enxofre e nitrogênio contidos nas frações de petróleo estão sujeitos a grandes desvios, a reconciliação de dados foi utilizada para satisfazer o balanço de massa elementar. Os resultados indicaram um desvio de 30 a $50 \%$ para os teores de enxofre e 25 a $50 \%$ para os teores de nitrogênio.

Finalmente, uma função objetivo de mínimos quadrados de peso clássico foi usado para reconciliar os dados de vazão medidos de unidade de coqueamento retardado. A metodologia proposta mostrou ser eficaz para se obter dados mais precisos das vazões das correntes de processo, bem como: na determinação dos teores de enxofre e de nitrogênio. 


\subsection{Modelagem matemática}

A estratégia de determinar as características do reciclo através de cálculo ponto de orvalho no topo do reator, juntamente com o balanço de massa e aferindo a temperatura de operação do reator, apresentou uma curva de destilação de ponto de ebulição verdadeiro bastante consistente, o resultado mostrou que a corrente de reciclo é constituída de $80 \%$ da faixa de corte do gasóleo pesado.

Através de balanço de massa, de energia, de cálculo de equilíbrio líquido-vapor, foram determinados os perfis de pressão e fração vaporizada no interior da serpentina. A Tabela 6.4 mostrou uma conversão de nafta na saída do forno de $5,74 \%$ massa.

As Figuras 6.19 e 6.20 mostram os perfis de pressão e de velocidade do produto ao longo do interior da serpentina. Foi observado um aumento da velocidade ao longo da serpentina devido craqueamento térmico e vaporização de produto.

Este trabalho possibilitou compreender o processo de coqueamento retardado, avaliando as características das cargas residuais e as variáveis operacionais na qualidade do coque verde e no desempenho da unidade. Dentre eles, o entendimento da influência do resíduo de carbono Conradson (CCR) e do teor de asfalteno mínimo no atendimento da especificação do coque verde grau anodo, do craqueamento térmico e variáveis de processo no desempenho do forno de coqueamento.

A partir desse trabalho, foram implementados mudanças no processo de coqueamento da Refinaria Presidente Bernardes que proporcionou ganho econômico expressivo. 


\section{SUGESTÕES DE TRABALHO FUTUROS}

Perspectivas de trabalhos futuros devem abordar:

- Em função da complexidade do sistema reacional do processo de coqueamento retardado, foram estudados os modelos de craqueamento térmico empíricos e por agrupamentos. Uma proposta é desenvolver modelo composicional para o processo, com uma abordagem molecular. (KLEIN, 2006; TIAN, 2012)

- A evolução das reações químicas de craqueamento térmico da fração pesada de petróleo atinge um ponto de máxima estabilidade de mistura $\left(420\right.$ a $450{ }^{\circ} \mathrm{C}$, aproximadamente). A partir desse ponto ocorre a precipitação de uma segunda fase líquida rica em asfaltenos (HUS, 1981; SPEIGHT, 1998). Uma proposta seria estudar equações termodinâmicas que possam predizer o comportamento de equilíbrio líquido-líquido-vapor desde o forno de coqueamento até o reator de coque.

- O cálculo do calor de decomposição é bastante sensível ao valor do calor de combustão e dos rendimentos dos produtos. Logo, a introdução de pequenos erros no calor de combustão ou rendimentos de produtos provoca um erro significativo no valor do calor de decomposição. Portanto, aplicação dessa metodologia na determinação do calor de decomposição de frações pesadas tem baixa confiabilidade. Sugaya (2001) propôs um calor de reação de 800 $\mathrm{kJ} / \mathrm{kg}$ de produtos com ponto de ebulição abaixo de $204{ }^{\circ} \mathrm{C}$ (ASTM D-86) no cálculo do forno de coqueamento. Uma próxima etapa no estudo seria elaborar uma metodologia para determinar o calor de decomposição para frações pesadas de petróleo. 


\section{REFERÊNCIAS}

. Produção de alumínio primário fica estagnada em 2010, diz Abal. Valor Online. 13/jan/2011, economia. Disponível em: <http://g1.globo.com/economia/ noticia/2011/01/producao-de-aluminio-primario-fica-estagnada-em-2010.html>. Acesso em: 22/11/2011.

ABU-EL-ZEET, Z. H.; BECERRA, V. M.; ROBERTS, P. D. Combined bias and outlier identification in dynamic data reconciliation. Computer \& Chemical Engineering, v. 26, n. 6, p. $921-935,2002$.

AGORRETA, E. et al. Simulation model increases visbreaker conversion. PTQ, Quarterly 1, p. $29-35,2011$.

AGUILAR, R. A.; ANCHEYTA, J.; TREJO, F., Simulation and planning of a petroleum refinery based on carbon rejection processes. Fuel, v. 100, p. $80-90,2012$.

AKBAR, M.; GEELEN, H., Visbreaking uses soaker drum. Hydrocarbon Processing, v. 60, n. 5, p. 81 - 85, May 1981.

AKBARZADEH, K. et. al. A generalized regular solution model for asphaltene precipitation from $n$-alkane diluted heavy oils and bitumens. Fluid Phase Equilibria, v. 232, p. $159-170,2005$.

AKPABIO, E. J.; OBOT, O. W., Optimizing utilization of petroleum coke in Nigerian metallurgical industry. Journal of Minerals \& Materials Characterization \& Engineering, v. 10, n. 3, p. $267-278,2008$.

AL-HAJ IBRAHIM; H., AL-QASSIMI, M. M. Matlab program computes thermal efficiency of fired-heater. Polytech. Chem. Eng., v 52, n. 2, p. 61 - 69, 2008.

AL-HAJ IBRAHIM; H., AL-QASSIMI, M. M. Calculation of radiant section temperatures in fired process heaters. Chemical Engineering and Science, v. 1, n. 4, p. $55-61,2013$. 
ALHUMAIDAN, F. et al. Studies on thermal cracking behavior residues in Eureka process. Fuel, v. 109, p. $635-646,2013$.

ALLAN, D. E et al. Visbreaking gains renewed interest. Chemical Engineering Process, p. $85-89$, January 1983.

ALVES, R. M. B.; NASCIMENTO, C. A. O. Gross errors detection of industrial data by neural network and cluster techniques. Brazilian Journal of Chemical Engineering, v. 19, n. 4, p. $483-489,2002$.

ALVES, R. M. B.; NASCIMENTO, C. A. O. Analysis and detection of outliers and systematic errors industrial plant. Chemical Engineering Communications, v. 104, n. 3, p. 382 - 397, 2007.

API - AMERICAN PETROLEUM INSTITUTE. STD 530. Calculation of heater tube thickness in petroleum refineries, $5^{\text {th }}$ ed. Washington, D.C., USA, January 2003.

ASTM - AMERICAN SOCIETY FOR TESTING AND MATERIALS. D-86-96. Standard Test Method for Distillation of Petroleum Products at Atmospheric Pressure. West Conshohocken, PA, USA. 1996.

ASTM - AMERICAN SOCIETY FOR TESTING AND MATERIALS. ASTM D-189-06. Standard Test Method for Conradson Residue of Petroleum Products. West Conshohocken, PA, USA. 2008.

ASTM - AMERICAN SOCIETY FOR TESTING AND MATERIALS. ASTM D-409-08. Standard Test Method for Grindability of Coal by the Hardgrove-Machine Method. West Conshohocken, PA, USA. 2008.

ASTM - AMERICAN SOCIETY FOR TESTING AND MATERIALS. ASTM D-2887-97. Standard Test Method for Boiling Range Distribution of Petroleum Fractions by Gas Chromatography. West Conshohocken, PA, USA. 1997. 
ASTM - AMERICAN SOCIETY FOR TESTING AND MATERIALS. ASTM D-3175-11. Standard Test Method for Volatile Matter in the Analysis Sample of Coal and Coke. West Conshohocken, PA, USA. 2007.

ASTM - AMERICAN SOCIETY FOR TESTING AND MATERIALS. ASTM D-6560-00. Standard Test Method for Determination of Asphaltenes (Heptane Insolubles) in Crude Petroleum and Petroleum Products. West Conshohocken, PA, USA. 2007.

ASTM - AMERICAN SOCIETY FOR TESTING AND MATERIALS. ASTM D-7169. Standard Test Method for Boiling Point Distribution of Samples with Residues Such as Crude Oils and Atmospheric and Vacuum Residues by High Temperature Gas Chromatography. West Conshohocken, PA, USA. 2009.

BACHA, J. D., GORMANO, N. A. Petroleum coke VCM: characterization by thermogravimetric analysis, p. $515-516,1987$

BAKSHI, A. S.; LUTZ, I. H. Adding hydrogen donor to visbreaking improves distillate yields. Oil \& Gas Journal, 13, p. $84-87$, July. 1987.

BARLETA, T. Why vacuum unit fired heaters coke, PTQ, Autumn, p. $123-127$, 2002.

BAUKAL Jr, C. E. The John Zink Combustion Handbook, Boca Raton. Florida: CRC Press, 2001. $750 \mathrm{p}$.

BEGGS, H. D.; BRILL, J. P. A study of two-phase flow in inclined pipes. Journal of Petroleum Technology, 17, p. 607 - 617, May. 1973.

BOASHI, W. et. al., Experimental investigation of secondary reactions of intermediates in delayed coking. Research on Chemical Intermediates. v. 38, 2012, p. $2295-2307$. 
BODUSZYNSKI, M. M. Ch. 7, ref. 4. In: BUNGER, J. W. Li (Eds.), "Chemistry of Asphaltenes," American Chemical Society, Washington D.C., 1984.

BOZZANO, G.; DENTE, M. A mechanistic approach to delayed coking modeling. In: EUROPEAN SYMPOSIUM ON COMPUTER-AIDED PROCESS ENGINEERING $15,38^{\text {th }}$ EUROPEAN SYMPOSIUM OF THE WORKING PARTY ON COMPUTER AIDED PROCESS ENGINEERING. Anais London: Elsevier, 2005, p. 529 - 534.

BRASIL, N. I. et al., Processo de Refino e Esquema de Refino. In: Processamento de Petróleo e Gás: Petróleo e Seus Derivados, Processamento Primário, Processo de Refino, Petroquímica e Meio Ambiente. 2. Ed. Rio de Janeiro: LTC, 2014. P. $48-63$.

CARBONELL, M. M.; GUIRARDELLO, R. Modelling of slurry bubble column reactor applied to the hydroconversion of heavy oils. Chemical Engineering Science, v. 52, n. 21 - 22, p. 4179 - 4185. 1997.

CASTELLANOS, J. et al. Kinetic model predicts visbreaker yields. Oil \& Gas Journal, v. 89, n. 11, p. 76 - 82, March, 1991.

CASTIGLIONI, B. P., How to Predict Coker Yield. Hydrocarbon Processing, v. 62, n. 9 , p. 77 - 79, September. 1983.

CHEN, J.; ROMAGNOLI, J. A. a strategy for simultaneous dynamic data reconciliation and outlier detection. Computer \& Chemical Engineering, v. 22 , n. 4 - 5, p. $559-562,1998$.

CHEN, K. et al., Study of the thermal performance and interaction of petroleum residue fractions during the coking process. Energy \& Fuels, v. 26, p. $6343-6351$, 2012.

CHOUDHARY, T. V., MEIER, P. F. Characterization of heavy petroleum feedstocks. Fuel Processing Technology, v. 89, p. $697-703,2008$. 
CHURCHILL, S. W. Friction-factor equation spans all fluid-flow regimes. Chemical Engineering, p. 91-82, November 7, 1977.

COLNAGO, L. A.; ALMEIDA, R. C.; VALENTE, A. P. Espectrometria de Massa e RMN Multidimensional e Multinuclear: Revolução no Estudo de Macromoléculas Biológicas. Química Nova na Escola, n. 16, p. 9 - 14, novembro 2002.

CORBETT, L. W. Densimetric method for characterizing asphalt. Analytical Chemistry, v. 36, n. 10, p. 1967 -1971, September 1964.

CROWE, C. M.; GARVCIA CAMPOS, Y. A.; HRYMAK, A. Reconciliation of process flow rates by matrix projection - part I: linear case, AIChE Journal, v. 29, n. 6, p. 881 - 888, November 1983.

DeBIASE, R. et al. Coking process reflects trends innovations. Oil \& Gas Journal, 19, p. 81 - 88, April 1982.

Del BIANCO et al. Thermal cracking of petroleum residues. 1. Kinetic analysis of the reaction, FUEL, V. 72, p. 75 - 80, 1993.

DENCHFIELD, T. D., Rapid calculator solutions ASTM/TBP: other probability plot problems. Oil \& Gas Journal, 79, pp. 179 - 184, April 27, 1981.

DERAKHSHESH, M. et. al., Effect of Asphaltene Stability on Fouling at Delayed Coking Process Furnace Conditions. Energy \& Fuels, p. 1856 - 1864, v. 27, February, 2013.

EDWARDS, L. The history and future challenges of calcined petroleum coke production and use in aluminum smelting. Journal of the Minerals, Metals \& Materials Society (JOM), v. 67, n. 2, p. $308-321,2015$.

ELLIOTT, J. D. Optimize coker operations. Hydrocarbon Processing, p. 85 - 90, September 2003. 
ELLIOT, J. D. Impact of feed properties and operating parameters on delayed coker petcoke quality, ERTC 2008 Coking and Gasification Conference. Disponível em: $<$ http://www.fwc.com/publications/tech papers/files/PetcokeQuality2008ERTCC\%26GA-4.pdf> Acesso em 22/11/2010.

ELLIOTT, J. D. Managing shot coke: design \& operations. Disponível em: $<$ http://www.fwc.com/publications/tech papers/files/ManagingShotCoke-Design\%26 OperationA-4Rev1.pdf>. Acesso em: 22/11/2010.

ELLIS, P. J.; PAUL, C. A. Tutorial: delayed coking fundamentals. AIChE 1998 Spring National Meeting, International Conference on Refinery Processes Topical Conference Preprints, Session 29, Paper 29a, 1998, New Orleans, p. 151 - 169.

ELLIS, P. J.; PAUL, C. A. Tutorial: petroleum coke calcining and uses of calcined petroleum coke, AIChE 2000 Spring National Meeting, $3^{\text {rd }}$ International Conference on Refining Process, Session T9005, 2000, Atlanta, p. $1-30$.

ELLIS, P. J.; HARDIN, E. E. How petroleum delayed coke forms in a drum. Light Metals, p. $509-515,1993$.

FAEGH, A. A.; COLLINS, J. Coke drum monitoring essentials. Hydrocarbon Engineering, February, 2010.

GARY, J. H.; HANDWERK, G. E.; KAISER, M. J. Coking and thermal process In: Petroleum refining: technology and economics, $5^{\text {th }}$ ed. New York: CRC Press, 2007. p. 97 - 120.

GOMIDE, R. Processo de combustão In: Estequiometria Industrial, $3 .^{a}$ edição, São Paulo: [s.n.], 1984. p. $211-265$.

GRAY, M. R. Consistency of asphaltene chemical structures with pyrolysis and coking behavior. Energy \& Fuels, v. 17, p. 1566 - 1569, 2003. 
GRAY, M. R. Upgrading oilsands bitumen and heavy oil. Edmonton, Ca: The University of Alberta Press, 2015.

GUO, A., ZHANG, X., WANG, Z. Simulated delayed coking characteristics of petroleum residues and fractions by thermogravimetry. Fuel Processing Technology, v. 89, p. $643-650,2008$.

CUO, A. et. al., Hydrogen transfer and coking propensity of petroleum residues under thermal processing. Energy \& Fuels, v. 24, p. 3093 - 3100, 2010.

GUO, A. et. al, Investigation on shot-coke-forming propensity and controlling of coke morphology during heavy oil coking. Fuel Processing Technology, v. 104, p. $332-$ 342, 2012.

HECK, S. B. Jr. Design techniques for delayed coker illustrated. Oil \& Gas Journal, 24, July, 1972.

HeRnándeZ, H. J. P.; HuRTAdo, A. C.; AGRedA, E. F. P., Morphological classification of coke formed from the castilla and jazmín crude oils. Ciencia, Tecnologia y Futuro, v. 3, n. 4, 2008, p. $169-183$.

$\mathrm{HON}, \mathrm{K}$. et al. Improving the precision and productivity of green coke volatile matter analysis, Lights Metals, p. 1267 - 1272, 2012.

HUS, M. Visbreaking process has strong revival. Oil \& Gas Journal, 13, p. 109-120, April 1981.

HSU, C. S.; ROBINSON, P. R. Practical advances in petroleum processing, In: , $1^{\text {st }}$ Edition, Springer science and business media, USA, v. 1, 2006, p. 23.

JAKOB, R. R. Coke quality and how to make it. Hydrocarbon Processing, p. $132-$ 136, September, 1971. 
JANSSEN, H. R.; LEAMAN, G. L. Improved coking design can up liquid yields. Oil \& Gas Journal, v. 25, p. 79-83, June, 1984.

JEWELL, D. M. et al. Ion exchange, coordination, and adsorption chromatographic separation of heavy end petroleum distillates. Analytical Chemistry, v. 44, n. 8 , 1972.

JOSHI, N. R. (1979). Relative grindability of bituminous coals on volume basis. Fuel, $58,477-478,1979$.

KATARIA, K. L. et al. Kinetic studies of low severity visbreaking. Industrial \& Engineering Chemistry Research, v. 43, p. 1373-387, 2004.

KERN, D. Q.; Seaton, R. E. A Theoretical Analysis of Thermal Surface Fouling. British Chem. Eng., 4, p. 258, 1959.

KERN, D. Q., Processos de transmissão de calor, Tradução: Luiz, A. M. Guanabara Dois Editora, 1982. Capítulo 19: Cálculo para fornos. Dwyer, J. B.

KERN, R., How to size processing piping for two-phase flow. Hydrocarbon Processing, v. 48, n. 10, p. 105 - 116, October, 1969.

KIM, I. W. et al. Robust data reconciliation and gross error detection: the modified MIMT using NLP. Computers \& Chemical Engineering, v. 21, n. 7, p. $775-782$, 1997.

KLEIN, M. T. et al. Molecular Modeling in Heavy Hydrocarbon Conversions, New York: Taylor \& Francis, 2006.

KUO, C. J. Effects of crude types on visbreaker conversion. Oil \& Gas Journal, 24, p. $100-102$, September 1984.

KUIKARNI, R. P. Modeling of multiphase reactors: visbreaking. 2005. $\mathrm{Ph}$.

D. Thesis, University of Mumbai, Mumbai, India, 2005. 
LEE, J. M. et al., Characterization of green and calcined coke properties used for aluminium anode-grade carbon. In $217^{\text {th }}$ ACS National Meeting, Dallas, Reprints of Simposia, Division of Fuel Chemistry, v 43, 1998.

LEÓN, A. Y.; PARRA, M. GROSSO, J. L. Estimation of critical properties of typically Colombian vacuum residue SARA fractions, Ciencia, Tecnologia y Futuro, v. 3, n. 4, p. $129-142,2008$.

LIEBERMAN, N. P., Delayed Coking Process, In: .Troubleshooting processing operations, $3^{\text {rd }}$ Edition, Tulsa: PennWell Books, 1991, p. $73-89$.

LEIBMAN, M. J.; EDGAR, T. J.; LASDON, L. S. Efficient data reconciliation and estimation for dynamics process using nonlinear programming techniques, Computers \& chemical engineering, v. 16, .n. 10 -11, p. 963-986, 1992.

LOBO, W. E.; EVANS, J. E. Heat transfer in radiant section of petroleum heaters. Transactions of the American Institute of Chemical Engineers. v. 35, p. $748-$ 778, 1939.

MAHDAOURI, F. et al., Effect of the progressive precipitation of petroleum asphaltenes on the Re-Os radioisotope system. Chemical Geology, v. 358, p. $90-$ 100, 2013.

MAPLES, R. E. Petroleum Refinery Process Economics. $2^{\text {nd }}$ ed. Tulsa, Oklahoma: PennWell Company. 2000. 371 p.

MARTINS, N. Manual de Medição de Vazão através de Placas de Orifício, Bocais e Venturi. Rio de Janeiro, RJ: Interciência, 1998.

MATEUS, F. A. D. Desenvolvimento de modelo computacional para craqueamento térmico. 2008. 138p . Dissertação (Mestrado) Universidade Estadual de Campinas, Campinas. 2008. 
McKETTA, J. J. Petroleum processing handbook. New York. Marcel Dekker, 1992.

MEKLER, L. A.; FAIRALL, R. S. Evaluation of radiant heat absorption rates in tubular heaters. Petroleum Refiner, v. 38, n. 6, p. 169, June 1959.

MITTAL, S. et al., Modelling and simulation of visbreaker. In: Proceedings of Third International Petroleum Conference and Exploration, PETROTECH-99, New Delhi, India, p. 349, 1999.

MONTGOMERY, R. L. Alternate Datum States for Enthalpies of Petroleum Fractions. In: EDMISTER, W. C. Applied Hydrocarbon Thermodynamics. 2. ${ }^{\text {nd }}$ Edition. Houston: Gulf Publishing Company, 1988. v. 2. p. $230-236$.

MORAES, M. C. et. al., Espectrometria de Massa com lonização por Electrospray Aplicada ao Estudo de Espécie Inorgânicas e Organometálicas. Química Nova na Escola, São Paulo, v. 26, n. 4, p. 556 - 553, jul./ago. 2003.

MOTAGHI, M.; SHREE, K.; KRISHNAMURTHY, S. Anode-grade coke from traditional crudes, PTQ, Quarterly 2, p. 15 - 18, 2010.

NELSON, W. L. Thermal cracking and decomposition process. In: Petroleum Refinery Engineering. $4^{\text {th }}$ Ed. New York: McGraw-Hill Book, 1958. p. $626-693$.

NOEL, F. Alternative to the Conradson Carbon Residue. Fuel, v. 63, p. 931 - 934, July, 1984.

QUINTERO, L. C. N. Fracionamento e análise de asfaltenos extraídos de petróleos brasileiros. 2009. P. 186, Tese - Universidade Federal do Rio de Janeiro, Rio de Janeiro, 2009.

PARKASH, S. Residuum Processing In: Refining Process Handbook. New York: Gulf Professional Publishing, 2003. p. 176 - 209. 
PERRUCHOUD, R. C., MEIER, M. W., FISCHER, W. K., Coke characteristics from the refiners to the smelters. R \& D Carbon Ltd, Switzerland, 2008.

PREDEL, H. Theoretical and practical methods for coke yield calculation and optimization. Light Metals, 92, 1992, p. p. $601-607$.

POLLEY, G. T. et. al., The fouling limit in crude oil preheat train retrofits. Hydrocarbon Processing, v. 84, n. 7, p. 71 - 80, July 2005.

REN, J. et al. Analysis and calculation model of energy consumption and product yields of delayed coking units. Petroleum Science, v. 9, n. 1, pp. $100-105$, March 2012.

REZA, S.; MOHADDECY, S.; SADIGHI, S. Simulation and kinetic modeling of vacuum residue soaker-visbreaking. Petroleum \& Coal, v. 53, n. 1, p. 26 - 34, 2011.

RIAZI, M. R. Characterization and Properties of Petroleum Fractions. West Conshohocken, PA: ASTM International, 2005.

ROGEL, E., CARBPGNANI, L. Density estimation of asphaltenes using molecular dynamics simulations. Energy \& Fuels, v. 17, p. 378 - 386, 2003.

ROMAGNOLI. J. A.; SCHACHEZ, M. C. Data Processing and reconciliation for chemical process operations. San Diego, CA, USA: Academic Press, 2000.

ROMERO, S., Delayed coker fired heater - design and operations. In: RIO OIL AND GAS EXPO AND CONFERENCE, 2010, Rio de Janeiro. Anais... Rio de Janeiro: IBP, 2010. p. $1-10$.

ROSAL, A. G. C. Desenvolvimento de modelo matemático e simulação do forno de uma unidade de coqueamento retardado. 2013, 152 p, Tese - Universidade Federal de Pernambuco, Recife. 2013. 
ROSE, K. E., Delayed Coking - What You Should Know. Hydrocarbon Processing, v. 50, n. 7 , p. $85-92$, July 1971.

SABBAH, H. et al., Comparing Laser Desorption/Laser lonization Mass Spectra of Asphaltenes and Model Compounds. Energy \& Fuels, v. 24, p. 3589 - 3594, 2010.

SANDLER, S. I. Chemical and Engineering Thermodynamics. Third edition, New York, USA: John Wiley \& Sons, 1999, 772 p.

SAWARKAR, A. N.; PANDIT, A. B.; JOSHI, J. B. Studies in coking of Arabian mix vacuum residue, Trans IChemE, Part A. Chemical Engineering Research and Design, v. 85, p. $481-491,2007$.

SAYLES, S.; ROMERO, S. Comparison of thermal cracking and hydrocracking yield distributions. — $\quad$ September 2011. Disponível em: <http://www.digitalrefining.com/article 1000070.pdf>. Acesso em: 15 mar. 2015.

SHEA Jr., F. L.; HEIGHTS, A., Production of coke from petroleum hydrocarbon. Patent US2775549, December 25, 1956. New York, NY, US. Disponível em:< http://www.archpatent.com/patents/2775549>.Acesso em: 15 jul. 2013.

SMITH, A. et al. Refinery Modeling, Advanced Chemical Engineering Design, University of Oklahoma: Norman, OK, 2006.

SINGH, J. et al. Reaction pathways and product yields in mild thermal cracking of vacuum residues: multi-lump kinetic model. Chemical Engineering Journal, v. 108, p. $239-248,2005$.

SISKIN, M. et al. Asphaltene molecular structure and chemical influences on the morphology of coke produced in delayed coking. Energy \& Fuels, v. 20, p. 1227 1234, 2006. 
SPEIGHT, J. G. An evaluation of the delayed coking product yield of heavy feedstocks using asphaltene content and carbon residue. Revue De L'Institut Français du Pétrole, v. 52, n. 1, Janvier-Février 1997.

SPEIGHT, J. G. The chemistry and physics of coking. Korean Journal of Chemical Engineering, v. 15, n. 1, January 1998.

SPEIGHT, J. G. The Chemistry and Technology of Petroleum. $3^{\text {rd }}$ edition, New York: Marcel Dekker, 1999.

SPEIGHT, J. G. Chemical methods. In: Handbook of Petroleum Analysis, $1^{\text {st }}$ Edition. New York: John Wiley \& Sons, 2001. p. $197-221$

SPEIGHT, J. G. The Chemistry and Technology of Petroleum. $4^{\text {th }}$ edition, New York: CRC Press, 2006.

STEFANI, A. Reduce the impact of coke fines on delayed cokers. Hydrocarbon Processing, p. $110-113$, August 1997.

STRATIEV, D.; NIKOLAEV, N. Dependence of visbreaker residue properties on unit operation severity and residual fuel oil specification. Petroleum \& Coal, v. 51, n. 2, p. 140 - 145, 2009.

SUGAYA, M. F. Cinética e modelagem do craqueamento térmico de frações residuais de petróleo. 1994. 200p, Dissertação (Mestrado) - Universidade Estadual de Campinas, Campinas. 1994.

TAKATSUBA, T.; WATARI, R.; HAYAKAWA, H. Renewed attention to the eureka process: thermal cracking process and related technologies for residual oil upgrading. Studies in Surface Science and Catalysis, v. 100, p. $293-301,1996$.

TIAN, L.; SHEN, B.; LIU, J. A delayed coking model built using the structure-oriented lumping method. Energy \& Fuels, v. 26, n. 2, p. 1715 - 1724, 2012. 
TIAN, L.; SHEN, B.; LIU, J. Building and application of delayed coking structureoriented lumping model. Industrial \& Engineering Chemistry Research, v. 51, n. 10, p. $3923-3931,2012$.

TWU, C. H. Internally consistent correlation for predicting liquid viscosities of petroleum fractions. Industrial \& Engineering Chemistry Process Design and Development, v. 24, p. $1287-1293,1985$.

WANG, H. -L. et al. Eight-lump kinetic model for upgrading residue by carbon rejection in a fluidized-bed reactor. Energy \& Fuels, v. 26, p. 4177 - 4188, 2012.

WATSON, K. M. et al. Characterization of petroleum fractions. Industrial and Engineering Chemistry, v. 27, n. 12, p. $1460-1464,1935$.

WIEHE, I. A. A solvent-resid phase diagram for tracking resid conversion. Industrial \& Engineering Chemistry Research, v. 31, p. 530 - 536, 1992.

WIEHE, I. Petroleum Fouling: Causes, Tools, and Mitigation Methods, AICHE Chicago Symposium 2006. Disponível em: <http://www.aichechicago.org/symposium06/wiehe.pdf>. Acesso em: 22/11/2011.

WIMPRESS, R. N. Rating fired heaters. Hydrocarbon Processing and Petroleum Refiner, v. 42, n. 10, p. $115-126,1963$.

WIMPRESS, R. N. Generalized method predicts fired-heater performance. Chemical Engineering, v. 85, n. 12, p. 95 - 102, 1978.

WODNIK, R., HUGHES, G. C. Delayed Coking Advances, PTQ, p. 1 - 4, Quarterly 2, 2005.

WOLFGANG, P. et al. How to drive a modern coke cutting system, EngineerLive, London, [2010?]. Disponível em: <http://www.ruhrpumpen.de/files/Brochures/ OilGas publication.pdf>. Acesso em 22/11/2011. 
WOOD, J. R. Coil-design visbreaker for HGO recovery has advantages. Oil \& Gas Journal, 22, p. 80 - 84, April 1985.

WOODLE, R. A. New ways to estimate characterization of lube cuts. Hydrocarbon Processing, pp. $171-173$, July 1980.

VOLK, M.; WISECARVER, K. D.; SHEPPARD, C. M. Fundamentals of Delayed Coking University of Tulsa, Tulsa, OK, USA, July 2002, 182 p.

$\mathrm{XIAO}$, J. et. al. Modeling for product distribution in thermal conversion of heavy oil. Petroleum Science Technology, v. 20, n. 5-6, p. $605-612,2002$.

XINXUE, L.; RUISEN, L. Composition of recycle oil helps determine coke yield. Oil \& Gas Journal, 5, p. 64 - 66, March 2001.

$X U, Z$. et. al. Detailed characterization of virgin heavy oil resid and its thermally cracked resid, Energy \& Fuels, v. 28, p. 1664 - 1673, 2014.

ZHAO, S. et al., Systematic characterization of petroleum residua based on SFEF. Fuel, v. 84, p. $635-645,2005$.

ZHOU, X. L.; CHEN, S. Z.; LI, C. L. A predictive kinetic model for delayed coking. Petroleum Science and Technology, v. 25, n 12, p. 1539 - 1548, 2007.

ZHOU, X. L.; DI, X.; YU, G. -X; LU, R. -X; LI, C. L. Simulation of delayed coking reaction in coke drum. Petroleum Science and Technology, v. 28, n. 3, p. $277-$ 285, 2010.

YANG, C. et al. Hydroconversion characteristics and kinetics of residue narrow fractions. Fuel, v. 84, n. 6, p. $675-684,2005$. 


\section{A. ESPECTROMETRIA DE MASSA EM IDENTIFICAÇÃO QUÍMICA}

\section{A.1 - Espectrometria de Massa em Identificação Química}

O espectrômetro de massa é um instrumento que mede a razão massa-carga $(\mathrm{m} / \mathrm{z})$ de íons na fase gasosa e fornece a abundância de cada espécie iônica. Em geral, a carga é unitária, de maneira que a escala é calibrada em Dalton ou em unidade de massa atômica.

Na Figura A.1, é apresentado um diagrama de blocos com as partes básicas de um espectrômetro de massas. A entrada é o local de transferência de amostra para o interior da câmara vácuo do equipamento. Na fonte de ionização, as moléculas da amostra são volatilizadas, ionizadas em fase gasosa e aceleradas para o analisador de massas. No analisador de massas, ocorre a separação dos íons moleculares conforme a razão massa-carga. Após a separação, eles são detectados, e um sinal é transferido para um sistema de aquisição de dados. Como é requerido um percurso livre de colisão para os íons, o espectrômetro funciona sob a condição de alto vácuo.

Figura A.1 - Diagrama de blocos do espectrômetro de massa.

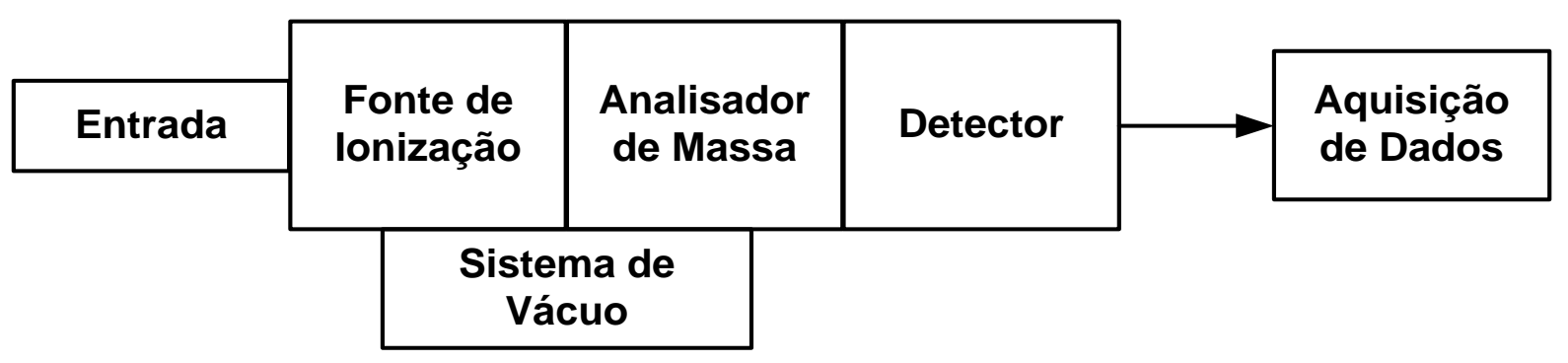

Embora existam várias estratégias de separação e de detecção, a etapa de ionização é aquela com maior número de estratégias. Isso se deve aos tipos variados de amostra e às espécies de interesse. (MORAES, 2003)

Na Tabela A.1, estão apresentadas diversas estratégias de ionização de moléculas e suas características. 
A seguir, estão relacionadas algumas definições importantes na interpretação dos resultados da espectrometria de massa:

- pico base: é o pico com a intensidade relativa de $100 \%$, representando íon mais abundante do espectro de massa.

— íon molecular: íon com mesma massa nominal da molécula neutra.

— massa: medida em Dalton ou em amu (unidade de massa atômica).

— razão massa-carga $(\mathrm{m} / \mathrm{z})$ : refere-se à massa do íon.

— abundância absoluta: resposta do sistema de detecção.

- resolução: é a capacidade do equipamento em separar os feixes de íons com razão $\mathrm{m} / \mathrm{z}$ diferente, sendo determinado pela razão $\mathrm{m} / \Delta \mathrm{m}$.

Tabela A.1 - Várias fontes de ionização.

\begin{tabular}{|c|c|c|}
\hline N. ${ }^{\circ}$ & Estratégia de lonização & Características \\
\hline 1 & $\begin{array}{l}\text { Ionização Elétrons } \\
\text { (El - Electron lonization) }\end{array}$ & $\begin{array}{l}\text { Impacto de elétrons com energia } \\
\text { média de } 70 \mathrm{eV} \text {. }\end{array}$ \\
\hline 2 & $\begin{array}{l}\text { Ionização Química } \\
\text { (Cl-Chemical Ionization) }\end{array}$ & Transferência de $\mathrm{H}^{+}$de $\mathrm{CH}_{5}^{+}$. \\
\hline 3 & $\begin{array}{l}\text { Ionização por Campo Elétrico } \\
\text { (FI - Field Ionization) }\end{array}$ & Elevado campo elétrico (12 kV). \\
\hline 4 & $\begin{array}{l}\text { Bombardeio de Átomos Rápidos } \\
\text { (FAB - Fast Atom Bombardment) }\end{array}$ & Feixe de átomos de Xenon. \\
\hline 5 & $\begin{array}{l}\text { Dessorção por Campo Elétrico } \\
\text { (FD - Field Desorption) }\end{array}$ & Elevado campo elétrico (12 kV). \\
\hline 6 & $\begin{array}{l}\text { Ionização e Desorção de Matriz Assistida por Laser } \\
\text { (MALDI - Matrix-Assisted Laser Desorption Ionization }\end{array}$ & $\begin{array}{l}\text { Feixe de laser sobre a amostra da } \\
\text { matriz de absorção ultravioleta. }\end{array}$ \\
\hline 7 & $\begin{array}{l}\text { Ionização por Espalhamento de Elétrons } \\
\text { (ESI - Electrospray Ionization) }\end{array}$ & $\begin{array}{l}\text { Espalhamento e desolvatação de } \\
\text { íns pré-formados. }\end{array}$ \\
\hline
\end{tabular}

Como neste trabalho foi utilizada a espectrometria de massa por MALDI-TOF na análise dos asfaltenos presentes nas correntes de petróleo e dos resíduos, esta técnica será discutida com mais detalhes. 


\section{A.2 Espectrometria de Massa por MALDI-TOF}

A técnica de MALDI é baseada numa matriz de absorção de luz ultravioleta, onde a matriz e a amostra são misturadas uniformemente. Quando o pulso de laser de nitrogênio (luz ultravioleta com comprimento de onda de $337 \mathrm{~nm}$ ) é sintonizado na frequência adequada, a energia é transferida para a matriz que absorve e converte em energia térmica. Ao mesmo tempo, uma pequena quantidade de matriz é aquecida rapidamente, vaporizando-se com a amostra. Os vários disparos de laser são usados para melhorar a relação sinal-ruído e as formas de picos, bem como a melhoria do resultado da determinação da razão massa-carga.

$$
M+\text { Laser } \Rightarrow(M+H)^{+}
$$

O princípio de operação do MALDI-TOF envolve a determinação do tempo de percurso de um íon molecular entre a fonte de geração e o detector de íons. Como todos os íons estão sujeitos ao mesmo acréscimo de energia cinética durante a aceleração, eles são separados progressivamente em grupos, em função dos diferentes valores de razão de $\mathrm{m} / \mathrm{z}$, conforme sua velocidade através da região livre de campo. Estes íons são identificados sequencialmente, no detector, em ordem Crescente de $\mathrm{m} / \mathrm{z}$, produzindo pulsos elétricos.

As principais vantagens da técnica de MALDI-TOF são as necessidades de pequena quantidade de amostra, baixa ou nenhuma fragmentação das moléculas e aplicável no estudo de macromoléculas.

\section{a) Determinação da razão massa-carga $(\mathrm{m} / \mathrm{z})$}

Existem diversos dispositivos para separar os íons com diferentes valores de razão massa-carga. Neste trabalho, foi utilizado um analisador de massa do tipo tempo de vôo (TOF - Time of Flight). Um fluxo de íons formado na fonte de ionização é acelerado por um campo elétrico através de uma pequena distância de percurso, para obter uma velocidade V. A energia potencial de uma partícula carregada 
através de um campo elétrico é função da carga e partículas e do campo elétrico aplicado conforme a equação (A.1).

Onde:

$E_{\text {potencial }}=z \cdot e U$

Onde:

Ep - energia potencial;

z - carga da partícula;

$U$ - diferencial de tensão.

Quando a partícula carregada é acelerada no tubo de vôo pelo campo elétrico, sua energia potencial é convertida em energia cinética. A energia cinética de qualquer massa é representa pela equação (A.2):

$$
E_{\text {cinetrica }}=\frac{1}{2} \cdot m \cdot v^{2}
$$

Considerando a energia potencial convertida em energia cinética, as equações (A.1) e (A.2) são iguais, resultando na equação (A.3).

$$
v=\sqrt{\frac{2 \cdot e U}{(m / z)}}
$$

A velocidade das partículas de íons para percorrer uma distância $L$, num intervalo de tempo t, no tubo de desvio, pode ser determinada pela equação (A.4).

$$
\begin{aligned}
& v=\frac{L}{t} \\
& v=\frac{L}{\sqrt{2 \cdot e U}} \cdot \sqrt{\left(\frac{m}{z}\right)}
\end{aligned}
$$


Através dos rearranjos das equações (A.4) e (A.5), obtém-se a equação (A.6):

$t=\left(\frac{L^{2}}{2 \cdot e U}\right) \cdot \sqrt{\left(\frac{m}{z}\right)}$

$v$ — velocidade do íon após aceleração

e - é a carga do íon

$U$ - é a diferença de tensão entre os pontos A e B.

$t=k \cdot \sqrt{\left(\frac{m}{z}\right)}$

Conforme a equação (A.7), o tempo de vôo dos íons varia com a raiz quadrada da razão de massa-carga $(\mathrm{m} / \mathrm{z})$.

Como a equação (A.6) relaciona a massa com a carga ao longo do tempo, ela é usada para aferir a calibração do equipamento MALDI-TOF.

$\left(\frac{m}{z}\right)=2 \cdot e U \cdot \frac{\left(t-t_{0}\right)^{2}}{L^{2}}$

$\left(\frac{m}{z}\right)=a \cdot\left(t-t_{0}\right)^{2}$

b) Aplicação

O uso de laser de baixa energia (laser de nitrogênio - $330 \mathrm{~nm}$ ) forma íns em macromoléculas sem fragmentação. A maior parte da energia do laser é absorvida pela matriz, impedindo a fragmentação do íon molecular. Na Figura 5, são ilustrados 
o princípio da técnica e um gráfico de intensidade em função de m/z. (CALNAGO, 2002)

Figura A.2 - Diagrama de um espectrômetro de massa com dessorção por laser.

(CALNAGO, 2002)

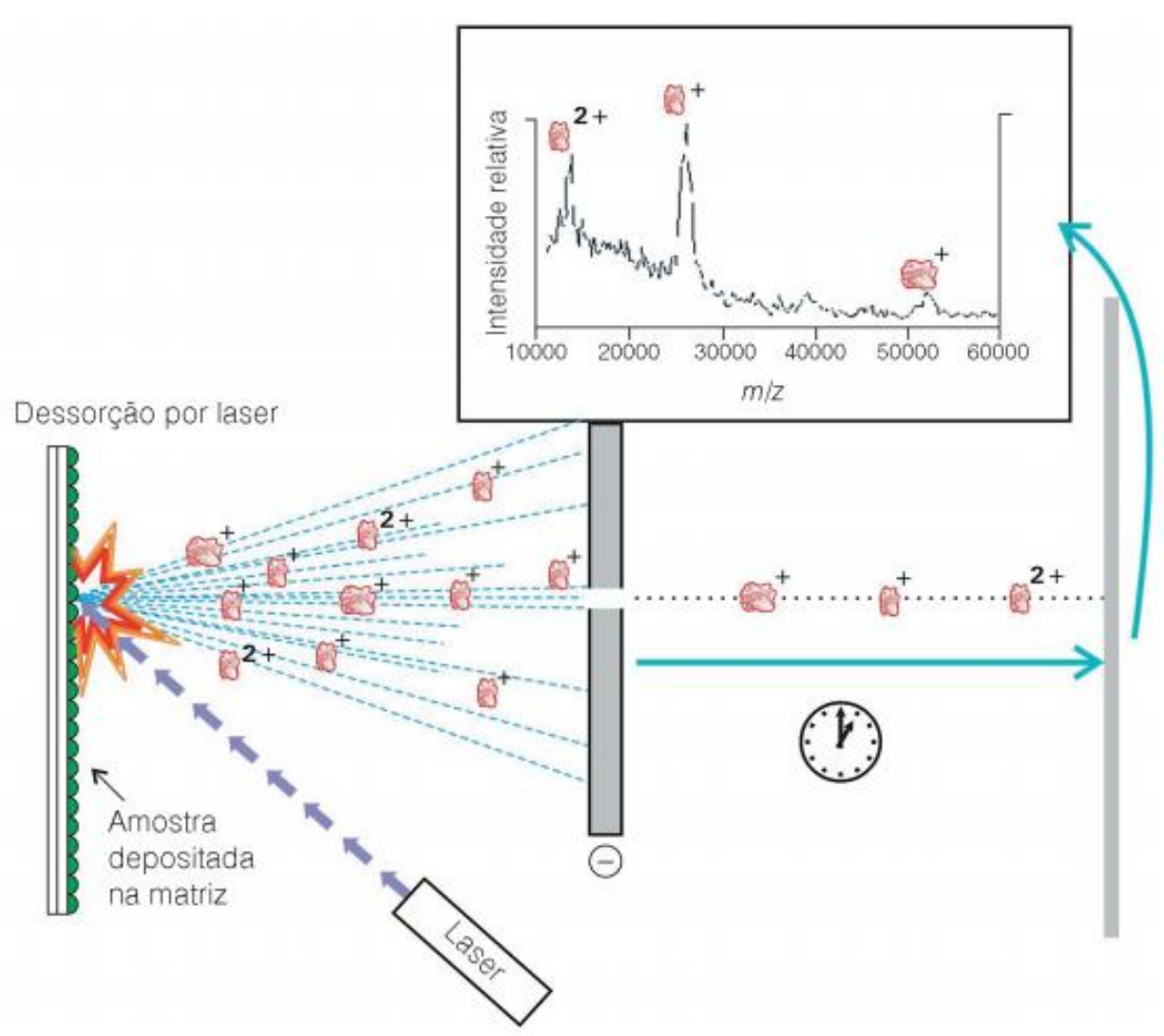




\section{B. DETERMINAÇÃO DO VAPOR DE TOPO DO REATOR COQUE}

$\mathrm{Na}$ Tabela B.1 estão as características dos pseudo-componentes calculados, considerando a temperatura e a pressão de operação no topo do reator em $445^{\circ} \mathrm{C}$ e 3,76 bar abs, respectivamente.

Tabela B.1 - Características dos pseudo-componentes calculados.

\begin{tabular}{|c|c|c|c|c|c|c|c|}
\hline $\begin{array}{l}\text { Pseudo- } \\
\text { componente }\end{array}$ & NBP, $\mathrm{K}$ & $\begin{array}{c}\text { Peso } \\
\text { Molecular }\end{array}$ & SG & Tc, K & $\begin{array}{c}\text { Pc, bar } \\
\text { abs }\end{array}$ & $\begin{array}{c}\mathrm{Vc} \\
\mathrm{cm}^{3} / \mathrm{gmol}\end{array}$ & $\begin{array}{c}\text { Fator } \\
\text { acêntrico }\end{array}$ \\
\hline PC40 & 311.15 & 74.9846 & 0.6310 & 474.86 & 33.62 & 317.21 & 0.2284 \\
\hline PC50 & 318.15 & 77.3885 & 0.6482 & 482.87 & 32.78 & 329.42 & 0.2404 \\
\hline PC60 & 328.15 & 80.9736 & 0.6700 & 494.20 & 31.63 & 347.34 & 0.2577 \\
\hline PC70 & 338.15 & 84.7408 & 0.6890 & 506.48 & 31.26 & 358.84 & 0.2684 \\
\hline PC80 & 348.15 & 91.9681 & 0.7094 & 520.78 & 31.47 & 365.93 & 0.2737 \\
\hline PC90 & 358.15 & 97.3346 & 0.7206 & 533.67 & 31.05 & 377.85 & 0.2902 \\
\hline PC100 & 368.15 & 102.7540 & 0.7310 & 545.92 & 30.50 & 391.34 & 0.3072 \\
\hline PC110 & 378.15 & 108.2321 & 0.7408 & 557.78 & 29.82 & 406.89 & 0.3215 \\
\hline PC120 & 388.15 & 113.7823 & 0.7498 & 569.38 & 29.08 & 423.83 & 0.3364 \\
\hline PC130 & 398.15 & 119.4220 & 0.7584 & 580.83 & 28.30 & 441.96 & 0.3521 \\
\hline PC140 & 408.15 & 125.1706 & 0.7663 & 592.17 & 27.51 & 461.45 & 0.3662 \\
\hline PC150 & 418.15 & 131.0473 & 0.7738 & 603.42 & 26.71 & 480.74 & 0.3881 \\
\hline PC160 & 428.15 & 137.0710 & 0.7808 & 614.55 & 25.92 & 502.28 & 0.4016 \\
\hline PC170 & 438.15 & 143.2588 & 0.7874 & 625.57 & 25.15 & 524.93 & 0.4136 \\
\hline PC180 & 448.15 & 149.6261 & 0.7937 & 636.42 & 24.39 & 546.70 & 0.4356 \\
\hline PC190 & 458.15 & 156.1865 & 0.7996 & 647.09 & 23.65 & 570.38 & 0.4513 \\
\hline PC200 & 468.15 & 162.9514 & & & 22.93 & 594.94 & 0.4669 \\
\hline PC210 & 478.15 & 169.9304 & 0.8106 & 667.75 & 22.22 & 620.50 & 0.4823 \\
\hline PC220 & 488.15 & 177.1309 & 0.8158 & 677.71 & 21.51 & 647.20 & 0.4975 \\
\hline PC230 & 498.15 & 184.5588 & 0.8208 & 687.39 & 20.82 & 675.26 & 0.5125 \\
\hline PC240 & 508.15 & 192.2181 & 0.8256 & 696.04 & 20.20 & 700.81 & 0.5302 \\
\hline PC250 & 518.15 & 200.1111 & 0.8302 & 704.65 & 19.60 & 727.12 & 0.5477 \\
\hline PC260 & 528.15 & 208.2387 & 0.8348 & 712.97 & 19.08 & 751.37 & 0.5664 \\
\hline PC270 & 538.15 & 216.6005 & 0.8393 & 721.35 & 18.60 & 775.37 & 0.5850 \\
\hline PC280 & 548.15 & 225.1947 & 0.8436 & 729.74 & 18.16 & 798.85 & 0.6034 \\
\hline PC290 & 558.15 & 234.0183 & 0.8480 & 743.88 & 17.95 & 822.61 & 0.6076 \\
\hline РС300 & 568.15 & 243.0674 & 0.8523 & 753.19 & 17.31 & 860.15 & 0.6217 \\
\hline РC310 & 578.15 & 252.3371 & 0.8565 & 762.42 & 16.69 & 899.19 & 0.6358 \\
\hline PC320 & 588.15 & 261.8217 & 0.8608 & 771.58 & 16.09 & 939.68 & 0.6500 \\
\hline РС330 & 598.15 & 271.5148 & 0.8650 & 780.67 & 15.52 & 981.57 & 0.6643 \\
\hline РС340 & 608.15 & 281.4095 & 0.8693 & 789.69 & 14.97 & 1024.79 & 0.6789 \\
\hline PC350 & 618.15 & 291.4986 & 0.8735 & 798.66 & 14.45 & 1069.27 & 0.6936 \\
\hline PC360 & 628.15 & 301.7745 & 0.8777 & 807.56 & 13.95 & 1114.91 & 0.7086 \\
\hline
\end{tabular}




\begin{tabular}{lcllllll}
\hline PC370 & 638.15 & 313.7164 & 0.8757 & 814.69 & 13.22 & 1179.93 & 0.7280 \\
PC380 & 648.15 & 324.5956 & 0.8792 & 823.30 & 12.75 & 1230.38 & 0.7441 \\
PC390 & 658.15 & 335.6846 & 0.8826 & 831.84 & 12.31 & 1282.03 & 0.7607 \\
PC400 & 668.15 & 346.9523 & 0.8860 & 840.34 & 11.88 & 1334.40 & 0.7779 \\
PC410 & 678.15 & 358.3342 & 0.8896 & 848.86 & 11.49 & 1386.60 & 0.7955 \\
PC420 & 688.15 & 369.9635 & 0.8929 & 857.27 & 11.12 & 1440.03 & 0.8139 \\
PC430 & 698.15 & 381.7820 & 0.8961 & 865.62 & 10.76 & 1493.80 & 0.8331 \\
PC440 & 708.15 & 393.7861 & 0.8992 & 873.93 & 10.43 & 1547.60 & 0.8532 \\
PC450 & 720.65 & 409.2662 & 0.9023 & 884.10 & 10.02 & 1616.73 & 0.8802 \\
PC460 & 723.15 & 411.5602 & 0.9053 & 886.73 & 10.01 & 1621.61 & 0.8843 \\
PC480 & 743.15 & 437.0858 & 0.9096 & 902.82 & 9.43 & 1729.86 & 0.9319 \\
PC500 & 763.15 & 463.3863 & 0.9135 & 918.85 & 8.93 & 1831.48 & 0.9851 \\
PC520 & 783.15 & 489.4135 & 0.9193 & 935.39 & 8.56 & 1913.52 & 1.0434 \\
PC540 & 803.15 & 515.6353 & 0.9255 & 936.86 & 7.54 & 2039.18 & 1.2919 \\
PC560 & 823.15 & 541.9952 & 0.9320 & 952.67 & 7.07 & 2189.45 & 1.3359 \\
PC580 & 843.15 & 568.3357 & 0.9389 & 968.60 & 6.63 & 2346.77 & 1.3783 \\
PC600 & 848.15 & 571.7264 & 0.9461 & 974.94 & 6.70 & 2339.19 & 1.3789 \\
PC650 & 908.15 & 656.3099 & 0.9587 & 1018.99 & 5.34 & 2967.68 & 1.5147 \\
PC700 & 943.15 & 698.2036 & 0.9762 & 1049.09 & 4.91 & 3274.13 & 1.5714 \\
PC850 & 1073.15 & 830.9825 & 1.0463 & 1163.77 & 3.74 & 4581.11 & 1.7467 \\
\hline
\end{tabular}

